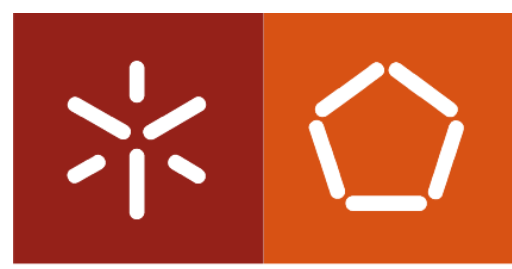

Universidade do Minho

Hugo Miguel Andrade Lopes Figueiredo da Silva

Determination of the material/geometry of the section most adequate for a static loaded beam subjected to a combination of bending and torsion

Guimarães, 2011 


\section{ABSTRACT}

The Finite Element Method (FEM) is widely used to solve structural analysis problems. In this work, a novel Finite Element Model Updating methodology for static analysis is presented. The aim of the work is to improve the quality of the results using the Finite Element Updating techniques, by optimizing geometric parameters of the models and material properties in order to minimize deflection. Deflection can be minimized by increasing the Inertia moment of the section and/or Young modulus of the material. The Young modulus can be optimized by selecting an adequate material. In this work, material selection charts were used to determine the most reliable material. The selected material was then tested by tensile and extensometry tests to obtain Young modulus, Yield stress, and Poisson coefficient. The Inertia moment can be maximized by improving the geometry of the section, such as adding ribs or webs. A substantial improvement of the deflection can be achieved, but, in order to obtain the best results, optimization must be used. A MATLAB program was used to optimize the ANSYS models using a programming code. In order to know if the results are getting worse or better in relation to the previous iterations, an objective function was defined. The model is optimized when is not possible to further optimize the objective function. 


\section{RESUMO}

O método dos elementos finitos (FEM) é amplamente utilizado para resolver problemas de análise estrutural estática. Neste trabalho é apresentada uma nova metodologia de melhoria de modelos de elementos finitos para análise estática. O objectivo do trabalho é melhorar a qualidade dos resultados utilizando as técnicas de melhoramento de elementos finitos, através da optimização de parâmetros geométricos dos modelos e propriedades do material, de modo a reduzir os deslocamentos. Os deslocamentos podem ser minimizados através do aumento do momento de Inércia da secção e/ou módulo de Young do material. O módulo de Young pode ser optimizado através da escolha de um material adequado. Neste trabalho foram usadas cartas de selecção de materiais para determinar o material mais adequado. Foram feitos ensaios de extensometria e de tracção ao material seleccionado para obter as propriedades relevantes do material: módulo de Young, tensão de Cedência e coeficiente de Poisson. O momento de inércia pode ser maximizado melhorando a geometria da secção com nervuras ou redes longitudinais. Uma melhoria substancial do deslocamento pode ser obtida, mas, de modo a obter os melhores resultados, tem de se usar optimização. O programa MATLAB foi utilizado para optimizar os modelos do ANSYS com um código de programação. De modo a saber se os resultados estão a melhorar ou a piorar em cada iteração, em relação às iterações anteriores, uma função objectivo foi definida. O modelo está optimizado quando não é possível optimizar mais a função objectivo. 


\section{KEYWORDS}

FINITE ELEMENT METHOD

FINITE ELEMENT MODEL UPDATING

OPTIMIZATION

STRUCTURAL STATIC ANALYSIS

MATERIALS SELECTION

MECHANICAL TESTS 


\section{ACKNOWLEDGMENTS}

This work was a real pleasure, because it is strongly multi-subject, it gave to me scientific knowledge in those subjects and it has practical applications.

I want to acknowledge:

-My scientific supervisor Professor José Filipe Meireles, for all the dedication, help, and time spent in the orientation of my work.

-My father David, my mother Cidália, my sister Mara, my godmother Sónia, and my friend Daniel Veiga, for the incredible support, encouragement, and belief in the conclusion of this work.

-Mr. Araújo, material tests laboratory technician, for all the dedication in the mechanical tests performed during this thesis. 


\section{INDEX}

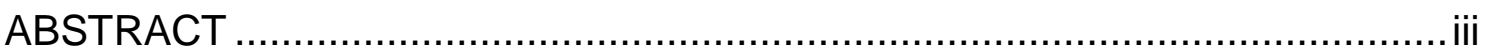

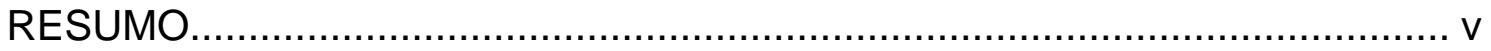



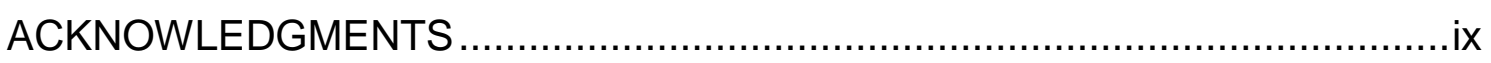

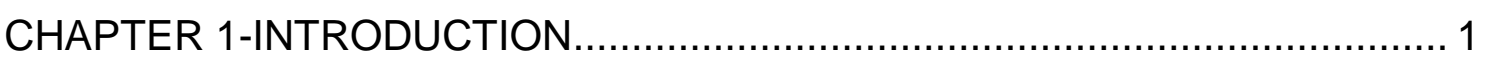

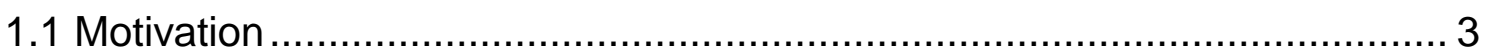

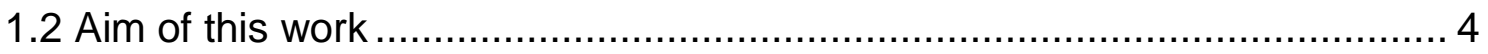

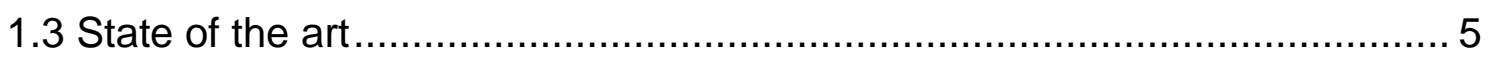

1.3.1 Rigidity and the Finite Element Method ..................................... 5

1.3.2 About Optimization methods ................................................... 8

1.4 Context and purpose of the work and structure of the thesis..................... 9

CHAPTER 2-RELATED THEORY ...................................................... 11

2.1 Introduction to Finite Element Method ................................................. 13

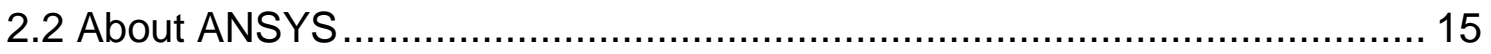

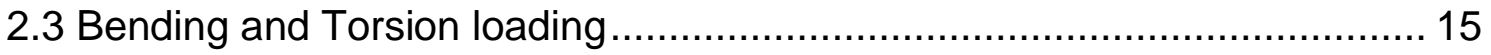

2.3.1 Mechanical deflection ...................................................... 16

2.3.1.1Differential elastic curve .................................................. 16

2.3.1.2 Torsion deflection ............................................................. 17

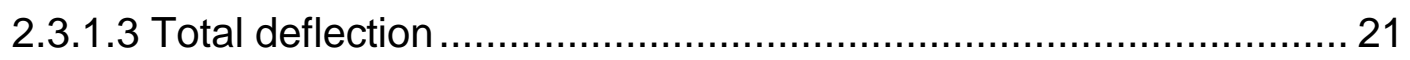

2.4 Stresses in torsion and bending loading ............................................ 21

2.5 Rigidity indices of materials .......................................................... 22

2.6 Relation between structural rigidity and material properties ..................... 24

2.7 Mechanical tests.................................................................................... 26

2.7.1 About tensile test ................................................................. 26

2.7.2 Elastic and Plastic domains .................................................... 27

2.7.3 Relevant properties obtained from a tensile test............................ 28

2.7.3.1 Modulus of Elasticity................................................... 28

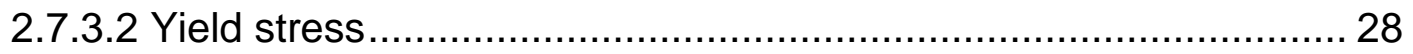

2.7.3.3 Rupture stress ....................................................... 28

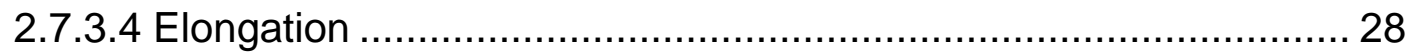

2.7.3.5 Ultimate Tensile Strength ................................................. 29

2.7.4 Determination of the Young modulus in tensile test.......................... 30

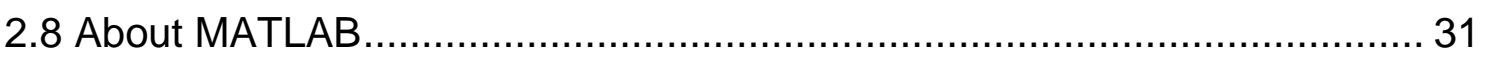

2.9 Mathematical formulation of optimization methods ............................. 32 


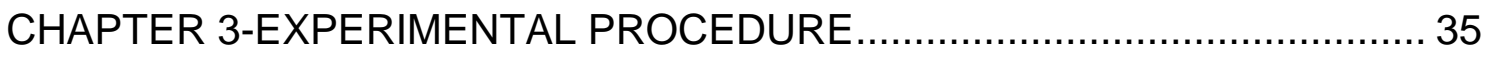

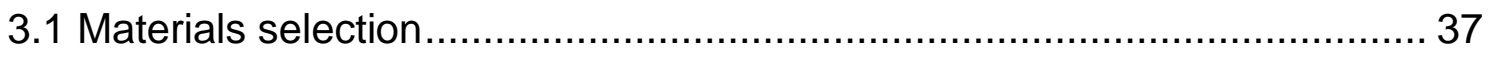

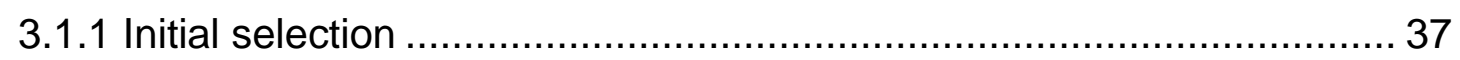

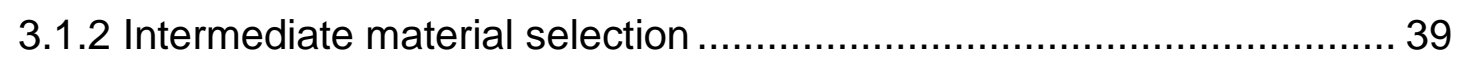

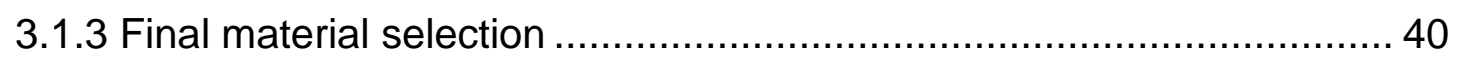

3.1.4 About commercial dual phase steels (High strength steels) .............. 41

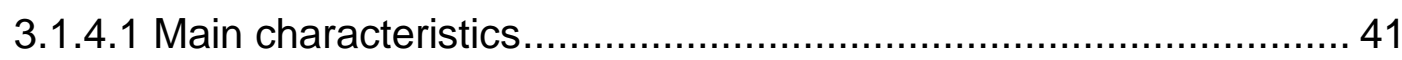

3.1.4.2 About DOCOL dual phase steels ........................................... 42



3.2.1 Section Optimization: Main purposes............................................. 44

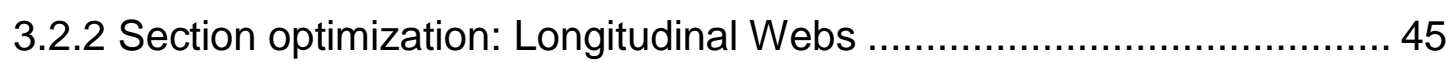



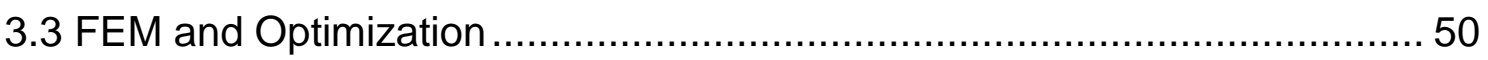

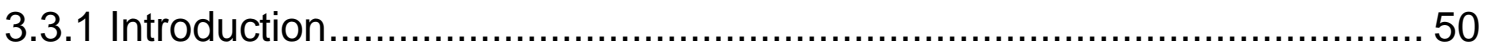

3.3.2 Finite Element Method experimental procedure …............................ 50

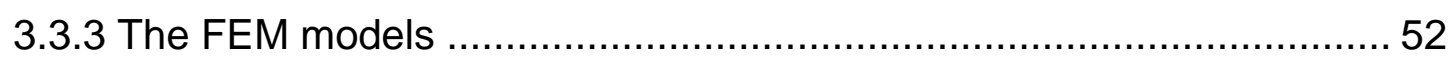

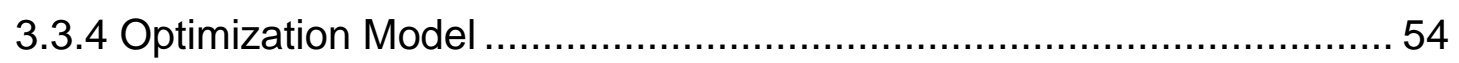

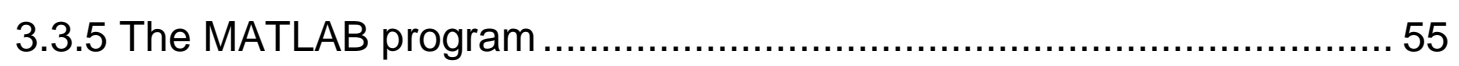

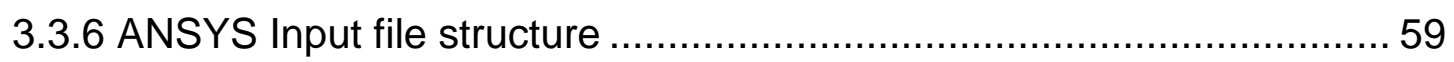

4.1 Numeric approximation- Comparison between numeric and analytic

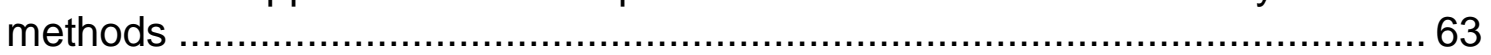

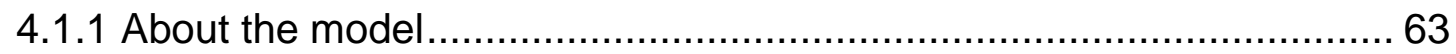

4.1.2 Beam Deflection by the Analytic method ......................................... 63

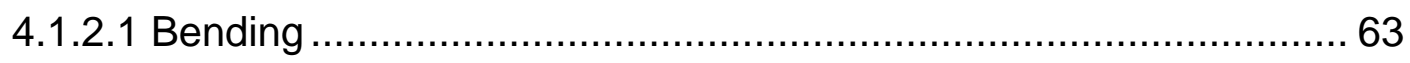

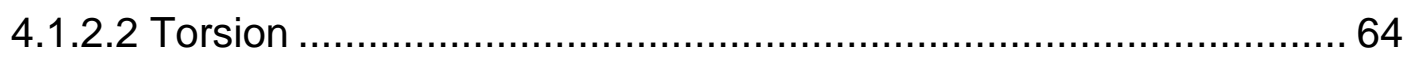

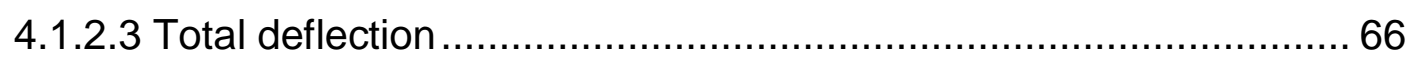

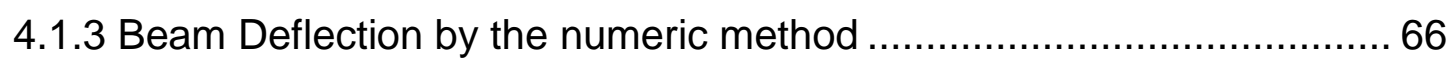

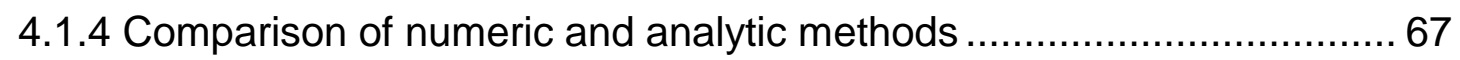

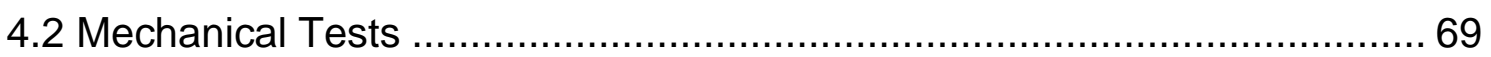

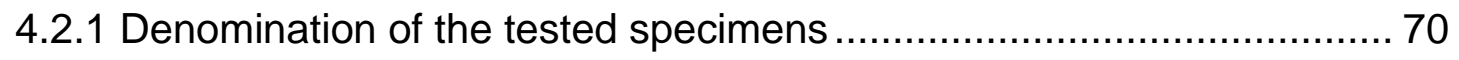

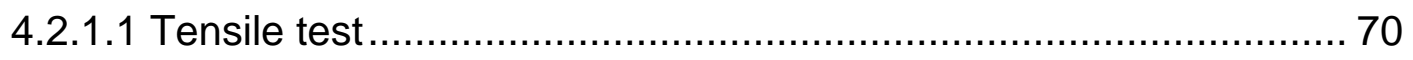

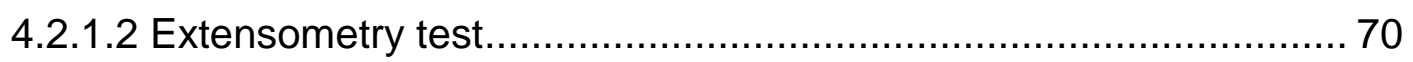

4.2.2 Tensile test experimental results ................................................. 70

4.2.2.1 Stress-Strain and Stress-Extension charts .................................. 70

4.2.2.2 Determination of Young modulus in tensile test .......................... 70

4.2.2.3 Determination of Yield stress in tensile test................................. 71

4.2.2.4 Determination of the Poisson coefficient, normal stress, and Young

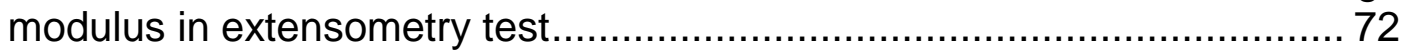






4.3.1 Variable analysis of model 1- ribbed plate .......................................... 74

4.3.2 Variable analysis of model 2- tubular beam ........................................ 74

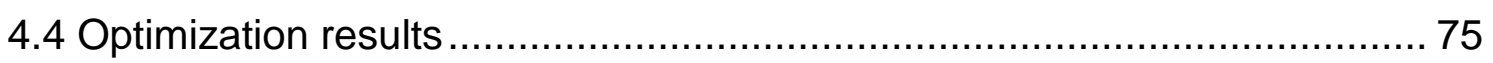

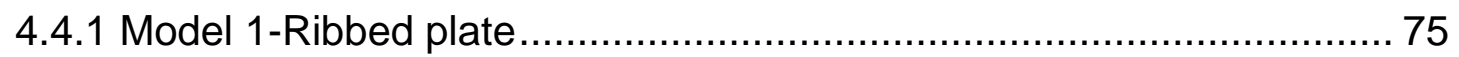

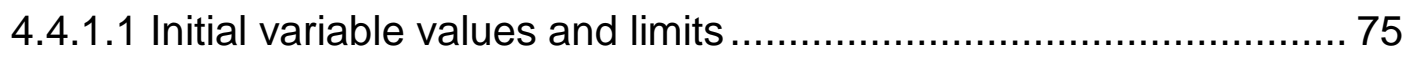

4.4.1.2 Geometric parameters optimization results .................................. 76

4.4.1.3 Material properties optimization results .................................... 76

4.4.1.4 Optimization results using all variables ........................................ 77

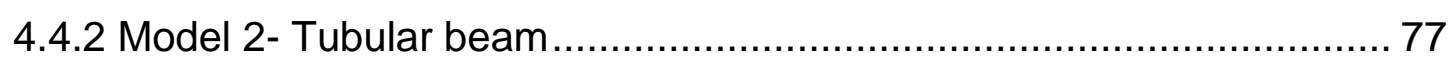

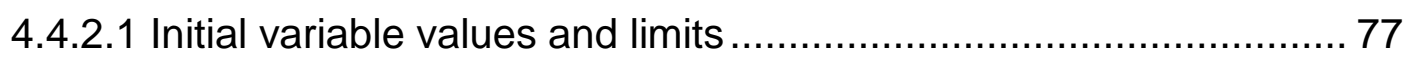

4.4.2.2 Geometric parameters optimization results ................................ 78

4.4.2.3 Material properties optimization results ...................................... 79

4.4.2.4 Optimization results using all variables ...................................... 79

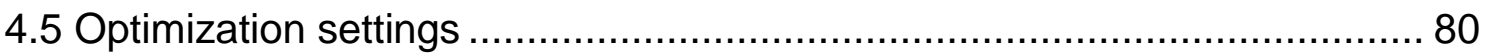

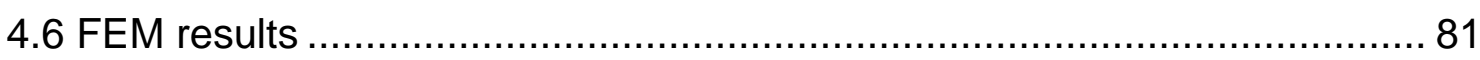

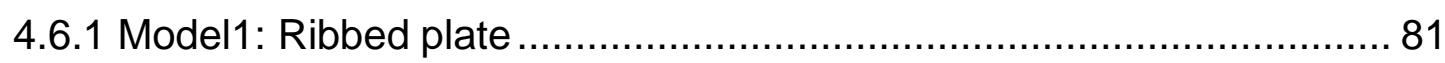

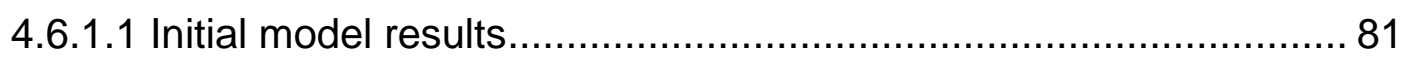

4.6.1.2 Geometric parameters ANSYS results ......................................... 81

4.6.1.3 Material properties ANSYS results ........................................... 82

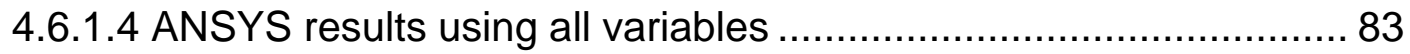

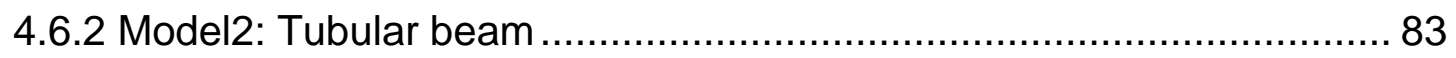

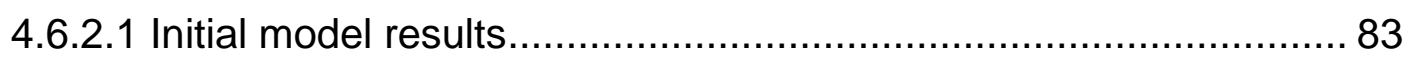

4.6.2.2 Geometric parameters ANSYS results ...................................... 84

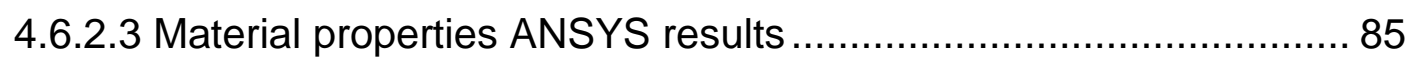

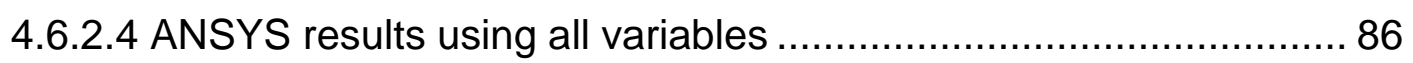

CHAPTER 5-RESULTS DISCUSSION AND CONCLUSIONS........................ 87

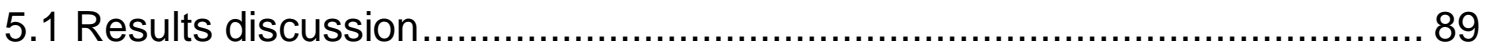

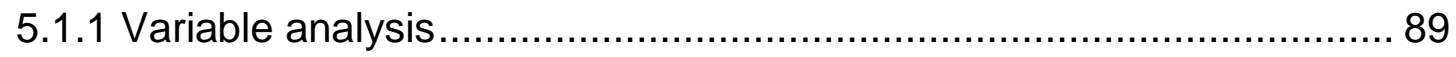

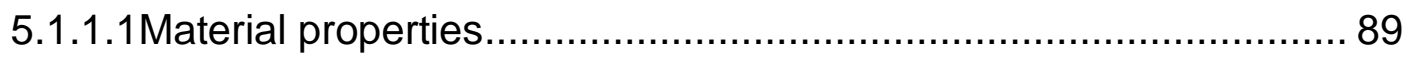

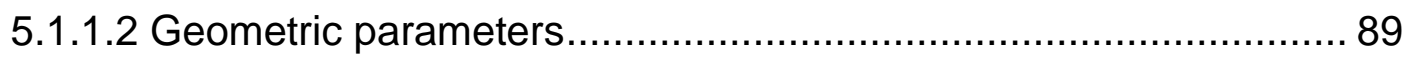

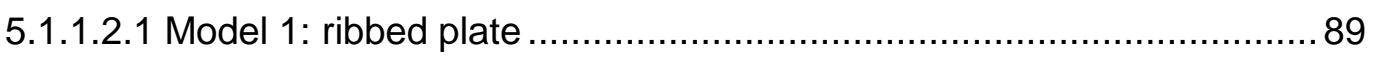

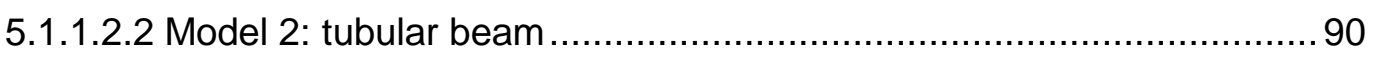

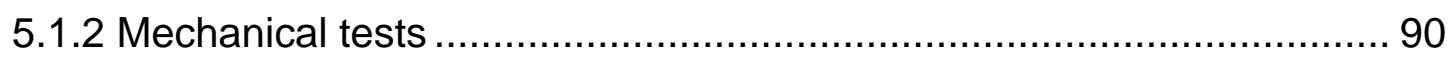

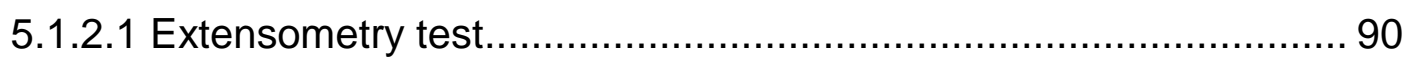

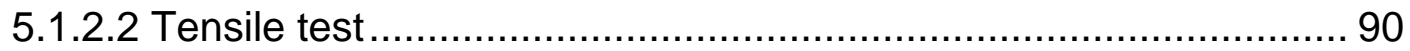

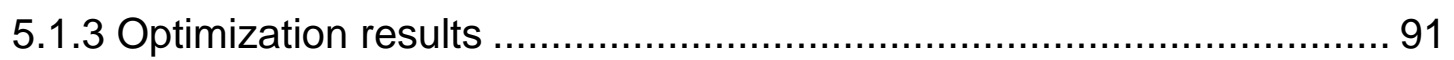




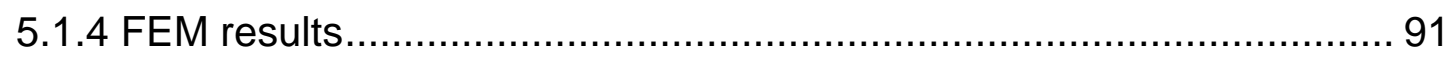

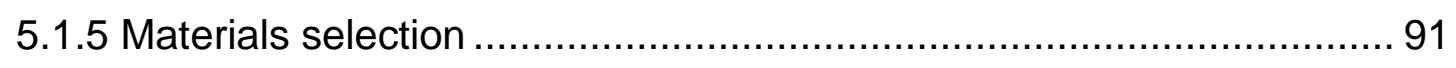

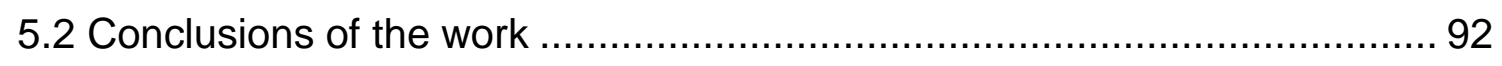

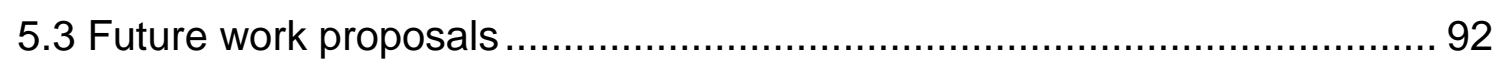

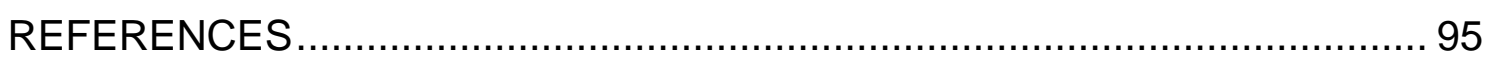

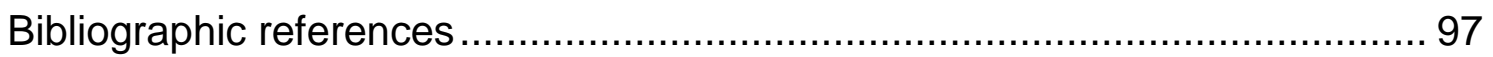

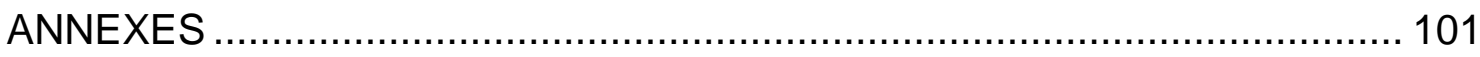

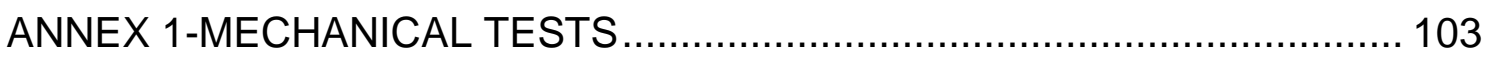

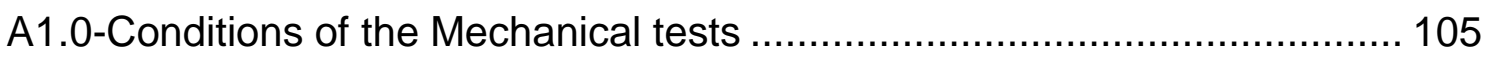



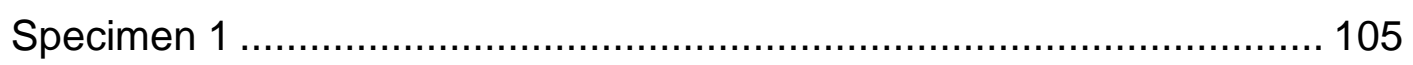

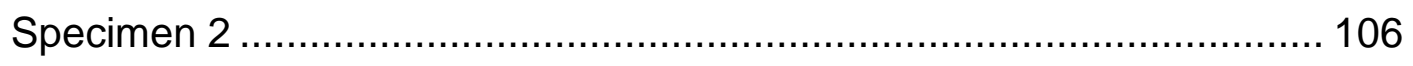

A1.2-Determination of Young modulus in tensile test................................. 107

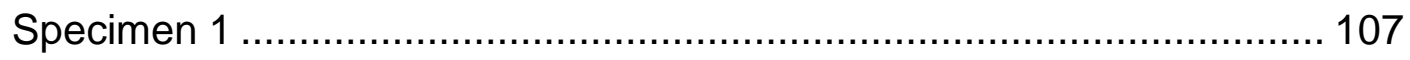

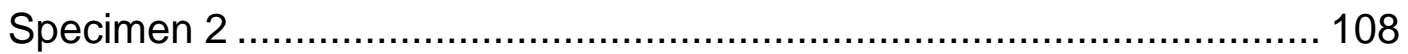

A1.3-Charts used to determine Yield stress .............................................. 108

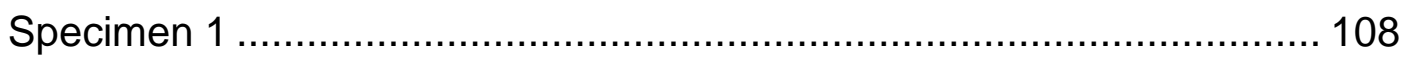

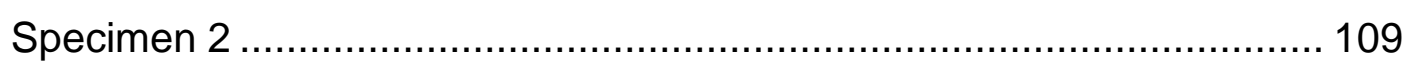

A1.4-Determination of Poisson coefficient and Young modulus in extensometry

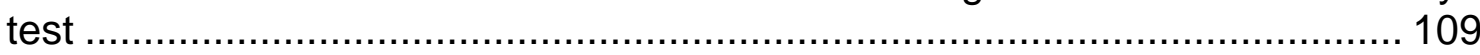

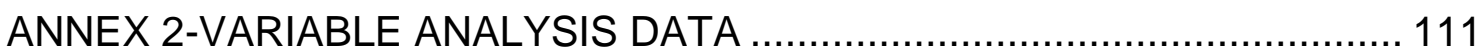

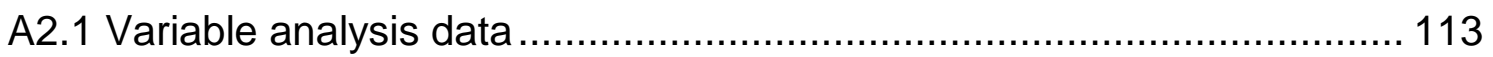

A2.1.1 Model 1- Ribbed plate .............................................................. 113

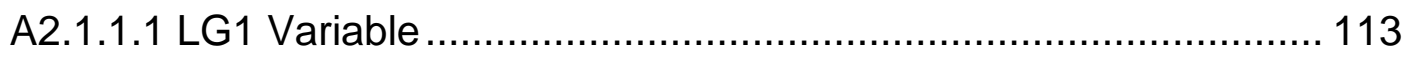

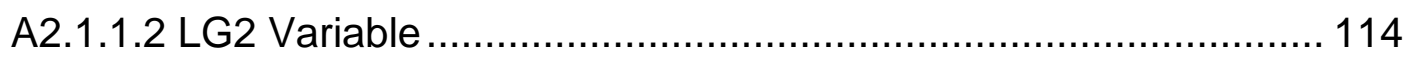

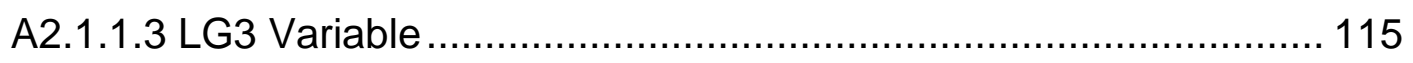

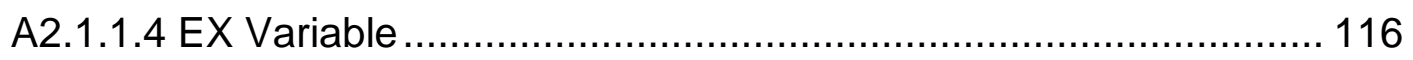

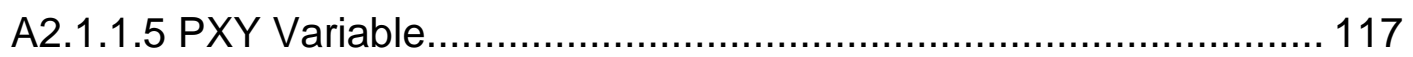

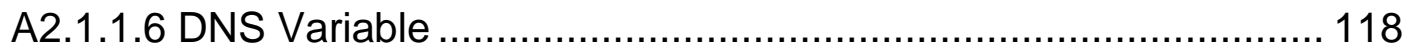

A2.1.2 Model 2- Tubular beam ...................................................... 119

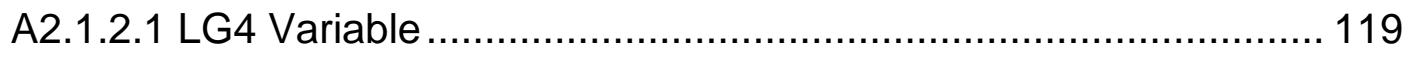

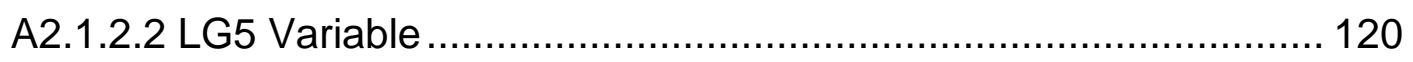



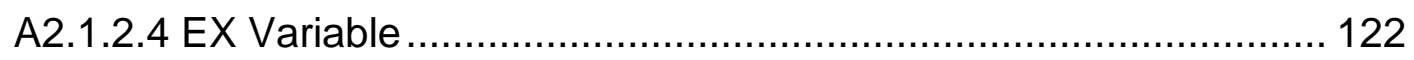

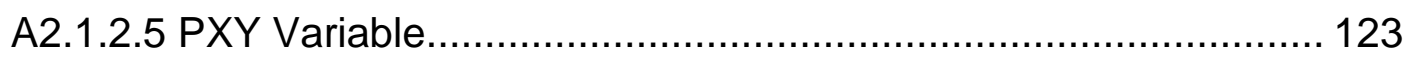

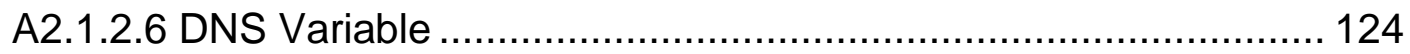

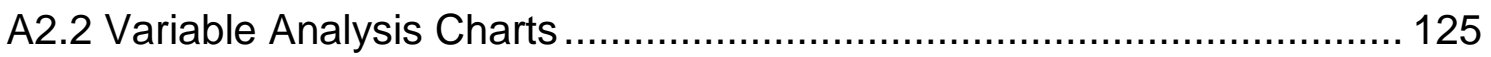




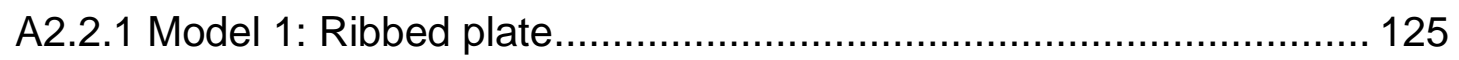

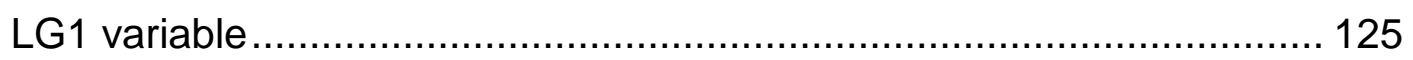

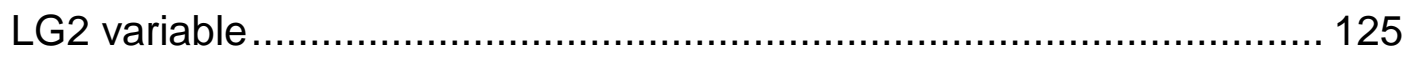

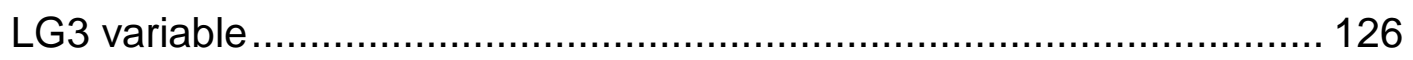

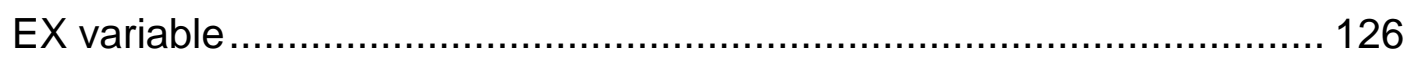

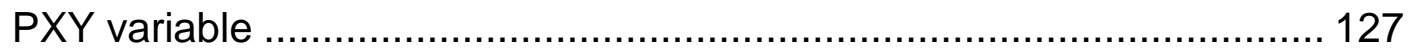

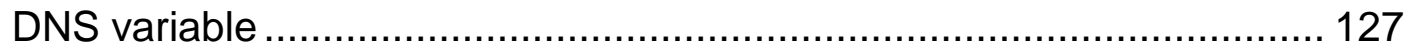

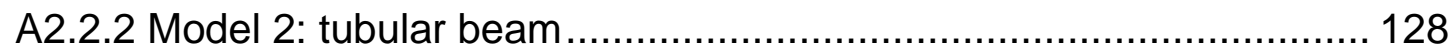

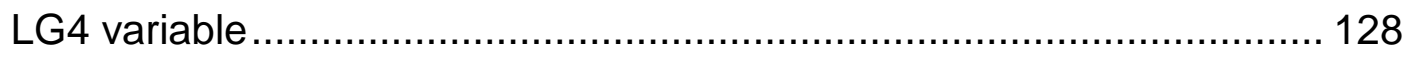

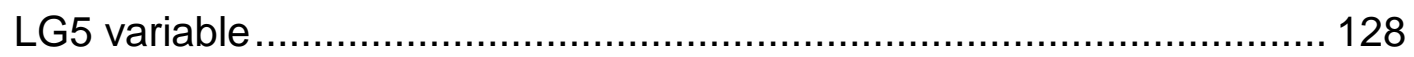

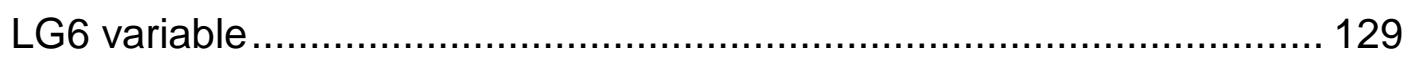

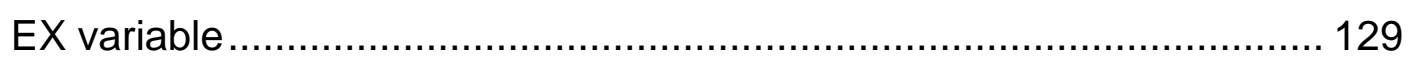

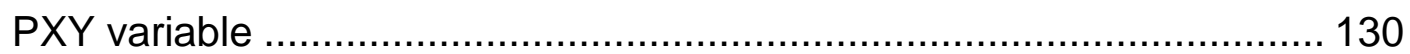

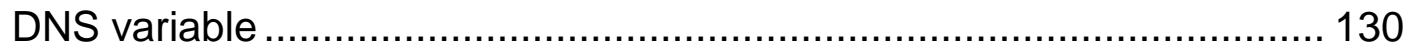

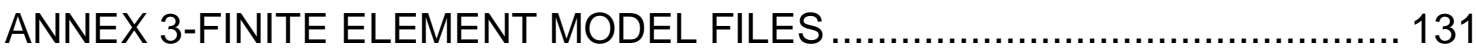

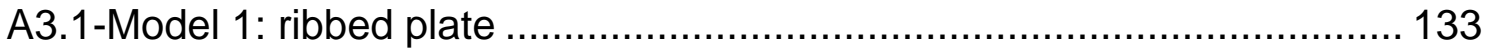

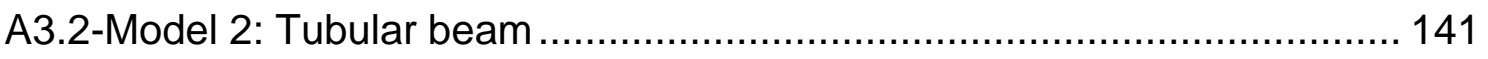





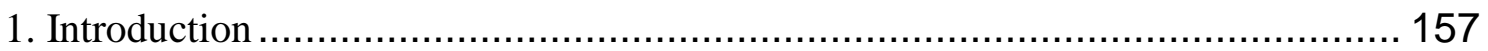

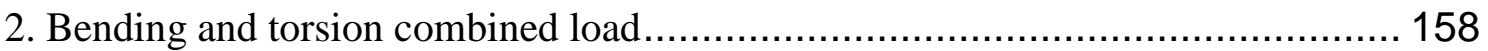

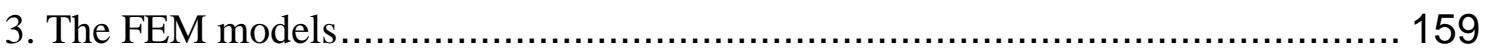

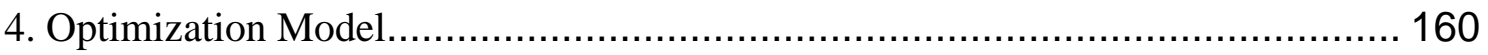

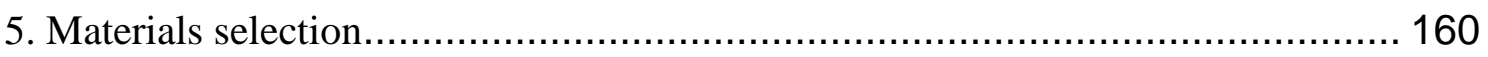

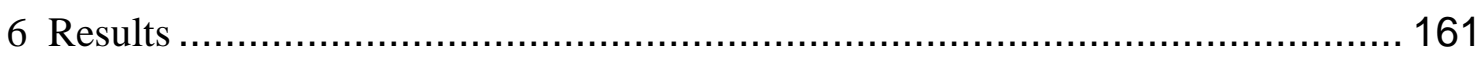

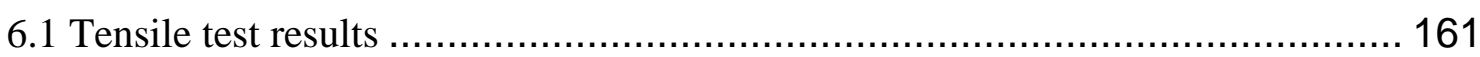

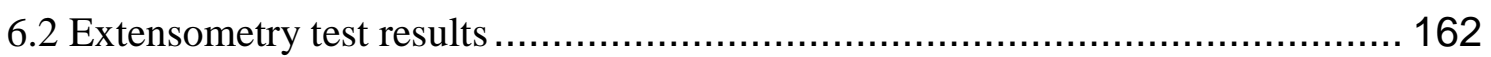



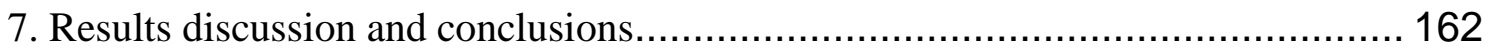

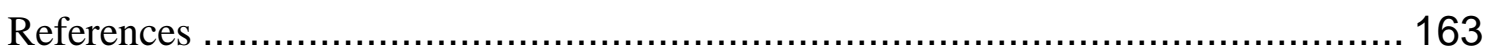




\section{Nomenclature}

\section{Scalar}

Symbol Units Description

\begin{tabular}{|c|c|c|}
\hline $\mathrm{a}$ & $\mathrm{m} / \mathrm{s}^{2}$ & Acceleration \\
\hline$a_{\mathrm{s}}$ & & Scalar \\
\hline$a_{s 1}$ & & Scalar lower bound \\
\hline$a_{\mathrm{s} 2}$ & & Scalar upper bound \\
\hline A & $\mathrm{m}^{2}$ & Area of the cross section \\
\hline $\mathrm{A}_{\mathrm{i}}$ & $\mathrm{m}^{2}$ & Cross sectional area on the node $\mathrm{i}$ \\
\hline $\mathrm{A}_{\mathrm{i}+1}$ & $\mathrm{~m}^{2}$ & Cross sectional area on the node $i+1$ \\
\hline$A_{m}$ & & Coefficient matrix \\
\hline $\mathrm{A}_{0}$ & $\mathrm{~m}^{2}$ & Area of the mean line \\
\hline ABS & & Absolute Value \\
\hline $\mathrm{b}$ & $\mathrm{m}$ & Section width \\
\hline$b_{1}$ & $\mathrm{~m}$ & Inner section width \\
\hline$b_{i}$ & $\mathrm{~m}$ & Distance between the binary forces \\
\hline $\mathrm{B}_{\mathrm{m}}$ & & Coefficient vector \\
\hline $\mathrm{c}\left(\mathrm{x}_{\mathrm{v}}\right)$ & & Function $x_{v}$ \\
\hline $\mathrm{C}$ & Pa.m & Shear flux \\
\hline $\mathrm{C}_{1}, \mathrm{C}_{2}$ & & Integration constants \\
\hline $\mathrm{D}$ & $\mathrm{m}$ & Diagonal length of the initial beam section \\
\hline $\mathrm{e}$ & $\mathrm{m}$ & Thickness \\
\hline $\mathrm{e}_{\mathrm{s}}$ & & Engineering strain \\
\hline $\mathrm{E}$ & $\mathrm{GPa}$ & Young modulus \\
\hline$f_{d}$ & $\mathrm{~m}$ & Maximum deflection \\
\hline$f\left(a_{s}\right)$ & & Scalar function \\
\hline$f(x)$ & & Function $\mathrm{f}$ \\
\hline $\mathrm{F}$ & $\mathrm{N}$ & Force \\
\hline $\mathrm{F}_{\mathrm{e}}$ & $\mathrm{N}$ & Force applied on each element \\
\hline $\mathrm{F}_{\mathrm{f}}\left(\mathrm{x}_{\mathrm{v}}\right)$ & & Function $F_{f}$ \\
\hline
\end{tabular}


$\mathrm{h}_{1}$

$\mathrm{h}(\mathrm{x})$

$\mathrm{H}$

I

$\mathrm{I}_{\mathrm{p}}$

$\mathrm{k}$

$\mathrm{K}\left(\mathrm{x}_{\mathrm{v}}, \mathrm{w}\right)$

1

$l_{b}$

$1_{\mathrm{t}}$

L

$\mathrm{L}_{\mathrm{i}}$

m

$\mathrm{m}_{1}$

$\mathrm{m}_{2}$

$\mathrm{m}_{\mathrm{a}}$

$\mathrm{m}_{\mathrm{e}}$

$\mathrm{m}_{\mathrm{f}}$

$\mathrm{M}_{\mathrm{f}}(\mathrm{x}) \quad$ N.m

$\mathrm{M}_{\mathrm{t}}$

$\mathrm{n}$

$q(x)$

$\mathrm{r}$

S

$\mathrm{u}_{\mathrm{b}}$

$\mathrm{u}_{\mathrm{i}}$

$\mathrm{u}_{\mathrm{i}+1}$

V

w

W
GPa

$\mathrm{m}$

$\mathrm{m}$

$\mathrm{m}^{4}$

$\mathrm{m}^{4}$

$\mathrm{m}$

m

m

$\mathrm{m}$

$\mathrm{kg}$

$\mathrm{kg}$

$\mathrm{kg}$

N.m

m

$\mathrm{m}$

$\mathrm{N}$

$\mathrm{N}$

$\mathrm{m}^{3}$

$\mathrm{m}^{3}$
Binary load

Function $g$

Transversal Elasticity Modulus

Section height

Inner section height

Function $\mathrm{h}$

Quadratic programming optimization Matrix

Axial Inertia moment

Polar inertia moment

Element stiffness

Function K

Element length

Lower Bound

Mean line perimeter

Length

Instantaneous length of the specimen on tensile test

Mass

Mass of the object 1

Mass of the object 2

Lower limit or upper limit constraints

Equality constraints

Inequality constraints

Bending moment

Torsion Moment

Safety coefficient

Objective function

Distance of the point to the action line of the force

Slope of the recta

Upper bound

Force on the elements at nodes $\mathrm{i}$

Force on the elements at nodes $i+1$

Volume

Weight of the optimization variables

Moment of resistance 
$\mathrm{y}_{\mathrm{b}}$

$\mathrm{y}_{\mathrm{bc} 1}$

$\mathrm{y}_{\mathrm{bc} 2}$

$\mathrm{y}_{\mathrm{c}}$

$\mathrm{y}_{\mathrm{t}}$

$\mathrm{y}_{\text {total }}$

Z

$\alpha$

$\beta$

$\gamma$

v

$\zeta$

$\lambda$

$\phi$

$\theta$

$\vartheta$

$\varepsilon$

$\tau$

$\eta$

$\mu$

$\delta$

$\sigma$

$\sigma_{\mathrm{b}}$

$\rho$ m

x coordinate

Optimization parameter 1

Optimization parameter 2

$\mathrm{m}$

m

m

m

$\mathrm{m}$

$\mathrm{m}$

$\mathrm{m}$

m

$\mathrm{m}$

$\mathrm{Kg} / \mathrm{m}^{3}$

degrees

$\mathrm{rad}$

$\mathrm{Pa}$

$\mathrm{Pa}$

$\mathrm{Pa}$

$\mathrm{m}$

Optimization parameter $\mathrm{n}$

y coordinate

Boundary condition 1

Boundary condition 2

Deflection due to torsion

$\mathrm{z}$ coordinate

Optimization parameter

Density

Poisson coefficient

Unitary work

Rigidity coefficient

Distortion angle

True strain

Shear stress

Relative displacement

Normal stress

Ultimate tensile strength

Curvature radius
Nodal deflection on node $\mathrm{i}$

Vector of the optimization variables

Mean y coordinate of the object 1

Mean y coordinate of the object 2

Deflection due to bending

Centre of mass coordinate of the system

Deflection due to bending and torsion combined load

Loading conditions coefficient

Diagonal angle of the initial beam

Work produced by the relative displacement of the forces

Ratio of the rib height to the original height

Ratio of the rib width to the original profile width 


\section{Subscriptions}

Symbol

Description

0

1

avg

0.2

eq

flex

gen

1

long

trans

tens

total

tors

$\mathrm{T}$

$\mathrm{u}$

$\mathrm{xx}$

y

\section{Operators}

Symbol

Description

ds

$\mathrm{dx}$

dy

$d^{2} x$

$d^{2} y$

$\Delta$
Initial

First

Relative to average value

Relative to Yield

Relative to equivalent

Relative to flexure (bending)

Relative to generalized rigidity index

Relative to the lower limit

Relative to longitudinal direction

Relative to transversal direction

Relative to tensile

Relative to torsion and bending combined load

Relative to torsion

Relative to transverse matrix

Relative to the upper limit

Relative to the $\mathrm{x}$ axis

Relative to y direction
Distance between two points

$1^{\text {st }}$ order differential of $\mathrm{x}$ coordinate

$1^{\text {st }}$ order differential of y coordinate

$2^{\text {th }}$ order differential of $\mathrm{x}$ coordinate

$2^{\text {th }}$ order differential of $y$ coordinate

Variation 


\section{Abbreviations}

Symbol

Description

ASCII

ANSYS

CFRP

CLM

Const

DOCOL

DOF

FEM

FGFEM

GFRP

HCT

HMAWV

MATLAB

MGA

PRDNS, DNS

PREX, EX

PRPXY, PXY

PRLG1,LG1

PRLG2,LG2

PRLG3,LG3

PRLG4,LG4

PRLG5,LG5

PRLG6,LG6

LG7

SQP

UTS

2D

$3 \mathrm{D}$
American Standard Code for Information Interchange

Commercial Finite Element Method program

Carbon Fiber reinforced polymer

Coupled Local Minimizers

Constant value

Commercial dual phase steel designation

Degrees of freedom

Finite element method

Fixed Grid Finite Element Method

Glass Fiber reinforced polymer

Commercial dual phase steel designation

Hybrid Model Aerial Working Vehicle

MATrix Laboratory software

Modeling to Generate Alternatives

Density variable

Young modulus variable

Poisson coefficient variable

Geometric variable 1

Geometric variable 2

Geometric variable 3

Geometric variable 4

Geometric variable 5

Geometric variable 6

Geometric constant

Sequential Quadratic Programming

Ultimate tensile strength

Two dimensional

Three dimensional 



CHAPTER 1-INTRODUCTION 


\subsection{Motivation}

The projects of industrial equipments have suffered severe changes, mainly because of the increasing accelerations caused by electrical motors. Those motors are able to cause movements with very high accelerations, sometimes going up to twelve times the acceleration of gravity. The improvement of the movement capability makes necessary an improvement on the resistance and rigidity of structures. The rigidity is one of the basic factors that determine the working capability of equipments, and it usually has a superior effect than resistance on the structure dimensioning. The deflection increase due to high accelerations can cause problems on the equipment regular behaviour before the lack of resistance is problematic. The lack of rigidity in structures causes an increase of friction and wear in the mobile parts, but the main problem are the exaggerated vibrations, which sometimes disturb the adequate operation. To improve rigidity it is necessary to increase the Young modulus of the material and/or the Inertia moment of the material section. The rigidity also depends of the geometrical characteristics, the length of the object and the type of load. In the other hand, it is possible that some composites, such as the glass fiber reinforcement polymer, even having a lower Young modulus than most metals, could have a good mechanical behaviour, as well. Due to the low density of those materials, one can strengthen the structure using more material, and therefore, improve the inertia moment, having a low weight object as a result. The only problem is the high cost of those materials, which are usually more expensive than any commercial steel. The present work focuses the optimization of relevant parameters in structural static analysis by the Finite Element Method. The tools used are the ANSYS program, used for Finite Element modelling and the MATLAB program, used to run and optimize ANSYS models, running a programming code written specifically for this purpose. 


\subsection{Aim of this work}

The main aim of this work is the development and analysis of a Finite Element Model Updating application for structural static analysis to optimize the mechanical behavior of the models when subjected to static combined loads. To achieve the aim, one must optimize geometric parameters and material properties, with the goal of maximizing the rigidity and minimizing the object mass. Rigidity is very important in what relates to engineering parts, because it determines the work capability of engineering industrial equipments. As told before, the importance of rigidity can be higher than resistance in what relates to equipment reliability. To achieve this aim, one has to focus on two main factors: The Young modulus and the Inertia moment. The Young modulus is only dependent of the chosen material, and the Inertia moment is highly dependent on the section of the object. In the other hand, a low mass is good because two factors: the material cost and the admissible acceleration. According to Newton $2^{\text {th }}$ law (eq.1):

$\mathrm{a}=\frac{\mathrm{F}}{\mathrm{m}}$

where:

$\mathrm{a}$ is the acceleration

$\mathrm{F}$ is the applied force

$\mathrm{m}$ is the mass

A lower mass can increase the admissible acceleration that is possible for a system, if the Force $\mathrm{F}$ is kept constant. This is important because of the increasing accelerations of new industrial equipments. In the other hand, a good mass position leads to a higher inertia moment. Rigidity is of special importance in machines performing accurate operations, such as metal cutting tools (example: Laser cutting), where the dimensional precision of the final product must be as higher as possible. Rigidity is also very important in some manufacturing machines, mainly those used commonly to manufacture transport vehicles, aircraft and rockets. Special attention is given to rigidity problems presenting high tensile strength or super-high tensile strength materials, where those materials may drastically increase deflections. In fact, there is the tendency of reducing the high-strength object thickness because the Yield stress is higher in highstrength steels than in regular steel. However, their Young modulus is similar, which 
means that if the material enters the plastic domain, the deflections should be similar if the objects have the same dimensions. Therefore, if the thickness of a high-strength steel object is decreased, there might be a drastic increase of deflection in comparison to a similar object, made of regular steel but with a higher thickness [1]. The applications of this work are the transversal beams of some industrial equipments, such as laser cutting machines and plotters.

\subsection{State of the art}

\subsubsection{Rigidity and the Finite Element Method}

Rigidity can be defined as the capability of a mechanical system to deflect as less as possible when subjected to external loads. If the rigidity of a system is higher in comparison to other considering the same applied loads and the same material, the deflections are lower. There are equations to evaluate the rigidity of structural parts by means of a stiffness coefficient. The stiffness coefficient is the ratio between the load $\mathrm{F}$ applied to a system and the maximum deformation $f$ that results from the application of the load. In the case of tension-compression of a beam with constant cross-section in the elastic domain, the stiffness coefficient complies with Hooke's law:

$\lambda_{\text {tens }}=\frac{F}{f}=\frac{E A}{L}$

where:

$\lambda_{\text {tens }}$ is the rigidity coefficient in tension-compression

$\mathrm{E}$ is the Elasticity Modulus of the material

$A$ is the area of cross section of the beam

$\mathrm{L}$ is the beam length measured along the action of the force

$\mathrm{F}$ is the applied load

$\mathrm{f}$ is the maximum deflection

When a beam with constant cross-section is subjected to torsion, the stiffness coefficient is the ratio between the applied torque moment $\mathrm{M}_{\mathrm{t}}$ and the twist angle $\theta$ (eq.3):

$\lambda_{\text {tors }}=\frac{\mathrm{M}_{\mathrm{t}}}{\theta}=\frac{\mathrm{GI}_{\mathrm{p}}}{\mathrm{L}}$ 
where:

$\lambda_{\text {tors }}$ is the rigidity coefficient in torsion

$\mathrm{G}$ is the Shear Modulus of the material

$I_{p}$ is the polar moment of inertia of beam section

$\mathrm{L}$ is the beam length measured along the action of the force

$\mathrm{M}_{\mathrm{t}}$ is the torsion moment

$\theta$ is the distortion angle

In the case of bending of a beam with constant cross-section, the stiffness coefficient can be expressed by the eq. 4 :

$\lambda_{\text {flex }}=\frac{F}{\mathrm{f}}=\frac{\alpha \mathrm{EI}}{\mathrm{L}^{3}}$

where:

$\lambda_{\text {flex }}$ is the rigidity coefficient in bending

I is the axial inertia moment of the beam's section

$\alpha$ is a coefficient depending upon loading conditions

$\mathrm{f}$ is the maximum deflection

As described, the rigidity of the constructions is governed by the factors:

-E in tension-compression and bending and $\mathrm{G}$ in torsion

-The moment of inertia $\mathrm{I}$ or $\mathrm{I}_{\mathrm{p}}$ respectively in bending or torsion loading

-Linear dimensions of the deformed body $\mathrm{L}$

-Type of loading and type of supports

The elasticity is a very stable characteristic of the metals and depends uniquely of the density of the atomic crystalline lattice (the mean inter-atomic distance). However, with the development of composite materials, it has become possible to have multiple materials in one object only with the aim of obtaining an adjustable mean Young modulus. In these circumstances, this strategy can be considered, along with Inertia moment improvement, the best practical way of improving rigidity of a system. Particularly in thin walled structures, like plates and shells, the stability of the systems is very important. One strategy that can be used against the lack of stability is the reinforcement of easily deformable sections in the system by introducing stiffness limits 
between the deforming section and the rigid units, and providing higher rigidity on connecting points. Together with the increase in external sizes and decrease of wall sections thickness it is necessary to increase rigidity in the transversal directions of acting bending forces and torsion moments in order to avoid losses of construction stability. Ribbing has wide application in improving rigidity, particularly in thin walled components. Strength may significantly increase when one increase the rib thickness, particularly at the critical regions. The influence of relative rib pitch and width of ribs upon the rigidity and strength of a part is not easily expressed in a generalized form. Because of this fact, an optimization process that can help the designer in the most adequate selection between the existing valid solutions is very interesting and useful. The use of numeric methods of calculus, such as the Finite Element Method (FEM), controlled by optimization processes, can be a precious help in these cases [1]. There are scientific works about the application of the Finite Element Method in structural static and dynamic analysis. Y. Liu and L. Gannon wrote a paper entitled "Finite element study of steel beams reinforced while under load", consisting of reinforcing a w-Shape steel beam with welded plates while under load. The Finite Element Method was used for its modeling with the finality of investigate the effect of some parameters related to the process [2]. Other authors, as G. Falsone, G. Ferro, demonstrated that "An exact solution for the static and dynamic analysis of FE discretized uncertain structures" can be obtained. The work is about the probabilistic analysis of FE discretized uncertain linear structures in the static and dynamic structural analysis. The authors concluded that the corresponding relationships between the response and the reduced number of variables may be trivially deduced from the exact ones [3]. The Fixed Grid Finite Element Method (FGFEM) method has been recently used by F. Daneshmand and M. Kazemzadeh-Parsi to study the "Static and dynamic analysis of 2D and 3D elastic solids using the modified FGFEM". In this work a modification of the FGFEM is presented and used for the static and dynamic analysis of 2D and 3D elastic solids. The accuracy and convergence of the proposed method was analyzed via some numeric examples and the results were compared with analytic and numeric solutions. The authors conclude that the results show good agreement with the analytic and numeric solutions [4]. The mechanical behavior of shells of revolution was studied in the work "Nonlinear static and dynamic analysis of shells of revolution", by C. Polat, Y. Calayir. In this work, geometrically nonlinear static and dynamic response of shells of revolution is investigated. During this work, a MATLAB code was developed to study geometrically 
linear and nonlinear static and dynamic responses of shells of revolution. The authors conclude that the nonlinearity affect the solutions significantly [5].

\subsubsection{About Optimization methods}

B. Zárate and J. Caicedo studied multiple alternatives to the Finite Element Model Updating technique in the work "Finite element model updating: Multiple alternatives". The authors studied a Finite Element Model Updating methodology of complex structural systems. Traditional Finite Element Model Updating techniques optimize an objective function to calculate one single optimal model that behaves similarly to the real structure and represents the physical characteristics of the structure. The author have discovered that a local minimum, rather than the global minimum could be a better representation of the physical properties of the structure, mainly due to numeric and identification errors, as well as the limited number of sensors in structures. The proposed method is based on MGA - Modeling to Generate Alternatives [6]. An optimization method called "Coupled Local Minimizers" was used by P. Bakir, E. Reynders, G. Roeck in the paper entitled "An improved Finite Element Model Updating method by the global optimization technique 'Coupled Local Minimizers' ".In this scientific work, a global optimization method called 'Coupled Local Minimizers' (CLM) is used for updating the Finite Element Model of a complex structure. The CLM method is compared with other local optimization methods such as the LevenbergMarquardt algorithm, Sequential Quadratic Programming and Gauss-Newton methods and the results show that the CLM algorithm gives better results in Finite Element Model Updating problems compared to the above-mentioned local optimization methods [7]. The paper "Discrete optimization problems of the steel bar structures", by S. Kalanta, J. Atkociunas, A. Venskus focus the optimal design problems of elastic and elastic-plastic bar structures. These problems are formulated as nonlinear discrete optimization. The main conclusions were: Elastic-plastic framed structure analysis confirmed the statement that often an optimal structure project is determined not by the strength, but the stiffness, stability and structural requirements, and, mathematical models and solution algorithms for $2 \mathrm{D}$ optimization problems can be adopted for solutions of 3D optimization problems [8]. X. Bin, C. Nan and C. Haunt have implemented "An integrated method of multi-objective optimization for complex mechanical structure", where the authors present an integrated method of multi- 
objective optimization for complex mechanical structures. It integrates prototype modeling, FEM analysis and optimization. To explore its advantages over traditional methods, optimization of a manipulator in hybrid mode aerial working vehicle (HMAWV) is adopted. The results indicated that this integrated method is effective and shows a potential in engineering applications. The authors concluded that this integrated method of multi-objective optimization has solved a practical problem successfully, and its efficiency has been improved greatly compared with enumerative methods [9]. Based on the work of this thesis, a scientific paper was written and oral presented on VI International Materials Symposium MATERIAIS 2011, held in University of Minho, Guimarães (Annex 4) [10].

\subsection{Context and purpose of the work and structure of the thesis}

The most important goal of this work is the minimization of nodal deflections due to applied loads. Ribbing is an effective way of maximizing inertia moment. Therefore, there is the need of optimizing ribbing-related variables, such as rib thickness, length between consecutive ribs, and rib height, in the particular case of plate objects. When those three parameters are optimized using a suitable objective function, one can achieve good results. In the case of the tubular beam considered in this work, the relevant variables are: distance from the center to the corner segment in each side; length of the center segment, and height of the center segment. In the other hand, material properties, such as Young modulus and Poisson coefficient also affect the deflection results. Having this fact in consideration, all the variables were studied alone, in order to know how its variation affects the value of the objective function. In chapter 1 , the state of the art is presented, as well as the motivation and the aim of this work. In chapter 2, the related theory is presented, including theory about mechanical tests, equation demonstrations and optimization. In Chapter 3, the experimental procedure is presented. This chapter is about the materials selection, section optimization, FEM models and the MATLAB optimization program. The results are presented on chapter 4. The chapter 4 is about mechanical tests results (tensile test and extensometry test), variable analysis of the two finite element models (ribbed plate and tubular beam), FEM results on ANSYS, and MATLAB optimization results (final values of the objective 
function and variables). The optimization variables were six, in both models: three variables are geometric, and three variables are material properties. The geometric parameters are different in the two FEM models. However, the studied material properties are the same for the two models. Chapter 5 is about the results discussion and conclusions. It features mechanical tests, FEM, and optimization results discussion and conclusions. The Annex 1 contains the tensile test and extensometry test charts, featuring stress-strain charts, stress-extension charts, and charts used to determine two mechanical properties of the material: Yield stress and Young modulus. In the Annex 1, there are also the tables used to calculate Young modulus and Poisson coefficient in extensometry test. In the Annex 2, one can see the variable analysis data, featuring nodal deflection values and the charts obtained in the variable analysis. In the Annex 3 one can see the Finite Element Model input files, used to optimize the models on MATLAB. In the Annex 4 there is the scientific paper published during this thesis. 
CHAPTER 2-RELATED THEORY 


\subsection{Introduction to Finite Element Method}

The Finite Element Method is a numeric procedure that can be used to obtain solutions to a large number of engineering problems involving stress, deflection, heat transfer and electromagnetic phenomena. The finite element method (FEM) consists in a computer model that is analyzed under certain conditions. FEM is used either in new product design, and existing product refinement. It is very useful to verify if a proposed design will be able to perform to the client's specifications before manufacturing. A modification in an existing product or structure is usually done with the purpose of qualify the product or structure for a new service condition. In case of structural failure, FEM may be used to help the design improvement in order to meet the new service condition [11]. In the case of structural static analysis, which is the subject of this work, the model is statically loaded. In this work, one is analyzing the elastic domain only, due to the nature of the application. In the elastic domain, there is a linear relation between stress and strain. The proportionality constant is the Young modulus E, as shown next in eq. 5 :

$\sigma=\mathrm{E} \varepsilon=\mathrm{E} \frac{\Delta \mathrm{L}}{\mathrm{L}_{0}}$

where:

$\sigma$ is the Normal stress

$\varepsilon$ is the Strain

$\mathrm{E}$ is the Young modulus

$\Delta \mathrm{L}$ is the length variation

$\mathrm{L}_{0}$ is the initial length of the object

In FEM, it is very important to assume a solution that approximates the behaviour of the elements. Considering the deflection of a solid member with a uniform cross-section A, a length $\mathrm{L}$ when subjected to a tensile Force F, one can say that the normal stress is given by eq. 6 :

$\sigma=\frac{\mathrm{F}}{\mathrm{A}}$ 
where:

$\mathrm{F}$ is the applied force

$\mathrm{A}$ is the area of the cross-section

Using Eq. 5 and 6, one can obtain a new equation (Eq.7):

$\mathrm{F}=\frac{\mathrm{AE}}{\mathrm{L}_{0}} \Delta \mathrm{L}$

The elastic behaviour of an element can be modelled by an equivalent linear spring according to the eq. 8 [12]:

$F_{e}=k_{e q}\left(u_{i+1}-u_{i}\right)=\frac{A_{a v g} E}{1}\left(u_{i+1}-u_{i}\right)=\frac{\left(A_{i+1}+A_{i}\right) E}{2 l}\left(u_{i+1}-u_{i}\right)$

where:

$\mathrm{F}_{\mathrm{e}}$ is the force on the elements

$A_{i}$ and $A_{i+1}$ are the cross sectional areas of the member at nodes $i$ and $i+1$

$\mathrm{A}_{\text {avg }}$ is the average area

1 is the length of the element

$\mathrm{u}_{\mathrm{i}}$ and $\mathrm{u}_{\mathrm{i}+1}$ are the forces on the elements at nodes $\mathrm{i}$ and $\mathrm{i}+1$, respectively

The equivalent element stiffness is $\mathrm{k}_{\mathrm{eq}}=\frac{\left(\mathrm{A}_{\mathrm{i}+1}+\mathrm{A}_{\mathrm{i}}\right) \mathrm{E}}{21}$

Despite the advantages of the FEM, it has limitations that can lead to errors in the analysis results. In many practical engineering problems one cannot obtain exact solutions. The difficulties to obtain exact solutions may be attributed to either the complex nature of the governing differential equations or the difficulties that arise from dealing with the boundary and initial conditions. The errors that contribute to the models limitations can be divided into: User errors, due to mistakes in the data input process, such as physical properties and dimensions, misuse of the selected elements, misapplication of DOF constraints, low discretization of the geometry of the structure, for example, due to an inappropriate rough mesh size or an inaccurate approximation of geometries and inherent numeric methods errors used to solve the equilibrium equations. These errors are due to the finite precision of the method, where conditions are not controllable, or expected. For complex structures, even when using correct meshes for each specific problem, errors can be substantial. These errors occur due to difficulties in adapting the meshes to the geometry of the model [13]. 


\subsection{About ANSYS}

The implementation of the Finite Element Method usually follows three steps: Preprocessing, solution and post-processing. Within these three basic steps, there are substeps. In pre-processing, one defines the geometric model and builds the mesh with the elements. In this work, the sequence of creating the geometric model was: keypoints, then lines by keypoints and then areas by lines. The mesh makes possible the discretization of the elements on the domain, by assigning to each element segment a partial differential equation. All the differential equations are discretized after integration in the area of the elements. The equations are then solved by algebraic methods, such as gauss elimination method. In the solution menu it's necessary to define the loads and the DOF displacements (constraints). After solving the model, the results can be viewed in the post-processing menu. For structural static analysis, as in this work, the most important are the stresses and the deflections. This work has the aim of obtaining the lowest possible deflections. Because of that, the results taken from the program were the deflections. The stresses are also an indicator of the mechanical behavior, since they are responsible for mechanical deflection. With FEM commercial software, such as ANSYS, all these steps can be performed through graphical interfaces or by command input.

\subsection{Bending and Torsion loading}

In practice is very common to find situations where the objects are loaded with a combination of bending and torsion. Bending is usually due to central transverse load, and torsion can be due to transverse load that is not centered. In some situations, these two types of loading act at the same time, and so, one have a combination of bending and torsion. In bending there are only normal stresses, and in torsion there are only shear stresses. The next figure (fig. 1) shows the FEM model, its loading and DOF constraints used in the preliminary analysis. The considered load was a centred bending load $\mathrm{F}$ of $3528 \mathrm{~N}$, which is 12 times the acceleration of gravity on a mass of $30 \mathrm{~kg}$ $(12 * 9,8 * 30=3528 \mathrm{~N})$ and a binary load $\mathrm{M}_{\mathrm{t}}=0,2 * \mathrm{~F}_{1}$ that produces torsion, in which $\mathrm{F}_{1}$ is equal to of $5120 \mathrm{~N}$ : 

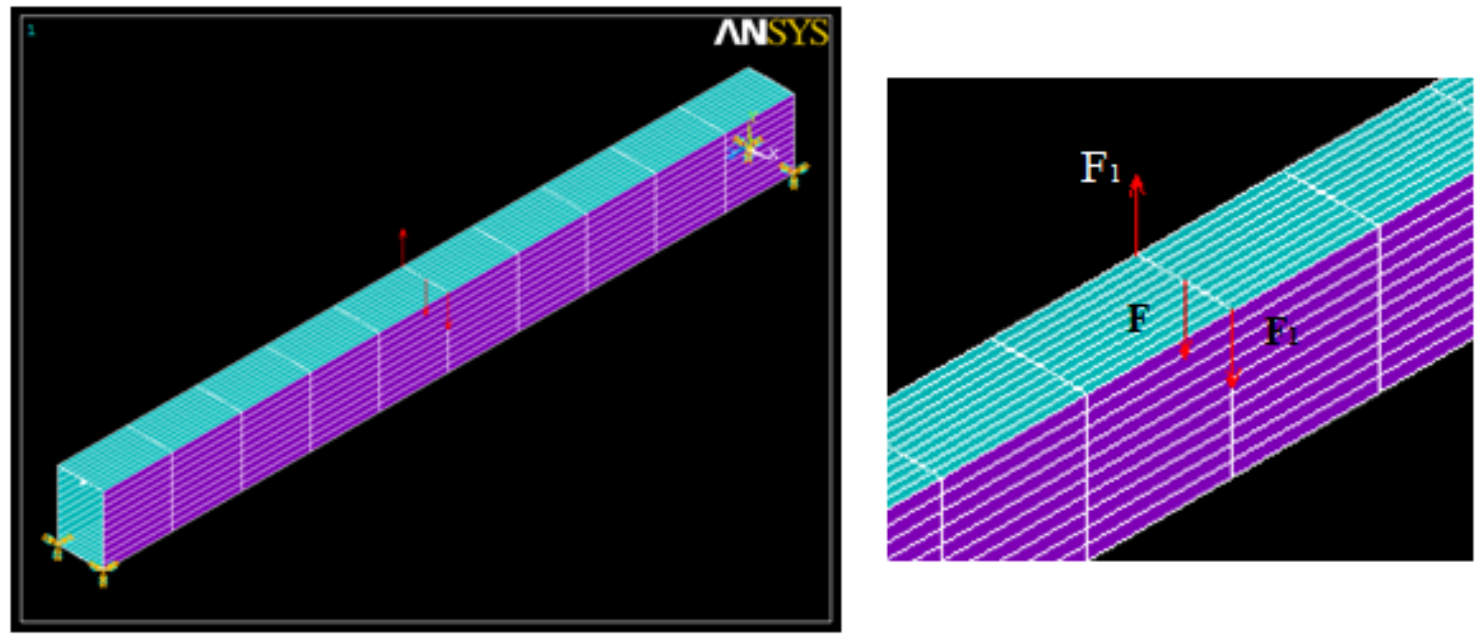

Fig. 1-Load applied to FEM models and DOF constrains

In torsion and bending combined loading, there are both shear stresses due to torsion and normal stresses due to bending. The total deflection is the sum of the deflection due to bending and the deflection due to torsion.

\subsubsection{Mechanical deflection}

\subsubsection{Differential elastic curve}

The initial equation is:

$\frac{1}{\rho}=\frac{M_{f}(x)}{E I}$

where:

$1 / \rho$ is the inverse of the curvature radius

$\mathrm{M}_{\mathrm{f}}(\mathrm{x})$ is the applied bending moment

An approximation can be used to obtain a term which is a function of $\frac{d^{2} y}{d x^{2}}$ :

$\frac{1}{\rho}=\frac{\frac{d^{2} y}{d x^{2}}}{\left[1+\left(\frac{d y}{d x}\right)^{2}\right]^{\frac{3}{2}}} \approx \frac{d^{2} y}{d x^{2}}$

Substituting and integrating:

$\mathrm{EI} \frac{1}{\rho}=\mathrm{EI} \frac{\mathrm{d}^{2} \mathrm{y}}{\mathrm{dx}^{2}}=\mathrm{Mr}(\mathrm{x})$ 


$$
\begin{aligned}
& \text { EI } \theta \approx E I \frac{d y}{d x}=\int_{0}^{x} M_{f}(x) d x+C_{1} \\
& \text { EIy }=\int_{0}^{x} d x \int_{0}^{x} M_{f}(x) d x+C_{1} x+C_{2} \\
& \text { EIy }=\int_{0}^{x} d x \int_{0}^{x} M_{f}(x) d x+C_{1} x+C_{2}
\end{aligned}
$$

Constants can be determined by applying boundary conditions. For a simply supported beam, one has:

$$
\mathrm{ybc} 1=0, \mathrm{ybc} 2=0
$$

The final equation used to obtain the deflection is:

$$
\mathrm{y}_{\mathrm{b}}=\frac{\mathrm{FL}^{3}}{48 \mathrm{EI}}\left(3 \frac{\mathrm{x}^{2}}{\mathrm{~L}^{2}}-4 \frac{\mathrm{x}^{3}}{\mathrm{~L}^{3}}\right)
$$

where:

$\mathrm{y}_{\mathrm{b}}$ is the deflection due to bending

$\mathrm{F}$ is the applied load

$\mathrm{L}$ is the length of the object

$\mathrm{x}$ is the $\mathrm{x}$ coordinate

One can see that the deflection is dependent of both the geometry of the object (Inertia moment I and length L) and the material (Young modulus E). The deflection is also dependent on the load $\mathrm{F}$ and is a function of the $\mathrm{x}$ coordinate [14].

\subsubsection{Torsion deflection}

As a simplification, one can admit that the shear stress is constant along the thickness, with a better accuracy the thinner the object is in relation to the dimensions of the section. One can then demonstrate that the shear flux $\mathrm{C}=\tau \mathrm{t}$ is constant, meaning that the shear stress is constant if the thickness is constant.

If $\mathrm{e}, \mathrm{e}_{1}$ are the thicknesses, and $\tau, \tau_{1}$ are the shear stresses in any two points $\mathrm{m}$ and $\mathrm{n}$, it is possible to know, by sectioning $\mathrm{n}$ and $\mathrm{m}$, that those sections are subjected to shear stresses equal to $\tau$ and $\tau_{1}$. The next figure (fig. 2 ) shows an illustration of a hollow-box 
object, along with the representation of the shear stresses $\tau, \tau_{1}$, the points $m, n$, the thicknesses $\mathrm{e}, \mathrm{e}_{1}$ and the distance between two points ds.

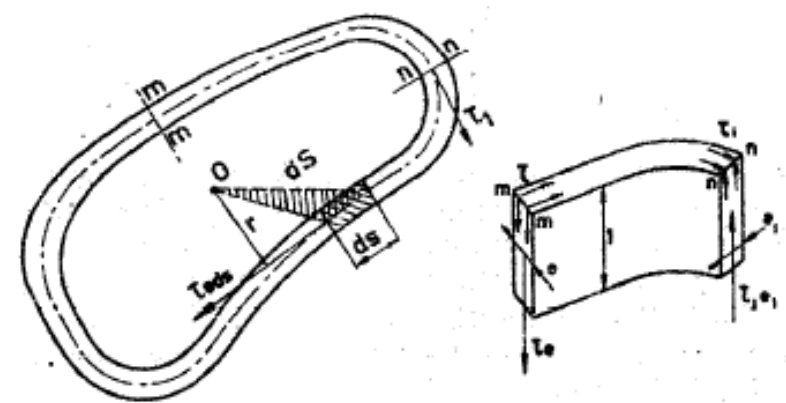

Fig. 2-Representation of a hollow-box object and relevant torsion parameters [15]

Considering two points located on the object wall, separated by a distance ds, the flux is the same for the two points:

$\mathrm{C}=\tau \mathrm{e}=\tau_{1} \mathrm{e}_{1}$

where:

$\mathrm{C}$ is the shear flux

$\tau$ is the shear stress

$\mathrm{e}$ is the object thickness

A face eds is subjected to a force $\tau$ eds, and the moment of this force in relation to any point of the section is $\tau$ erds, where $r$ is the distance of the considered point to the action line of the force $\tau$ eds. Considering that the sum of the moments in every point of the wall should be equal to the torsion moment:

$\int \tau \operatorname{erds}=\mathrm{Mt}$

Therefore, the flux $\tau \mathrm{e}$ can be expressed as a relation with the torsion moment $\mathrm{M}_{\mathrm{t}}$ :

$$
\tau \mathrm{e} \int \mathrm{rds}=\mathrm{M}_{\mathrm{t}}
$$

The above equation (Eq. 14) represents the double of the area $A_{0}$ of the inner side of the mean line. Solving the integral, one can find the expression of the shear stress due to torsion:

$\tau=\frac{\mathrm{M}_{\mathrm{t}}}{2 \mathrm{~A}_{\mathrm{oe}}}$ 
where:

$\tau$ is the shear stress

Mt is the torsion moment

$\mathrm{A}_{0}$ is the area of the mean line

$\mathrm{e}$ is the thickness

The unitary angle of torsion can be obtained by the laws of energy conservation, by considering equal the work of deformation of a beam part with unitary length to the inner work of the same part:

$\xi=\frac{\mathrm{M}_{\mathrm{t}} \theta}{2}$

where:

$\zeta$ is the unitary work

Mt is the torsion moment

$\theta$ is the twist angle due to torsion

The forces $\tau$ eds applied to the horizontal faces of the volume element suffer the relative displacement $\gamma$. The work produced by them is:

$\vartheta=\frac{1}{2} \tau \mathrm{e} \mu \mathrm{ds}$.

where:

$\vartheta$ is the work produced by the relative displacement of the applied forces

$\tau$ is the shear stress

$\mathrm{e}$ is the thickness

$\mu$ is the relative displacement

ds is the distance between the points $n$ and $m$

Because the shear flux $\tau e$ on the vertical faces of the element moves perpendicularly to it, the work produced by them is null. The inner work of the entire object is then:

$$
\xi 1=\frac{1}{2} \int \tau \mathrm{e} \mu \mathrm{ds}=\frac{1}{2} \int \frac{\tau^{2}}{\mathrm{G}} \mathrm{eds}
$$

Considering the equation 16 , one obtains: 
$\frac{\mathrm{M}_{\mathrm{t}} \theta}{2}=\frac{1}{2 \mathrm{G}} \int \tau^{2} \mathrm{eds}=\frac{1}{2 \mathrm{G}} \int \frac{\mathrm{M}_{\mathrm{t}}{ }^{2}}{4 \mathrm{~A}_{0}{ }^{2} \mathrm{e}^{2}} \mathrm{eds}=\frac{\mathrm{M}_{\mathrm{t}}{ }^{2}}{8 \mathrm{GA}_{0}{ }^{2}} \int \frac{\mathrm{ds}}{\mathrm{e}}$

The distortion angle is then:

$\theta=\frac{\mathrm{M}_{\mathrm{t}}}{4 \mathrm{GA}_{0}^{2}} \int \frac{\mathrm{ds}}{\mathrm{e}}$

If the thickness is constant, then the equation 18 , reduces to:

$\theta=\frac{\mathrm{Mtl}_{\mathrm{t}}}{4 \mathrm{GA}_{0}^{2} \mathrm{e}}=\frac{\mathrm{Cl}_{\mathrm{t}}}{2 \mathrm{GA} 0 \mathrm{e}}$

where:

$\theta$ is the twist angle

$\mathrm{C}$ is the shear flux

$l_{t}$ is the mean line perimeter

$\mathrm{G}$ is the transversal elasticity modulus

$\mathrm{A} 0$ is the mean line area

$\mathrm{e}$ is the object thickness

Mt is the torsion moment

The deflection due to torsion can then be calculated [15]:

$\mathrm{yt}_{\mathrm{t}}=\frac{\mathrm{D}}{2} \theta \mathrm{L}$

where:

$\mathrm{y}_{\mathrm{t}}$ is the deflection due to bending

$\mathrm{D}$ is the diagonal length of the object

$\mathrm{L}$ is the length

$\theta$ is the distortion angle

In the next figure (fig. 3), one can see an illustration of a hollow-box object subjected to torsion:

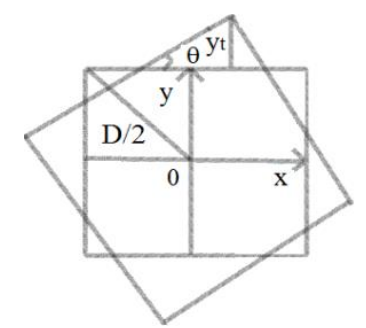

Fig. 3-Hollow-box object subjected to torsion and relevant parameters 
The fig. 3 shows the physical meaning of the torsion deflection $\mathrm{y}_{\mathrm{t}}$, twist angle $\theta$, and half of the diagonal lengh $\mathrm{D} / 2$.

\subsubsection{Total deflection}

The total deflection can be expressed as the sum of the contributions of bending and torsion:

$$
\mathrm{y} \text { total }=\mathrm{yb}+\mathrm{yt}
$$

where:

$\mathrm{y}_{\text {total }}$ is the deflection due to bending and torsion combined load

$\mathrm{y}_{\mathrm{b}}$ is the deflection due to bending

$\mathrm{y}_{\mathrm{t}}$ is the deflection due to torsion

In a bending and torsion combined load, the resulting stresses are the combination of the normal stresses due to bending and the shear stresses due to torsion.

\subsection{Stresses in torsion and bending loading}

This work focuses the deflection dimensioning. There is another possible dimensioning approach: the stress dimensioning, which is based on stress criteria. The most common criteria are the Von Mises criterion and the Tresca criterion. To determine the admissible stress for a system, it is necessary to determine the main stresses after obtaining the normal stress due to bending and shear stress due to torsion. The normal stress due to bending can be calculated by:

$\sigma= \pm \frac{\text { Mfy }}{\mathrm{I}}$

where:

$\sigma$ is the normal stress

Mf is the bending moment

$\mathrm{y}$ is the $\mathrm{y}$ coordinate

I is the Axial Inertia Moment 
The shear stresses due to torsion in thin walled objects can be calculated by:

$\tau=\frac{\mathrm{M}_{\mathrm{t}}}{2 \mathrm{t} \mathrm{A}_{0}}$

where:

$\tau$ is the shear stress due to torsion

$\mathrm{M}_{\mathrm{t}}$ is the torsion moment (torque)

$\mathrm{t}$ is the beam thickness

$\mathrm{A}_{0}$ is the section mean line area

After obtaining the admissible stress by the chosen criteria, one must chose a material with a Yield stress higher than the admissible stress as many times as the safety coefficient $n$ value.

\subsection{Rigidity indices of materials}

It is possible to obtain a generalized strength-rigidity index, by using the factors that represent the weight advantage in terms of strength: $\frac{\sigma_{0.2}}{\gamma}$ and rigidity advantage: $\frac{\mathrm{E}}{\gamma}$.

The generalized index is:

$\lambda_{\text {gen }}=\frac{\sigma_{0.2 \mathrm{E}}}{\gamma}$

where:

$\lambda_{\text {gen }}$ is the generalized rigidity index

$\sigma_{0.2}$ is the yield stress

$\mathrm{E}$ is the Young modulus

$\gamma$ is the density

This index represents the capability of a material to have the less deflection possible, and less weight when subjected to high loads. The fig. 4 shows the value of the generalized rigidity index for the most common engineering materials. The correspondence of the material to the number is as follows: 


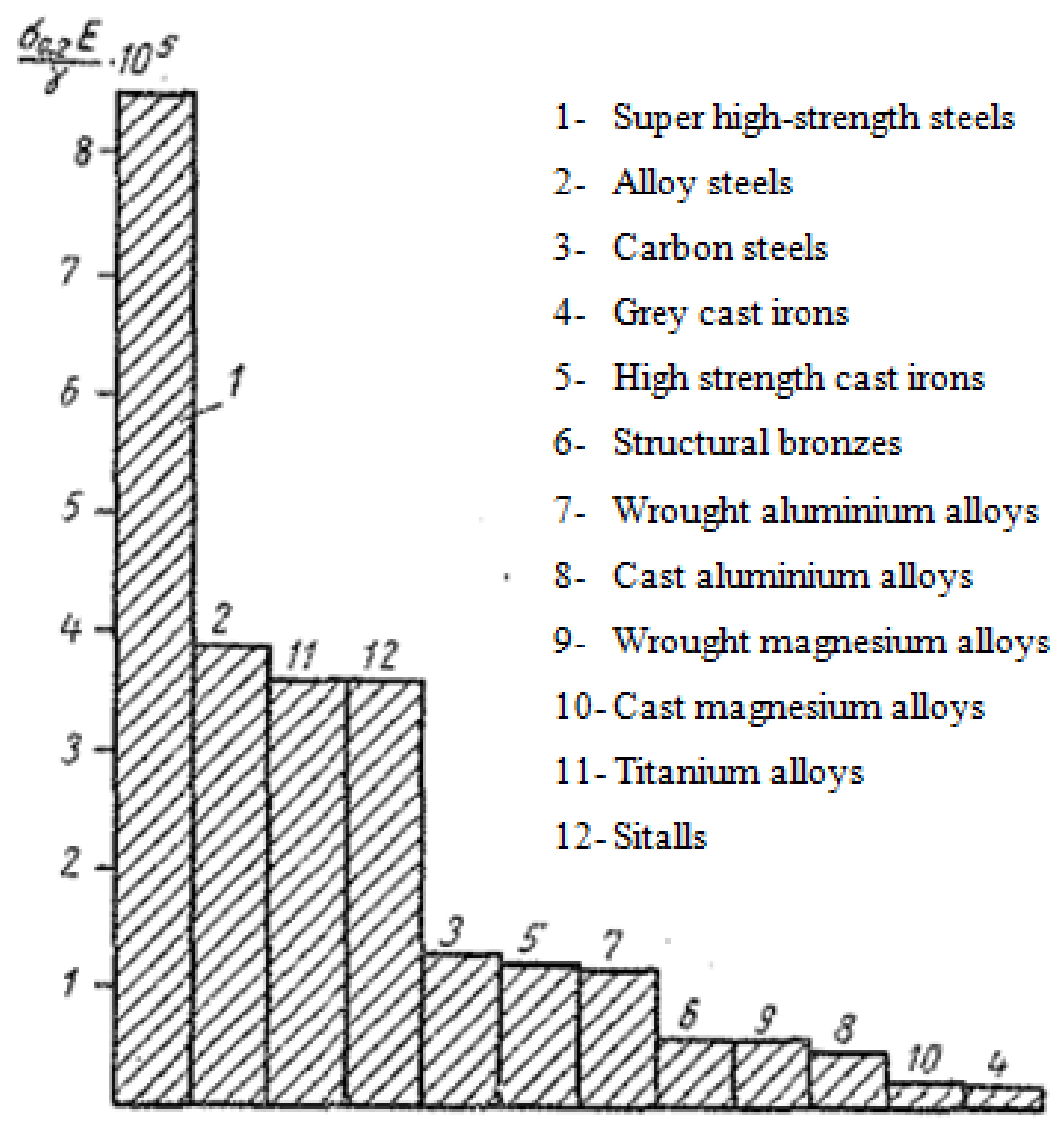

Fig. 4-Generalized strength-rigidity indices [1]

According to the fig. 4, the materials can be separated in four groups:

1-Super high-strength steels ( $\lambda$ gen $\approx 8^{*} 10^{5}$ )

2-Alloy steels, titanium alloys and sitalls $\left(3,5^{*} 10^{5} \leq \lambda_{\text {gen }} \leq 4 * 10^{5}\right)$

3 -Carbon steels, high strength cast irons and wrought aluminium alloys ( $\lambda_{\text {gen }} \approx 1 * 10^{5}$ )

4-Structural bronzes, wrought magnesium alloys, cast aluminium alloys, cast magnesium alloys, grey cast irons $\left.\left(\lambda_{\text {gen }}<0,5^{*} 10^{5}\right)\right)$.

In the table 1 one can see some properties of the most common structural materials, along with their rigidity characteristics. The material with highest generalized rigidity index is the high-strength steel, with a value of 8,4 . The alloy steels are the second best, but are much worse than the first, with a value of 3,8. Titanium alloys and Sitalls have a value of 3,6, a value close to the alloy steels. The other materials have an index much lower than titanium alloys. For some materials, the index is slightly higher than 1 , but for some materials it is substantially lower than one. 


\begin{tabular}{|c|c|c|c|c|c|}
\hline \multicolumn{2}{|c|}{ Materials } & $\begin{array}{c}\text { Density } \\
\left(\mathrm{kgf} / \mathrm{dm}^{3}\right. \\
)\end{array}$ & $\begin{array}{l}\text { Modulus } \\
\text { of } \\
\text { elasticity } \\
\left(\mathrm{kgf} / \mathrm{mm}^{2}\right)\end{array}$ & $\begin{array}{c}\text { Rigidity } \\
\text { characteristi } \\
\mathrm{c} \frac{\mathrm{E}}{\sigma_{\mathrm{b}}} * 10^{-3}\end{array}$ & $\begin{array}{l}\text { Generalized } \\
\text { factor } \\
\frac{\sigma_{0.2 \mathrm{E}}}{\gamma} * 10^{-5}\end{array}$ \\
\hline \multicolumn{2}{|c|}{ Carbon Steels } & \multirow{3}{*}{7,85} & \multirow{3}{*}{21000} & 2,6 & 1,3 \\
\hline \multicolumn{2}{|l|}{ Alloy Steels } & & & 1,17 & 3,8 \\
\hline \multicolumn{2}{|c|}{ High-strenght Steels } & & & 0,6 & 8,4 \\
\hline \multicolumn{2}{|c|}{ Grey cast irons } & 7,2 & 8000 & 2,3 & 0,3 \\
\hline \multicolumn{2}{|c|}{ High-Strenght cast irons } & 7,4 & 15000 & 1,9 & 1,1 \\
\hline \multirow{2}{*}{$\begin{array}{l}\text { Aluminium } \\
\text { alloys }\end{array}$} & Cast & \multirow{2}{*}{2,8} & \multirow{2}{*}{7200} & 2,9 & 0,45 \\
\hline & Wrought & & & 1,2 & 1,1 \\
\hline \multirow{2}{*}{$\begin{array}{l}\text { Magnesium } \\
\text { alloys }\end{array}$} & Cast & \multirow{2}{*}{1,8} & \multirow{2}{*}{4500} & 2,1 & 0,32 \\
\hline & Wrought & & & 1,4 & 0,52 \\
\hline \multicolumn{2}{|c|}{ Structural Bronzes } & 8,8 & 11000 & 1,85 & 0,6 \\
\hline \multicolumn{2}{|c|}{ Titanium alloys } & 4,5 & 12000 & 0,8 & 3,6 \\
\hline \multirow{3}{*}{$\begin{array}{l}\text { Structural } \\
\text { plastics }\end{array}$} & $\begin{array}{l}\text { Delta- } \\
\text { wood }\end{array}$ & 1,4 & 4000 & 2 & - \\
\hline & $\begin{array}{l}\text { Glass- } \\
\text { fibers }\end{array}$ & 1,6 & 5000 & 1,67 & - \\
\hline & GFAM & 1,9 & 6000 & 0,86 & - \\
\hline \multicolumn{2}{|l|}{ Sitalls } & 3 & 15000 & 1,87 & 3,6 \\
\hline
\end{tabular}

Table 1-Strenght and rigidity characteristics of structural materials [1]

The material selection for a structural application is determined by the strength-rigidity characteristics, but also by the relevant material properties for the considered application. The mechanical design has a very high importance, because it's possible to build an object with high rigidity and strength, even when the material is not so stiff and strong. The shape is therefore more relevant than the material for the mechanical deflections reduction [1].

\subsection{Relation between structural rigidity and material properties}


The rigidity of the structures is determined by the deflection. The deflection is dependent of the material properties and depends also of the geometric characteristics of the object. The bending deflection due to transverse load can be expressed, as told before, by:

$\mathrm{y}_{\mathrm{b}}=\frac{\mathrm{FL}^{3}}{48 \mathrm{EI}}\left(3 \frac{\mathrm{x}^{2}}{\mathrm{~L}^{2}}-4 \frac{\mathrm{x}^{3}}{\mathrm{~L}^{3}}\right)$

where:

$\mathrm{y}_{\mathrm{b}}$ is the deflection (function of $\mathrm{x}$ coordinate)

I is the axial inertia moment of the section

$\mathrm{E}$ is the Young modulus of the material

$\mathrm{L}$ is the beams length

$\mathrm{F}$ is the applied load

$\mathrm{x}$ is the $\mathrm{x}$ coordinate

One can see that the material selection plays an important role in this work, since there is a dependency of Young modulus on the deflection results. The results may vary drastically if a different material is used, mainly in terms of the Young modulus. The density is very important because the object mass is directly related to it:

$\gamma=\frac{\mathrm{m}}{\mathrm{V}}$

where:

$\gamma$ is the density of the material

$\mathrm{m}$ is the material mass

$\mathrm{V}$ is the object volume

As Newton's second law say that:

$\mathrm{a}=\frac{\mathrm{F}}{\mathrm{m}}$

where:

$\mathrm{m}$ is the mass of the material

$\mathrm{a}$ is the acceleration

$\mathrm{F}$ is the applied force

One can see that a lower mass can be important to obtain a good behavior of the structure, since for a certain load, the lower the mass, the higher can be the acceleration 
without structural failure, or/and undesirable vibrations. The density should be as low as possible because for an object of the same dimensions, the mass is lower the lower is the density. Two methodologies can be used in this work to achieve the goal of deflection minimization:

- The Young modulus of the material must be the highest possible, because the deflections are a function of it. This methodology is based on the importance of the material properties. The high-strength steels, such as dual-phase steels, seem to be the most suitable materials. This was the methodology used in this work.

- One can choose a material with not so high Young modulus, but with a relatively low density and low/medium cost that allows the maximization of the Inertia moment by means of object reinforcement with longitudinal webs or ribs. This methodology is based on the improvement of the Inertia moment. Some suitable materials for this methodology include composites, such as GFRP- Glass fiber reinforced polymer.

\subsection{Mechanical tests}

\subsubsection{About tensile test}

A tensile test, also known as tension test, is the most relevant type of mechanical test that can be performed on a material. It is used to determine the mechanical properties of metals and metallic alloys. The main advantages of tensile tests are: simplicity, they are relatively inexpensive, and fully standardized. As the test is performed, one will obtain a stress-strain curve similar to what is shown next: (fig. 5)

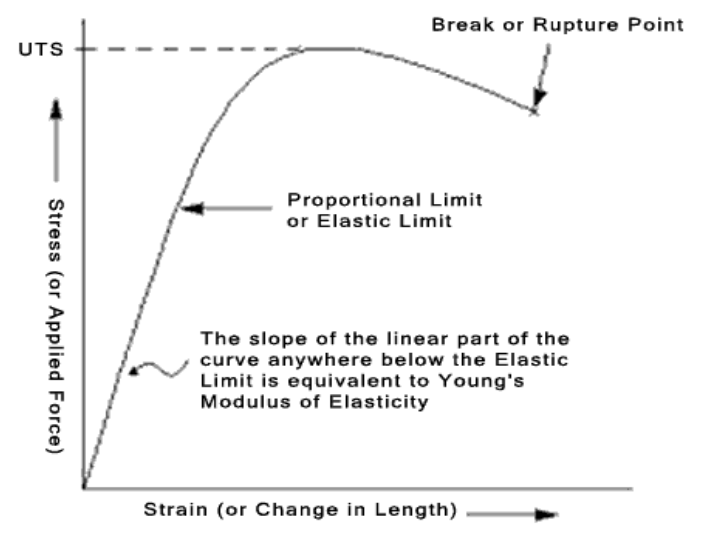

Fig. 5-Typical stress-strain curve on a tensile test [16] 
By performing this test, one can determine how the material reacts to the force being applied, and consequently, one is able to obtain the material's most important properties, such as Young modulus, elongation, Yield stress, stress at rupture, elongation until fracture (\%), and area reduction until fracture (\%). The results obtained from the test can be used to build a normal stress-strain chart and a normal stressextension chart. The test specimens can be round, having $12,7 \mathrm{~mm}$ of diameter or can be flat. When the original material has enough thickness, the specimens are usually round. The reference length in the center of the specimen is usually $51 \mathrm{~mm}$ [17]. In the fig. 6 one can see a tensile test machine.

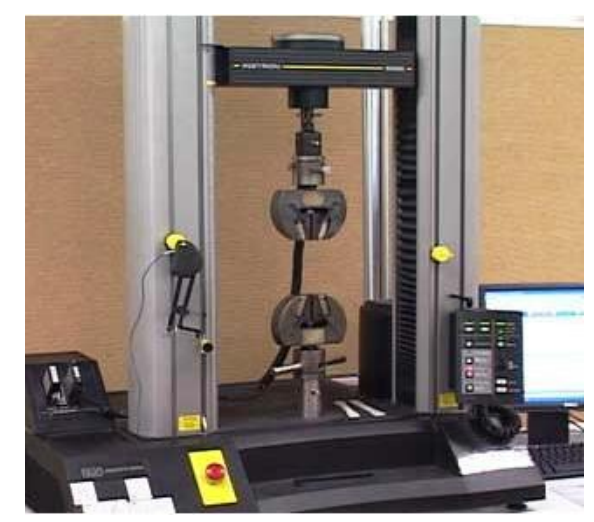

Fig. 6-Tensile test device [18]

\subsubsection{Elastic and Plastic domains}

The stress-strain chart shown on fig. 5 can be divided in two mechanical behavior domains. The elastic domain, used to estimate the Young modulus using Hooke's law, and the plastic domain. In graphical terms, the elastic domain is the linear part of the graphic, where the stress is directly proportional to the strain, being the Young modulus the proportionality constant. The plastic domain is represented by a non-linear curve. The difference between the elastic and plastic domains is that when a load is applied and the material doesn't leave the elastic domain, if the load is removed, then there will be no residual strain and the material returns to its original dimensions. If the plastic domain is reached, then there will be a residual strain after the load is removed, that will be higher the higher is the applied load when the load is removed. In the elastic domain, the Young modulus can be determined by the slope of the stress-strain curve [17]. 


\subsubsection{Relevant properties obtained from a tensile test}

\subsubsection{Modulus of Elasticity}

The modulus of elasticity is a measure of the stiffness of the material, but its determination is only valid in the linear region of the stress-strain chart. Even in the linear region of the chart, one cannot obtain the exact Young modulus, but an approximation. The Young modulus is constant in every point of the linear region of the stress-strain chart (elastic domain) [17].

\subsubsection{Yield stress}

The Yield stress of a material can be defined as the stress applied to the material at which plastic deformation starts to be relevant when the material is loaded. Because there is not a well defined point that is the end of the elastic domain region and the beginning of the plastic domain, one usually chooses a Yield stress for a certain plastic deformation. For structure projects, yield stress is usually calculated for a plastic deformation of 0,002 , which is $0,2 \%$. Yield stress is usually calculated by making a line, starting on the point 0,002 in the strain axis and stress equal to 0 . The line is parallel to the elastic domain curve. The point where the recta intersects the plastic domain of the stress-strain curve is the Yield stress (stress axis) and Yield strain (strain axis) [17].

\subsubsection{Rupture stress}

Rupture stress is the current stress when the specimen suffers rupture. In projects with ductile metallic alloys, the rupture stress is usually not an important value, because the correspondent strain is very high. However, rupture stress can give an indication about the presence of defects. When there are defects, such as pores or inclusions, the rupture stress may be lower than the expected [17.]

\subsubsection{Elongation}

One is able to determine the amount of stretch or elongation the specimen suffers during tensile test. This can be expressed as an absolute measurement in the change in length called extension or as a relative measurement called "strain". There are two types of strain, the "engineering strain" and "true strain". Engineering strain is probably the 
easiest and the most common expression of strain used. It is the ratio of the change in length to the original length:

$\mathrm{e}_{\mathrm{s}}=\frac{\mathrm{L}-\mathrm{L}_{0}}{\mathrm{~L}_{0}}=\frac{\Delta \mathrm{L}}{\mathrm{L}_{0}}$

where:

$\mathrm{e}_{\mathrm{s}}$ is the engineering strain

$\mathrm{L}$ is the final specimen length

$\mathrm{L}_{0}$ is the initial specimen length

The true strain is similar but based on the instantaneous length of the specimen as the test progresses:

$\varepsilon=\ln \left(\frac{\mathrm{Li}_{\mathrm{i}}}{\mathrm{L}_{0}}\right)$

where:

$\varepsilon$ is the true strain

$\mathrm{L}_{\mathrm{i}}$ is the instantaneous length

$\mathrm{L}_{0}$ the initial length.

The elongation is a measure of the material ductility. When the elongation is high, the material ductility is usually high, and when the elongation is low, the material ductility is usually low. The elongation can be obtained by joining the two parts of the specimen that break during the tensile test and measuring the length. The initial length is usually $51 \mathrm{~mm}$. The length should be delimited with a marker before the test, because one has no way of measuring the elongation if this is not done [16].

\subsubsection{Ultimate Tensile Strength}

The ultimate tensile strength (UTS) is the maximum load the specimen sustains during the test. The UTS may or may not be equal to the strength at break. This all depends on what type of material one is testing: brittle, ductile, or a substance that even exhibits both properties. The ductility depends on the conditions used, for example, sometimes a material may be ductile when tested in a laboratory, but when placed in service and exposed to extreme cold temperatures, it may suffer a transition to brittle behavior [17]. 


\subsubsection{Determination of the Young modulus in tensile test}

In tensile test, one obtained a results file. The results file has many columns, such as time (in seconds), extension (mm), strain 2\% (\%), Load (N), Tensile Stress (MPa), Tensile extension (mm), Tensile strain (\%), displacement (Strain 2 in $\mathrm{mm}$ ), True strain $\%$, position(mm), corrected position, toughness ( $\mathrm{gf} / \mathrm{tex})$, and true stress $(\mathrm{Pa})$. The results are sorted by time, and each line corresponds to a time instant. The relevant results are the extension, the strain $2 \%$, and the load. By dividing the load by the transversal area of the specimen one can find the nominal stress:

$$
\sigma=\frac{F}{A}
$$

where:

$\mathrm{F}$ is the applied load

A is the transversal area of the specimen

$\sigma$ is the normal stress

The Young modulus is given by equation 5:

$$
\mathrm{E}=\frac{\sigma}{\varepsilon}
$$

where:

$\mathrm{E}$ is the Young modulus

$\sigma$ is the normal stress

$\varepsilon$ is the strain

In order to determine Young modulus, one must do the linear fit of the stress-strain chart for the elastic domain data. The equation used to perform the linear fit is: $\mathrm{y}=\mathrm{s} x+\mathrm{b}_{\mathrm{c}}$

where:

$\mathrm{y}$ is the $\mathrm{y}$ coordinate

$\mathrm{x}$ is the $\mathrm{x}$ coordinate

$\mathrm{s}$ is the slope of the recta

$b_{c}$ is the $y$ coordinate on origin 
Because the tested material is a dual-phase steel, the expected Young modulus for the mechanical tests, either tensile and extensometry is $210 \mathrm{GPa}$, which is the regular value for a steel.

\subsection{About MATLAB}

MATLAB is a technical computing environment for high performance numeric computation and visualization. MATLAB features numeric analysis, matrix computation, signal processing and graphics in an easy-to-use environment. MATLAB features a family of solutions for specific applications called toolboxes. Toolboxes are collections of MATLAB functions (M-files) that were pre-programmed in order to extend MATLAB capabilities. MATLAB toolboxes can be related to many areas, including optimization, signal processing, control design, dynamic systems simulation, among others. In this work, the optimization toolbox was used in order to be possible to use a required optimization function named fmincon [19]. There are many types of optimization. According to the type of optimization (linear/nonlinear, constrained/nonconstrained), an objective function can be used for minimization or maximization. The optimization toolbox consists of functions that can be applied to each particular case, according to the optimization type. These routines require the definition of an objective function. The following table (table 2) show the functions provided in the optimization toolbox for different optimization problems.

\begin{tabular}{|c|c|c|}
\hline Type & Notation & Function \\
\hline Scalar Minimization & $\min _{\text {as }} f\left(a_{s}\right)$ such that as $<$ as $<$ as 2 & fminbnd \\
\hline Unconstrained Minimization & $\min _{x v} f\left(x_{v}\right)$ & $\begin{array}{l}\text { fminunc, } \\
\text { fminsearch }\end{array}$ \\
\hline Linear Programming & 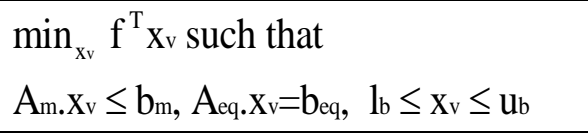 & linprog \\
\hline Quadratic Programming & $\begin{array}{l}\min _{\mathrm{x}_{\mathrm{v}}} \frac{1}{2} \mathrm{x}_{\mathrm{v}}{ }^{\mathrm{T}} \mathrm{Hx}_{\mathrm{v}}+\mathrm{f}^{\mathrm{T}} \mathrm{X}_{\mathrm{v}} \text { such that } \\
\mathrm{A}_{\mathrm{m} . \mathrm{X}_{\mathrm{v}}} \leq \mathrm{b}_{\mathrm{m}}, \mathrm{A}_{\text {eq. }} \mathrm{X}_{\mathrm{v}}=\mathrm{b}_{\mathrm{eq}}, \mathrm{lb}_{\mathrm{b}} \leq \mathrm{x}_{\mathrm{v}} \leq \mathrm{ub}\end{array}$ & quadprog \\
\hline Constrained Minimization & $\begin{array}{l}\min _{x} f\left(x_{v}\right) \text { such that } \\
c\left(x_{v}\right) \leq 0, c_{e q}\left(x_{v}\right)=0 \\
A_{m} \cdot X_{v} \leq b_{m}, A_{\text {eq. }} X_{v}=b_{\text {eq }}, l_{b} \leq x_{v} \leq u_{b}\end{array}$ & fmincon \\
\hline
\end{tabular}




\begin{tabular}{|c|c|c|}
\hline Goal Attainment & 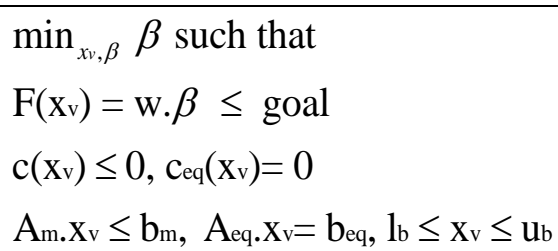 & fgoalattain \\
\hline Minimax & 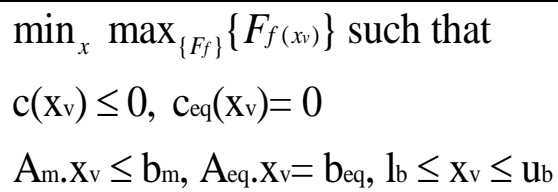 & fminimax \\
\hline Semi-Infinite Minimization & $\begin{array}{l}\min _{x} f\left(x_{v}\right) \text { such that } \\
K\left(X_{v}, w\right) \leq 0 \text { for all } w \\
c\left(X_{v}\right) \leq 0, c_{\text {eq }}\left(X_{v}\right)=0 \\
A_{m} . X_{v} \leq b_{m}, A_{\text {eq. }} X_{v}=b_{\text {eq }}, l_{b} \leq X_{v} \leq u_{b}\end{array}$ & fseminf \\
\hline
\end{tabular}

Table 2- MATLAB Minimization functions [20]

In this work, the function fmincon was used to optimize the objective function. The function fmincon is used for "constrained minimization" optimization type [20].

\subsection{Mathematical formulation of optimization methods}

To achieve an optimal solution one must understand the mathematical formulation of the optimization methods, since it is needed to establish correct mathematical conditions. Optimization techniques are used to determine a set of parameters $\mathrm{x}=[\mathrm{x} 1, \mathrm{x} 2 . . \mathrm{xn}]^{\mathrm{T}}$ that can be defined as optimum in certain conditions. Those parameters are the optimization variables. An objective function $\mathrm{q}(\mathrm{x})$ is subject to a process of minimization or maximization, which can be linear or non-linear, and constrained or non-constrained. The constraints are functions that restrict the optimization variables, and can be of three types: equality constraints, inequality constraints, and upper/lower limit constraints as shown next:

$\mathrm{g}_{\mathrm{i}}(\mathrm{x})=0\left(\mathrm{i}=1, \ldots, \mathrm{m}_{\mathrm{e}}\right)$; with $\mathrm{m}_{\mathrm{e}}$ equality constraints

$h_{j}(x) \leq 0\left(j=1, \ldots, m_{f}\right) ;$ with $m_{f}$ inequality constraints

$\mathrm{Xk}^{1}{ }^{1}, \mathrm{Xk}^{\mathrm{u}}\left(\mathrm{k}=1, \ldots, \mathrm{m}_{\mathrm{a}}\right)$, with $\mathrm{m}_{\mathrm{a}}$ lower limit or upper limit constraints

An optimization problem is usually described by the minimization (or maximization) of the objective function $\mathrm{q}(\mathrm{x})$ :

$\min q(x)$

subjected to the constraints conditions:

$g(x)=0$ 


$$
\begin{aligned}
& \mathrm{h}(\mathrm{x}) \leq 0 \\
& \mathrm{Xl} \leq \mathrm{x} \leq \mathrm{Xu}
\end{aligned}
$$

where:

$\mathrm{x}$ is the vector of the optimization parameters

$\mathrm{q}(\mathrm{x}), \mathrm{g}(\mathrm{x})$ and $\mathrm{h}(\mathrm{x})$ are functions.

To achieve an efficient solution, one must consider not only the number of constraints and optimization variables, but also the characteristics of the objective and constraining functions. In linear programming, all the optimization functions have linear behavior. In quadratic programming, a quadratic function is minimized or maximized and linearly constrained. For both optimization types, there are numeric procedures to obtain the solution. For non-linear optimization, there is the need to run an iterative procedure, achieved by the solution of a linear programming, quadratic programming, or even a non-constrained optimization problem. The objective function $\mathrm{q}(\mathrm{x})$ has the purpose of establishing a relation between the objective of the project and its variables. Such variables can be material properties or geometric parameters. In this work, both material properties and geometric parameters are the optimization variables. Usually, the variables have linear behavior, but, if at least a single variable has non-linear behavior, non-linear programming must be used [13]. 
CHAPTER 3-EXPERIMENTAL PROCEDURE 


\subsection{Materials selection}

\subsubsection{Initial selection}

The first step in the materials selection is the identification of the relevant properties of the application. For this application the relevant properties are:

- Young modulus

- Toughness

- Inertia moment

- Cost of the material (cost of matter and manufacturing process)

- Density

The desired properties are:

- Young modulus

- Toughness

- Inertia moment

- Cost of the material

- Density (highest possible)

(highest possible)

(highest possible)

(lowest possible)

(lowest possible)

There are some properties that depend on the material, and some that are independent of the material. This independency is shown next:

- Young modulus

- Toughness

- Inertia moment

- Cost of the material

- Density (dependent)

(dependent)

(independent)

(dependent)

(dependent)

The inertia moment is not dependent of the material. In fact, the inertia moment depends of the geometrical characteristics of the objects, and doesn't depend on which specific material is chosen. 
For the materials selection one can only focus the material dependent properties. For the first materials selection it is necessary to choose a material class, not a specific material. This is true because one has more mobility to change to a material in the same class with better properties for the application. The materials selection was done using materials selection charts. In those charts one has two properties in 2 axes (2D) and inside the chart there are the materials classes. This kind of diagrams make the materials selection more organized, more simple and more effective than other methods, for example, search in handbooks for reliable materials for a specific application. The charts used for the first selection of the material were the Young modulus/Cost and Young modulus/density. They are shown next (fig. 7) and (fig. 8):

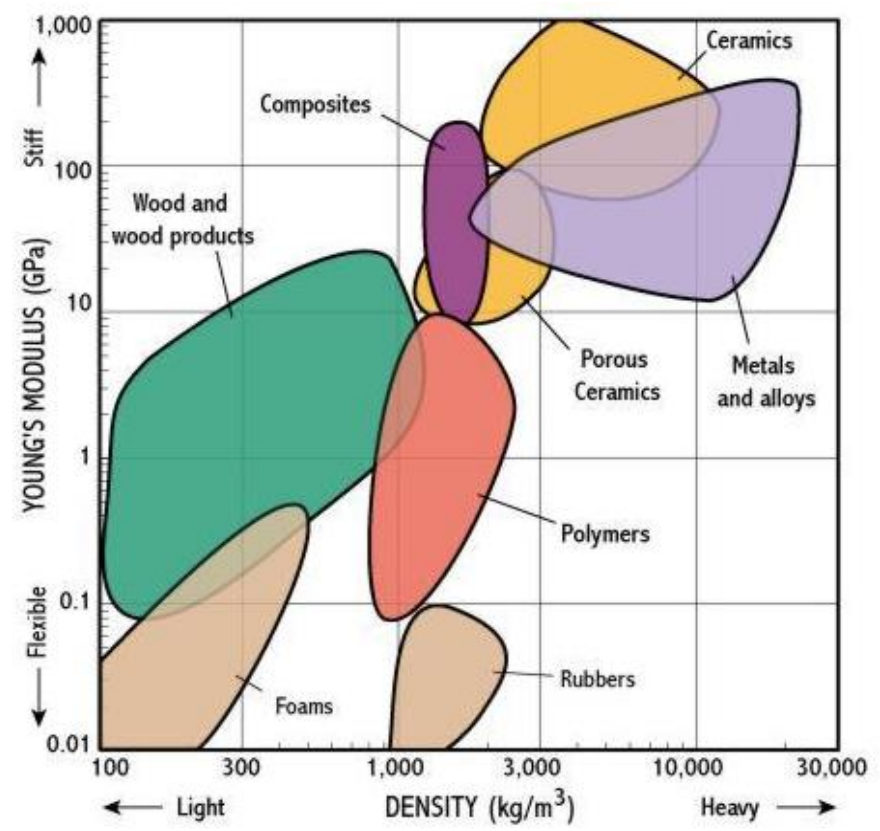

Fig. 7-Materials selection chart Young modulus/density [21]

In this chart (fig. 7), one should select a class of the closest possible to the top left corner (ideally) to obtain the highest possible Young modulus and lowest possible density. There are no such materials, so one must look and find the best existing classes. They are the ceramics, the composites and the metals. The ceramics are too brittle for this application, the composites are too expensive, although GFRP- Glass Fiber Reinforced Polymer is not very expensive in absolute terms, costing slightly more than two Euros a kilogram [21], it is expensive comparing to most of the common metals. The CFRP- Carbon Fiber reinforced Polymer is very expensive, with a cost of more than 23 Euros a kilogram [21]. The metals have a high Toughness and high Young 
modulus. The only problem is they have a high density. But one can choose a specific material inside the class that has a relatively low density to improve this.

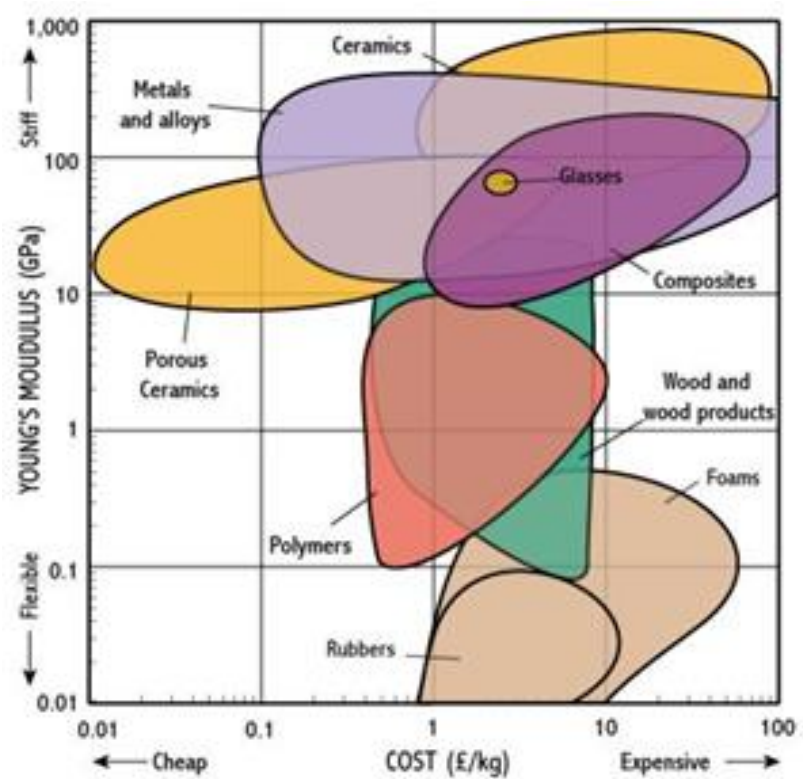

Fig. 8-Materials selection chart Young modulus/Cost [21]

In this chart (fig. 8), one should select a material's class that is the closest possible to the up left corner as in the previous chart to obtain the highest possible Young modulus and the lowest possible cost. As in the previous chart, there is no such material class. The best material classes are: Metals and alloys, the Composites and the Ceramics. The Composites have lower Young modulus than the Metals, and their cost is higher, so they are not the best choice. The composites have a much lower density but with a higher cost. The selection of the composites is only suitable for high performance applications where the equipment cost is high, like boats. The ceramics, as told, are brittle and they may fracture easily in an application such as this one. One can then conclude that in the current state of art, the best material class is the Metals and Alloys, which is the best class in both charts [21].

\subsubsection{Intermediate material selection}

If one details the Young modulus/density diagram (fig. 9), one sees that the best materials for this application are: Steel, Cast Iron and Nickel, whose have a high Young modulus and a relatively low density (they have the best relation between the two properties). 


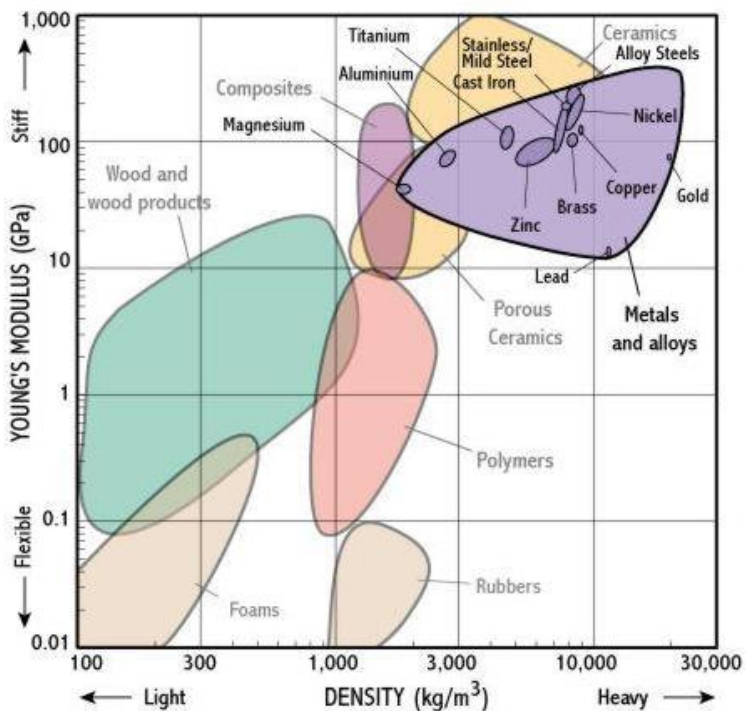

Fig. 9-Materials selection chart Young modulus/density [21]

A detailed view of the diagram Young modulus/Cost (fig. 10) shows that the best materials for this application are: Low alloy Steels and Stainless Steel, whose have a high Young modulus and a relatively low cost (they have the best relation between the properties Cost and Young modulus:

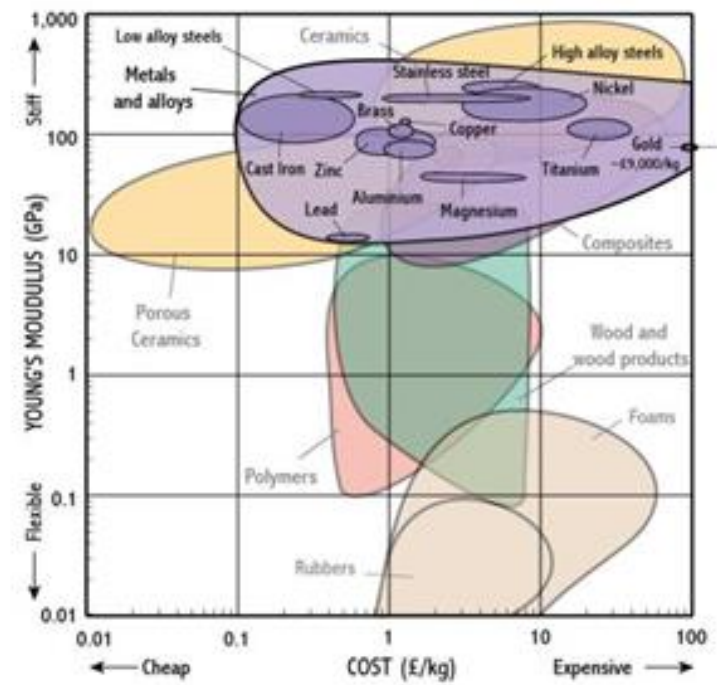

Fig. 10-Materials selection chart Young modulus/Cost [21]

One can say that the best material for this application is the Steel, which has a good position in both diagrams. [21]

\subsubsection{Final material selection}

Of all steels, the dual-phase steels seem to be the most promising material for this application. The dual phase steels have higher Yield stress, which means they can resist 
higher stresses without entering the plastic domain. In the plastic domain, unlike the elastic domain, stress is not proportional to the strain and the strain is not totally relieved after removal of the load. As in this application one desires that the object works all the time in the elastic domain, this material seems to be highly suitable for this application. The commercial dual phase steel DOCOL is the selected material. With the dual phase steels it can be possible to obtain lower area sections having enough mechanical resistance for the involved solicitations.

\subsubsection{About commercial dual phase steels (High strength steels)}

\subsubsection{Main characteristics}

The main incentive for adopting dual phase steels for engineering structures manufacture is the significant reduction in processing costs that are possible. The three major direct cost savings are: no spheroidisation anneal, no quench and temper treatment and no post Q\&T descaling necessary. The Dual-phase steel has a soft ferrite microstructure, with a matrix containing islands of martensite (increasing yield to tensile strength) in the secondary phase (with proportional volume fraction increase in analogue to tensile strength.) The fig. 11 shows the microstructure of some commercial steels of this type, known as HCT:

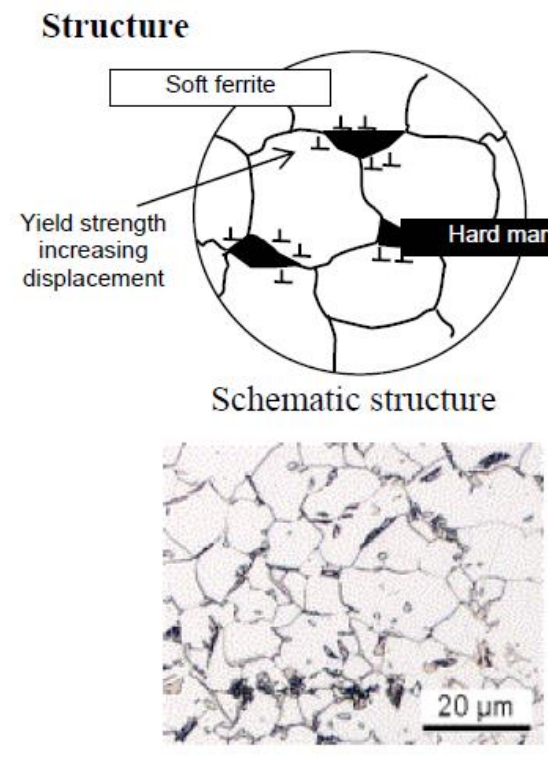

HCT500XD

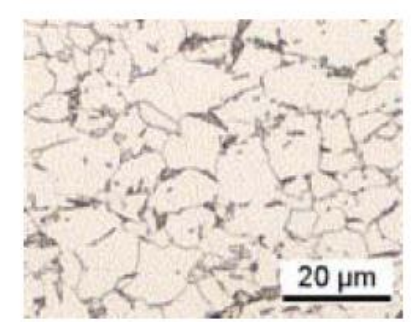

HCT450XD

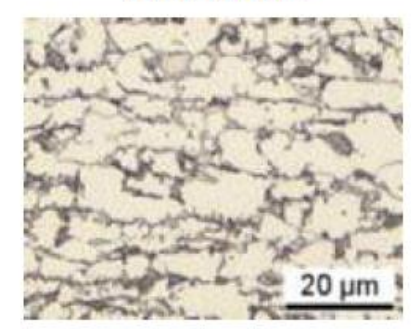

HCT600XD

Fig. 11-Microstructure of commercial dual phase steels [22] 
This type of steel features a low yield to tensile strength ratio, high tensile strength and high work hardening rate. The high tensile strength is mainly achieved by the composition, with manganese, chromium and silicone. The increase of the yield to strength ratio in the martensitic phase is achieved by quenching the material before it enters the zinc pot of the hot-dip galvanization unit. In the next figure (fig. 12) one can see the Stress-Strain Curves for HCT commercial dual phase steels:

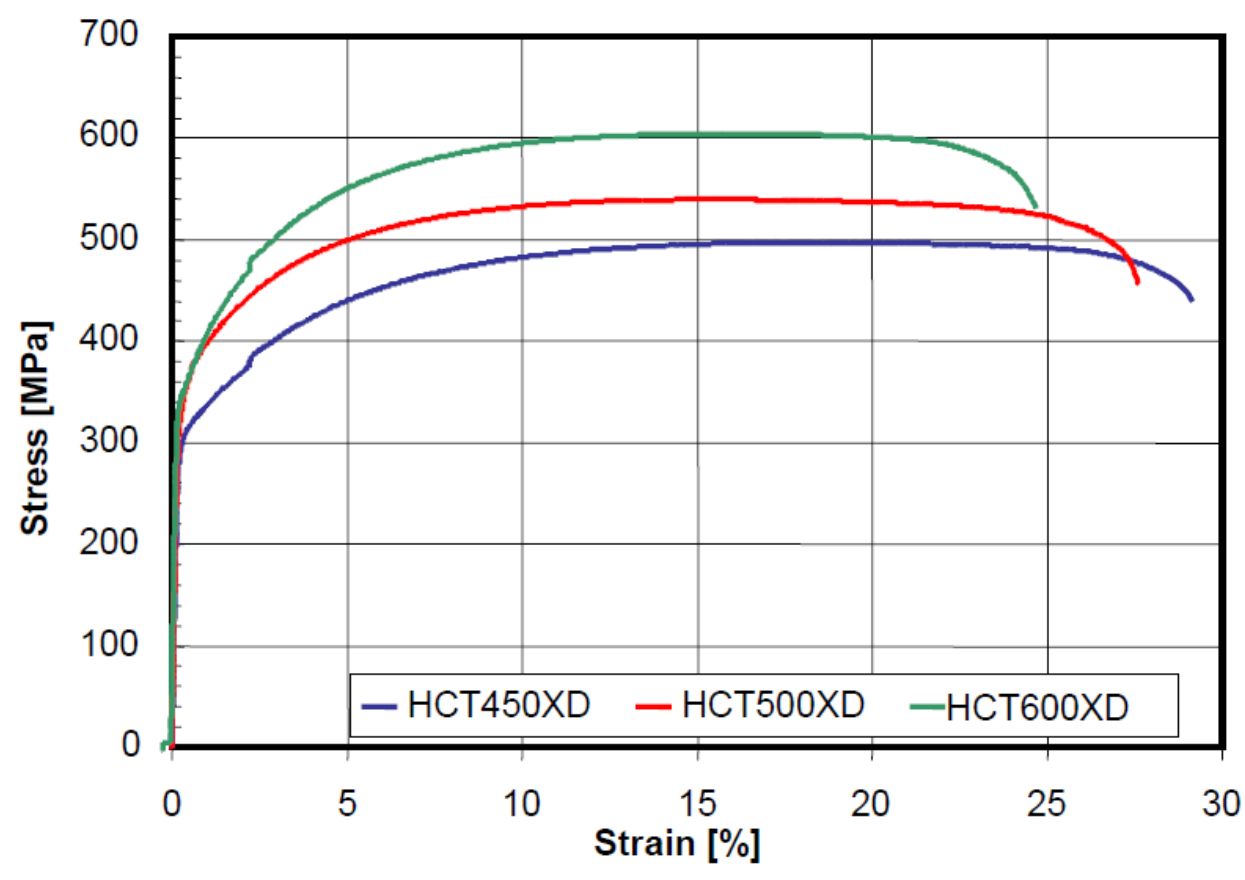

Fig. 12-Stress/Strain curves of some commercial dual phase steels [22]

The Stress-Strain curves are an excellent way to describe some of the most important mechanical properties of materials. In the above figure (fig. 12), one can see the mechanical behaviour of HCT450XD, HCT500XD and HCT600XD. It is notorious that their Young modulus is similar, because the elastic domain slope is similar, but their yield stress is quite different. The HCT600XD steel has the highest yield stress of all three materials shown in the chart (fig. 12) [22].

\subsubsection{About DOCOL dual phase steels}

Below (table 3) one can see the chemical composition of the DOCOL dual phase steels. Each steel designation number is related to tensile strength, eg. A DOCOL600 has a tensile strength of near 600 [23]. 


\begin{tabular}{|c|c|c|c|c|c|c|c|}
\hline Steel grade & $\begin{array}{l}C \\
\%\end{array}$ & $\begin{array}{l}\text { SI } \\
\%\end{array}$ & $\begin{array}{l}M n \\
\%\end{array}$ & $\begin{array}{l}P \\
\%\end{array}$ & $\begin{array}{l}S \\
\%\end{array}$ & $\begin{array}{l}\text { Nb } \\
\%\end{array}$ & $\begin{array}{l}A_{m} \\
\%\end{array}$ \\
\hline Docol 5000P & 0,08 & 0,30 & 0,70 & 0,015 & 0,015 & - & 0,04 \\
\hline Docol 5000L & 0,07 & 0,20 & 1,80 & 0,015 & 0,002 & - & 0,04 \\
\hline Docol $6000 \mathrm{P}$ & 0,11 & 0,40 & 0,90 & 0,015 & 0,006 & - & 0,04 \\
\hline Docol $6000 \mathrm{~L}$ & 0,10 & 0,40 & 1,50 & 0,015 & 0,002 & . & 0,04 \\
\hline Docol 8000P & 0,12 & 0,20 & 1,50 & 0,015 & 0,002 & 0,015 & 0,04 \\
\hline Docol $8000 \mathrm{~L}^{*}$ & 0,14 & 0,20 & 1,70 & 0,015 & 0,002 & 0,015 & 0,04 \\
\hline Docol 1000DP & 0,15 & 0,50 & 1,50 & 0,015 & 0,002 & 0,015 & 0.04 \\
\hline
\end{tabular}

Table 3-Chemical composition of some dual phase commercial steels [23]

The mechanical properties of these steels are shown in the next table (Table 4):

\begin{tabular}{|c|c|c|c|c|c|}
\hline Steel grade & $\begin{array}{l}\text { Yield } \\
\text { strength } \\
\mathbf{R}_{\mathrm{ppo}, 2} \\
\mathrm{~N} / \mathrm{mm}^{2} \\
\text { (min-max) }\end{array}$ & $\begin{array}{l}\text { Yield strength after Strain } \\
\text { hardening and Bake hardening } \\
\mathrm{R}_{\mathrm{p} 2,0}+\mathrm{BH} \\
\mathrm{N} / \mathrm{mm}^{2} \\
\text { (min) }\end{array}$ & $\begin{array}{l}\text { Tensile } \\
\text { strength } \\
\mathrm{R}_{\mathrm{m}} \\
\mathrm{N} / \mathrm{mm}^{2} \\
\text { (min-max) }\end{array}$ & $\begin{array}{l}\text { Elongation } \\
\mathrm{A}_{30} \\
\% \\
\text { (min) }\end{array}$ & $\begin{array}{l}\text { Min. radius } \\
\text { for } 90^{\circ} \text { bend }\end{array}$ \\
\hline Docol 500DP & $290-370$ & 400 & $500-600$ & 20 & $0 \mathrm{xt}$ \\
\hline Docol 500DL & $230-$ & - & $500-600$ & 25 & $0 \mathrm{xt}$ \\
\hline Docol 600DP & $350-450$ & 500 & $600-700$ & 16 & $0 \mathrm{xt}$ \\
\hline Docol 600DL & $280-360$ & 450 & $600-700$ & 20 & $0 \mathrm{xt}$ \\
\hline Docol 800DP & $500-650$ & 650 & $800-950$ & 10 & $1,0 \mathrm{xt}$ \\
\hline Docol 800DL & $390-$ & - & $800-950$ & 13 & $1,0 \mathrm{xt}$ \\
\hline Docol 1000DP & $700-950$ & 850 & $1000-1200$ & 7 & $2,0 \mathrm{xt}$ \\
\hline
\end{tabular}

Table 4-Mechanical properties of some dual phase commercial steels [23]

One can see that the Yield stress is presented in a range of values. Also, there is not a determined value for Young modulus. Therefore, there is the need to perform mechanical tests to determine a value for the Young modulus (extensometry test and tensile test) and for the Yield stress (tensile test). Poisson coefficient was also determined, due to its relevancy in the material deflection (extensometry test). In the Annex 1, one can see the Young Modulus, Poisson coefficient and Yield stress obtained in tensile test and extensometry test. The obtained values for the Young modulus are smaller than the expected $210 \mathrm{GPa}$ for all specimens. The Poisson coefficient is also smaller than the expected 0,29 for all specimens, but the values are very close to the expected value for most of the specimens. 


\subsection{Section Optimization}

\subsubsection{Section Optimization: Main purposes}

For the purpose of this work, rigidity is more important than resistance in what relates to its structural applications. The bending deflection $\mathrm{y}_{\mathrm{b}}$ is a function of the bending moment $\mathrm{M}_{\mathrm{f}}(\mathrm{x})$, the axial inertia moment $\mathrm{I}$ and the Young modulus E. It is directly proportional to $\mathrm{M}_{\mathrm{f}}(\mathrm{x})$ and inversely proportional to $\mathrm{I}$ and $\mathrm{E}$. However, in order to decrease deflection, it's important to choose a material with high Yield Stress, because with a material having high Yield stress, it's possible to reduce the object weight using a lower thickness and then improve the Inertia moment of the section with ribs, resulting in a lower deflection with a similar material cost. The bending deflection equation results from double integration of the eq. 28 , using the appropriate boundary conditions, as shown in chapter 2 :

$\frac{\mathrm{d}^{2} \mathrm{yb}}{\mathrm{dx}^{2}}=\frac{\mathrm{M}_{\mathrm{f}}(\mathrm{x})}{\mathrm{IE}}$

To increase rigidity one must increase the axial inertia moment I, as well as the Young modulus E. The aim is to obtain a minimal deflection $\mathrm{y}_{\mathrm{b}}$. There are ways of increasing the Inertia moment. One is by the use of webs inside the object, the other is by the use of ribs. Ribbing is usually less expensive than webs because of material costs (material required to web a structure is usually more than to rib the same structure). The increase of the axial Inertia moment of a modified object (usually ribbed or webbed) in comparison with the initial object is defined by the ratio $\mathrm{I} / \mathrm{I}_{0}$. As an example: a ratio of 2 means that the reinforced object has twice the inertia moment in comparison to the initial object. Ribbing is usually more effective in terms of $\mathrm{I} / \mathrm{I}_{0}$ than webbing. The higher $\mathrm{I} / \mathrm{I}_{0}$ one has in the ribbed structure, the higher the Inertia moment will be in comparison to the inertia moment of the initial structure (non-ribbed). As a result of the improvement of the Inertia moment, there is higher rigidity and consequently, lower deflections. In fig. 13, one can see a ribbed plate FEM model: 


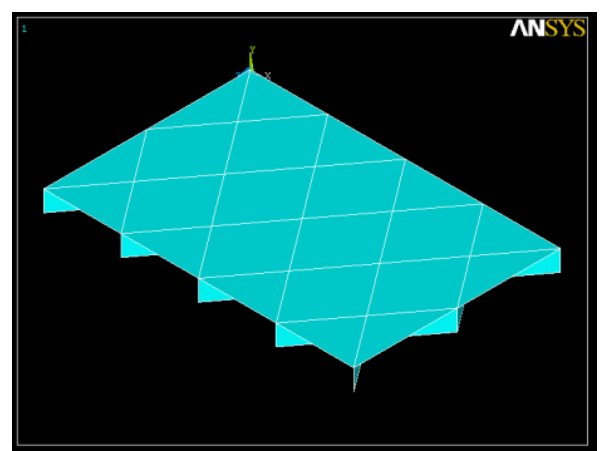

Fig. 13-Example of a ribbed plate

However, there are implications in the use of ribbing. The most critical implication is the deflection increase due to wrong ribbing. Also important is the mechanical resistance, due to high shear stresses in the ribs joints caused by transverse loads, especially when the rib thickness is low [1].

\subsubsection{Section optimization: Longitudinal Webs}

About longitudinal webs, the theory says that the best improvement obtained by adding longitudinal webs is achieved when there are two longitudinal webs, as in fig. 15. It was found in the literature that the webs minimize the lower deflections and stresses while almost not affecting the others, and ribs lower the high deflections and stresses while almost not affecting the lowers. The next figure (fig. 14) shows the possible types of longitudinal webs and the correspondent improvement of the axial inertia moment I.

\begin{tabular}{|c|c|c|c|c|c|}
\hline Profile & $\mathrm{I}_{\text {flex }}$ & $\mathrm{I}_{\text {tors }}$ & $\mathrm{m}$ & $\mathrm{I}_{\text {flex }} / \mathrm{m}$ & $\mathrm{I}_{\text {tors }} / \mathrm{m}$ \\
\hline & 1 & 1 & 1 & 1 & 1 \\
\hline & 1,17 & 2,16 & 1,38 & 0,85 & 1,56 \\
\hline & 1,55 & 3 & 1,26 & 1,23 & 2,4 \\
\hline
\end{tabular}

Fig. 14-Effect of longitudinal webs on Inertia moment [1] 
In the fig. 14, one can see that the objects with diagonal webs are the best. However, there is only a slight increase of bending rigidity $\mathrm{I}_{\mathrm{flex}}$ and torsion rigidity $\mathrm{I}_{\text {tors }}$ from one diagonal web to two diagonal webs. The $\mathrm{I}_{\text {flex }}$ increases from 1,55 to 1,78 and $\mathrm{I}_{\text {tors }}$ increases from 3 to 3,7. The two non-diagonal webs is not useful because the mass $\mathrm{m}$ is high $(1,38)$ and $I_{\text {tors }}$ and $I_{\text {flex }}$ are much lower than in the case of both one diagonal webbed beam and two diagonal webbed beam. The fig. 14 also shows $\mathrm{I}_{\text {flex }} / \mathrm{m}$ and $\mathrm{I}_{\text {tors }} / \mathrm{m}$. $\mathrm{I}_{\mathrm{flex}} / \mathrm{m}$ is a measure of how the bending rigidity increases per weight unit. In analogy, $\mathrm{I}_{\text {tors }} / \mathrm{m}$ is a measure of how the torsion rigidity increases per weight unit. One can see that the one diagonal beam is the best, because it has less weight than the two diagonal webbed beam. The non-diagonal webbed beam is even worse than the non-webbed beam, with a $\mathrm{I}_{\text {flex }} / \mathrm{m}$ of 0,85 , which means that the webs have a low efficient in terms of rigidity increase per weight unit in comparison to both of the diagonal webbed beams. In terms of $\mathrm{I}_{\text {tors }} / \mathrm{m}$ the two-diagonal webbed beam is the best, with a value of 2,45 . However, the single diagonal webbed beam has a value of 2,4 , which is very close. The non-diagonal webbed beam has a value of $\mathrm{I}_{\text {tors }} / \mathrm{m}$ equal to 1,56 , which is better than the non-webbed beam but much worse than both of the diagonal webbed objects [1].

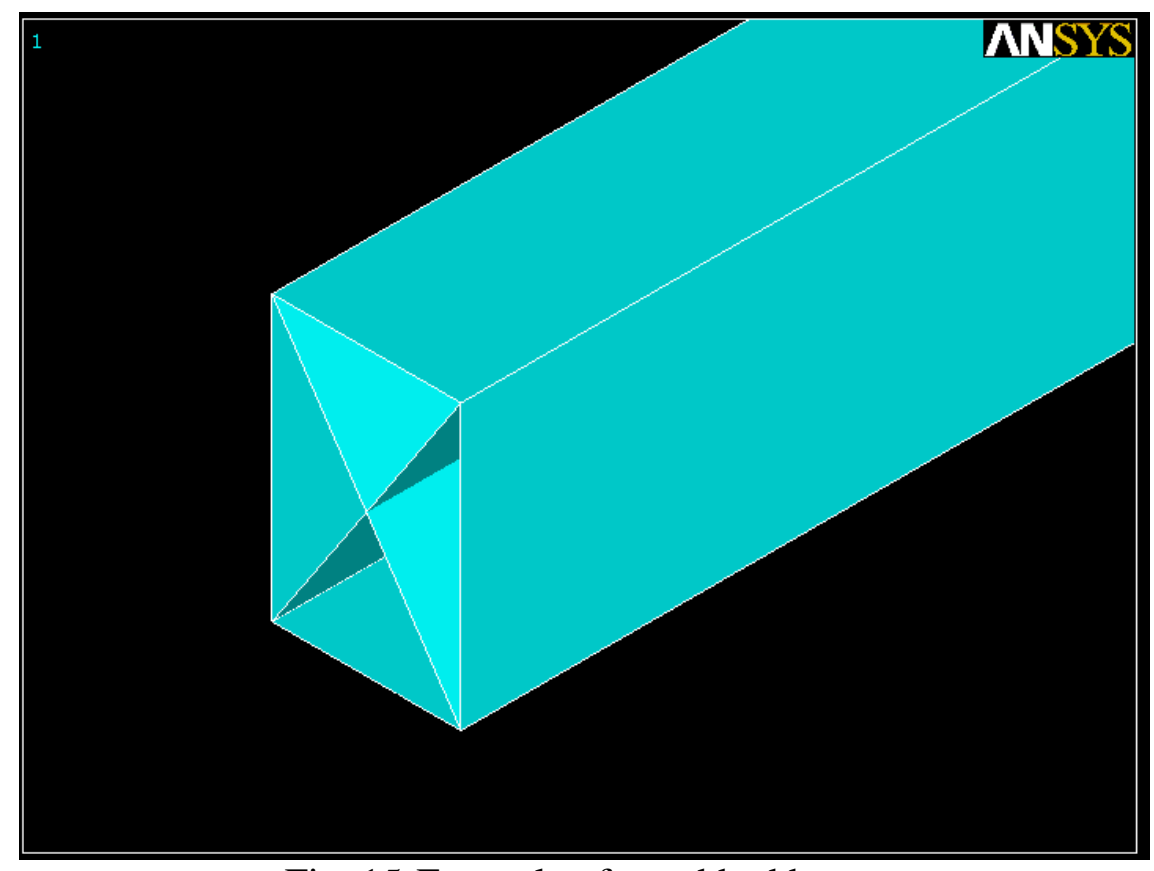

Fig. 15-Example of a webbed beam

The above figure (fig. 15) shows an example of a FEM model with two diagonal webs. 


\subsubsection{Section optimization: Ribbing}

The next figure (fig. 16) shows how ribs affect the moment of resistance $\mathrm{W}$ and the axial inertia moment I of beams. The moment of resistance $\mathrm{W}$ of a non-ribbed section is considered to be unitary.

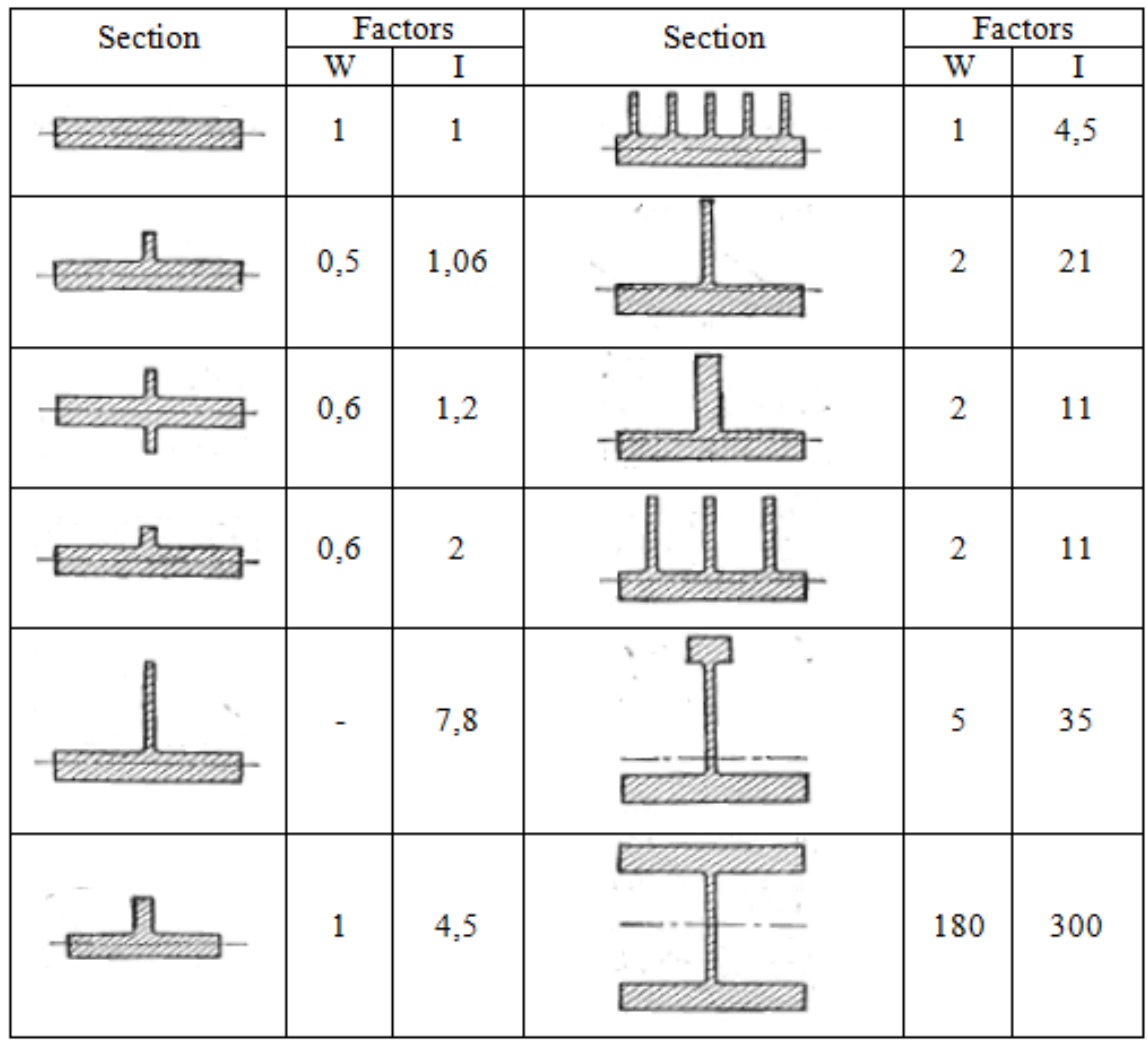

Fig. 16-Effect of Ribs on the inertia moment and W [1]

About ribbing, one can say that the best rib section has $\mathrm{W}=180$ and $\mathrm{I}=300$ as shown in the fig. 16. The rib sections on the left side of the fig. 16 don't have enough thickness and/or height. Due to this fact, the resistance moment $\mathrm{W}$ is equal or less than 1 for all cases, except for one case, that W wasn't determined. However, for some rib sections, there is a substantial increase of the inertia moment, with values of 4,5 for the last rib sections, and 7,8 for the fifth rib section. In the right side of the fig. 16, one can see that the second, third and forth solutions have a W=2 and a I of 21 for the second and 11 for the third and forth. The second best rib section is the fifth on the right side, with a $\mathrm{W}$ of 5 and a I of 35. The influence of rib height and rib thickness on the Inertia moment and moment of resistance can be expressed in a generalized form. For the inertia moment, the expression is: 
$\frac{\mathrm{I}}{\mathrm{I}_{0}}=1+\delta \eta^{3}+3 \delta \eta(1+\delta \eta)\left(\frac{1+\eta}{1+\delta \eta}\right)^{2}$

where:

$\eta=\frac{h}{h_{0}}=$ ratio of rib height $h$ to original profile height $h_{0}$

$\delta=\frac{\mathrm{b}}{\mathrm{b}_{0}}=$ ratio of rib width $\mathrm{b}$ to original profile width $\mathrm{b}_{0}$

The relation of the moments of resistance can also be expressed in a generalized form:

$\frac{\mathrm{W}}{\mathrm{W}_{0}}=\frac{1+\delta \eta}{1+2 \eta+\delta \eta^{2}}$

where:

$\eta=\frac{h}{h_{0}}=$ ratio of rib height $h$ to original profile height $h_{0}$

$\delta=\frac{\mathrm{b}}{\mathrm{b}_{0}}=$ ratio of rib width $\mathrm{b}$ to original profile width $\mathrm{b}_{0}$

When the distance between consecutive ribs is high and $\mathrm{h} / \mathrm{h}_{0}$ is not sufficiently high, the moment of resistance can drop several times in comparison to the original profile. In the next figure (fig. 17), one can see the chart of the rib pitch, known as $t_{0}$, in the abscissa, and the values of the increase of the moment of resistance $\mathrm{W} / \mathrm{W}_{0}$ for each rib height ratio. Rib pitch can be defined as the ratio between the distance between consecutive ribs and rib thickness. The rib height ratio is the increase of height caused by ribs in comparison to the original profile.

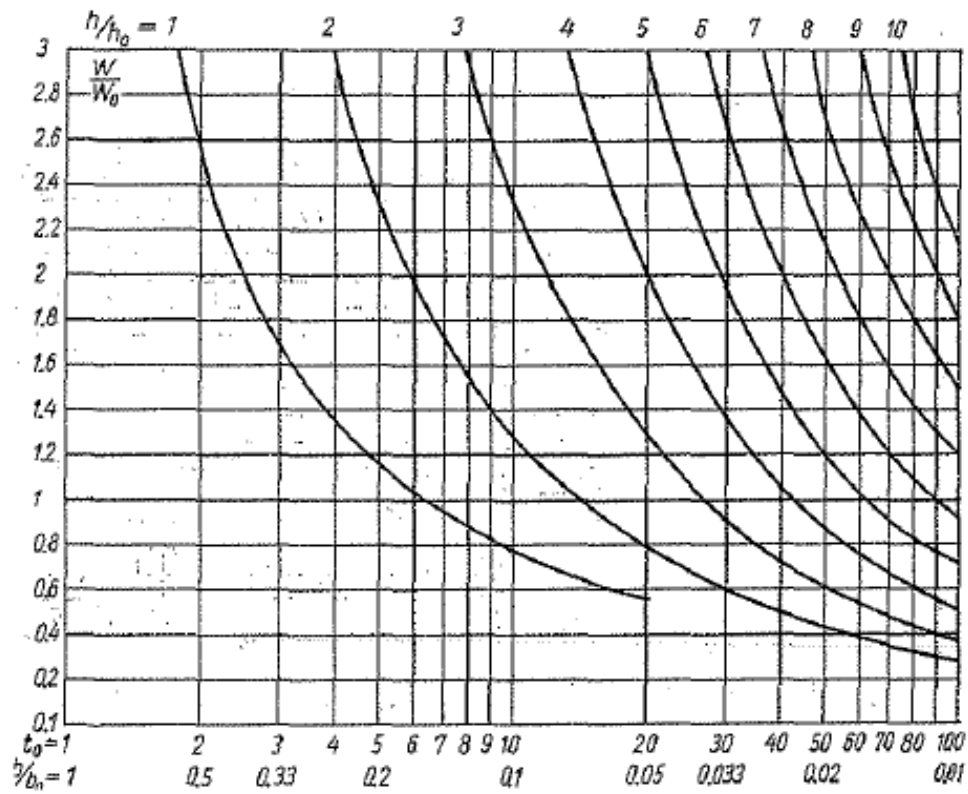

Fig. 17-Values of moment of resistance for different rib pitch and height ratio values [1] 
One can say that for some values of rib pitch and height ratio there is a decrease of the moment of resistance $\mathrm{W}$. This happens when $\mathrm{W} / \mathrm{W}_{0}<1$. The object will be weaker if the rib height decreases, and/or if there is a higher rib pitch. There are three ways of increasing rigidity of a ribbed structure: one has to increase rib height, to decrease rib pitch, or to increase rib thickness. Ribbing has shown to be a better way to improve the rigidity of beams than longitudinal webs. It is better in what concerns to material cost and in what concerns to deflections. However, one must consider the processing of the ribs. As the material processing of the ribs requires more structural detail, it is more expensive than webs (using the same processing method to be able to compare). This cost can be relatively high, if the ribbing structure has many ribs [1]. In the next illustration (fig. 18) one can see a ribbed structure.

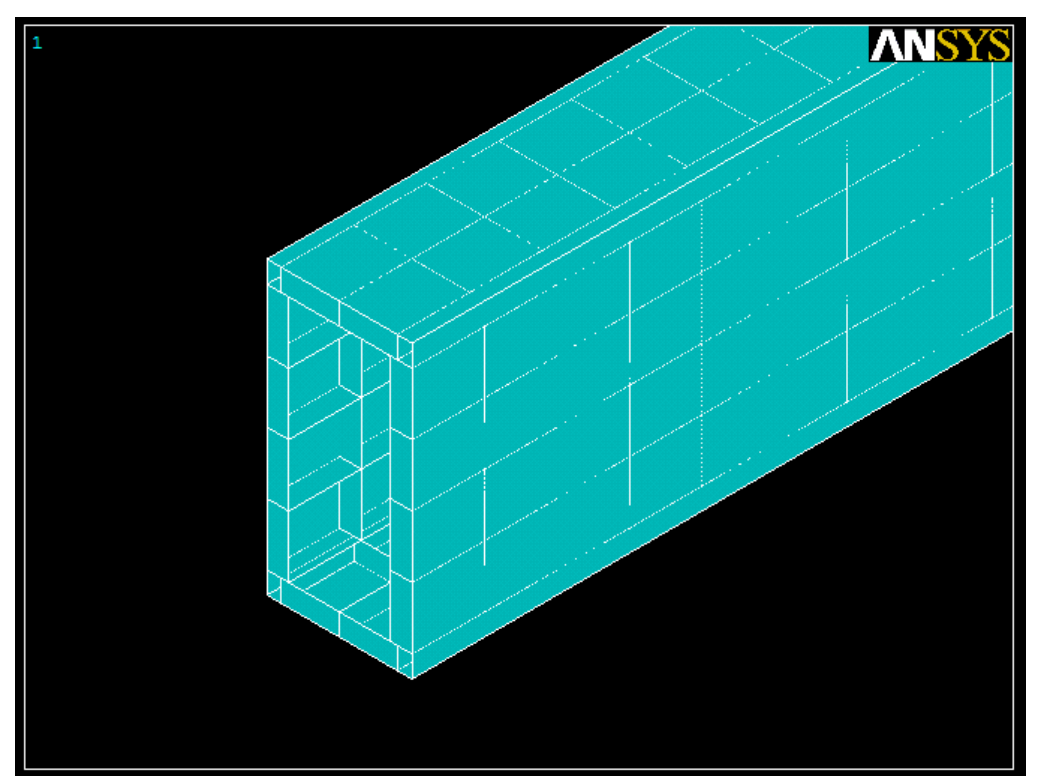

Fig. 18-Example of a ribbed beam

This sub-chapter was the base for the selection of the variables of the ribbed plate model. It was shown that rib thickness, rib height and rib pitch can substantially affect the deflection of ribbed objects, by influencing the rigidity and the resistance. The distance between consecutive inner ribs is represented on the ribbed plate model by the LG1 variable, the rib height is represented by the LG2 variable and the thickness is represented by the LG3 variable. Rib pitch concept was applied to the ribbed plate FEM model as the distance between consecutive inner ribs, for a question of simplicity. There is no need to define the ratio of distance between consecutive inner ribs divided by the thickness, and one can apply the rib thickness only to one variable (LG3). 


\subsection{FEM and Optimization}

\subsubsection{Introduction}

Nowadays, the engineering structures usually have a high level of complexity. The numeric methods, such as the FEM- Finite Element Method, are very useful to test if the engineering object specifications are adequate for the working conditions of the application. In the case of this work, the aim is to reduce the nodal deflections as much as possible in the FEM models. The commercial FEM software used was ANSYS. ANSYS can itself give deflection solutions. However, the aim is to reduce the deflections as much as possible. To be possible to achieve the aim, one has to use another program, called MATLAB (MATrix LABoratory) to optimize the models. A programming code was developed in this work for the control of the optimization processes. MATLAB is responsible for the control of the optimization processes, by collecting deflection data from the text file 15.glw that is filled by ANSYS, optimizing the variable values, and re-sending the model input file MODnume.txt with the new variable values to ANSYS to be re-analyzed. This process can be done as many times as needed to achieve an optimum solution, in an iterative process. The ANSYS input file is a text file with all instructions related to the model construction. The input files must be edited in order to have: the variables in the keypoints, the initial variable values, and to write the deflection results in the nodal points to a file named n5. lgw, used by MATLAB to calculate the objective function.

\subsubsection{Finite Element Method experimental procedure}

The ANSYS program is divided mainly in 3 sections: Pre-processor, Solution and Postprocessing:

-Modelling, definitions and meshing in Pre-processor

-Loads, DOF constraints and solution (solving) in Solution section.

-Plot results and query results (Total Strain) in Post-processing.

The steps to create and solve the FEM models were:

Preprocessor

Modelling 
Creation of keypoints, then lines by keypoints and then areas by lines Definitions

Definition of the Element Type

Definition of real constants: shell thickness

Material properties: Young modulus, density and Poisson coefficient

Attributes: Application of the definitions and material properties

Meshing: element divisions using mapped quadrilaterals elements

Solution

Loads: Binary load on the edges (torsion) and a centred load (bending)

DOF constraints: simply supported at its ends. In the program this can be done by applying displacements on keypoints of both sides

Solving: In order to solve the current model

Postprocessing:

Plot results

Strain solutions were obtained.

Query results

Strain results were queried on the central nodes on the top surface (centre in $\mathrm{x}$ coordinate) along the length of the model

In modelling, the model geometry was created, and in the definitions one chose the element type and the material properties. The material properties were the properties of the steel: density of $7890 \mathrm{~kg} / \mathrm{m}^{3}$, Young modulus of $210 \mathrm{GPa}$ and Poisson coefficient of 0,29 . The material properties used in the FEM modelling are standard values (were not determined experimentally). In this work, the element type used is Shell elastic 4 nodes (named as Shell63). In meshing one choose the mesh type (triangular or quadrilateral), and the mesh refinement (how many elements in each direction). In this work only quadrilateral element meshes were used. The mesh refinement is different in the two models. The main aim is to refine the mesh as much as needed for the results to have a good precision, but without a very long processing time to obtain the FEM solutions in ANSYS. After the mesh is created, one can apply the loads. As mentioned in chapter 2.3 , the considered load was a centred bending load $\mathrm{F}$ of $3528 \mathrm{~N}$, which is 12 times the acceleration of gravity on a mass of $30 \mathrm{~kg}(12 * 9,8 * 30=3528 \mathrm{~N})$ and a binary load $\mathrm{M}_{\mathrm{t}}=0,2 * \mathrm{~F}_{1}$ that produces torsion, in which $\mathrm{F}_{1}$ is equal to of $5120 \mathrm{~N}$. The loads applied on the FEM models are represented on fig.1 (Chapter 2). These values are used as a 
starting point, having in mind the common values for the laser cutting machines and plotters, which are the main applications of this work. The DOF constraints were: rotation in $\mathrm{x}, \mathrm{y}, \mathrm{z}$ and translation in $\mathrm{x}, \mathrm{y}, \mathrm{z}$. DOF means degrees of freedom and is in what directions the object is allowed to move with translation and/or rotation during the processing of the FEM solution by ANSYS. The solution sub-section allows solving the current model. After the results are ready, one can see the results in the Post-processing menu. In this case, the main aim is to study the deflections. In order to study the deflection in specific nodal points, the "Query results" submenu (in Post-processing) was used for the initial beam.

\subsubsection{The FEM models}

In order to validate the Finite Element Model Updating methodology done during this thesis two models were built: a ribbed plate (model one) and a tubular beam (model two). In both models one considered three geometric variables and three material properties variables. Due to the different nature of the two objects the geometric variables are different. However, the material properties were the same in the two models: Poisson coefficient, density and Young modulus. The loads must be applied on keypoints, because if the loads are applied on the nodes, the nodes move during the optimization, and the loads move along with the nodes. This means that in that case, one is also optimizing the loads. Optimizing load position is not the aim of this work, and because of that, the loads must be completely static. For that, loads must be applied on keypoints that belong to the model. One can see some small areas at the center of both models because those areas were made using the keypoints where the loads are applied. The next screenshot shows the ribbed plate model and its geometric variables (fig. 19):



Fig. 19-Areas (left) and variables (right) of the ribbed plate FEM model 
The variables for this model are:

Geometric variables:

LG1: Distance between consecutive inner ribs

LG2: Rib Height

LG3: Thickness

Material properties variables

EX: Young modulus

PXY: Poisson coefficient

DNS: Density

The ribbed plate model has length $\mathrm{L}=0,6 \mathrm{~m}$; width $\mathrm{b}=0,3 \mathrm{~m} \mathrm{e}=0,002 \mathrm{~m}$ and has 4 ribs having length $\mathrm{L}=0,6 \mathrm{~m}$; thickness $\mathrm{e}=0,002 \mathrm{~m}$ and height $\mathrm{h}=0,03 \mathrm{~m}$.

The next screenshot shows the tubular beam FEM model and its geometric variables (fig. 20):



Fig. 20-Areas (left) and variables (right) of the tubular beam FEM model

This model is useful to validate the FEM methodology because tubular beams are common in machine parts, such as laser cutting machines and industrial printers (plotters).

The variables for this model are:

Geometric variables:

LG4: Distance from the center to the corner segment

LG5: Half of the Center width on the wall

LG6: Height of the central part on the wall 
Material properties variables

EX: Young modulus

PXY: Poisson coefficient

DNS: Density

The tubular beam model has length $\mathrm{L}=1 \mathrm{~m}$, thickness $\mathrm{e}=0,002 \mathrm{~m}$, section width $\mathrm{b}=0,3$ $\mathrm{m}$, and section height $\mathrm{h}=\mathrm{b}=0,3 \mathrm{~m}$. There is the aim to prove that this Finite Element Model Updating methodology can be applied to different models, with different variables (rib related or rib unrelated) and different object nature (beams or plates).

\subsubsection{Optimization Model}

This section is about the methodology of the Finite Element Model Updating program developed in MATLAB. The main aim of this thesis is the development of a programming code in MATLAB, which, using an optimization model, can improve the deflections of the FEM models. The fig. 21 shows the interaction between ANSYS and the MATLAB optimization program. The MATLAB program is used together with ANSYS. MATLAB controls the optimization processes and ANSYS calculates the FEM problem, by sending the deflections in specific nodes to a text file, named n5. lgw that MATLAB can read. Then, MATLAB calculates the objective function value, changes variable values in modife. txt and sends orders to ANSYS to begin the new FEM calculation. The objective function $q(x)$ will be minimized by a MATLAB function named fmincon. The fmincon function is a Sequential Quadratic Programming-SQP optimization function.

The objective function $\mathrm{q}$ is defined as:

$$
\mathrm{q}(\mathrm{x})=\Sigma \operatorname{ABS}\left(\mathrm{x}_{\mathrm{i}}\right)
$$

where:

$\mathrm{q}(\mathrm{x})$ is the objective function

$\mathrm{X}_{\mathrm{i}}$ is the deflection on each node

ABS is absolute value of an argument 


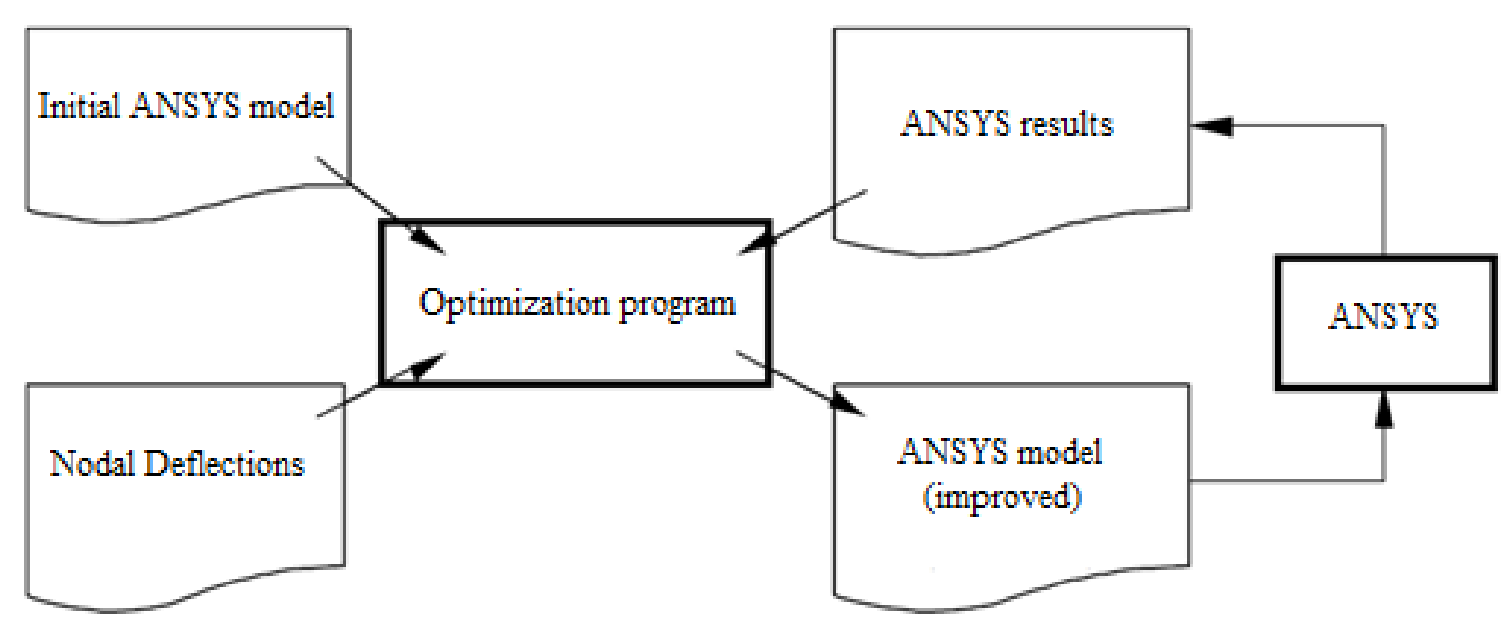

Fig. 21-Functional fluxogram of the optimization methodology used in this work [13]

The analysis of the deflection results and the change of variables values is done by the Finite Element Updating program, without any user action (is totally automated), using the implemented optimization methodology. For the solution to be possible, it is needed that ANSYS modify the input file modife.txt and the output file $n 5.1 \mathrm{gw}$, to be possible for the Finite Element Model updating program to read and write relevant information about the FEM models, such as the objective function value and the variables values [13].

\subsubsection{The MATLAB program}

The MATLAB program was developed using . $m$ files. The . $m$ files are programming files that MATLAB can read, write and run. The objective of the program is to modify the models variables in a manner that the deflections in the nodal points (nodes) are as close as possible to zero. The main program is called exper $33 \mathrm{x} . \mathrm{m}$, and is the program used to run the optimization. There are several smaller programs named corri $9 x . m$, escri9x.m, calcon2lax.m, nlcOUT6x.m, escrimx3.m and MACfun6x.m. Each one has a specific purpose in the program. During the execution of expert $33 \mathrm{x} . \mathrm{m}$, the other programs are executed. One could have all programming code in only one . $m$ file, but the program is much more organized this way. The next figure (fig. 22) is about what the program does (in the order of execution). Some programs run inside others: escrimx $3 . \mathrm{m}$ is executed inside nlcOUT6x.m. 
exper33x;

1-corri9x;

Run the initial input numeric model in ANSYS and leave after obtaining the results

\section{2-escri9x;}

Counts the lines of the MODnume.txt file

Creates the modife.txt file, similar to MODnume.txt at the beginning.

The modife.txt is modified during the optimization routine.

Open the modife.txt for write access and saves it.

3 -Creates a set of global variables (expert33x)

4-Establish the weight of each variable (expert33x)

5- Identifies the lines with parameters and saves them in arrays. Calculates constraints

for use in $\mathrm{x}_{0}$ vector and writes the results on the array table.

6-calcon21ax;

Identifies the lines with parameters and saves them in Arrays

Calculate constraints

Does a loop to remove the letters of the string

Concatenate letter by letter

7-nlcOUT6x;

Writes the modified file (modife.txt)

Runs the modified input file on ANSYS and leaves after results

8-escrimx3;

Changes the modife. txt file in order to write the updated parameters

9- Initializes the initial values, including the initial vector $\mathrm{x}_{0}$ and initial values of PRNX array (exper33x)

10-Builds matrix PRNx containing initial constraint values, with the objective to modify the modife.txt file according to the new values obtained by the MATLAB program. (exper33x)

11- Builds a constraint matrix (exper33x)

12- Builds the matrix of Lower Bound 'LB' and Upper Bound 'UB' constraints. (exper33)

13- Calls the optimization routine, using the fmincon function and the Macfun6x objective function code (exper33x)

14- Prints on the screen the optimization results (exper33x)

\section{5-nlcOUT6x;}

Writes the modife.txt file with the optimum design variables and executes it

16-escrimx3;

Changes the modife.txt file in order to write the updated parameters

17- Clear the contents of the used variables (exper33x)

Fig. 22-MATLAB program instructions

The main program (exper33x.m) runs ANSYS to start the static analysis of the FEM models, using the ANSYS input file that contains every instruction. The MATLAB program calls the function escri9x.m that copies the initial ANSYS input file, named MODnume.txt to a new file, named modife.txt. This step is performed to 
avoid the edition of the original input file that can be needed to run other optimization processes. The modife.txt file is modified during the optimization routine, being the variables values updated in every evaluation. The function calcon $21 \mathrm{ax} . \mathrm{m}$ identifies the lines of the ANSYS input file where the variables are. The same function saves the variables in a table and associates each variable with a variation factor. The variation factor can be different for the upper bound limit and the lower bound limit. Then, the main program (exper $33 \mathrm{x} . \mathrm{m}$ ) defines the vector of initial values $\mathrm{x}_{0}$, and does the calculations, using the variation factor, of the lower bound and upper bound limits of the chosen variables. The next step of the program is to extract the nodal deflections results from the $n 5.1 \mathrm{gw}$ file that was previously filled with values by ANSYS. This is done in the MACfun $6 \mathrm{x} . \mathrm{m}$ file. The optimization function fmincon is then called by the main program. The fmincon function reads the initial values vector $\mathrm{x}_{0}$, and calls the objective function MACfun6x.m. After all iterations, the main program receives the optimum value of the variables and the optimum value of the objective function. The function Corri $9 x . m$ runs the ANSYS input file in ANSYS and leaves after the execution. In the next figure (fig. 23), one can see the operation sequence of the function corri $9 x . m$ :

\section{Calls ANSYS}

2. Executes the ANSYS input file MODnume.txt

3. Close ANSYS

Fig. 23-Operation sequence of the corri $9 x$ function

The function escri $9 x . m$ reads the MODnume. txt file, saves it in a column matrix, identified by [FID] and writes its content in a new file, called modife.txt. The modife.txt file is then saved in [OLA], which is a column matrix. These operations are shown in the next figure (fig. 24)

1. Open the ANSYS input file

2. Saves the ANSYS input file in [FID]

3. Creates the modified input file modife.txt

4. Saves the modified file in [OLA]

Fig. 24-Operation sequence of the escri $9 x . m$ function 
The function calcon2lax.m creates and fills the [PRN] and \{PRNs $\}$ matrix. The $[\mathrm{PRN}]$ and $\{\mathrm{PRNs}\}$ are matrix with the information necessary to inform the program the value of the variables. In the next figure (fig. 25), one can see the operation sequence of this function:

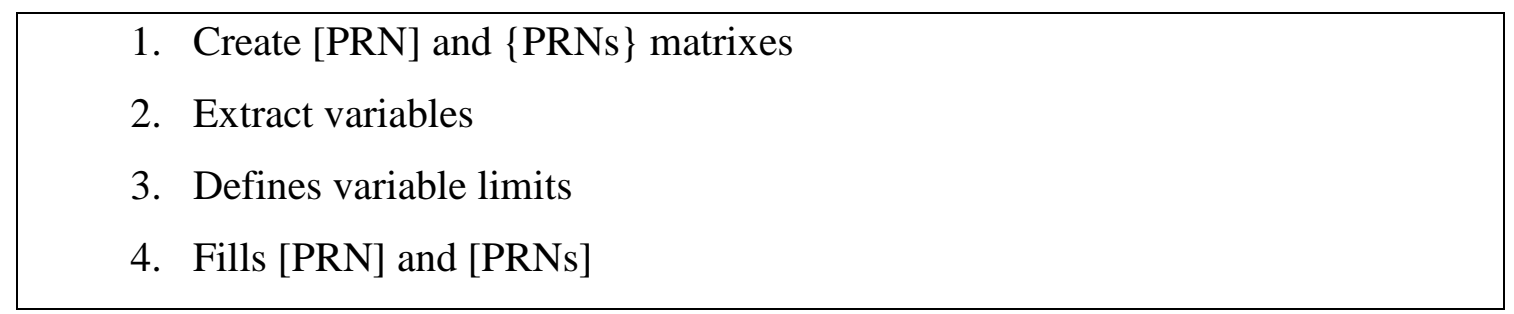

Fig. 25-Operation sequence of the calcon21ax.m function

The MATLAB program builds a matrix denominated [PRN] which has five columns. Each column has several lines, and the columns have, respectively:

1. The number of the line in the file where the parameter is located

2. The position where the equality signal is located

3. The value of the parameter

4 The lower bound limit

5 The upper bound limit

The program also builds a second table [PRNs], with one column containing a text string with the parameter description in text. The function escrimx $3 . \mathrm{m}$ reads the modife.txt file, saves it in a column matrix identified by [OLAM] and changes the lines corresponding to the variables, according with the information received in the optimization routine. This information is received by a column matrix denominated [PRNx]. The next figure (fig. 26) shows the operation sequence.

1. Reads the input file modife.txt

2. Modifies the [OLAM] matrix using the $[\mathrm{PRNx}]$ values

3. Saves the input file in [OLAM]

Fig. 26-Operation sequence of the escrimx3.m function

The function nlcOUT $6 x . m$ runs escrimx $3 . m$ and runs the modife.txt in ANSYS, as shown in the figure below (fig. 27) 
1. Runs escrimlx.m

2. Runs modife.txt in ANSYS

Fig. 27-Operation sequence of the nlcOUT $6 \mathrm{x}$. m function

The function MACfun $6 \mathrm{x} . \mathrm{m}$ calculates the objective function value in every evaluation. It opens the results file $\mathrm{n} 5 . \operatorname{lgw}$, and calculates the sum of all deflections, which is the objective function. The fig. 28 shows the operation sequence of the MAC fun 6x.m function [13]:

1. Runs nlcoUT6x.m

2. Load the results file $n 5.1 \mathrm{gw}$

3. Calculates the number of nodal deflections on the n5. Igw file

4. Calculate the value of the objective function

5. Prints in the screen the value of the objective function

Fig. 28-Operation sequence of the MACfun $6 \mathrm{x}$. m function

The Finite Element Model Updating methodology presented in this chapter is based on the coordination of ANSYS and MATLAB: ANSYS is used for the FEM calculations and MATLAB is used for the optimization processes. The optimization type is Sequential Quadratic Programming (SQP). The fmincon function of MATLAB's optimization toolbox is used to control the optimization process. An important aim of this work is to validate this Finite Element Model Updating methodology by testing it on two FEM models with different geometric variables.

\subsubsection{ANSYS Input file structure}

The ANSYS program is able to write and read text files that contain, in ANSYS programming language, all instructions done during the model construction. Those files are called ANSYS input files. They are needed in the optimization process, because ANSYS calculates the deflections in the nodal points by running them. The ANSYS input file (MODnume.txt) structure for both models is shown in the table 5. The code instructions are of two types: code generated by ANSYS during the FEM model construction, or ANSYS-dependent instructions, but not generated by ANSYS. The 
write of results to output file, the definition of initial variable values, the keypoints coordinate modification in order to include the variables, and the commands to get nodal deflections are the ANSYS-dependent instructions that were not originated during the construction of the model.

\begin{tabular}{|l|l|}
\hline User instruction & \multicolumn{1}{|c|}{ Defines initial variable values } \\
\hline \multirow{2}{*}{ ANSYS-Preprocessor-Modeling } & Creates Keypoints (with variables) \\
\cline { 2 - 2 } & Creates Lines \\
\cline { 2 - 2 } & Creates Areas \\
\hline ANSYS-Preprocessor-Element type & Select element type- Shell63 \\
\hline ANSYS-Preprocessor-Real constants & Defines shell thickness \\
\hline $\begin{array}{l}\text { ANSYS-Preprocessor- Material } \\
\text { properties }\end{array}$ & Define Material properties \\
\hline ANSYS-Preprocessor- Mesh tool & Creates mesh \\
\hline ANSYS-Solution- Loads & Apply Loads and Displacements \\
\hline ANSYS-Solution & Solves the Model \\
\hline User instruction & Get nodal deflections from the model \\
\hline User instruction & Writes results to output file n5.1gw \\
\hline
\end{tabular}

Table 5-Sequence of the ANSYS input files operations.

The ANSYS input file code for the ribbed plate and tubular beam models is shown on the Annex 3- Finite Element Model files. 
CHAPTER 4-RESULTS 


\subsection{Numeric approximation- Comparison between numeric and analytic methods}

\subsubsection{About the model}

In order to compare the numeric and the analytic methods, the calculations must be done for the same object points in the two methods. The results can be compared using a non-dimensional deflection ratio. The deflection ratio is better the closer it is to 1 . The beam was subjected to a double load of $5120 \mathrm{~N}$ (torsion) and a centred load of $3528 \mathrm{~N}$ (simple bending). The beams areas are shown next (fig. 29.):

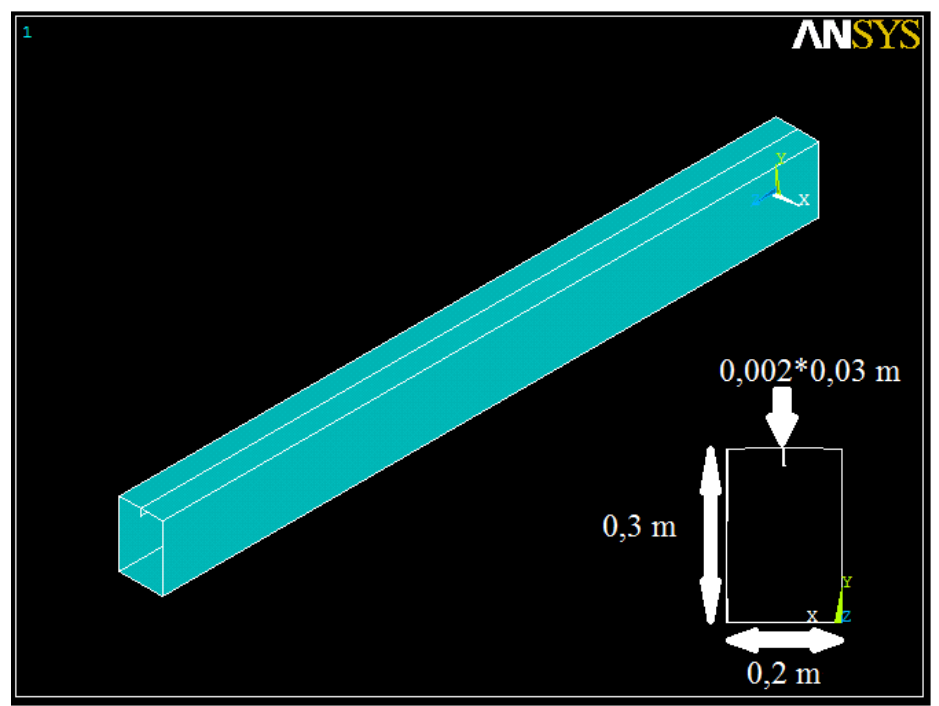

Fig. 29-Areas of the initial finite element model

The beam dimensions are: width of the section $b=0,2 \mathrm{~m}$, height of the section $\mathrm{h}=0,3 \mathrm{~m}$, thickness $t=0,002 \mathrm{~m}$, length $\mathrm{L}=3 \mathrm{~m}$. In addition, a rib with dimensions of $\mathrm{t}=0,002 \mathrm{~m}$, $\mathrm{h}=0,03 \mathrm{~m}$ and $\mathrm{L}=3 \mathrm{~m}$ was designed together with the beam. The rib is located on the inner side of the beam's top face.

\subsubsection{Beam Deflection by the Analytic method}

\subsubsection{Bending}

In order to calculate the deflection due to bending, one must consider the effect of the longitudinal rib. This can be done by calculating the Inertia moment in relation to the centre of mass. The first step is to calculate the y coordinate of the centre of mass $y_{c}$ : 


$$
\mathrm{y}_{\mathrm{c}}=\frac{\mathrm{m}_{1} \mathrm{y}_{1}+\mathrm{m}_{2} \mathrm{y}_{2}}{\mathrm{~m}_{1}+\mathrm{m}_{2}}=\frac{2 * 0,285+47 * 0,15}{2+47}=0,1556 \mathrm{~m}
$$

where:

$\mathrm{y}_{\mathrm{c}}$ is the centre of mass coordinate of the system

$\mathrm{m}_{1}$ is the mass of the object 1 (rib)

$\mathrm{m}_{2}$ is the mass of the object 2 (beam without rib)

$\mathrm{y}_{1}$ is the mean $\mathrm{y}$ coordinate of the object 1 (rib)

$y_{2}$ is the mean y coordinate of the object 2 (beam without rib)

The inertia moment of the object in relation to the $\mathrm{x}$ axis is:

$$
\mathrm{I}_{\mathrm{xx}}=\frac{\mathrm{bh}^{3}}{12}-\frac{\mathrm{b}_{1} \mathrm{~h}_{1}{ }^{3}}{12}=\frac{0,2^{*} 0,3^{3}}{12}-\frac{0,196 * 0,296^{3}}{12} *=2,64 * 10^{-5} \mathrm{~m}^{4}
$$

where:

$\mathrm{I}_{\mathrm{xx}}$ is the inertia moment in relation to the $\mathrm{x}$ axis

$b$ is the section width of the beam

$h$ is the section height of the beam

$b_{1}$ is the inner section width

$\mathrm{h}_{1}$ is the inner section height

The inertia moment in relation to the centre of mass can now be obtained:

$$
I_{m}=I_{x x}+A_{y_{c}}{ }^{2}=2,64 * 10^{-5}+0,002 * 0,03 * 0,1556^{2}=2,7853 * 10^{-5} \mathrm{~m}^{4}
$$

where:

$I_{m}$ is the inertia moment in relation to the centre of mass

$\mathrm{A}$ is the transversal rib area

The deflection due to bending can now be calculated using the calculated inertia moment:

$$
\begin{aligned}
& \mathrm{y}_{\mathrm{b}}=\frac{\mathrm{FL}^{3}}{48 \mathrm{EI}}\left(3 \frac{\mathrm{x}^{2}}{\mathrm{~L}^{2}}-4 \frac{\mathrm{x}^{3}}{\mathrm{~L}^{3}}\right)=\frac{3528 * 3^{3}}{48 * 210^{*} 10^{9} * 2,7853^{*} 10^{-5}}\left(3 * \frac{1,5^{2}}{3^{2}}-4 * \frac{1,5^{3}}{3^{3}}\right) \\
& =8,482 * 10^{-5} \mathrm{~m}
\end{aligned}
$$

\subsubsection{Torsion}

In torsion, the rigidity is governed by the transversal elasticity modulus G: 


$$
\mathrm{G}=\frac{\mathrm{E}}{2 *(1+v)}=\frac{210^{*} 10^{9}}{2 *(1+0,29)}=8,14 * 10^{10} \mathrm{~Pa}
$$

The torsion moment can be calculated by multiplying the applied load $\mathrm{P}$ by the distance between the line of action of the two binary forces. In this case the distance between the line of action of the two binary forces $b_{i}$ is equal to the section width $b$. The torsion moment is then:

$\mathrm{M}_{\mathrm{t}}=\mathrm{P}^{*} \mathrm{~b}=5120^{*} 0,2=1024$ N.m

The area of the mean line is necessary to calculate the distortion angle $\theta$ :

$$
\mathrm{A}_{0}=(\mathrm{b}-\mathrm{e}) *(\mathrm{~h}-\mathrm{e})=(0,2-0,002) *(0,3-0,002)=0,059 \mathrm{~m}^{2}
$$

The shear stresses must be calculated, in order to be possible to calculate the shear flux:

$$
\tau=\frac{\mathrm{Mt}}{2 * \mathrm{e}^{*} \mathrm{~A}_{0}}=\frac{1024}{2 * 0,002 * 0,059}=4338983,1 \mathrm{~Pa}
$$

The shear flux can now be calculated, by multiplying the shear stress by the thickness of the object:

$$
\mathrm{C}=\tau^{*} \mathrm{t}=4338983,1 * 0,002=8678 \text { Pa.m }
$$

The mean line perimeter $l_{t}$ must be calculated, in order to be possible to calculate the distortion angle:

$\mathrm{l}_{\mathrm{t}}=2 *((\mathrm{~h}-\mathrm{e})+(\mathrm{b}-\mathrm{e}))=2 *((0,3-0,002)+(0,2-0,002))=0,992 \mathrm{~m}$

The distortion angle can now be calculated:

$$
\theta=\frac{\mathrm{Cl}_{\mathrm{t}}}{2 \mathrm{GAoe}}=\frac{8678 * 0,992}{2 * 8,14 * 10^{10} * 0,059 * 0,002}=4,48 * 10^{-4} \mathrm{rad}
$$

To be possible to calculate the deflection due to torsion, one must calculate the diagonal length of the object. It is necessary to calculate the angle of the section:

$$
\begin{gathered}
\operatorname{Tg} \phi=\frac{0,5^{*} \mathrm{~b}}{0,5^{*} \mathrm{~h}}=\frac{0,1}{0,15} \\
\phi=\operatorname{Tg}^{-1}\left(\frac{0,1}{0,15}\right)=33,7^{\circ}
\end{gathered}
$$


The length of the diagonal can then be calculated:

$$
\mathrm{D}=\frac{\mathrm{h}}{\cos \phi}=\frac{0,3}{\cos 33,7}=0,430 \mathrm{~m}
$$

The deflection due to torsion can now be calculated by multiplying half of the section diagonal by the distortion angle and by the length:

$$
\mathrm{y}_{\mathrm{t}}=\frac{\mathrm{D}}{2} \theta \mathrm{L}=\frac{0,430}{2} * 4,48 * 10^{-4} * 3=2,89 * 10^{-4} \mathrm{~m}
$$

Because the rib is longitudinal, it has not a significant effect on the torsion deflection. As a simplification, the rib was not considered in the calculation of the torsion deflection $\mathrm{y}_{\mathrm{t}}$.

\subsubsection{Total deflection}

The total deflection can be expressed as the sum of the torsion and bending deflections:

$$
\mathrm{y}_{\text {total }}=\mathrm{y}_{\mathrm{b}}+\mathrm{y}_{\mathrm{t}}=8,482 * 10^{-5}+2,89 * 10^{-4}=3,74 * 10^{-4} \mathrm{~m}
$$

\subsubsection{Beam Deflection by the numeric method}

The element type used in the initial beam is the shell elastic four nodes, named shell63. The constraints were applied on the two lower keypoints in each side of the beam (four in total), which means that the beam is simply supported as its ends. The total deflection results are shown next (fig. 30):

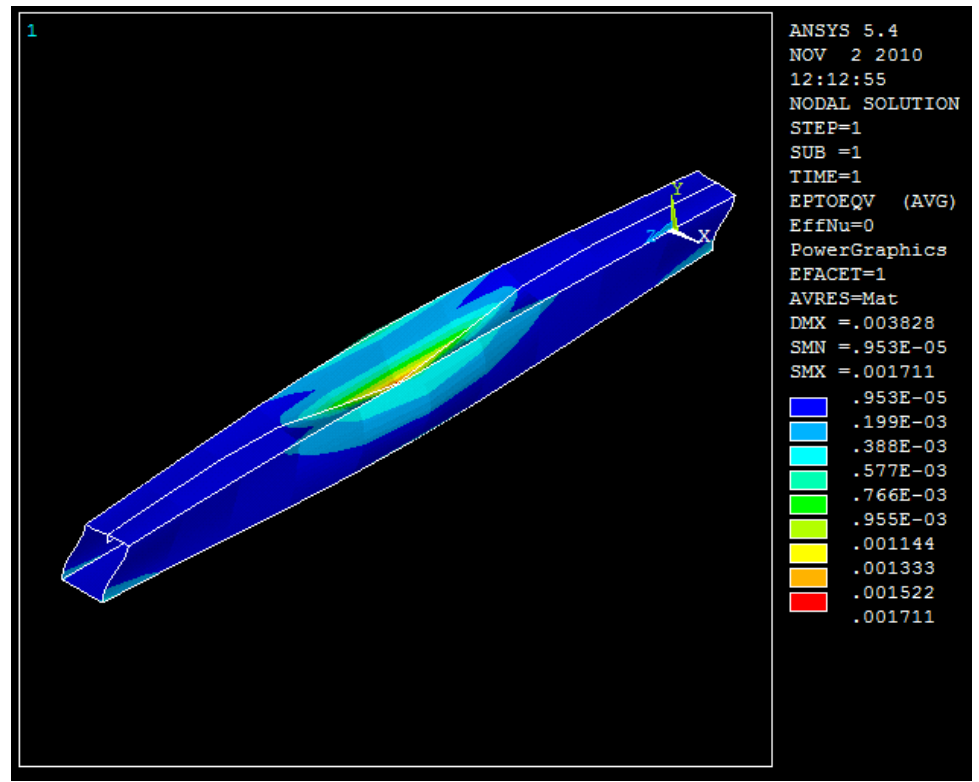

Fig. 30-Deflection results for the initial FEM model 
One can see that the value obtained for the total deflection by the analytic method belongs to the interval of values obtained by the numeric method. One can also see that there is a much higher deflection in the central region of the beam, due to the applied loads.

\subsubsection{Comparison of numeric and analytic methods}

As told before, the comparison between analytic and numeric methods was done using a deflection ratio. The next figure (fig. 31) shows the points were deflections were queried on the numeric method (on ANSYS).

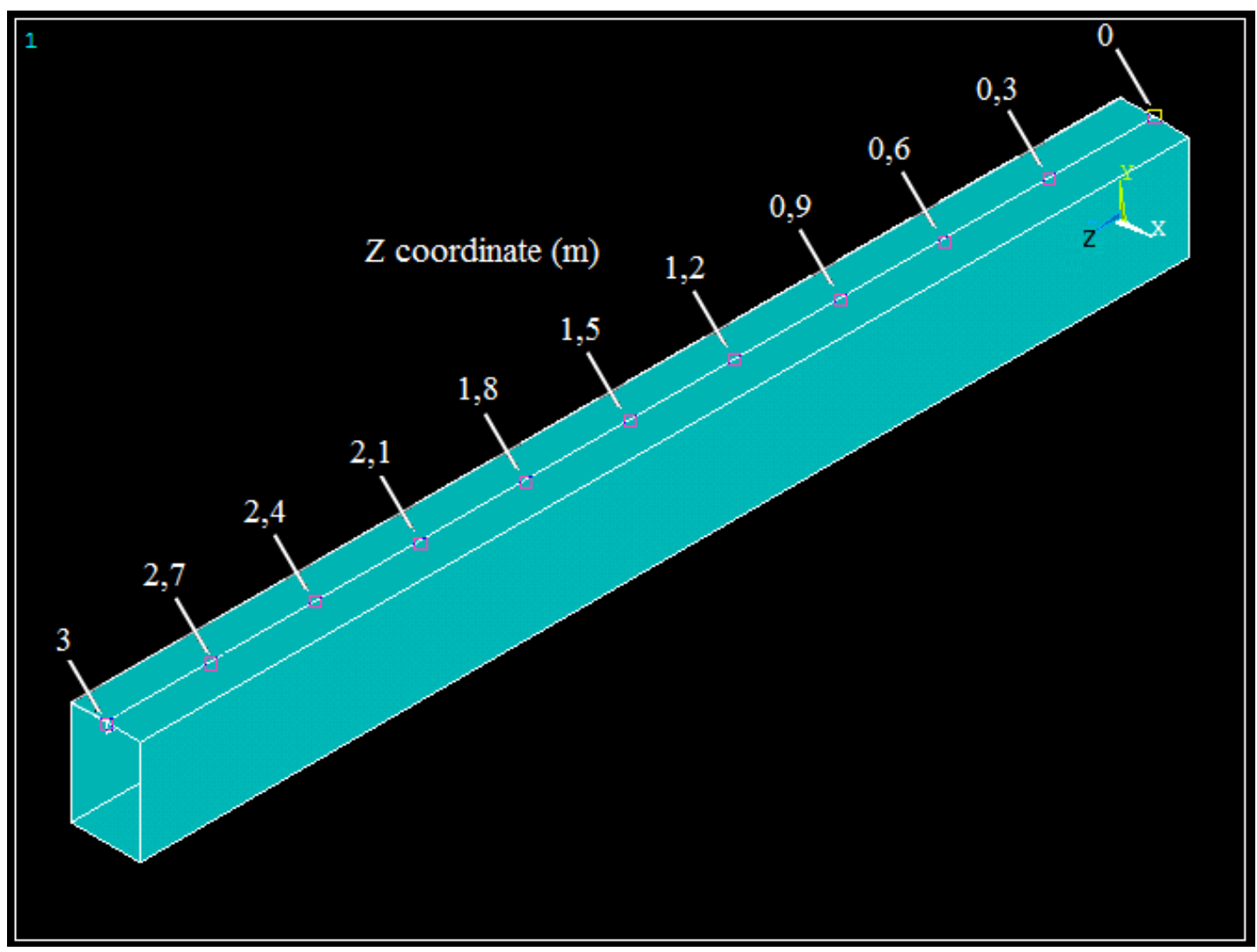

Fig. 31- Points were results were queried on ANSYS

One can see that the results were queried on the top surface of the object, having the points $x$ coordinate of $0,1, y$ coordinate of 0,3 and $z$ coordinate shown in fig. 31 . In the next table (table 6) one can see the deflection results by the two methods. The deflection ratio was calculated and is also shown on the same table: 


\begin{tabular}{|c|c|c|c|c|c|}
\hline & \multicolumn{3}{|c|}{ Analytic } & Numeric & \\
\hline Z coordinate $[\mathrm{m}]$ & $\mathrm{y}_{\mathrm{b}}[\mathrm{m}]$ & $\mathrm{y}_{\mathrm{t}}[\mathrm{m}]$ & $\mathrm{y}_{\text {total }}[\mathrm{m}]$ & $\begin{array}{c}\text { Total } \\
\text { deflection[m] }\end{array}$ & $\begin{array}{c}\text { Deflection } \\
\text { ratio }\end{array}$ \\
\hline 0 & $0,00 \mathrm{E}+00$ & $2,89 \mathrm{E}-04$ & $2,89 \mathrm{E}-04$ & $2,50 \mathrm{E}-04$ & 1,16 \\
\hline 0,3 & $8,82 \mathrm{E}-06$ & $2,89 \mathrm{E}-04$ & $2,98 \mathrm{E}-04$ & $2,60 \mathrm{E}-04$ & 1,15 \\
\hline 0,6 & $2,98 \mathrm{E}-05$ & $2,89 \mathrm{E}-04$ & $3,19 \mathrm{E}-04$ & $2,77 \mathrm{E}-04$ & 1,15 \\
\hline 0,9 & $5,49 \mathrm{E}-05$ & $2,89 \mathrm{E}-04$ & $3,44 \mathrm{E}-04$ & $2,50 \mathrm{E}-04$ & 1,38 \\
\hline 1,2 & $7,60 \mathrm{E}-05$ & $2,89 \mathrm{E}-04$ & $3,65 \mathrm{E}-04$ & $8,99 \mathrm{E}-05$ & 4,06 \\
\hline 1,5 & $8,48 \mathrm{E}-05$ & $2,89 \mathrm{E}-04$ & $3,74 \mathrm{E}-04$ & $1,32 \mathrm{E}-03$ & 0,28 \\
\hline 1,8 & $7,60 \mathrm{E}-05$ & $2,89 \mathrm{E}-04$ & $3,65 \mathrm{E}-04$ & $8,99 \mathrm{E}-05$ & 4,06 \\
\hline 2,1 & $5,49 \mathrm{E}-05$ & $2,89 \mathrm{E}-04$ & $3,44 \mathrm{E}-04$ & $2,50 \mathrm{E}-04$ & 1,38 \\
\hline 2,4 & $2,98 \mathrm{E}-05$ & $2,89 \mathrm{E}-04$ & $3,19 \mathrm{E}-04$ & $2,77 \mathrm{E}-04$ & 1,15 \\
\hline 2,7 & $8,82 \mathrm{E}-06$ & $2,89 \mathrm{E}-04$ & $2,98 \mathrm{E}-04$ & $2,60 \mathrm{E}-04$ & 1,15 \\
\hline 3 & $0,00 \mathrm{E}+00$ & $2,89 \mathrm{E}-04$ & $2,89 \mathrm{E}-04$ & $2,50 \mathrm{E}-04$ & 1,16 \\
\hline
\end{tabular}

Table 6-Comparison between numeric and analytic method in terms of strain

The bending deflection is a function of the distance to the supports, and the deflection due to torsion is constant. In the next figure (fig. 32), one can see the deflection ratio for the analytic and numeric methods. The deflection ratio is better, the closer it is to 1 .

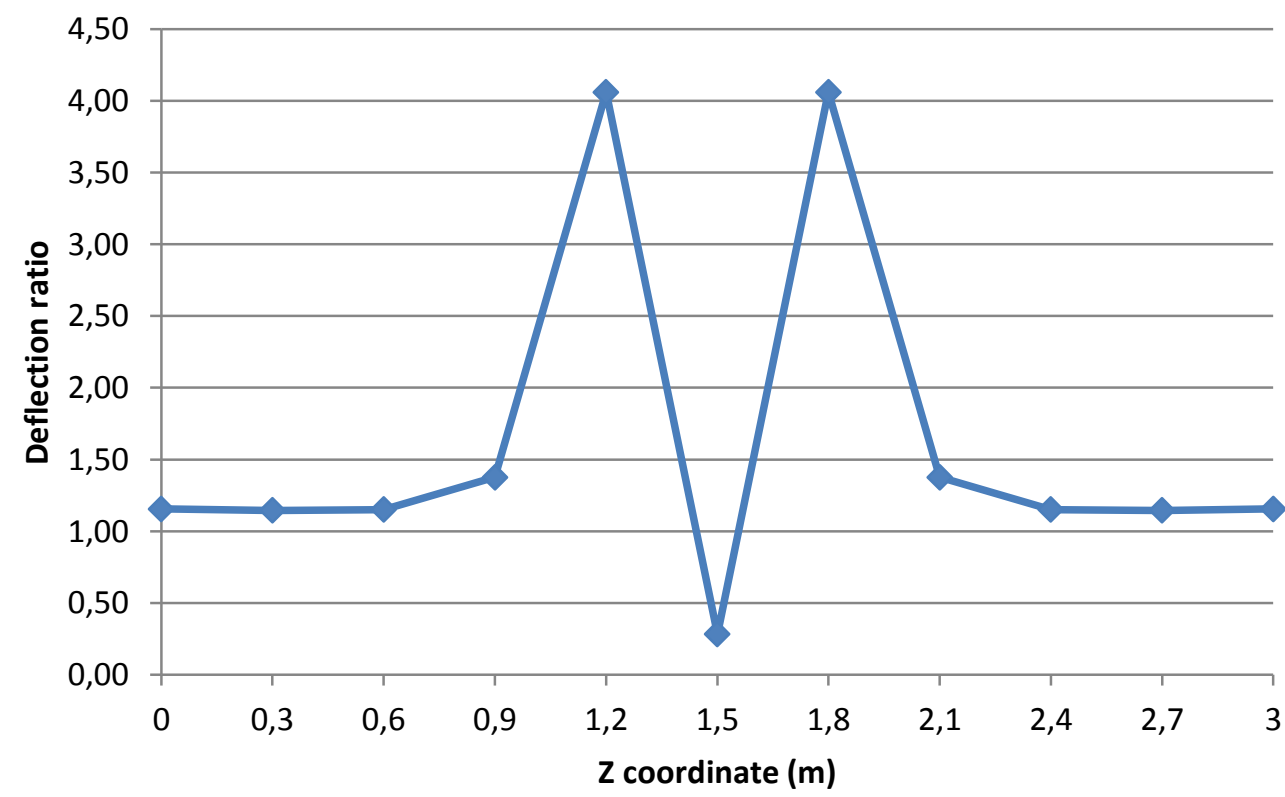

Fig. 32-Deflection Ratio in function of the $\mathrm{z}$ coordinate 
The deflection ratio is close to 1 for most of the considered points, except for the center point and for the two points near center. The low deflection ratio in the center of the beam is due to stress concentration in the numeric method, because one load is concentrated and applied in the center of the beam. Because there is stress concentration in the center of the object, it is normal that there is less stress in the surrounding zones. This fact can explain the high stress ratios in the points $\mathrm{z}=1,2$ and $\mathrm{z}=1,8$. One can also see that the deflection ratio results are symmetric (fig. 32).

\subsection{Mechanical Tests}

In the chapter 3, the selected material was the DOCOL dual-phase steel. However, there is no Young modulus or Poisson coefficient value in the DOCOL dual-phase steels catalogue. Also, there is a range of values for the Yield stress. Because the lack of material properties values in the catalogue, there is the need to perform mechanical tests to determine a value for the Young modulus, Poisson coefficient and Yield stress. The mechanical tests performed were two: tensile test and extensometry test. The tensile test has the aim of determining Yield stress with $0,2 \%$ offset and Young modulus. The extensometry test has the aim of determining Poisson coefficient, and was also used to determine Young modulus. Because in tensile test the material suffers rupture, both the elastic and plastic domains can be studied. The Yield stress was determined only in tensile test, because in extensometry test the material is always in the elastic domain. The Young modulus can be determined in both tensile and extensometry tests. In tensile test, one considers the Stress-Strain chart and selects only the points that belong to the elastic domain. By using a linear fit, one can obtain the Young modulus, because of the proportionality between the stresses and strains in the elastic domain. In extensometry test, one determines the stress by dividing the load by the transversal area of the specimen. Then, dividing the obtained Stress by the longitudinal strain, one can obtain the Young modulus. The Poisson coefficient is determined in extensometry test by applying relatively small loads, and measuring the longitudinal and transversal strain using an extensometer. The Poisson coefficient is the ratio between the transversal and longitudinal strain. 


\subsubsection{Denomination of the tested specimens}

\subsubsection{Tensile test}

Specimen 1- DOCOL 600 DL Long

Specimen 2- DOCOL 800 DP Long

\subsubsection{Extensometry test}

Specimen 3- DOCOL 600 DL Trans

Specimen 4- DOCOL 600 DL Long

Specimen 5- DOCOL 800 DP Trans

Specimen 6- DOCOL 800 DP Long

\subsubsection{Tensile test experimental results}

\subsubsection{Stress-Strain and Stress-Extension charts}

The Annex 1.1 shows the Stress-Extension and the Stress-Strain Charts for the tensile test. One can conclude that the specimen 1 has much lower Yield stress than the specimen 2. This is expected, because the specimen 1 is DOCOL600 and specimen 2 is DOCOL800. The designation of the steels is usually related to Yield stress. The higher the number in the designation, the higher Yield stress is expected. The extension at break is much higher in the specimen 1 than in the specimen 2. This is due to a higher ductility of the specimen 1 .

\subsubsection{Determination of Young modulus in tensile test}

After performing the tensile test, one obtained a . raw file with the results. The . raw file can be opened in Microsoft Excel. In order to determine Young modulus, one has to select only points that belong to the elastic domain. For that, one must select a point in the Stress-Strain chart that belongs to the elastic domain and then select all points of the chart until that point. Then, one must plot the Stress-Strain chart of the elastic domain only, and perform a linear fit to find the slope of the straight line, which is the Young modulus. The charts used to determine Young modulus are in the Annex 1.2. 
The obtained Young modulus is shown on the table 7:

\begin{tabular}{|c|c|c|}
\hline Specimen number & Specimen designation & Young modulus Value \\
\hline Specimen 1 & DOCOL 600 DL Long & $193,2 \mathrm{GPa}$ \\
\hline Specimen 2 & DOCOL 800 DP Long & $168,2 \mathrm{GPa}$ \\
\hline
\end{tabular}

Table 7-Young modulus results in tensile test

The Young modulus is lower than the regular value for the steel, which is $210 \mathrm{GPa}$. This can be due to the low quantity of martensite precipitated on the grain boundaries. The material was subjected to a heat treatment below the eutectoid temperature A1 that reduced the quantity of martensite. By reducing the quantity of martensite, the formability and ductility of the material increased but the mechanical resistance (in terms of the Yield Stress) and the material rigidity (Young modulus) decreased.

\subsubsection{Determination of Yield stress in tensile test}

The yield stress was calculated using an offset of $0,2 \%$. To calculate Yield stress, one had to find the origin $y$ coordinate $b_{s}$ by using the $y=s x+b_{s}$ equation obtained in the linear fit. One has to substitute y (stress) by $0, \mathrm{x}$ (strain) by 0,002 and s by the Young modulus obtained in the linear fit. One can then find the value of the origin y coordinate $b_{s}$. Then, one has to plot a straight line together with the original Stress-Strain chart. By selecting the intercepting point between the two charts, one can obtain the Yield stress, which is the Y coordinate of the intersection point. The charts used to determine Yield stress are in the Annex 1.3. The obtained Yield stress is shown on table 8:

\begin{tabular}{|c|c|c|}
\hline Specimen number & Specimen designation & Yield stress value \\
\hline Specimen 1 & DOCOL 600 DL Long & $309,12 \mathrm{MPa}$ \\
\hline Specimen 2 & DOCOL 800 DP Long & $555,06 \mathrm{MPa}$ \\
\hline
\end{tabular}

Table 8-Yield stress values obtained in tensile test

The values obtained for the Yield stress are inside the interval of the catalogue for the two specimens, as expected. The values are close to the values presented in the table 4 . One can conclude that the tensile test results in terms of Yield stress are similar to the catalogue data presented by the manufacturer, and shown in the end of the chapter 3Materials selection. 


\subsubsection{Determination of the Poisson coefficient, normal stress, and Young modulus in extensometry test}

In the Annex 1.4, one can see the tables containing the extensometry test results. In the extensometry test, one can obtain the longitudinal strain Elong and the transversal strain Etrans when the material is subjected to a non-constant tensile load in the elastic domain, by using an extensometer in each specimen. For every specimen, two reads was done, in order to minimize read errors. The table 9 shows the Young modulus range and the mean Poisson coefficient for the 4 specimens:

\begin{tabular}{|c|c|c|}
\hline Specimen number & Mean Poisson coefficient & Young modulus range \\
\hline Specimen 3 & 0,285 & $182-198 \mathrm{GPa}$ \\
\hline Specimen 4 & 0,284 & $176-186 \mathrm{GPa}$ \\
\hline Specimen 5 & 0,287 & $186-192 \mathrm{GPa}$ \\
\hline Specimen 6 & 0,270 & $184-203 \mathrm{GPa}$ \\
\hline
\end{tabular}

Table 9- Mean Poisson coefficient and mean Young modulus obtained in the extensometry test.

The regular Poisson coefficient of the steel is 0,29. The mean values of Poisson coefficient are close to 0,29 for the specimen 3,4 and 5. For the specimen 6 the obtained Poisson coefficient is 0,27 . The obtained values for the specimens 3,4 and 5 were slightly lower than the expected. For the specimen 6, the values are lower than the expected. The obtained Young modulus was less than the expected for all the specimens. The specimen with the highest Young modulus is the specimen 6, with an upper limit value of $203 \mathrm{GPa}$ and the specimen with the lowest Young modulus is the specimen 4, with a lower limit value of $176 \mathrm{GPa}$.

\subsection{Variable analysis}

In order to know if the models variables are being well implemented and have the desired physical meaning in the MODnume.txt file, one needs to do a variable analysis. The variable analysis consists of changing one variable at each time, keeping all other variables constant, and calculate the resulting objective function. In practice, the MODnume.txt file was executed on ANSYS after the change of the initial values of the variables and the results were written to a results file $n 5.1 \mathrm{gw}$. The results were copied to a Microsoft Excel worksheet, to be possible to perform the calculations of the 
objective function. This type of analysis was done for the two models: the ribbed plate, and the tubular beam. The optimization variables are subjected to constraints limits $\mathrm{l}_{\mathrm{b}} \leq \mathrm{X}_{0} \leq \mathrm{ub}_{\mathrm{b}}$

where:

$l_{b}$ is the lower bound

$\mathrm{x}_{0}$ is the initial value

$\mathrm{u}_{\mathrm{b}}$ is the upper bound

The limits are different for the geometric variables in the two models, since its initial value is also different. The vector $\mathrm{x}_{0}$ is the initial values vector (line vector). The variable names start in PR(PRLG1,PRLG2,PRLG3,PREX,etc.), however, in the optimization there is the need that the initial variables values are all of the same order (for example, in the geometric parameters optimization if PRLG1 has a value of 0,2, then PRLG2 and PRLG3 value must belong to the interval [0,1;1[ ). This detail is for the MATLAB optimization program to deal with all variables in the same order of value. Having that fact in consideration, one must define a relation between the PR variables, and the variables used by the program, because the initial variable values have a different order of value. A relation variable has the same name as the original, but without the PR (PRLG1 relation variable is denoted by LG1, PREX has a relation variable of EX, and so on). The variable analysis can be useful to determine the importance of each variable in the optimization program, but it can also be used to have a rough idea if the variables are being well written in the ANSYS input file. For example, if the objective function decreases with the decrease of the LG3 variable "rib thickness", then something is wrong in the ANSYS input file. A decrease of the PRLG3 variable must originate a worse (higher) objective function. In the Annex 2.1, one can see the deflection results for each considered nodal point, when one variable value changes. The variable values are also shown on each table. The objective function was calculated by the sum of the absolute values of the deflections in all considered nodal points. The objective function values were used to make one chart per each variable per model, representing the variation of the objective function as dependent variable with the value of each considered variable as independent variable. 


\subsubsection{Variable analysis of model 1- ribbed plate}

About the variable analysis of model 1, one can say that the variation of the three material properties variables seems to be logical: the objective function decreases linearly with the increase of Young modulus. The higher the Young modulus, the higher rigidity the material has, and, as a consequence, the lower are the deflections. About Poisson coefficient, one can say that an increase of the Poisson coefficient leads to lower deflections. This happens because the higher the Poisson coefficient, the higher is the transversal deformation in relation to the longitudinal deformation. Because there is less longitudinal deformation the resulting deflections are lower. The density does not affect in any way the objective function, being the objective function totally independent of the density value. About the LG1 variable, the results are not so logical. There is a decrease of the objective function value from $L G 1=0,01 \mathrm{~m}$ to $L G 1=0,025 \mathrm{~m}$ and then a sudden increase from $\mathrm{LG} 1=0,025 \mathrm{~m}$ to $\mathrm{LG} 1=0,03 \mathrm{~m}$. This could happen due to the small number of considered nodes (15) used to calculate the objective function. In fact, one can see that the nodes 7 and 8 in the model 1 for LG1=0,03 have much higher deflection than for $\mathrm{LG} 1=0,025$. If the number of considered nodes was higher, ideally all nodes, the expected results were a decrease of the objective function with a decrease of the LG1 variable. About LG2, one can say that the objective function decreases with the increasing value of the rib height, except for $L G 2=0,65$. This can be due to the small number of nodal points considered for the calculations that can lead to a high error in results, as for the LG1 variable. The variation of the LG3 variable, which is the thickness, seems to be logical: the higher the thickness, the lower is the objective function, in an approximate inverse proportionality. In the Annex 2 one can see the variable analysis tables and charts for this model.

\subsubsection{Variable analysis of model 2- tubular beam}

About the variable analysis of Model 2, one can say that the material properties have an expected influence on the objective function, like in the model 1. The LG4 variable has an expected behavior, because the higher the distance of the center to the corner segment of the cross section, the lower rigidity the object has. As a consequence, the objective function is higher. The LG5 variable has a non-linear behavior, which could happen due to the self non-linearity of the variable, or due to the small number of 
considered nodes, like in the LG1 and LG2 variables of the ribbed plate model. The LG6 variable has an expected influence on the objective function: the higher the LG6 variable, the higher the object rigidity, and, as a consequence, the objective function is lower. In the Annex 2, one can see the variable analysis tables and charts for the tubular beam model.

\subsection{Optimization results}

The ANSYS input file MODnume.txt is used by MATLAB and ANSYS in the optimization routines and the modifications that occur during the optimization processes are written to another file called modife.txt. First, the three geometric variables were optimized. Then the three material properties were optimized. Then one uses the optimized variables values of both geometric parameters optimization and material properties optimization and runs an optimization with all six variables. The results were analyzed in terms of optimization, having in consideration the initial variable values, the final variable values and the final value of the objective function in each optimization routine for both models, but also in terms of the FEM results, which are useful to show that the models deflections decreased in a global way, and not only on the considered nodal points.

\subsubsection{Model 1-Ribbed plate}

\subsubsection{Initial variable values and limits}

The initial variable values and the variable limits for the geometric parameters optimization were: (Table 10):

\begin{tabular}{|c|c|c|c|}
\hline Variable & Lower Bound & Initial Value & Upper Bound \\
\hline LG1 $[\mathrm{m}]$ & 0,025 & 0,100 & 0,230 \\
\hline LG2[m] & 0,0075 & 0,030 & 0,069 \\
\hline LG3[m] & 0,0005 & 0,002 & 0,0046 \\
\hline
\end{tabular}

Table 10-Variable limits for the geometric optimization (ribbed plate)

The initial values and the limits for the material properties optimization were: (table 11)

\begin{tabular}{|c|c|c|c|}
\hline Variable & Lower Bound & Initial Value & Upper Bound \\
\hline EX[GPa $]$ & 21 & 210 & 231 \\
\hline PXY & 0,145 & 0,29 & 0,435 \\
\hline DNS $\left[\mathrm{kg} / \mathrm{m}^{3}\right]$ & 3945 & 7890 & 15780 \\
\hline
\end{tabular}


Table 11-Variable limits for the material properties optimization (ribbed plate) For all variables optimization, the initial variable values and the variable limits were: (table 12):

\begin{tabular}{|c|c|c|c|}
\hline Variable & Lower Bound & Initial Value & Upper Bound \\
\hline LG1[m] & 0,00625 & 0,025 & 0,0575 \\
\hline LG2[m] & 0,01275 & 0,0510 & 0,11730 \\
\hline LG3[m] & 0,001150 & 0,0046 & 0,010580 \\
\hline EX [GPa] & 23,1 & 231 & 254,1 \\
\hline PXY & 0,2175 & 0,435 & 0,6525 \\
\hline DNS $\left[\mathrm{kg} / \mathrm{m}^{3}\right]$ & 3945 & 7890 & 15780 \\
\hline
\end{tabular}

Table 12-Variable limits for all variables optimization (tubular beam)

\subsubsection{Geometric parameters optimization results}

The final value of the objective function is: $\mathrm{q}(\mathrm{x})=0,00092 \mathrm{~m}$

The optimum design variables are (table 13):

\begin{tabular}{|c|c|}
\hline Variable & Value \\
\hline LG1[m] & 0,025 \\
\hline LG2[m] & 0,0510 \\
\hline LG3[m] & 0,0046 \\
\hline
\end{tabular}

Table 13-Final variable values for the geometric parameters optimization (ribbed plate)

The final value of the LG1 variable is the lower limit. In the LG1 variable analysis one can see that the minimum objective function is obtained when $L G 1=0,025 \mathrm{~m}$, which is the final LG1 variable value. The optimum value of the LG2 variable is closer to the upper bound than to the lower bound, as expected. The optimum value of LG3 is the upper bound. The LG3 variable behavior can be understood by looking at the variable analysis, where one can see that the objective function always decreases with an increasing value of LG3 variable, which means that the optimum value is always the upper bound. With that fact in consideration, there is no need to change the variable limits.

\subsubsection{Material properties optimization results}

The final value of the objective function is: $\mathrm{q}(\mathrm{x})=0,04258 \mathrm{~m}$

The optimum design variables are: (table 14) 


\begin{tabular}{|c|c|}
\hline Variable & Value \\
\hline EX $[\mathrm{GPa}]$ & 231 \\
\hline PXY & 0,435 \\
\hline DNS $\left[\mathrm{kg} / \mathrm{m}^{3}\right]$ & 7890 \\
\hline
\end{tabular}

Table 14-Final variable values for the material properties optimization (ribbed plate)

The final variables values for the EX and PXY variables are the upper bound limits. In fact, the variable analysis showed that the value of the objective function always decreases with an increase of the EX and PXY variables values. The density has no influence on the objective function, as demonstrated in the variable analysis.

\subsubsection{Optimization results using all variables}

The final value of the objective function is: $q(x)=0,00077 \mathrm{~m}$

The optimum design variables are (table 15):

\begin{tabular}{|c|c|}
\hline Variable & Value \\
\hline LG1 $[\mathrm{m}]$ & 0,025 \\
\hline LG2[m] & 0,051 \\
\hline LG3[m] & 0,0046 \\
\hline EX [GPa] & 231 \\
\hline PXY & 0,435 \\
\hline DNS $\left[\mathrm{kg} / \mathrm{m}^{3}\right]$ & 7890 \\
\hline
\end{tabular}

Table 15-Final variable values for all variables optimization (ribbed plate)

One can say that the results are quite similar to the obtained before in the materials properties optimization and in the geometric parameters optimization. This means that the MATLAB optimization program is not able to further optimize the models. This can be due to already fully optimized values or the function tolerance is not sufficiently low, and therefore MATLAB has no resolution to further optimize the models.

\subsubsection{Model 2- Tubular beam}

\subsubsection{Initial variable values and limits}

For the geometric parameters optimization, the initial variable values and the variable limits were (table 16): 


\begin{tabular}{|c|c|c|c|}
\hline Variable & Lower Bound & Initial Value & Upper Bound \\
\hline LG4[m] & 0,0213 & 0,0850 & 0,1955 \\
\hline LG5[m] & 0,0075 & 0,0300 & 0,0690 \\
\hline LG6[m] & 0,0088 & 0,0350 & 0,0805 \\
\hline
\end{tabular}

Table 16-Variable limits for the geometric parameters optimization (tubular beam)

For the material properties optimization, the initial variable values and variable limits were (table 17):

\begin{tabular}{|c|c|c|c|}
\hline Variable & Lower Bound & Initial Value & Upper Bound \\
\hline EX [GPa] & 21 & 210 & 231 \\
\hline PXY & 0,145 & 0,29 & 0,435 \\
\hline DNS[kg/m $\left.{ }^{3}\right]$ & 3945 & 7890 & 15780 \\
\hline
\end{tabular}

Table 17-Variable limits for the material properties optimization (tubular beam)

For all variables optimization, the initial variable values and the variable limits were (table 18):

\begin{tabular}{|c|c|c|c|}
\hline Variable & Lower Bound & Initial Value & Upper Bound \\
\hline LG4[m] & 0,00531 & 0,0213 & 0,04888 \\
\hline LG5[m] & 0,001905 & 0,0076 & 0,017526 \\
\hline LG6[m] & 0,02013 & 0,0805 & 0,18515 \\
\hline EX [GPa] & 23,1 & 231 & 254,1 \\
\hline PXY & 0,1460 & 0,2919 & 0,4378 \\
\hline DNS $\left[\mathrm{kg} / \mathrm{m}^{3}\right]$ & 3945 & 7890 & 15780 \\
\hline
\end{tabular}

Table 18-Variable limits for all variables optimization (tubular beam)

\subsubsection{Geometric parameters optimization results}

The final value of the objective function is: $\mathrm{q}(\mathrm{x})=0,00053 \mathrm{~m}$

The optimum design variables are presented in table 19:

\begin{tabular}{|c|c|}
\hline Variable & Value \\
\hline LG4[m] & 0,0213 \\
\hline LG5[m] & 0,0076 \\
\hline LG6[m] & 0,0805 \\
\hline
\end{tabular}

Table 19-Final variable values for the geometric optimization

One can say that the optimum value for the LG4 variable is the lower bound. In fact, in the variable analysis charts (Annex 2.2) one can see that the objective function always increase with the increase of the LG4 variable. If the variable limits were changed, the optimum value would be always the lower bound. If the lower bound had a lower value, 
one could have serious design problems on the model, due to keypoint displacement. One can say that the LG5 optimum value $0,0076 \mathrm{~m}$ is very close to the lower bound $0,0075 \mathrm{~m}$. About LG6, one can say that the optimum value is the upper bound. This can be explained by the variable analysis (Annex 2.2), where one can see that the objective function strictly decreases with the increase of the LG6 variable.

\subsubsection{Material properties optimization results}

The final value of the objective function is: $q(x)=0,01151 \mathrm{~m}$

The optimum design variables are (table 20):

\begin{tabular}{|c|c|}
\hline Variable & Value \\
\hline EX $[\mathrm{GPa}]$ & 231 \\
\hline $\mathrm{PXY}$ & 0,2919 \\
\hline $\mathrm{DNS}\left[\mathrm{kg} / \mathrm{m}^{3}\right]$ & 7890 \\
\hline
\end{tabular}

Table 20-Final variable values for the geometric optimization

The variable EX has the same value as the upper bound, exactly as in the ribbed plate model. The final value of the variable PXY is very close to the initial value. This could happen due to the combined effects of the 3 variables. The variable DNS has no effect on the objective function, and because of that, the DNS variable value remains unchanged.

\subsubsection{Optimization results using all variables}

The final value of the objective function is: $\mathrm{q}(\mathrm{x})=0,00046 \mathrm{~m}$

The optimum design variables are (table 21):

\begin{tabular}{|c|c|}
\hline Variable & Value \\
\hline LG4[m] & 0,0213 \\
\hline LG5[m] & 0,0076 \\
\hline LG6[m] & 0,0805 \\
\hline EX[GPa] & 231 \\
\hline PXY & 0,2919 \\
\hline DNS $\left[\mathrm{kg} / \mathrm{m}^{3}\right]$ & 7890 \\
\hline
\end{tabular}

Table 21-Final variable values for all variables optimization

The LG4 and LG5 variables values are the same in all variables optimization in comparison to the geometric parameters optimization. The LG6 variable has also the same value that was obtained in the geometric parameters optimization. This could be 
due to the value of the function tolerance $\left(10^{-6}\right)$, which allows relatively fast results processing time, but with a loss of resolution in the optimization process. The optimized values of the material properties are the same than the obtained in the previous materials optimization routine: the density did not change because, as told before, the objective function value does not depend of it, and the Young modulus and Poisson coefficient remain unchanged because they already have the optimum value for the used function tolerance.

\subsection{Optimization settings}

The optimization settings were the following:

'MaxFunEvals'=300

'MaxIter',=200

'DiffMaxChange' $=10$

'DiffMinChange' $=1 * 10^{-1}$

'TolFun' $=1 * 10^{-6}$

where:

MaxFunEvals is the maximum evaluations that can be run on a single iteration

MaxIter is the maximum number of iterations allowed in the optimization process.

DiffMaxChange is the maximum value that a variable can change at once

DiffMinChange is the minimum value that a variable can change at once

TolFun is the function tolerance

In every optimization routine done in this work, the optimization ended with the following message: "Local minimum found that satisfies the constraints. Optimization completed because the objective function is non-decreasing in feasible directions, to within the selected value of the function tolerance, and constraints were satisfied to within the default value of the constraint tolerance." 


\subsection{FEM results}

\subsubsection{Model1: Ribbed plate}

\subsubsection{Initial model results}

In the fig. 33, one can see the FEM results for the initial ribbed plate model.

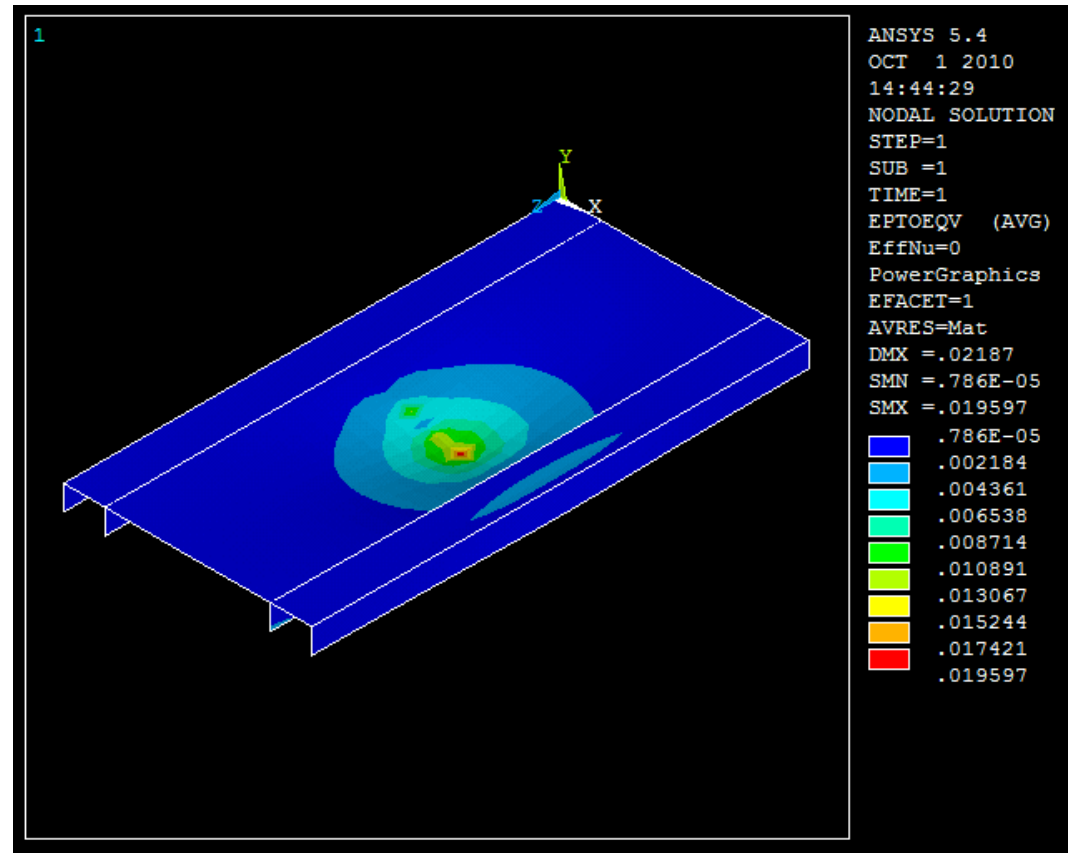

Fig. 33-Deflections of the initial ribbed plate model

There are much higher deflections in the center region of the plate than in the rest of the object, due to a load being applied on the center of the object (bending), which lead to higher stress concentration that result in higher deflections.

\subsubsection{Geometric parameters ANSYS results}

It is possible to see that the distance between the inner ribs decreased substantially, and the rib height is substantially higher (fig. 34) in comparison to the initial model (Fig 33).The thickness also increased. 


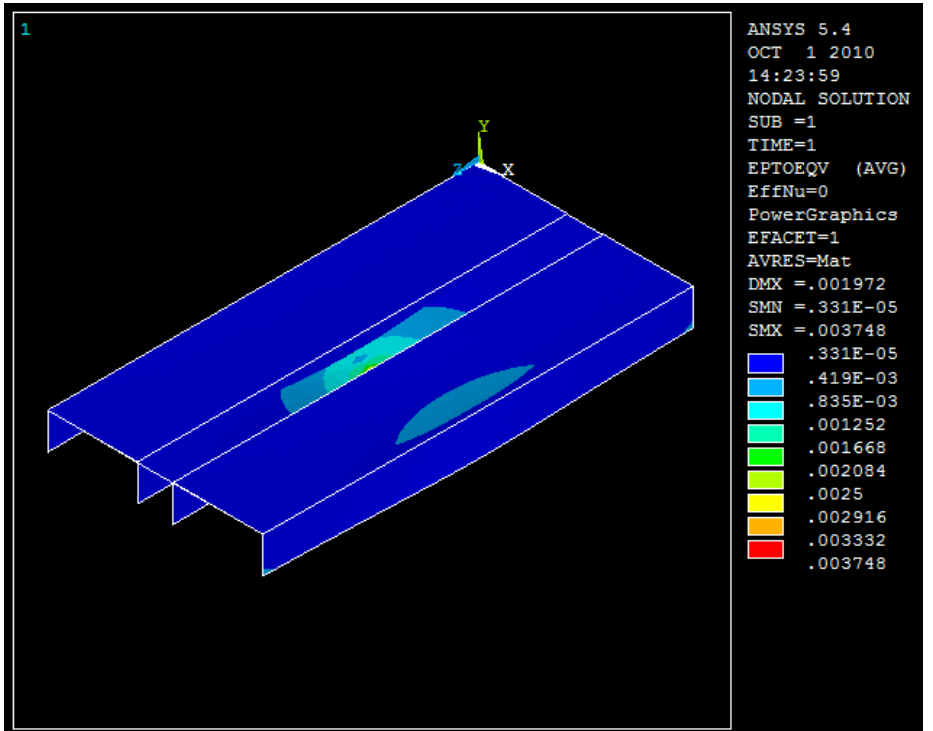

Fig. 34-Deflections of the ribbed plate model after geometric parameters optimization Because the element type is shell, it is not possible to know by the screenshot if the thickness is lower or higher in comparison to the initial model, it is only possible to know by the optimization results. The deflections reduced greatly in comparison to the initial model: the maximum deflection decreased from $0,019597 \mathrm{~m}$ to $0,003748 \mathrm{~m}$, which is great. The minimum deflection decreased from $0,786 * 10^{-5} \mathrm{~m}$ to $0,331 * 10^{-5} \mathrm{~m}$, which means that the minimum deflection of the optimized model is near half of the initial model.

\subsubsection{Material properties ANSYS results}

The deflection results of the material properties optimization seem to be higher (fig. 35) than the initial model (fig. 33).

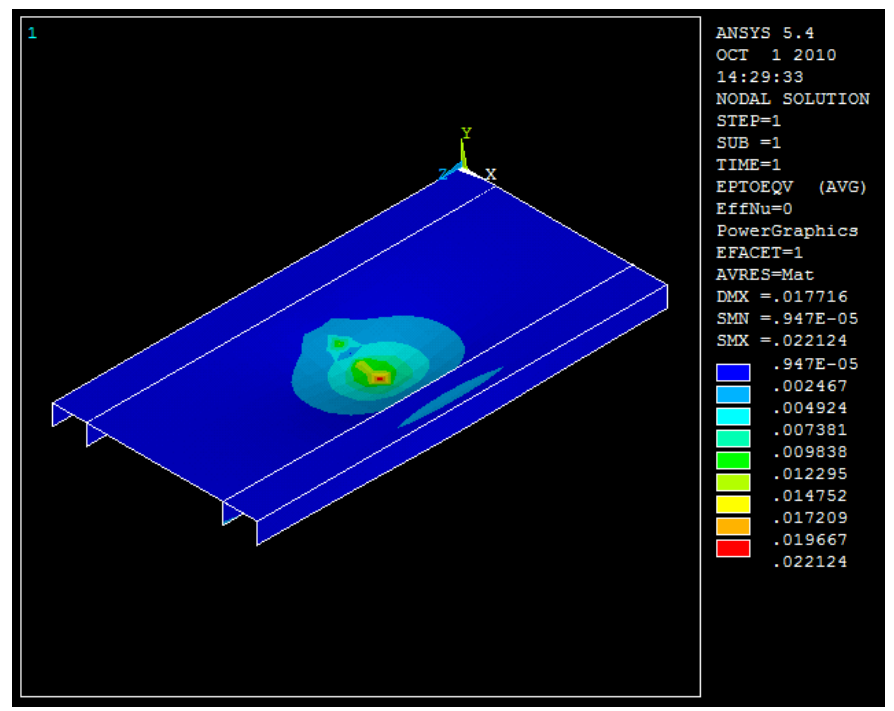

Fig. 35-Deflections of the ribbed plate model after material properties optimization 
This was surely true if the colors of the two figures were exactly the same. One can see that there is a higher quantity of dark blue in the fig. 35, which means that the deflection in that area reduced. In fact, the dark blue deflection range in the fig. 35 is $\left[0,947^{*} 10^{-5}\right.$, $\left.2,467 * 10^{-3}\right] \mathrm{m}$ and the blue deflection in the fig. 33 is $\left[2,184 * 10^{-3}-4,361 * 10^{-3}\right] \mathrm{m}$, which means there is a deflection reduction. The nodes with deflection higher than $2,184 * 10^{-3}$ $\mathrm{m}$ in the fig. 35 can have a higher deflection than in the fig. 33 , but in general terms, there is a deflection reduction.

\subsubsection{ANSYS results using all variables}

The FEM results of all variables optimization show that the deflections have decreased strongly (fig. 36) in comparison to the initial model (fig. 33).



Fig. 36-Deflections of the ribbed plate model after all variables optimization

There is a larger area of dark blue, which means that the deflections have reduced in that area. When comparing the deflection value range of each color, one can see that there is a strong decrease of the deflections for all colors.

\subsubsection{Model2: Tubular beam}

\subsubsection{Initial model results}

The initial tubular beam model is represented on the next figure (fig. 37). 


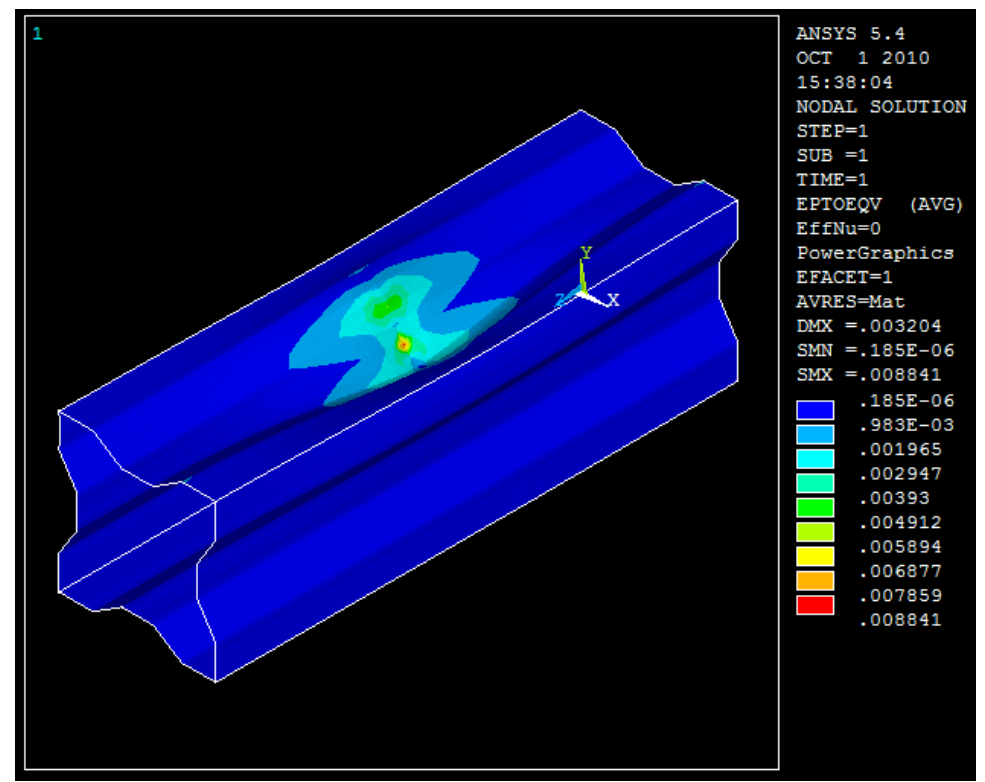

Fig. 37-Nodal deflection for the initial tubular beam model

In fig. 37 one can see the nodal deflections of the initial tubular beam model. Like in the ribbed plate model, one can see much higher deflections in the center region of the object, because there is one load applied exactly in the center of the object (bending), and there is also a binary load that is equivalent to a torsion moment. One can say that the initial tubular beam model has low deflections, and has a good rigidity.

\subsubsection{Geometric parameters ANSYS results}

It is possible to see that the cross section shape of the tubular beam suffered a severe change during the optimization (fig. 37 and fig. 38).

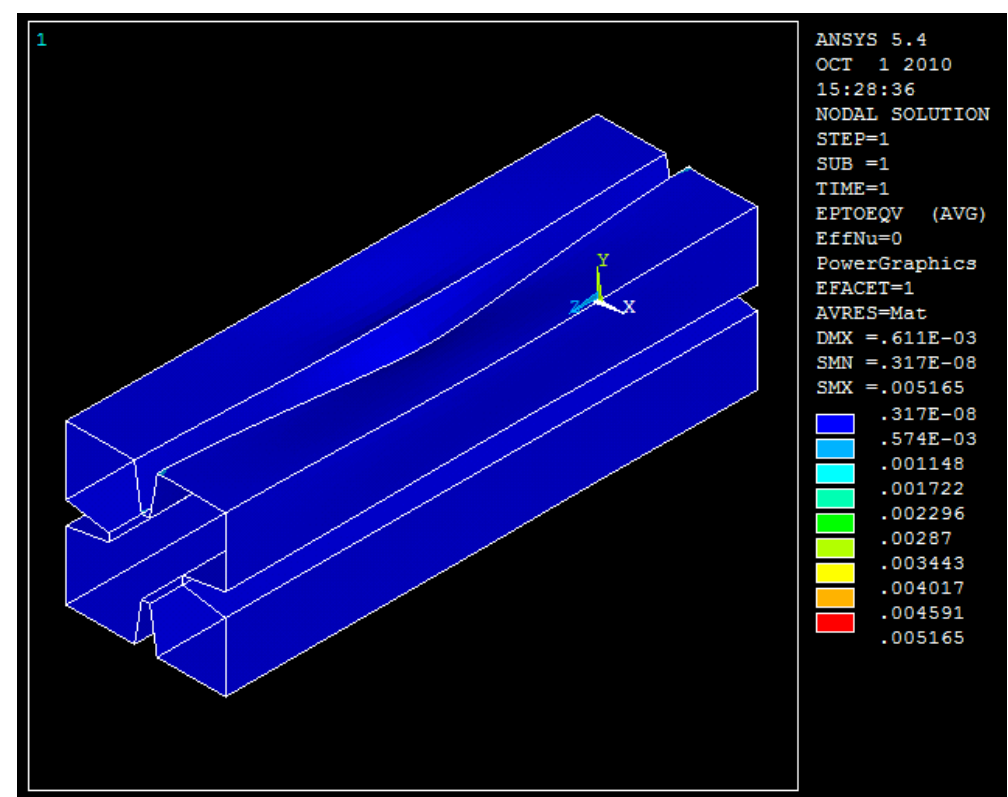

Fig. 38-Nodal deflections for the geometrically optimized tubular beam model 
In fact, one can see an increase of the height of the center segment of the section wall (LG6 variable), which led to a higher rigidity. The distance of the center to the corner segment decreased (LG4 variable) and the center segment length has decreased (LG5 variable). The deflections reduced strongly in comparison to the initial model, specially the lowest deflections (dark blue color). The results also show that the deflection in the area around the point of application of the loads reduced strongly, as one can see by the screenshots (fig. 37 and fig. 38). In the geometric parameters optimization results, there is only the dark blue color, which is the color of the lowest deflections.

\subsubsection{Material properties ANSYS results}

It is possible to see that the deflections have reduced after the materials optimization (fig. 39) in comparison to the initial model (fig. 37).

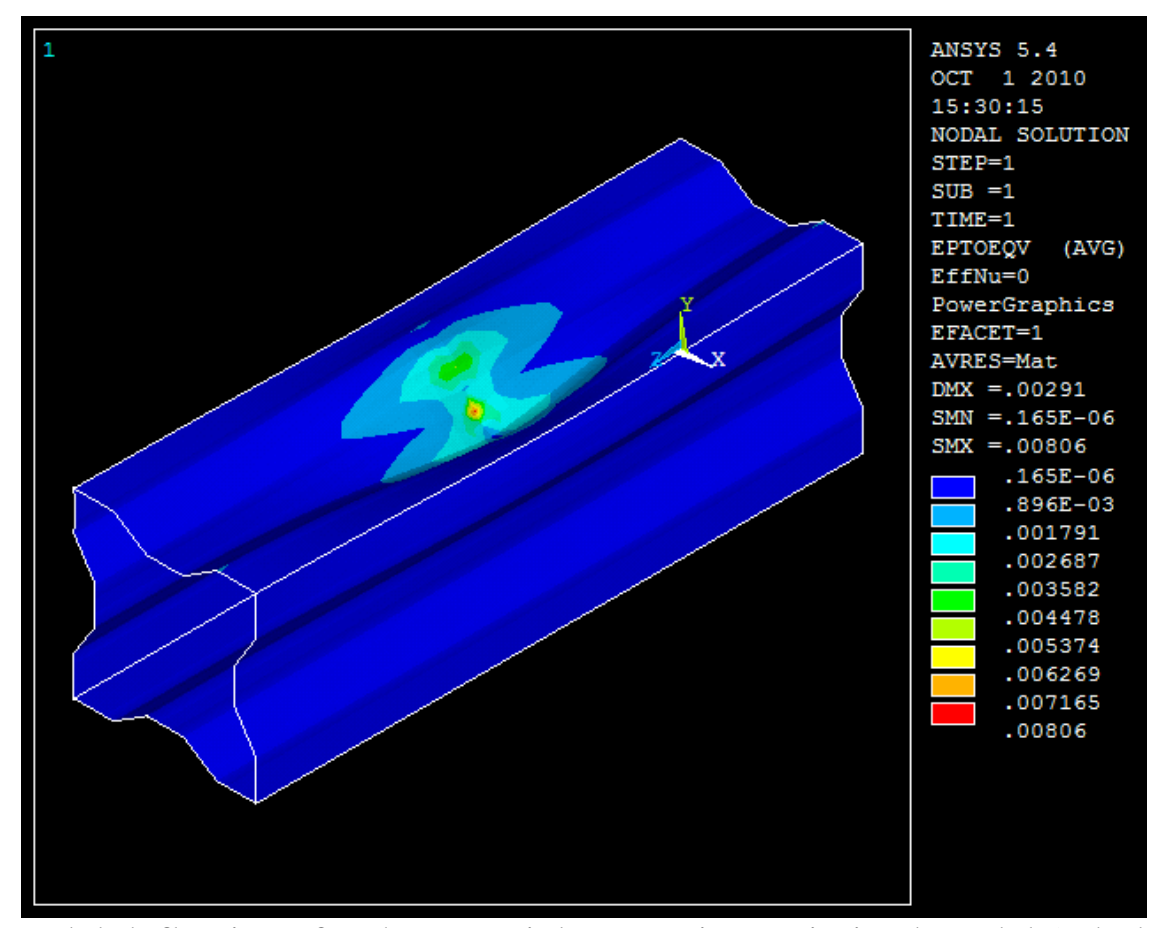

Fig. 39-Nodal deflections for the material properties optimized model (tubular beam)

The deflection reduction is much less sharp than in the geometric parameters optimization results. The colors in the screenshots have a similar distribution. One can then conclude that there is a global deflection reduction, because all the deflection 
values are lower in the fig. 39 than in the fig. 37 and the color distribution in the two screenshots is very similar.

\subsubsection{ANSYS results using all variables}

The FEM screenshots for all-variables optimization (fig. 40) show that the geometric parameters values are quite similar than in the geometric parameters optimization, due to the similar shape of the object cross section.



Fig. 40-Nodal deflections for all variables optimized model (tubular beam)

There is only one color in the fig. 40, which is dark blue. This means that the deflections are very low in every zones of the model. All the deflection values are lower than in the initial model. A huge decrease in the deflection can be seen in the lower bound of dark blue color: $0,292 * 10^{-8} \mathrm{~m}$ in the optimized model (fig. 40 ) and $0,185^{*} 10^{-6}$ $m$ in the initial model (fig. 37). 
CHAPTER 5-RESULTS DISCUSSION AND CONCLUSIONS 


\subsection{Results discussion}

\subsubsection{Variable analysis}

\subsubsection{Material properties}

The variables EX, PXY, and DNS have the physical meaning of: Young modulus, Poisson coefficient, and density, respectively. The variable analysis tables and charts are on the Annex 2.1 and Annex 2.2, respectively. The variable analysis charts for those variables have a similar curve for both models. One can see that there is a linear dependency between the objective function and the Young modulus. The objective function decreases with the increase of Young modulus. This behavior is expected, because a higher material rigidity leads to higher object rigidity. There is an almost linear dependency between the Poisson coefficient and the objective function. The objective function decreases with the increase of the Poisson coefficient. This behavior is expected, because when the longitudinal strain is higher and the transversal strain is kept constant the Poisson coefficient decreases. The objective function is not dependent of the density, as one can see by the results.

\subsubsection{Geometric parameters}

\subsection{Model 1: ribbed plate}

The chart $\mathrm{q}(\mathrm{x})=\mathrm{f}(\mathrm{LG} 1)$ shows a non-linear dependency between the distance of the inner ribs to the center (LG1 variable) and the objective function. One can see that the minimum value of the objective function occurs for $L G 1=0,025 \mathrm{~m}$. According to this fact, the geometrically optimized model has a LG1 value of $0,025 \mathrm{~m}$ in order to minimize the objective function. One can say that the objective function decreases with LG2 from $L G 2=0,036 \mathrm{~m}$ to $\mathrm{LG} 2=0,061 \mathrm{~m}$. From $\mathrm{LG} 2=0,061 \mathrm{~m}$ to $\mathrm{LG} 2=0,066 \mathrm{~m}$ there is a significant increase of the objective function. There is a decrease of the objective function with an increase of the LG3 variable (thickness). The variation is similar to an inverse proportionality. An increase of the LG3 variable will necessarily result in a higher Inertia moment, and will originate a lower objective function $\mathrm{q}(\mathrm{x})$. 


\subsection{Model 2: tubular beam}

The objective function always increases with the increase of the LG4 variable in the considered interval $[0,015 ; 0,027]$. About LG5, the objective function suffers little variation from the interval $[0,005 ; 0,01]$, and then decreases sharply for LG5=0,011. The variable analysis chart is similar to an inverse proportionality for LG6 variable. In LG6 variable analysis chart, the objective function always decreases in the chosen interval $[0,066 ; 0,096]$.

\subsubsection{Mechanical tests}

A great variety of materials were analyzed for this application. However, one can conclude that the dual-phase steel is the most adequate material because: it has a high Young modulus, despite not as high as expected, its cost is relatively low, and their Yield stress is high, which means that the material has high mechanical resistance, and can be subjected to high loads before entering the plastic domain. Because of these reasons, dual-phase specimens were obtained and mechanically tested to determine the most relevant properties for the application: Yield stress, Young modulus and Poisson coefficient.

\subsubsection{Extensometry test}

The obtained Poisson coefficient was near 0,29, which is the normal value for a steel, except for the specimen 6. For the specimen 6, the obtained Poisson coefficient was near 0,27 . The Young modulus obtained by the extensometry test ranged from near 180 to $200 \mathrm{GPa}$. Those values are lower than the regular value of the steel, which is 210 $\mathrm{GPa}$.

\subsubsection{Tensile test}

The specimen 1 has the highest Young modulus of the two specimens tested: 193,2 GPa. The specimen 2 has a Young modulus of near 168,2 GPa, which is much lower than the expected $210 \mathrm{GPa}$. The Specimen 1 has a lower Yield stress, which is expected, because its designation is 600 and the designation of the specimen 2 is 800 . This number is related to the Yield stress in relative terms, which means that a lower number 
designation means a lower Yield stress when comparing two specimens. The Yield stress was measured using a $0,2 \%$ proportionality straight line that is parallel to the elastic domain of the stress-strain curve. The Yield stress can be determined by the intersection of the stress-strain curve with the straight line.

\subsubsection{Optimization results}

The final variable values usually comply with the results of the variable analysis. When this does not happen, it's because the variables when studied alone have different behavior then when studied in combination with others. The obtained objective function is lower in the geometric parameters optimization than in the material properties optimization for both models. One can then conclude that the optimization of the geometry is more important than the optimization of the material to achieve deflection reduction.

\subsubsection{FEM results}

One can say that sometimes is obvious the deflection decrease between optimized and non-optimized models. In the other cases, mainly in the material properties optimized models, the deflections may seem to increase. This is not true, because the material properties optimization screenshots have a larger area of dark blue. So, some values may be higher in the material optimized model screenshot, but there is a deflection decrease in most of the nodes of the object.

What could have happened during this work is that the considered number of nodal points in both models was small (15 nodal points in the ribbed plate model and 21 in the tubular beam model), and due to that fact, there can be a high error when comparing the FEM results with the optimization results.

\subsubsection{Materials selection}

The material selection charts made possible the material selection for the applications of this work. The analysed charts were Young modulus/Cost and Young modulus/density. The desirable properties are: highest possible Young modulus to improve material stiffness, lowest possible Cost for the solution to be reliable and lowest possible density for the improvement of the admissible acceleration, having in mind that a lower density 
means a lower mass for objects with the same dimensions. The combination of those factors dictates the best material. It was found that the best material is the high-strength steel. The specific material is the DOCOL dual-phase steel.

\subsection{Conclusions of the work}

The conclusions of this work are:

- The Finite Element Model Updating code developed in this work can be successfully used to optimize both geometric parameters and material properties.

- The geometric parameters play a more important role in the optimization process than the material properties, because the obtained objective function is lower in the geometric parameters optimization than in the material properties optimization.

- The DOCOL dual phase steels tested by tensile test and extensometry test have a lower Young modulus than the expected. The expected value was $210 \mathrm{GPa}$.

- The Young modulus and the Poisson coefficient are relevant properties for the deflection reduction, because they have influence on the objective function, as shown on the variable analysis.

- The density has no influence on the objective function.

- The material properties influence on the objective function is the same for the two models studied in this work. However, the value of the objective function was not the same, because the objects are of different nature.

- The tested materials have high Yield stresses, which mean that the material can be subjected to high loads before entering the plastic domain. In the practical applications of this work (plotters and laser cutting machines) it is very important to ensure that the material doesn't reach the plastic domain, otherwise the permanent deformation will negatively affect the machine operation. Considering this fact, the dual phase steels are an adequate material for the applications of this work.

\subsection{Future work proposals}

A graphical interface could be created in order to implement the Finite Element Model Updating code developed in this work in a user-friendly environment. The programming code could then be used to create an executable file, in order to avoid the 
need of having MATLAB installed on the computer. Other models can be tested by this novel methodology, such as hollow-box rectangular section ribbed beams and hollowbox square section ribbed beams, to optimize both geometric parameters and material properties. 
REFERENCES 


\section{Bibliographic references}

[1] P. Orlov, 1976, "Fundamentals of Machine design", $1^{\text {st }}$ volume, MIR Publishers, Moscow.

[2] Y. Liu and L. Gannon, 2009, "Finite element study of steel beams reinforced while under load", Elsevier, Engineering Structures, volume 31, pages 2630-2642

[3] G.Falsone, G. Ferro, 2007, "An exact solution for the static and dynamic analysis of FE discretized uncertain structures", Elsevier, Computer Methods in Applied Mechanics and Engineering, volume 196, pages 2390-2400

[4] F. Daneshmand, M. J. Kazemzadeh-Parsi, 2009, "Static and dynamic analysis of 2D and $3 D$ elastic solids using the modified FGFEM", Elsevier, Finite Elements in Analysis and Design, volume 45, pages 755-765

[5] C. Polat, Y. Calayir, 2010, "Nonlinear static and dynamic analysis of shells of revolution", Elsevier, Mechanics Research Communications, volume 37, pages 205-209

[6] B. A. Zárate, J. M. Caicedo, 2008, "Finite element model updating: Multiple alternatives", Elsevier, Engineering Structures, volume 30, pages 3724-3730

[7] P. G. Bakir, E. Reynders, G. De Roeck, 2008, "An improved finite element model updating method by the global optimization technique Coupled Local Minimizers", Elsevier, Computers and Structures, volume 86, pages 1339-1352

[8] S. Kalanta, J. Atkociunas, A. Venskus, 2009, "Discrete optimization problems of the steel bar structures", Elsevier, Engineering Structures, volume 31, pages 1298-1304

[9] X. Bin , C. Nan, C. Huajun, 2010, "An integrated method of multi-objective optimization for complex mechanical structure", Elsevier, Advances in Engineering Software, Volume 41, pages 277-285 
[10] H. M. Silva, J. F. Meireles, 2011, “Determination of material/geometry of the section most adequate for a static loaded beam subjected to a combination of bending and torsion", VI International Materials Symposium, Guimarães, Portugal

[11] http://www.sv.vt.edu/classes/MSE2094_NoteBook/97ClassProj/num/widas /history.html, 1997.

[12] S. Moaveni, 2003, "Finite Element Analysis- Theory and Applications with ANSYS", Prentice Hall, Second Edition.

[13] J. F. B. Meireles, 2007, "Análise dinâmica de estruturas por modelos de elementos finitos identificados experimentalmente", Ph.D. Thesis, University of Minho.

[14] F. Beer, Johnston, De Wolf, 2001, “Mechanics of Materials, McGraw Hill, Third Edition.

[15] C. Massonnet, 1968, "Resistance des matériaux", DUNOD, deuxiéme édition, Paris.

[16] http://www.instron.us/wa/applications/test_types/tension/default.aspx.

[17] W. F. Smith, 1996, "Princípios de ciência e engenharia dos materiais", McGraw Hill, Third Edition.

[18] http://www.rutlandplastics.co.uk/materials_datasheets_tensile.shtml.

[19] http://www.math.tu-dresden.de/ schwetli/teaching/tools/using_ml.pdf.

[20] http://www.math.tu-berlin.de/Vorlesungen/WS03/NonLinOpt/optim_tb.pdf.

[21] http://www-materials.eng.cam.ac.uk/mpsite/interactive_charts/default.html. 
[22] Material data sheet, Dual-phase steel, 2005, "Continuously hot-dip coated strip made of multiphase steels for cold forming in hot-dip galvanized".

[23] SSAB- Swedish Steel, 2009, "DOCOL DP/DL-Cold reduced dual phase steel”. 


\section{ANNEXES}


ANNEX 1-MECHANICAL TESTS 


\section{A1.0-Conditions of the Mechanical tests}

The mechanical tests were performed on a Instron 8874 device. The used extensometer was a RS Type 632168 with $5 \mathrm{~mm}$ length. The load cell was a dynacell with load capacity of $25 \mathrm{KN}$, maximum torsion moment of $100 \mathrm{~N} . \mathrm{m}$ and weight of $2,5 \mathrm{~kg}$. The data acquisition system was SPIDER 8 and the computational software used was CATM. The specimens are sheet specimens with a transversal area of $24,8 \mathrm{~mm}^{2}$. The fixture type is 4-point.

\section{A1.1-Stress-strain and stress-extension charts}

\section{Specimen 1}

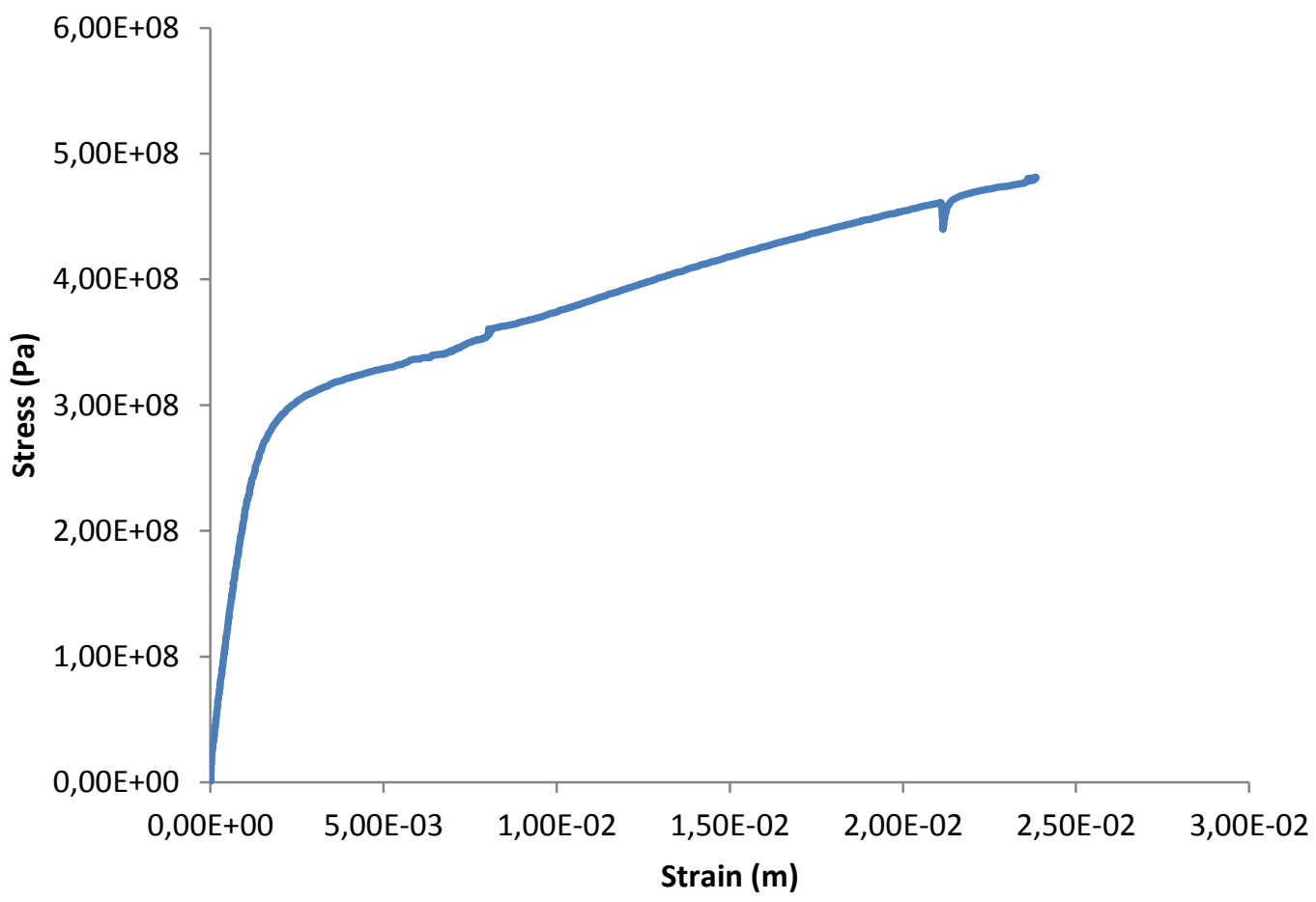

Fig. A1-Stress-Strain chart for the specimen 1 


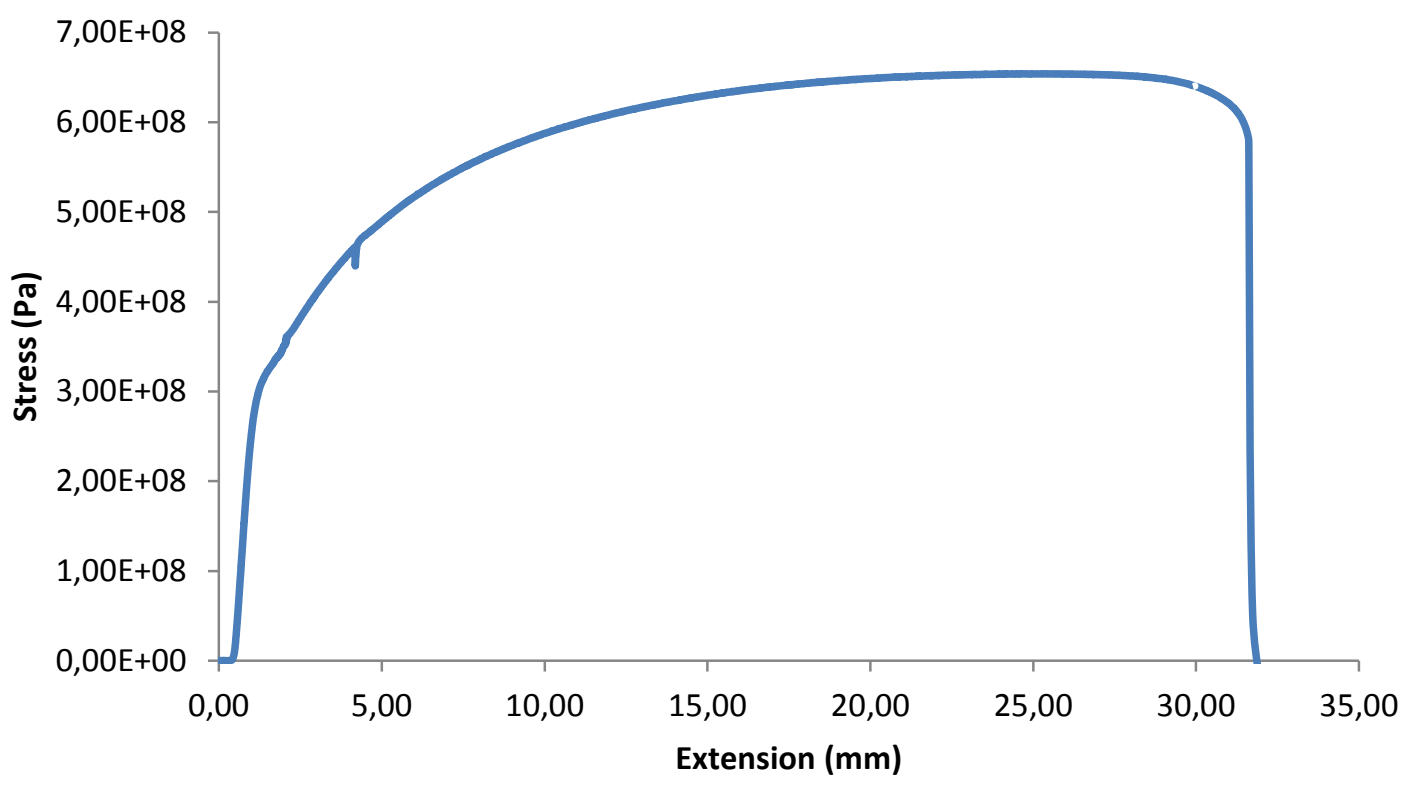

Fig. A2-Stress-Extension chart for the specimen 1

\section{Specimen 2}

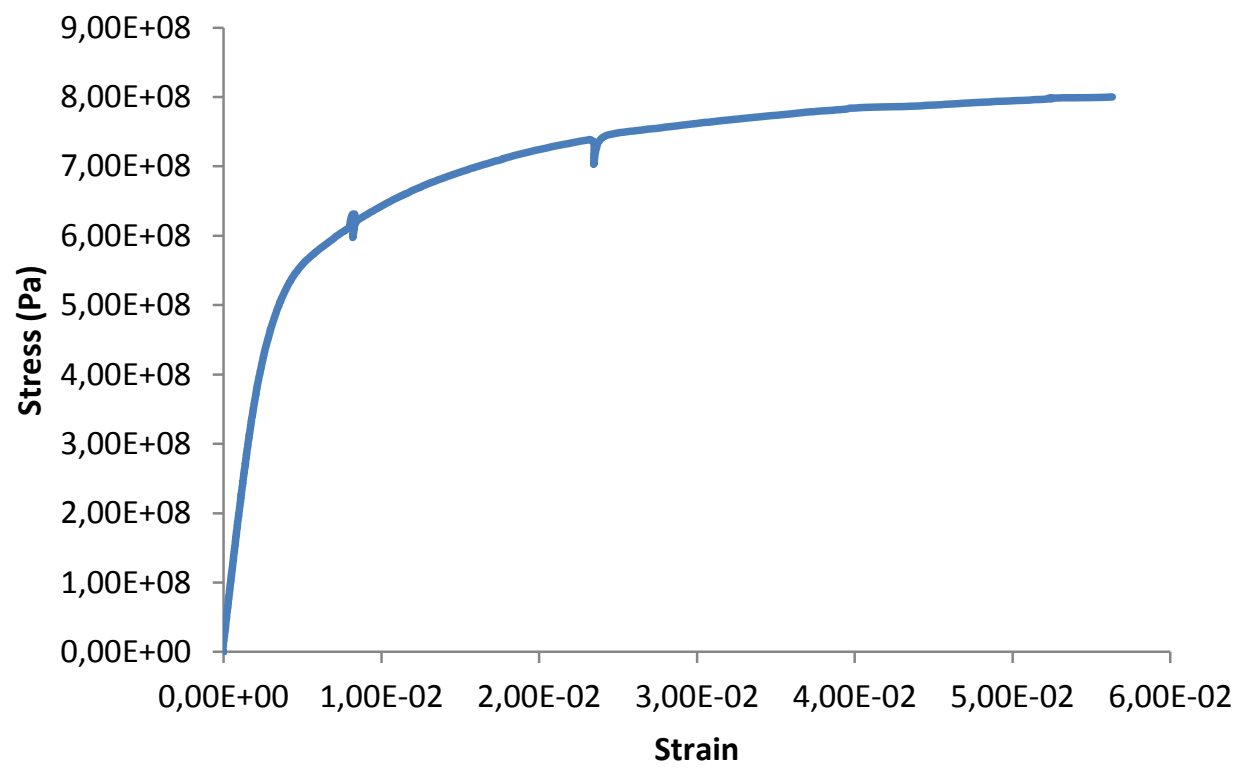

Fig. A3-Stress-Strain chart for the specimen 2 


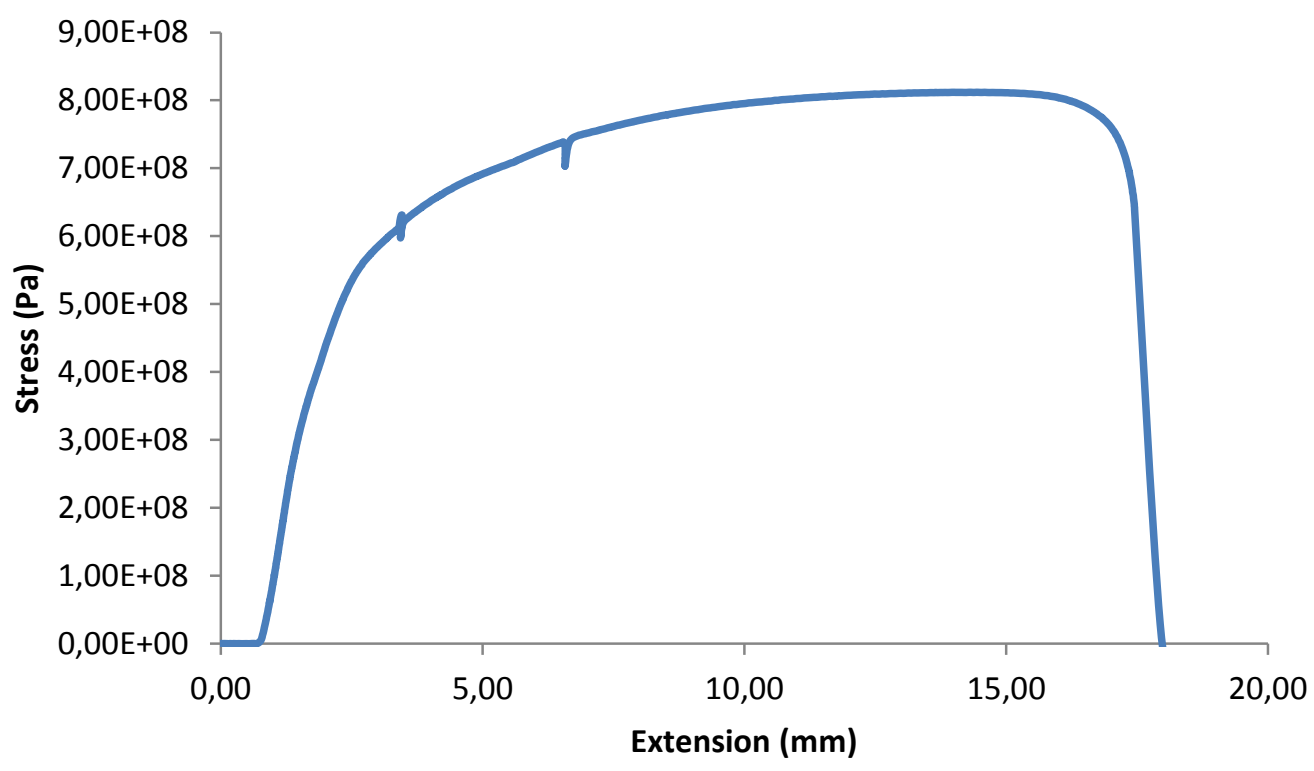

Fig. A4-Stress-Extension chart for the specimen 2

\section{A1.2-Determination of Young modulus in tensile test}

\section{Specimen 1}

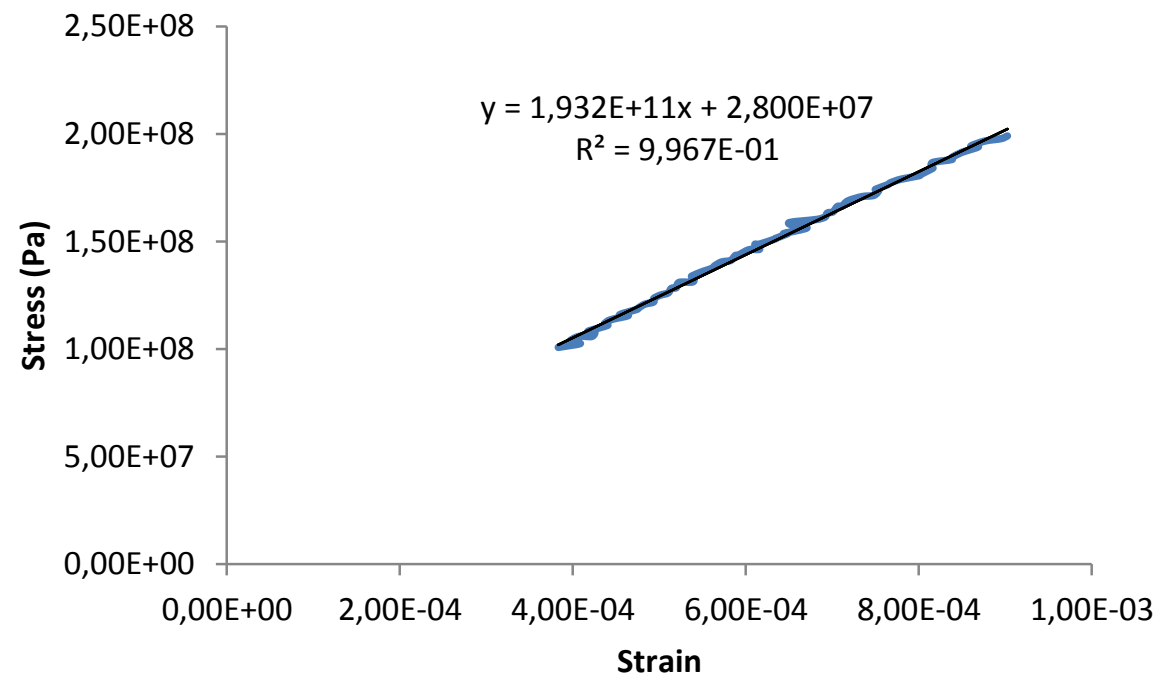

Fig. A5-Linear fit of the stress-strain curve (elastic domain) in order to obtain Young modulus for the Specimen 1 


\section{Specimen 2}

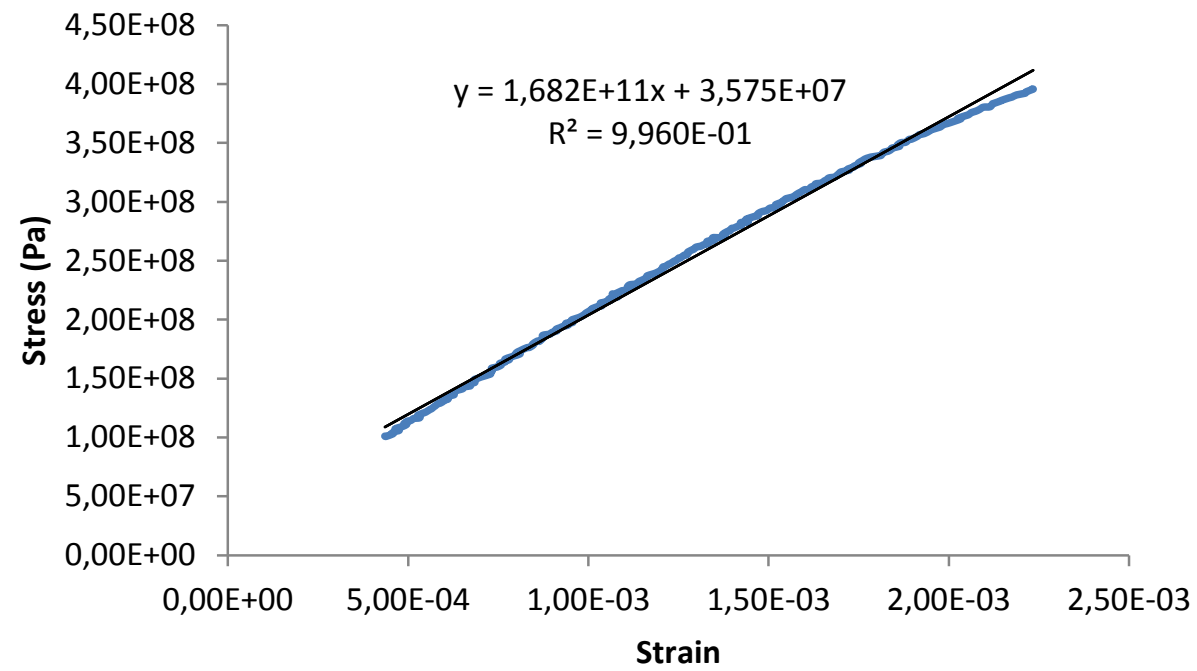

Fig. A6-Linear fit of the stress-strain curve (elastic domain) in order to obtain Young modulus for the Specimen 2

\section{A1.3-Charts used to determine Yield stress}

\section{Specimen 1}

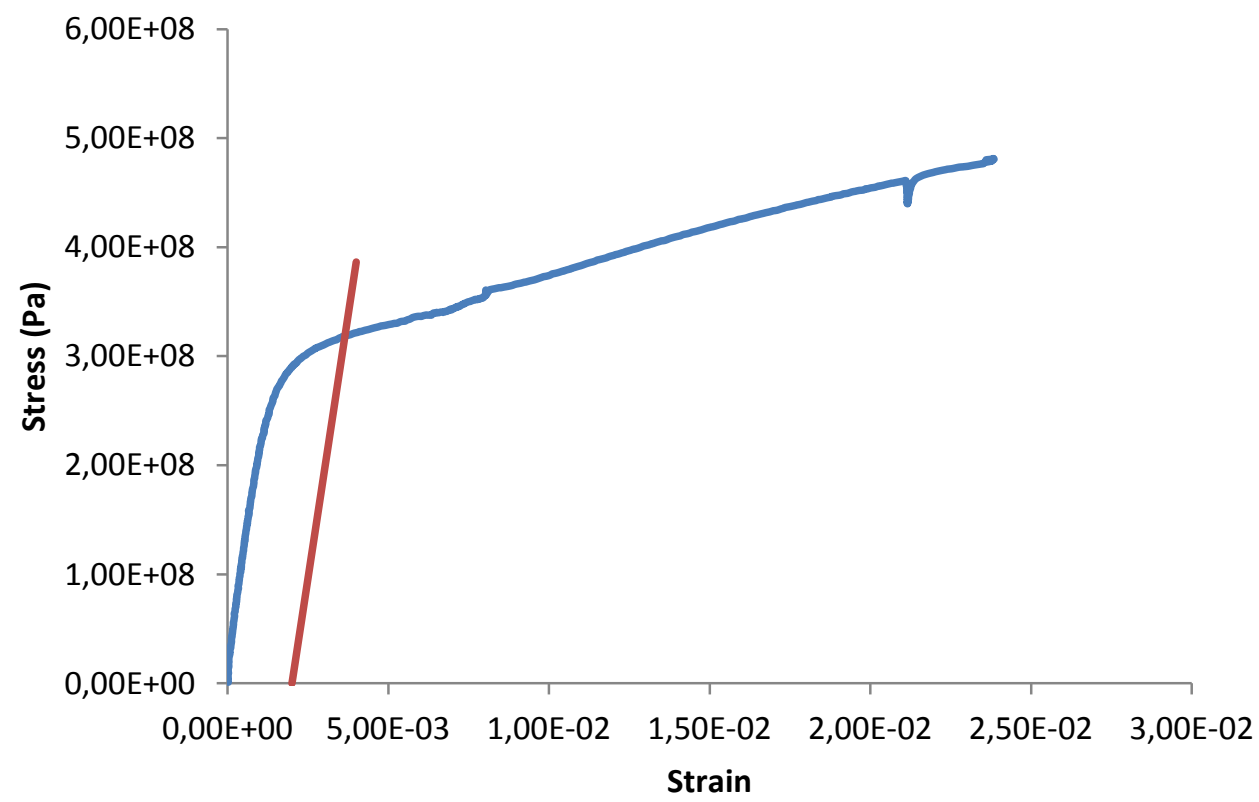

Fig. A7-Determination of the Yield stress for the specimen 1 


\section{Specimen 2}

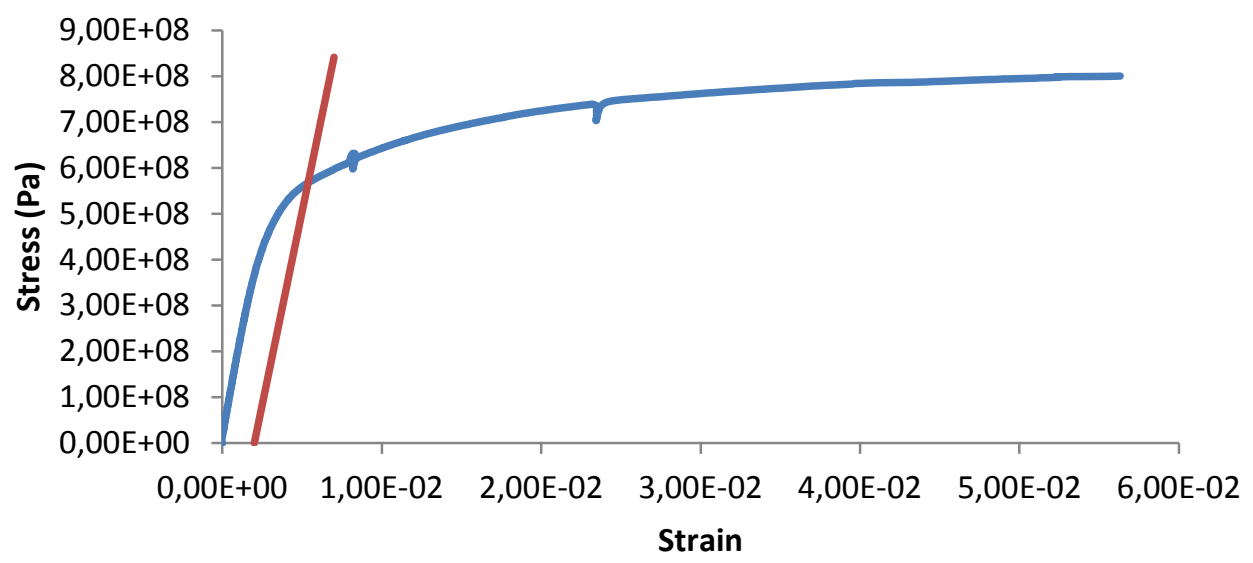

Fig. A8-Determination of the Yield stress for the specimen 2

\section{A1.4-Determination of Poisson coefficient and Young modulus in extensometry test}

\begin{tabular}{|c|c|c|c|c|c|c|}
\hline Load & clong & ctrans & $\begin{array}{c}\text { Poisson } \\
\text { coeficient }\end{array}$ & Stress & $\begin{array}{c}\text { Young } \\
\text { modulus(Pa) }\end{array}$ & $\begin{array}{c}\text { Young } \\
\text { modulus(GPa) }\end{array}$ \\
\hline 2066 & 424 & -124 & 0,2925 & $8,33 \mathrm{E}+07$ & $1,9648 \mathrm{E}+11$ & 196,48 \\
\hline 3043 & 624 & -126 & 0,2011 & $1,23 \mathrm{E}+08$ & $1,9664 \mathrm{E}+11$ & 196,64 \\
\hline 4028 & 834 & -248 & 0,2974 & $1,62 \mathrm{E}+08$ & $1,9475 \mathrm{E}+11$ & 194,75 \\
\hline 5000 & 1103 & -335 & 0,3037 & $2,02 \mathrm{E}+08$ & $1,8279 \mathrm{E}+11$ & 182,79 \\
\hline
\end{tabular}

Table A1-Poisson coefficient, Normal Stress, and Young modulus for specimen 4, $1^{\text {st }}$ read

\begin{tabular}{|c|c|c|c|c|c|c|}
\hline Load & clong & ctrans & $\begin{array}{c}\text { Poisson } \\
\text { coeficient }\end{array}$ & Stress & $\begin{array}{c}\text { Young } \\
\text { modulus(Pa) }\end{array}$ & $\begin{array}{c}\text { Young } \\
\text { modulus (GPa) }\end{array}$ \\
\hline 2010 & 416 & -123 & 0,2957 & $8,10 \mathrm{E}+07$ & $1,9483 \mathrm{E}+11$ & 194,83 \\
\hline 3100 & 634 & -187 & 0,2950 & $1,25 \mathrm{E}+08$ & $1,9716 \mathrm{E}+11$ & 197,16 \\
\hline 4040 & 821 & -243 & 0,2960 & $1,63 \mathrm{E}+08$ & $1,9842 \mathrm{E}+11$ & 198,42 \\
\hline 5010 & 1044 & -311 & 0,2979 & $2,02 \mathrm{E}+08$ & $1,9350 \mathrm{E}+11$ & 193,50 \\
\hline
\end{tabular}

Table A2-Poisson coefficient, Normal Stress, and Young modulus for specimen 4, $2^{\text {nd }} \mathrm{read}$

\begin{tabular}{|c|c|c|c|c|c|c|}
\hline Load & Elong & Etrans & $\begin{array}{c}\text { Poisson } \\
\text { coeficient }\end{array}$ & Stress & $\begin{array}{c}\text { Young } \\
\text { modulus(Pa) }\end{array}$ & $\begin{array}{c}\text { Young } \\
\text { modulus (GPa) }\end{array}$ \\
\hline 2060 & 459 & -129 & 0,2810 & $8,31 \mathrm{E}+07$ & $1,8097 \mathrm{E}+11$ & 180,97 \\
\hline 3010 & 663 & -187 & 0,2821 & $1,21 \mathrm{E}+08$ & $1,8306 \mathrm{E}+11$ & 183,06 \\
\hline 4060 & 885 & -252 & 0,2847 & $1,64 \mathrm{E}+08$ & $1,8498 \mathrm{E}+11$ & 184,98 \\
\hline 5020 & 1148 & -333 & 0,2901 & $2,02 \mathrm{E}+08$ & $1,7632 \mathrm{E}+11$ & 176,32 \\
\hline
\end{tabular}

Table A3-Poisson coefficient, Normal Stress, and Young modulus for specimen 5, $1^{\text {st }} \mathrm{read}$ 


\begin{tabular}{|c|c|c|c|c|c|c|}
\hline Load & Elong & ctrans & $\begin{array}{c}\text { Poisson } \\
\text { coeficient }\end{array}$ & Stress & $\begin{array}{c}\text { Young } \\
\text { modulus(Pa) }\end{array}$ & $\begin{array}{c}\text { Young } \\
\text { modulus (GPa) }\end{array}$ \\
\hline 2100 & 465 & -131 & 0,2817 & $8,5 \mathrm{E}+07$ & $1,8210 \mathrm{E}+11$ & 182,10 \\
\hline 3100 & 676 & -191 & 0,2825 & $1,3 \mathrm{E}+08$ & $1,8491 \mathrm{E}+11$ & 184,91 \\
\hline 4045 & 873 & -247 & 0,2829 & $1,6 \mathrm{E}+08$ & $1,8683 \mathrm{E}+11$ & 186,83 \\
\hline 5050 & 1107 & -315 & 0,2846 & $2 \mathrm{E}+08$ & $1,8395 \mathrm{E}+11$ & 183,95 \\
\hline
\end{tabular}

Table A4-Poisson coefficient, Normal Stress, and Young modulus for specimen 5, $2^{\text {nd }}$ read

\begin{tabular}{|c|c|c|c|c|c|c|}
\hline Load & clong & etrans & $\begin{array}{c}\text { Poisson } \\
\text { coeficient }\end{array}$ & Stress & $\begin{array}{c}\text { Young } \\
\text { modulus(Pa) }\end{array}$ & $\begin{array}{c}\text { Young } \\
\text { modulus (GPa) }\end{array}$ \\
\hline 2018 & 437 & -126 & 0,2883 & $8,14 \mathrm{E}+07$ & $1,8620 \mathrm{E}+11$ & 186,20 \\
\hline 4030 & 859 & -244 & 0,2841 & $1,63 \mathrm{E}+08$ & $1,8917 \mathrm{E}+11$ & 189,17 \\
\hline 6020 & 1285 & -369 & 0,2872 & $2,43 \mathrm{E}+08$ & $1,8890 \mathrm{E}+11$ & 188,90 \\
\hline
\end{tabular}

Table A5-Poisson coefficient, Normal Stress, and Young modulus for specimen 6, $1^{\text {st }}$ read

\begin{tabular}{|c|c|c|c|c|c|c|}
\hline Load & Elong & Etrans & $\begin{array}{c}\text { Poisson } \\
\text { coeficient }\end{array}$ & Stress & $\begin{array}{c}\text { Young } \\
\text { modulus(Pa) }\end{array}$ & $\begin{array}{c}\text { Young } \\
\text { modulus (GPa) }\end{array}$ \\
\hline 2040 & 428 & -126 & 0,2944 & $8,23 \mathrm{E}+07$ & $1,9219 \mathrm{E}+11$ & 192,19 \\
\hline 4050 & 852 & -243 & 0,2852 & $1,63 \mathrm{E}+08$ & $1,9167 \mathrm{E}+11$ & 191,67 \\
\hline 6100 & 1277 & -365 & 0,2858 & $2,46 \mathrm{E}+08$ & $1,9261 \mathrm{E}+11$ & 192,61 \\
\hline
\end{tabular}

Table A6-Poisson coefficient, Normal Stress, and Young modulus for specimen 6, $2^{\text {nd }}$ read

\begin{tabular}{|c|c|c|c|c|c|c|}
\hline Load & Elong & etrans & $\begin{array}{c}\text { Poisson } \\
\text { coeficient }\end{array}$ & Stress & $\begin{array}{c}\text { Young } \\
\text { modulus(Pa) }\end{array}$ & $\begin{array}{c}\text { Young } \\
\text { modulus (GPa) }\end{array}$ \\
\hline 2120 & 420 & -117 & 0,2786 & $8,55 \mathrm{E}+07$ & $2,0353 \mathrm{E}+11$ & 203,53 \\
\hline 4060 & 867 & -234 & 0,2699 & $1,64 \mathrm{E}+08$ & $1,8882 \mathrm{E}+11$ & 188,82 \\
\hline 6060 & 1325 & -355 & 0,2679 & $2,44 \mathrm{E}+08$ & $1,8442 \mathrm{E}+11$ & 184,42 \\
\hline
\end{tabular}

Table A7-Poisson coefficient, Normal Stress, and Young modulus for specimen 7, $1^{\text {st }}$ read

\begin{tabular}{|c|c|c|c|c|c|c|}
\hline Load & Elong & ctrans & $\begin{array}{c}\text { Poisson } \\
\text { coeficient }\end{array}$ & Stress & $\begin{array}{c}\text { Young } \\
\text { modulus(Pa) }\end{array}$ & $\begin{array}{c}\text { Young } \\
\text { modulus (GPa) }\end{array}$ \\
\hline 2140 & 435 & -118 & 0,2713 & $8,63 \mathrm{E}+07$ & $1,9837 \mathrm{E}+11$ & 198,37 \\
\hline 4120 & 879 & -235 & 0,2673 & $1,66 \mathrm{E}+08$ & $1,8900 \mathrm{E}+11$ & 189,00 \\
\hline 6100 & 1313 & -351 & 0,2673 & $2,46 \mathrm{E}+08$ & $1,8733 \mathrm{E}+11$ & 187,33 \\
\hline
\end{tabular}

Table A8-Poisson coefficient, Normal Stress, and Young modulus for specimen 7, $2^{\text {nd }}$ read 
ANNEX 2-VARIABLE ANALYSIS DATA 


\section{A2.1 Variable analysis data}

\section{A2.1.1 Model 1- Ribbed plate}

\section{A2.1.1.1 LG1 Variable}

\begin{tabular}{|c|c|c|c|c|c|c|c|c|}
\hline $\begin{array}{c}\text { Variable } \\
\text { values }\end{array}$ & LG1 & 0,01 & 0,015 & 0,02 & 0,025 & 0,03 & 0,035 & 0,04 \\
\hline & LG2 & 0,051 & 0,051 & 0,051 & 0,051 & 0,051 & 0,051 & 0,051 \\
\hline & LG3 & 0,0046 & 0,0046 & 0,0046 & 0,0046 & 0,0046 & 0,0046 & 0,0046 \\
\hline & EX & $2,10 \mathrm{E}+11$ & $2,10 \mathrm{E}+11$ & $2,10 \mathrm{E}+11$ & $2,10 \mathrm{E}+11$ & $2,10 \mathrm{E}+11$ & $2,10 \mathrm{E}+11$ & $2,10 \mathrm{E}+11$ \\
\hline & PXY & 0,29 & 0,29 & 0,29 & 0,29 & 0,29 & 0,29 & 0,29 \\
\hline & DNS & 7890 & 7890 & 7890 & 7890 & 7890 & 7890 & 7890 \\
\hline \multirow[t]{15}{*}{$\begin{array}{c}\text { Nodal } \\
\text { deflections }\end{array}$} & Node 1 & $6,00 \mathrm{E}-07$ & $1,10 \mathrm{E}-07$ & $4,10 \mathrm{E}-07$ & $9,50 \mathrm{E}-07$ & $1,50 \mathrm{E}-06$ & $2,10 \mathrm{E}-06$ & 2,73E-06 \\
\hline & Node 2 & $9,24 \mathrm{E}-06$ & $8,26 \mathrm{E}-06$ & 7,34E-06 & $6,49 \mathrm{E}-06$ & $4,45 \mathrm{E}-06$ & $3,88 \mathrm{E}-06$ & $3,36 \mathrm{E}-06$ \\
\hline & Node 3 & $5,16 \mathrm{E}-05$ & $4,88 \mathrm{E}-05$ & $4,61 \mathrm{E}-05$ & $4,34 \mathrm{E}-05$ & $4,78 \mathrm{E}-05$ & $4,53 \mathrm{E}-05$ & $4,28 \mathrm{E}-05$ \\
\hline & Node 4 & $8,06 \mathrm{E}-06$ & 7,20E-06 & 6,41E-06 & $5,66 \mathrm{E}-06$ & 7,39E-05 & $6,94 \mathrm{E}-05$ & $6,49 \mathrm{E}-05$ \\
\hline & Node 5 & 7,97E-05 & 7,58E-05 & 7,19E-05 & $6,80 \mathrm{E}-05$ & $4,11 \mathrm{E}-05$ & $3,81 \mathrm{E}-05$ & $3,53 \mathrm{E}-05$ \\
\hline & Node 6 & 2,97E-05 & 2,77E-05 & $2,57 \mathrm{E}-05$ & $2,38 \mathrm{E}-05$ & $3,00 \mathrm{E}-04$ & $2,95 \mathrm{E}-04$ & 2,90E-04 \\
\hline & Node 7 & $1,70 \mathrm{E}-05$ & $1,58 \mathrm{E}-05$ & $1,46 \mathrm{E}-05$ & $1,35 \mathrm{E}-05$ & $4,60 \mathrm{E}-04$ & $4,53 \mathrm{E}-04$ & $4,47 \mathrm{E}-04$ \\
\hline & Node 8 & 5,19E-06 & 4,82E-06 & $4,48 \mathrm{E}-06$ & $4,15 \mathrm{E}-06$ & $1,06 \mathrm{E}-03$ & $1,05 \mathrm{E}-03$ & $1,04 \mathrm{E}-03$ \\
\hline & Node 9 & $4,83 \mathrm{E}-04$ & 4,77E-04 & 4,71E-04 & 4,66E-04 & $3,34 \mathrm{E}-04$ & $3,30 \mathrm{E}-04$ & $3,24 \mathrm{E}-04$ \\
\hline & Node 10 & $1,32 \mathrm{E}-04$ & $1,30 \mathrm{E}-04$ & $1,27 \mathrm{E}-04$ & $1,24 \mathrm{E}-04$ & $1,05 \mathrm{E}-04$ & $1,02 \mathrm{E}-04$ & $1,00 \mathrm{E}-04$ \\
\hline & Node 11 & $2,42 \mathrm{E}-05$ & 2,39E-05 & $2,34 \mathrm{E}-05$ & $2,30 \mathrm{E}-05$ & $9,44 \mathrm{E}-05$ & $9,24 \mathrm{E}-05$ & $9,02 \mathrm{E}-05$ \\
\hline & Node 12 & 8,53E-06 & 8,39E-06 & $8,25 \mathrm{E}-06$ & $8,08 \mathrm{E}-06$ & 5,34E-05 & $5,66 \mathrm{E}-05$ & $6,01 \mathrm{E}-05$ \\
\hline & Node 13 & $8,72 \mathrm{E}-05$ & $8,60 \mathrm{E}-05$ & $8,46 \mathrm{E}-05$ & $8,31 \mathrm{E}-05$ & $3,90 \mathrm{E}-05$ & $4,13 \mathrm{E}-05$ & $4,38 \mathrm{E}-05$ \\
\hline & Node 14 & $1,12 \mathrm{E}-05$ & $1,18 \mathrm{E}-05$ & $1,24 \mathrm{E}-05$ & $1,31 \mathrm{E}-05$ & $5,33 \mathrm{E}-05$ & $5,65 \mathrm{E}-05$ & $6,00 \mathrm{E}-05$ \\
\hline & Node 15 & $3,99 \mathrm{E}-05$ & $4,22 \mathrm{E}-05$ & $4,46 \mathrm{E}-05$ & $4,71 \mathrm{E}-05$ & $8,09 \mathrm{E}-05$ & $7,92 \mathrm{E}-05$ & 7,72E-05 \\
\hline $\begin{array}{l}\text { Objective } \\
\text { function }\end{array}$ & $q(x)$ & $9,87 \mathrm{E}-04$ & $9,67 \mathrm{E}-04$ & $9,48 \mathrm{E}-04$ & $9,30 \mathrm{E}-04$ & $2,75 \mathrm{E}-03$ & 2,71E-03 & $2,68 \mathrm{E}-03$ \\
\hline
\end{tabular}

Table A9-Variable values, obtained nodal deflections, and objective function for the

LG1 variable analysis (ribbed plate model) 


\section{A2.1.1.2 LG2 Variable}

\begin{tabular}{|c|c|c|c|c|c|c|c|c|}
\hline $\begin{array}{l}\text { Variable } \\
\text { values }\end{array}$ & LG1 & 0,025 & 0,025 & 0,025 & 0,025 & 0,025 & 0,025 & 0,025 \\
\hline & LG2 & 0,035 & 0,04 & 0,045 & 0,05 & 0,055 & 0,06 & 0,065 \\
\hline & LG3 & 0,0046 & 0,0046 & 0,0046 & 0,0046 & 0,0046 & 0,0046 & 0,0046 \\
\hline & EX & $2,10 \mathrm{E}+11$ & $2,10 \mathrm{E}+11$ & $2,10 \mathrm{E}+11$ & $2,10 \mathrm{E}+11$ & $2,10 \mathrm{E}+11$ & $2,10 \mathrm{E}+11$ & $2,10 \mathrm{E}+11$ \\
\hline & PXY & 0,29 & 0,29 & 0,29 & 0,29 & 0,29 & 0,29 & 0,29 \\
\hline & DNS & 7890 & 7890 & 7890 & 7890 & 7890 & 7890 & 7890 \\
\hline \multirow[t]{15}{*}{$\begin{array}{c}\text { Nodal } \\
\text { deflections }\end{array}$} & Node 1 & $2,56 \mathrm{E}-06$ & $1,20 \mathrm{E}-06$ & $1,10 \mathrm{E}-06$ & $9,50 \mathrm{E}-07$ & $7,90 \mathrm{E}-07$ & $6,70 \mathrm{E}-07$ & $9,00 \mathrm{E}-08$ \\
\hline & Node 2 & $9,12 \mathrm{E}-05$ & $6,62 \mathrm{E}-06$ & $6,56 \mathrm{E}-06$ & $6,49 \mathrm{E}-06$ & $6,43 \mathrm{E}-06$ & $6,38 \mathrm{E}-06$ & $6,00 \mathrm{E}-08$ \\
\hline & Node 3 & $7,68 \mathrm{E}-05$ & $4,85 \mathrm{E}-05$ & $4,56 \mathrm{E}-05$ & $4,34 \mathrm{E}-05$ & $4,18 \mathrm{E}-05$ & $4,07 \mathrm{E}-05$ & $1,12 \mathrm{E}-06$ \\
\hline & Node 4 & $4,42 \mathrm{E}-05$ & $5,81 \mathrm{E}-06$ & $5,73 \mathrm{E}-06$ & $5,66 \mathrm{E}-06$ & $5,60 \mathrm{E}-06$ & $5,55 \mathrm{E}-06$ & $6,15 \mathrm{E}-05$ \\
\hline & Node 5 & $8,30 \mathrm{E}-06$ & $7,64 \mathrm{E}-05$ & $7,15 \mathrm{E}-05$ & $6,80 \mathrm{E}-05$ & $6,54 \mathrm{E}-05$ & $6,37 \mathrm{E}-05$ & $7,01 \mathrm{E}-05$ \\
\hline & Node 6 & $3,77 \mathrm{E}-04$ & $2,59 \mathrm{E}-05$ & $2,47 \mathrm{E}-05$ & $2,38 \mathrm{E}-05$ & 2,32E-05 & $2,27 \mathrm{E}-05$ & $5,52 \mathrm{E}-05$ \\
\hline & Node 7 & 4,89E-04 & $1,44 \mathrm{E}-05$ & $1,39 \mathrm{E}-05$ & $1,35 \mathrm{E}-05$ & $1,32 \mathrm{E}-05$ & $1,29 \mathrm{E}-05$ & $7,57 \mathrm{E}-05$ \\
\hline & Node 8 & $9,31 \mathrm{E}-05$ & $4,69 \mathrm{E}-06$ & $4,38 \mathrm{E}-06$ & $4,15 \mathrm{E}-06$ & $3,98 \mathrm{E}-06$ & $3,88 \mathrm{E}-06$ & $6,71 \mathrm{E}-05$ \\
\hline & Node 9 & $8,74 \mathrm{E}-05$ & $4,80 \mathrm{E}-04$ & $4,72 \mathrm{E}-04$ & $4,66 \mathrm{E}-04$ & $4,61 \mathrm{E}-04$ & $4,57 \mathrm{E}-04$ & $2,59 \mathrm{E}-05$ \\
\hline & Node 10 & $4,91 \mathrm{E}-04$ & $1,28 \mathrm{E}-04$ & $1,26 \mathrm{E}-04$ & $1,24 \mathrm{E}-04$ & $1,22 \mathrm{E}-04$ & $1,21 \mathrm{E}-04$ & $2,62 \mathrm{E}-05$ \\
\hline & Node 11 & $1,13 \mathrm{E}-04$ & $3,81 \mathrm{E}-05$ & $2,91 \mathrm{E}-05$ & $2,30 \mathrm{E}-05$ & $1,87 \mathrm{E}-05$ & $1,60 \mathrm{E}-05$ & $5,95 \mathrm{E}-05$ \\
\hline & Node 12 & $3,03 \mathrm{E}-05$ & $1,31 \mathrm{E}-05$ & $1,01 \mathrm{E}-05$ & $8,08 \mathrm{E}-06$ & $6,66 \mathrm{E}-06$ & $5,80 \mathrm{E}-06$ & $9,78 \mathrm{E}-04$ \\
\hline & Node 13 & $1,67 \mathrm{E}-04$ & $1,40 \mathrm{E}-04$ & $1,06 \mathrm{E}-04$ & $8,31 \mathrm{E}-05$ & $6,67 \mathrm{E}-05$ & $5,68 \mathrm{E}-05$ & $1,50 \mathrm{E}-04$ \\
\hline & Node 14 & 3,17E-06 & $2,20 \mathrm{E}-05$ & $1,67 \mathrm{E}-05$ & $1,31 \mathrm{E}-05$ & $1,06 \mathrm{E}-05$ & $9,03 \mathrm{E}-06$ & $1,42 \mathrm{E}-05$ \\
\hline & Node 15 & $5,13 \mathrm{E}-06$ & $8,12 \mathrm{E}-05$ & $6,09 \mathrm{E}-05$ & $4,71 \mathrm{E}-05$ & $3,75 \mathrm{E}-05$ & $3,18 \mathrm{E}-05$ & $5,25 \mathrm{E}-05$ \\
\hline $\begin{array}{l}\text { Objective } \\
\text { function }\end{array}$ & $q(x)$ & $2,08 \mathrm{E}-03$ & $1,09 \mathrm{E}-03$ & $9,94 \mathrm{E}-04$ & $9,30 \mathrm{E}-04$ & $8,83 \mathrm{E}-04$ & $8,55 \mathrm{E}-04$ & $1,64 \mathrm{E}-03$ \\
\hline
\end{tabular}

Table A10-Variable values, obtained nodal deflections, and objective function for the LG2 variable analysis (ribbed plate model) 


\section{A2.1.1.3 LG3 Variable}

\begin{tabular}{|c|c|c|c|c|c|c|c|c|}
\hline $\begin{array}{l}\text { Variable } \\
\text { values }\end{array}$ & LG1 & 0,025 & 0,025 & 0,025 & 0,025 & 0,025 & 0,025 & 0,025 \\
\hline & LG2 & 0,051 & 0,051 & 0,051 & 0,051 & 0,051 & 0,051 & 0,051 \\
\hline & LG3 & 0,0031 & 0,0036 & 0,0041 & 0,0046 & 0,0051 & 0,0056 & 0,0061 \\
\hline & $\mathrm{EX}$ & $2,10 \mathrm{E}+11$ & $2,10 \mathrm{E}+11$ & $2,10 \mathrm{E}+11$ & $2,10 \mathrm{E}+11$ & $2,10 \mathrm{E}+11$ & $2,10 \mathrm{E}+11$ & $2,10 \mathrm{E}+11$ \\
\hline & PXY & 0,29 & 0,29 & 0,29 & 0,29 & 0,29 & 0,29 & 0,29 \\
\hline & DNS & 7890 & 7890 & 7890 & 7890 & 7890 & 7890 & 7890 \\
\hline $\begin{array}{c}\text { Nodal } \\
\text { deflections }\end{array}$ & Node 1 & $1,80 \mathrm{E}-06$ & $1,45 \mathrm{E}-06$ & $1,17 \mathrm{E}-06$ & $9,50 \mathrm{E}-07$ & $7,50 \mathrm{E}-07$ & $5,90 \mathrm{E}-07$ & $4,50 \mathrm{E}-07$ \\
\hline & Node 2 & $2,15 \mathrm{E}-05$ & $1,37 \mathrm{E}-05$ & $9,21 \mathrm{E}-06$ & 6,49E-06 & $4,74 \mathrm{E}-06$ & $3,56 \mathrm{E}-06$ & $2,73 \mathrm{E}-06$ \\
\hline & Node 3 & $1,32 \mathrm{E}-04$ & $8,60 \mathrm{E}-05$ & $5,97 \mathrm{E}-05$ & $4,34 \mathrm{E}-05$ & $3,28 \mathrm{E}-05$ & $2,56 \mathrm{E}-05$ & $2,05 \mathrm{E}-05$ \\
\hline & Node 4 & $1,86 \mathrm{E}-05$ & $1,19 \mathrm{E}-05$ & $8,01 \mathrm{E}-06$ & $5,66 \mathrm{E}-06$ & $4,15 \mathrm{E}-06$ & $3,13 \mathrm{E}-06$ & 2,41E-06 \\
\hline & Node 5 & $2,05 \mathrm{E}-04$ & $1,34 \mathrm{E}-04$ & $9,32 \mathrm{E}-05$ & $6,80 \mathrm{E}-05$ & $5,16 \mathrm{E}-05$ & $4,04 \mathrm{E}-05$ & $3,24 \mathrm{E}-05$ \\
\hline & Node 6 & $7,45 \mathrm{E}-05$ & $4,82 \mathrm{E}-05$ & $3,31 \mathrm{E}-05$ & $2,38 \mathrm{E}-05$ & $1,78 \mathrm{E}-05$ & $1,37 \mathrm{E}-05$ & $1,09 \mathrm{E}-05$ \\
\hline & Node 7 & $4,27 \mathrm{E}-05$ & $2,75 \mathrm{E}-05$ & $1,88 \mathrm{E}-05$ & $1,35 \mathrm{E}-05$ & $1,00 \mathrm{E}-05$ & 7,69E-06 & $6,05 \mathrm{E}-06$ \\
\hline & Node 8 & $1,23 \mathrm{E}-05$ & $8,10 \mathrm{E}-06$ & $5,66 \mathrm{E}-06$ & $4,15 \mathrm{E}-06$ & $3,16 \mathrm{E}-06$ & $2,49 \mathrm{E}-06$ & $2,01 \mathrm{E}-06$ \\
\hline & Node 9 & $1,49 \mathrm{E}-03$ & $9,59 \mathrm{E}-04$ & $6,53 \mathrm{E}-04$ & $4,66 \mathrm{E}-04$ & $3,44 \mathrm{E}-04$ & $2,62 \mathrm{E}-04$ & $2,05 \mathrm{E}-04$ \\
\hline & Node 10 & $3,98 \mathrm{E}-04$ & $2,56 \mathrm{E}-04$ & 1,74E-04 & $1,24 \mathrm{E}-04$ & $9,16 \mathrm{E}-05$ & $6,98 \mathrm{E}-05$ & $5,45 \mathrm{E}-05$ \\
\hline & Node 11 & $3,45 \mathrm{E}-05$ & $2,96 \mathrm{E}-05$ & $2,59 \mathrm{E}-05$ & $2,30 \mathrm{E}-05$ & $2,07 \mathrm{E}-05$ & $1,87 \mathrm{E}-05$ & $1,71 \mathrm{E}-05$ \\
\hline & Node 12 & $1,21 \mathrm{E}-05$ & $1,04 \mathrm{E}-05$ & $9,10 \mathrm{E}-06$ & $8,08 \mathrm{E}-06$ & $7,27 \mathrm{E}-06$ & $6,59 \mathrm{E}-06$ & $6,03 \mathrm{E}-06$ \\
\hline & Node 13 & $1,25 \mathrm{E}-04$ & $1,07 \mathrm{E}-04$ & $9,36 \mathrm{E}-05$ & $8,31 \mathrm{E}-05$ & 7,47E-05 & $6,77 \mathrm{E}-05$ & $6,18 \mathrm{E}-05$ \\
\hline & Node 14 & $1,94 \mathrm{E}-05$ & $1,67 \mathrm{E}-05$ & $1,47 \mathrm{E}-05$ & $1,31 \mathrm{E}-05$ & $1,18 \mathrm{E}-05$ & $1,08 \mathrm{E}-05$ & $9,91 \mathrm{E}-06$ \\
\hline & Node 15 & $6,96 \mathrm{E}-05$ & $6,01 \mathrm{E}-05$ & $5,28 \mathrm{E}-05$ & 4,71E-05 & $4,26 \mathrm{E}-05$ & $3,89 \mathrm{E}-05$ & $3,57 \mathrm{E}-05$ \\
\hline $\begin{array}{l}\text { Objective } \\
\text { function }\end{array}$ & $q(x)$ & $2,66 \mathrm{E}-03$ & $1,77 \mathrm{E}-03$ & $1,25 \mathrm{E}-03$ & $9,30 \mathrm{E}-04$ & $7,18 \mathrm{E}-04$ & $5,72 \mathrm{E}-04$ & $4,67 \mathrm{E}-04$ \\
\hline
\end{tabular}

Table A11-Variable values, obtained nodal deflections, and objective function for the LG3 variable analysis (ribbed plate model) 


\section{A2.1.1.4 EX Variable}

\begin{tabular}{|c|c|c|c|c|c|c|c|c|}
\hline $\begin{array}{l}\text { Variable } \\
\text { values }\end{array}$ & LG1 & 0,025 & 0,025 & 0,025 & 0,025 & 0,025 & 0,025 & 0,025 \\
\hline & LG2 & 0,051 & 0,051 & 0,051 & 0,051 & 0,051 & 0,051 & 0,051 \\
\hline & LG3 & 0,0046 & 0,0046 & 0,0046 & 0,0046 & 0,0046 & 0,0046 & 0,0046 \\
\hline & EX & $1,95 \mathrm{E}+11$ & $2,00 \mathrm{E}+11$ & $2,05 \mathrm{E}+11$ & $2,10 \mathrm{E}+11$ & $2,15 \mathrm{E}+11$ & $2,20 \mathrm{E}+11$ & $2,25 \mathrm{E}+11$ \\
\hline & PXY & 0,29 & 0,29 & 0,29 & 0,29 & 0,29 & 0,29 & 0,29 \\
\hline & DNS & 7890 & 7890 & 7890 & 7890 & 7890 & 7890 & 7890 \\
\hline \multirow[t]{15}{*}{$\begin{array}{c}\text { Nodal } \\
\text { deflection }\end{array}$} & Node 1 & $1,02 \mathrm{E}-06$ & 9,90E-07 & $9,70 \mathrm{E}-07$ & $9,50 \mathrm{E}-07$ & $9,20 \mathrm{E}-07$ & $9,00 \mathrm{E}-07$ & 8,80E-07 \\
\hline & Node 2 & $6,99 \mathrm{E}-06$ & $6,82 \mathrm{E}-06$ & $6,65 \mathrm{E}-06$ & 6,49E-06 & $6,34 \mathrm{E}-06$ & $6,20 \mathrm{E}-06$ & $6,06 \mathrm{E}-06$ \\
\hline & Node 3 & $4,68 \mathrm{E}-05$ & $4,56 \mathrm{E}-05$ & $4,45 \mathrm{E}-05$ & $4,34 \mathrm{E}-05$ & $4,24 \mathrm{E}-05$ & $4,15 \mathrm{E}-05$ & $4,05 \mathrm{E}-05$ \\
\hline & Node 4 & $6,10 \mathrm{E}-06$ & $5,95 \mathrm{E}-06$ & $5,80 \mathrm{E}-06$ & $5,66 \mathrm{E}-06$ & $5,53 \mathrm{E}-06$ & $5,41 \mathrm{E}-06$ & 5,29E-06 \\
\hline & Node 5 & 7,33E-05 & $7,14 \mathrm{E}-05$ & $6,97 \mathrm{E}-05$ & $6,80 \mathrm{E}-05$ & $6,65 \mathrm{E}-05$ & $6,49 \mathrm{E}-05$ & $6,35 \mathrm{E}-05$ \\
\hline & Node 6 & 2,57E-05 & $2,50 \mathrm{E}-05$ & $2,44 \mathrm{E}-05$ & $2,38 \mathrm{E}-05$ & $2,33 \mathrm{E}-05$ & $2,28 \mathrm{E}-05$ & $2,23 \mathrm{E}-05$ \\
\hline & Node 7 & $1,45 \mathrm{E}-05$ & $1,41 \mathrm{E}-05$ & $1,38 \mathrm{E}-05$ & $1,35 \mathrm{E}-05$ & $1,32 \mathrm{E}-05$ & $1,29 \mathrm{E}-05$ & $1,26 \mathrm{E}-05$ \\
\hline & Node 8 & 4,47E-06 & $4,36 \mathrm{E}-06$ & $4,25 \mathrm{E}-06$ & $4,15 \mathrm{E}-06$ & $4,06 \mathrm{E}-06$ & $3,96 \mathrm{E}-06$ & $3,88 \mathrm{E}-06$ \\
\hline & Node 9 & 5,01E-04 & 4,89E-04 & 4,77E-04 & $4,66 \mathrm{E}-04$ & $4,55 \mathrm{E}-04$ & 4,44E-04 & $4,35 \mathrm{E}-04$ \\
\hline & Node 10 & $1,34 \mathrm{E}-04$ & $1,30 \mathrm{E}-04$ & $1,27 \mathrm{E}-04$ & $1,24 \mathrm{E}-04$ & $1,21 \mathrm{E}-04$ & $1,18 \mathrm{E}-04$ & $1,16 \mathrm{E}-04$ \\
\hline & Node 11 & $2,48 \mathrm{E}-05$ & $2,42 \mathrm{E}-05$ & $2,36 \mathrm{E}-05$ & 2,30E-05 & $2,25 \mathrm{E}-05$ & $2,20 \mathrm{E}-05$ & $2,15 \mathrm{E}-05$ \\
\hline & Node 12 & $8,71 \mathrm{E}-06$ & $8,49 \mathrm{E}-06$ & $8,28 \mathrm{E}-06$ & $8,08 \mathrm{E}-06$ & 7,90E-06 & 7,72E-06 & $7,55 \mathrm{E}-06$ \\
\hline & Node 13 & $8,95 \mathrm{E}-05$ & $8,73 \mathrm{E}-05$ & $8,52 \mathrm{E}-05$ & $8,31 \mathrm{E}-05$ & $8,12 \mathrm{E}-05$ & $7,93 \mathrm{E}-05$ & $7,76 \mathrm{E}-05$ \\
\hline & Node 14 & $1,41 \mathrm{E}-05$ & $1,37 \mathrm{E}-05$ & $1,34 \mathrm{E}-05$ & $1,31 \mathrm{E}-05$ & $1,28 \mathrm{E}-05$ & $1,25 \mathrm{E}-05$ & $1,22 \mathrm{E}-05$ \\
\hline & Node 15 & $5,08 \mathrm{E}-05$ & $4,95 \mathrm{E}-05$ & $4,83 \mathrm{E}-05$ & 4,71E-05 & $4,61 \mathrm{E}-05$ & $4,50 \mathrm{E}-05$ & $4,40 \mathrm{E}-05$ \\
\hline $\begin{array}{c}\text { Objective } \\
\text { function }\end{array}$ & $q(x)$ & $1,00 \mathrm{E}-03$ & $9,76 \mathrm{E}-04$ & $9,53 \mathrm{E}-04$ & $9,30 \mathrm{E}-04$ & $9,08 \mathrm{E}-04$ & $8,88 \mathrm{E}-04$ & 8,68E-04 \\
\hline
\end{tabular}

Table A12-Variable values, obtained nodal deflections, and objective function for the EX variable analysis (ribbed plate model) 


\section{A2.1.1.5 PXY Variable}

\begin{tabular}{|c|c|c|c|c|c|c|c|c|}
\hline $\begin{array}{l}\text { Variable } \\
\text { values }\end{array}$ & LG1 & 0,025 & 0,025 & 0,025 & 0,025 & 0,025 & 0,025 & 0,025 \\
\hline & LG2 & 0,051 & 0,051 & 0,051 & 0,051 & 0,051 & 0,051 & 0,051 \\
\hline & LG3 & 0,0046 & 0,0046 & 0,0046 & 0,0046 & 0,0046 & 0,0046 & 0,0046 \\
\hline & $\mathrm{EX}$ & $2,10 \mathrm{E}+11$ & $2,10 \mathrm{E}+11$ & $2,10 \mathrm{E}+11$ & $2,10 \mathrm{E}+11$ & $2,10 \mathrm{E}+11$ & $2,10 \mathrm{E}+11$ & $2,10 \mathrm{E}+11$ \\
\hline & PXY & 0,23 & 0,25 & 0,27 & 0,29 & 0,31 & 0,33 & 0,35 \\
\hline & DNS & 7890 & 7890 & 7890 & 7890 & 7890 & 7890 & 7890 \\
\hline \multirow[t]{15}{*}{$\begin{array}{c}\text { Nodal } \\
\text { deflection }\end{array}$} & Node 1 & $7,20 \mathrm{E}-07$ & 7,90E-07 & $8,70 \mathrm{E}-07$ & $9,50 \mathrm{E}-07$ & $1,02 \mathrm{E}-06$ & $1,10 \mathrm{E}-06$ & $1,18 \mathrm{E}-06$ \\
\hline & Node 2 & $6,76 \mathrm{E}-06$ & $6,67 \mathrm{E}-06$ & $6,58 \mathrm{E}-06$ & $6,49 \mathrm{E}-06$ & $6,39 \mathrm{E}-06$ & $6,29 \mathrm{E}-06$ & $6,18 \mathrm{E}-06$ \\
\hline & Node 3 & 4,46E-05 & $4,42 \mathrm{E}-05$ & 4,39E-05 & $4,34 \mathrm{E}-05$ & 4,30E-05 & $4,25 \mathrm{E}-05$ & $4,20 \mathrm{E}-05$ \\
\hline & Node 4 & 5,91E-06 & $5,83 \mathrm{E}-06$ & $5,75 \mathrm{E}-06$ & $5,66 \mathrm{E}-06$ & 5,57E-06 & $5,48 \mathrm{E}-06$ & $5,38 \mathrm{E}-06$ \\
\hline & Node 5 & $6,97 \mathrm{E}-05$ & 6,92E-05 & $6,87 \mathrm{E}-05$ & $6,80 \mathrm{E}-05$ & $6,74 \mathrm{E}-05$ & $6,66 \mathrm{E}-05$ & $6,59 \mathrm{E}-05$ \\
\hline & Node 6 & $2,46 \mathrm{E}-05$ & 2,44E-05 & $2,41 \mathrm{E}-05$ & $2,38 \mathrm{E}-05$ & 2,35E-05 & 2,32E-05 & $2,29 \mathrm{E}-05$ \\
\hline & Node 7 & $1,40 \mathrm{E}-05$ & $1,38 \mathrm{E}-05$ & $1,37 \mathrm{E}-05$ & $1,35 \mathrm{E}-05$ & $1,33 \mathrm{E}-05$ & $1,31 \mathrm{E}-05$ & $1,29 \mathrm{E}-05$ \\
\hline & Node 8 & $4,29 \mathrm{E}-06$ & $4,25 \mathrm{E}-06$ & $4,20 \mathrm{E}-06$ & 4,15E-06 & $4,10 \mathrm{E}-06$ & $4,05 \mathrm{E}-06$ & $3,99 \mathrm{E}-06$ \\
\hline & Node 9 & $4,81 \mathrm{E}-04$ & $4,76 \mathrm{E}-04$ & $4,71 \mathrm{E}-04$ & $4,66 \mathrm{E}-04$ & $4,60 \mathrm{E}-04$ & $4,54 \mathrm{E}-04$ & $4,47 \mathrm{E}-04$ \\
\hline & Node 10 & 1,29E-04 & $1,27 \mathrm{E}-04$ & $1,26 \mathrm{E}-04$ & $1,24 \mathrm{E}-04$ & $1,22 \mathrm{E}-04$ & $1,20 \mathrm{E}-04$ & $1,18 \mathrm{E}-04$ \\
\hline & Node 11 & 2,31E-05 & 2,31E-05 & $2,30 \mathrm{E}-05$ & $2,30 \mathrm{E}-05$ & 2,30E-05 & 2,29E-05 & $2,29 \mathrm{E}-05$ \\
\hline & Node 12 & $8,18 \mathrm{E}-06$ & $8,15 \mathrm{E}-06$ & $8,12 \mathrm{E}-06$ & $8,08 \mathrm{E}-06$ & $8,05 \mathrm{E}-06$ & $8,02 \mathrm{E}-06$ & 7,99E-06 \\
\hline & Node 13 & $8,35 \mathrm{E}-05$ & $8,34 \mathrm{E}-05$ & $8,33 \mathrm{E}-05$ & $8,31 \mathrm{E}-05$ & $8,30 \mathrm{E}-05$ & $8,28 \mathrm{E}-05$ & $8,27 \mathrm{E}-05$ \\
\hline & Node 14 & $1,31 \mathrm{E}-05$ & $1,31 \mathrm{E}-05$ & $1,31 \mathrm{E}-05$ & $1,31 \mathrm{E}-05$ & $1,31 \mathrm{E}-05$ & $1,31 \mathrm{E}-05$ & $1,31 \mathrm{E}-05$ \\
\hline & Node 15 & 4,71E-05 & 4,71E-05 & 4,71E-05 & $4,71 \mathrm{E}-05$ & 4,72E-05 & $4,72 \mathrm{E}-05$ & $4,72 \mathrm{E}-05$ \\
\hline $\begin{array}{l}\text { Objective } \\
\text { function }\end{array}$ & $q(x)$ & $9,55 \mathrm{E}-04$ & $9,47 \mathrm{E}-04$ & $9,39 \mathrm{E}-04$ & $9,30 \mathrm{E}-04$ & $9,20 \mathrm{E}-04$ & $9,10 \mathrm{E}-04$ & $8,99 \mathrm{E}-04$ \\
\hline
\end{tabular}

Table A13-Variable values, obtained nodal deflections, and objective function for the PXY variable analysis (ribbed plate model) 


\section{A2.1.1.6 DNS Variable}

\begin{tabular}{|c|c|c|c|c|c|c|c|c|}
\hline $\begin{array}{c}\text { Variable } \\
\text { values }\end{array}$ & LG1 & 0,025 & 0,025 & 0,025 & 0,025 & 0,025 & 0,025 & 0,025 \\
\hline & LG2 & 0,051 & 0,051 & 0,051 & 0,051 & 0,051 & 0,051 & 0,051 \\
\hline & LG3 & 0,0046 & 0,0046 & 0,0046 & 0,0046 & 0,0046 & 0,0046 & 0,0046 \\
\hline & EX & $2,10 \mathrm{E}+11$ & $2,10 \mathrm{E}+11$ & $2,10 \mathrm{E}+11$ & $2,10 \mathrm{E}+11$ & $2,10 \mathrm{E}+11$ & $2,10 \mathrm{E}+11$ & $2,10 \mathrm{E}+11$ \\
\hline & PXY & 0,29 & 0,29 & 0,29 & 0,29 & 0,29 & 0,29 & 0,29 \\
\hline & DNS & 7860 & 7870 & 7880 & 7890 & 8000 & 8100 & 8200 \\
\hline $\begin{array}{c}\text { Nodal } \\
\text { deflection }\end{array}$ & Node 1 & $9,50 \mathrm{E}-07$ & $9,50 \mathrm{E}-07$ & $9,50 \mathrm{E}-07$ & $9,50 \mathrm{E}-07$ & $9,50 \mathrm{E}-07$ & $9,50 \mathrm{E}-07$ & $9,50 \mathrm{E}-07$ \\
\hline & Node 2 & $6,49 \mathrm{E}-06$ & $6,49 \mathrm{E}-06$ & $6,49 \mathrm{E}-06$ & $6,49 \mathrm{E}-06$ & $6,49 \mathrm{E}-06$ & 6,49E-06 & $6,49 \mathrm{E}-06$ \\
\hline & Node 3 & $4,34 \mathrm{E}-05$ & $4,34 \mathrm{E}-05$ & $4,34 \mathrm{E}-05$ & $4,34 \mathrm{E}-05$ & $4,34 \mathrm{E}-05$ & $4,34 \mathrm{E}-05$ & $4,34 \mathrm{E}-05$ \\
\hline & Node 4 & $5,66 \mathrm{E}-06$ & $5,66 \mathrm{E}-06$ & $5,66 \mathrm{E}-06$ & $5,66 \mathrm{E}-06$ & $5,66 \mathrm{E}-06$ & $5,66 \mathrm{E}-06$ & $5,66 \mathrm{E}-06$ \\
\hline & Node 5 & $6,80 \mathrm{E}-05$ & $6,80 \mathrm{E}-05$ & $6,80 \mathrm{E}-05$ & $6,80 \mathrm{E}-05$ & $6,80 \mathrm{E}-05$ & $6,80 \mathrm{E}-05$ & $6,80 \mathrm{E}-05$ \\
\hline & Node 6 & $2,38 \mathrm{E}-05$ & $2,38 \mathrm{E}-05$ & $2,38 \mathrm{E}-05$ & 2,38E-05 & $2,38 \mathrm{E}-05$ & $2,38 \mathrm{E}-05$ & $2,38 \mathrm{E}-05$ \\
\hline & Node 7 & $1,35 \mathrm{E}-05$ & $1,35 \mathrm{E}-05$ & $1,35 \mathrm{E}-05$ & $1,35 \mathrm{E}-05$ & $1,35 \mathrm{E}-05$ & $1,35 \mathrm{E}-05$ & $1,35 \mathrm{E}-05$ \\
\hline & Node 8 & $4,15 \mathrm{E}-06$ & $4,15 \mathrm{E}-06$ & $4,15 \mathrm{E}-06$ & $4,15 \mathrm{E}-06$ & $4,15 \mathrm{E}-06$ & $4,15 \mathrm{E}-06$ & $4,15 \mathrm{E}-06$ \\
\hline & Node 9 & $4,66 \mathrm{E}-04$ & $4,66 \mathrm{E}-04$ & $4,66 \mathrm{E}-04$ & $4,66 \mathrm{E}-04$ & $4,66 \mathrm{E}-04$ & $4,66 \mathrm{E}-04$ & $4,66 \mathrm{E}-04$ \\
\hline & Node 10 & $1,24 \mathrm{E}-04$ & $1,24 \mathrm{E}-04$ & $1,24 \mathrm{E}-04$ & $1,24 \mathrm{E}-04$ & $1,24 \mathrm{E}-04$ & $1,24 \mathrm{E}-04$ & $1,24 \mathrm{E}-04$ \\
\hline & Node 11 & 2,30E-05 & $2,30 \mathrm{E}-05$ & $2,30 \mathrm{E}-05$ & $2,30 \mathrm{E}-05$ & $2,30 \mathrm{E}-05$ & $2,30 \mathrm{E}-05$ & 2,30E-05 \\
\hline & Node 12 & $8,08 \mathrm{E}-06$ & $8,08 \mathrm{E}-06$ & $8,08 \mathrm{E}-06$ & $8,08 \mathrm{E}-06$ & $8,08 \mathrm{E}-06$ & $8,08 \mathrm{E}-06$ & $8,08 \mathrm{E}-06$ \\
\hline & Node 13 & $8,31 \mathrm{E}-05$ & $8,31 \mathrm{E}-05$ & $8,31 \mathrm{E}-05$ & $8,31 \mathrm{E}-05$ & $8,31 \mathrm{E}-05$ & $8,31 \mathrm{E}-05$ & $8,31 \mathrm{E}-05$ \\
\hline & Node 14 & $1,31 \mathrm{E}-05$ & $1,31 \mathrm{E}-05$ & $1,31 \mathrm{E}-05$ & $1,31 \mathrm{E}-05$ & $1,31 \mathrm{E}-05$ & $1,31 \mathrm{E}-05$ & $1,31 \mathrm{E}-05$ \\
\hline & Node 15 & $4,71 \mathrm{E}-05$ & $4,71 \mathrm{E}-05$ & $4,71 \mathrm{E}-05$ & 4,71E-05 & 4,71E-05 & 4,71E-05 & 4,71E-05 \\
\hline $\begin{array}{l}\text { Objective } \\
\text { function }\end{array}$ & $q(x)$ & $9,30 \mathrm{E}-04$ & $9,30 \mathrm{E}-04$ & $9,30 \mathrm{E}-04$ & $9,30 \mathrm{E}-04$ & $9,30 \mathrm{E}-04$ & $9,30 \mathrm{E}-04$ & $9,30 \mathrm{E}-04$ \\
\hline
\end{tabular}

Table A14-Variable values, obtained nodal deflections, and objective function for the DNS variable analysis (ribbed plate model) 
A2.1.2 Model 2- Tubular beam

\section{A2.1.2.1 LG4 Variable}

\begin{tabular}{|c|c|c|c|c|c|c|c|c|}
\hline $\begin{array}{l}\text { Variable } \\
\text { values }\end{array}$ & LG4 & 0,015 & 0,017 & 0,019 & 0,021 & 0,023 & 0,025 & 0,027 \\
\hline & LG5 & 0,008 & 0,008 & 0,008 & 0,008 & 0,008 & 0,008 & 0,008 \\
\hline & LG6 & 0,081 & 0,081 & 0,081 & 0,081 & 0,081 & 0,081 & 0,081 \\
\hline & EX & $2,10 \mathrm{E}+11$ & $2,10 \mathrm{E}+11$ & $2,10 \mathrm{E}+11$ & $2,10 \mathrm{E}+11$ & $2,10 \mathrm{E}+11$ & $2,10 \mathrm{E}+11$ & $2,10 \mathrm{E}+11$ \\
\hline & PXY & 0,29 & 0,29 & 0,29 & 0,29 & 0,29 & 0,29 & 0,29 \\
\hline & DNS & 7890 & 7890 & 7890 & 7890 & 7890 & 7890 & 7890 \\
\hline \multirow[t]{21}{*}{$\begin{array}{c}\text { Nodal } \\
\text { deflection }\end{array}$} & Node 1 & $2,60 \mathrm{E}-07$ & $3,50 \mathrm{E}-07$ & $5,30 \mathrm{E}-07$ & $7,90 \mathrm{E}-07$ & $1,14 \mathrm{E}-06$ & 1,57E-06 & 2,09E-06 \\
\hline & Node 2 & $5,00 \mathrm{E}-08$ & $5,00 \mathrm{E}-08$ & $5,00 \mathrm{E}-08$ & $5,00 \mathrm{E}-08$ & $4,00 \mathrm{E}-08$ & 4,00E-08 & $4,00 \mathrm{E}-08$ \\
\hline & Node 3 & $1,08 \mathrm{E}-06$ & $1,00 \mathrm{E}-06$ & 8,70E-07 & $7,00 \mathrm{E}-07$ & $5,00 \mathrm{E}-07$ & 2,60E-07 & $2,00 \mathrm{E}-08$ \\
\hline & Node 4 & $2,66 \mathrm{E}-06$ & $2,72 \mathrm{E}-06$ & $2,68 \mathrm{E}-06$ & $2,57 \mathrm{E}-06$ & $2,39 \mathrm{E}-06$ & $2,13 \mathrm{E}-06$ & $1,81 \mathrm{E}-06$ \\
\hline & Node 5 & $1,05 \mathrm{E}-05$ & $1,13 \mathrm{E}-05$ & $1,21 \mathrm{E}-05$ & $1,30 \mathrm{E}-05$ & $1,39 \mathrm{E}-05$ & $1,49 \mathrm{E}-05$ & $1,60 \mathrm{E}-05$ \\
\hline & Node 6 & $2,00 \mathrm{E}-08$ & $1,00 \mathrm{E}-08$ & $0,00 \mathrm{E}+00$ & $1,00 \mathrm{E}-08$ & 2,00E-08 & $3,00 \mathrm{E}-08$ & $3,00 \mathrm{E}-08$ \\
\hline & Node 7 & 4,09E-06 & $4,45 \mathrm{E}-06$ & 4,82E-06 & $5,22 \mathrm{E}-06$ & $5,63 \mathrm{E}-06$ & 6,07E-06 & $6,54 \mathrm{E}-06$ \\
\hline & Node 8 & $9,53 \mathrm{E}-06$ & $1,03 \mathrm{E}-05$ & $1,10 \mathrm{E}-05$ & $1,19 \mathrm{E}-05$ & $1,27 \mathrm{E}-05$ & $1,36 \mathrm{E}-05$ & $1,46 \mathrm{E}-05$ \\
\hline & Node 9 & $1,92 \mathrm{E}-04$ & $2,00 \mathrm{E}-04$ & $2,06 \mathrm{E}-04$ & $2,11 \mathrm{E}-04$ & $2,15 \mathrm{E}-04$ & $2,18 \mathrm{E}-04$ & $2,20 \mathrm{E}-04$ \\
\hline & Node 10 & $3,90 \mathrm{E}-06$ & 4,2 & $4,54 \mathrm{E}-06$ & $4,85 \mathrm{E}-06$ & $5,16 \mathrm{E}-06$ & $5,48 \mathrm{E}-06$ & $5,80 \mathrm{E}-06$ \\
\hline & Node 11 & $6,49 \mathrm{E}-05$ & $6,69 \mathrm{E}-05$ & $6,84 \mathrm{E}-05$ & $6,96 \mathrm{E}-05$ & $7,04 \mathrm{E}-05$ & $7,10 \mathrm{E}-05$ & $7,14 \mathrm{E}-05$ \\
\hline & Node 12 & $1,78 \mathrm{E}-04$ & $1,85 \mathrm{E}-04$ & $1,92 \mathrm{E}-04$ & $1,97 \mathrm{E}-04$ & $2,01 \mathrm{E}-04$ & $2,04 \mathrm{E}-04$ & $2,06 \mathrm{E}-04$ \\
\hline & Node 13 & $1,00 \mathrm{E}-08$ & $1,00 \mathrm{E}-08$ & $1,00 \mathrm{E}-08$ & $1,00 \mathrm{E}-08$ & $1,00 \mathrm{E}-08$ & $1,00 \mathrm{E}-08$ & $1,00 \mathrm{E}-08$ \\
\hline & Node 14 & $1,20 \mathrm{E}-07$ & $1,30 \mathrm{E}-07$ & $1,50 \mathrm{E}-07$ & $1,70 \mathrm{E}-07$ & $1,90 \mathrm{E}-07$ & $2,20 \mathrm{E}-07$ & $2,50 \mathrm{E}-07$ \\
\hline & Node 15 & $3,00 \mathrm{E}-08$ & $3,00 \mathrm{E}-08$ & $4,00 \mathrm{E}-08$ & $5,00 \mathrm{E}-08$ & $7,00 \mathrm{E}-08$ & $8,00 \mathrm{E}-08$ & $9,00 \mathrm{E}-08$ \\
\hline & Node 16 & $0,00 \mathrm{E}+00$ & $0,00 \mathrm{E}+00$ & $0,00 \mathrm{E}+00$ & $0,00 \mathrm{E}+00$ & $0,00 \mathrm{E}+00$ & $0,00 \mathrm{E}+00$ & $0,00 \mathrm{E}+00$ \\
\hline & Node 17 & $6,00 \mathrm{E}-08$ & $6,00 \mathrm{E}-08$ & $6,00 \mathrm{E}-08$ & $6,00 \mathrm{E}-08$ & $6,00 \mathrm{E}-08$ & $5,00 \mathrm{E}-08$ & $5,00 \mathrm{E}-08$ \\
\hline & Node 18 & $2,00 \mathrm{E}-08$ & $2,00 \mathrm{E}-08$ & $2,00 \mathrm{E}-08$ & $2,00 \mathrm{E}-08$ & $1,00 \mathrm{E}-08$ & $1,00 \mathrm{E}-08$ & $1,00 \mathrm{E}-08$ \\
\hline & Node 19 & $0,00 \mathrm{E}+00$ & $0,00 \mathrm{E}+00$ & $0,00 \mathrm{E}+00$ & $0,00 \mathrm{E}+00$ & $0,00 \mathrm{E}+00$ & $0,00 \mathrm{E}+00$ & $0,00 \mathrm{E}+00$ \\
\hline & Node 20 & $1,00 \mathrm{E}-07$ & $1,00 \mathrm{E}-07$ & $1,00 \mathrm{E}-07$ & $9,00 \mathrm{E}-08$ & $9,00 \mathrm{E}-08$ & $9,00 \mathrm{E}-08$ & $8,00 \mathrm{E}-08$ \\
\hline & Node 21 & $4,00 \mathrm{E}-08$ & $4,00 \mathrm{E}-08$ & $3,00 \mathrm{E}-08$ & $3,00 \mathrm{E}-08$ & $3,00 \mathrm{E}-08$ & $3,00 \mathrm{E}-08$ & $3,00 \mathrm{E}-08$ \\
\hline $\begin{array}{l}\text { Objective } \\
\text { function }\end{array}$ & $q(x)$ & 4,67E-04 & 4,87E-04 & $5,03 \mathrm{E}-04$ & $5,17 \mathrm{E}-04$ & $5,28 \mathrm{E}-04$ & 5,37E-04 & $5,45 \mathrm{E}-04$ \\
\hline
\end{tabular}

Table A15-Variable values, obtained nodal deflections, and objective function for the LG4 variable analysis (tubular beam model) 


\section{A2.1.2.2 LG5 Variable}

\begin{tabular}{|c|c|c|c|c|c|c|c|c|}
\hline $\begin{array}{l}\text { Variable } \\
\text { values }\end{array}$ & LG4 & 0,021 & 0,021 & 0,021 & 0,021 & 0,021 & 0,021 & 0,021 \\
\hline & LG5 & 0,005 & 0,006 & 0,007 & 0,008 & 0,009 & 0,01 & 0,011 \\
\hline & LG6 & 0,081 & 0,081 & 0,081 & 0,081 & 0,081 & 0,081 & 0,081 \\
\hline & $\mathrm{EX}$ & $2,10 \mathrm{E}+11$ & $2,10 \mathrm{E}+11$ & $2,10 \mathrm{E}+11$ & $2,10 \mathrm{E}+11$ & $2,10 \mathrm{E}+11$ & $2,10 \mathrm{E}+11$ & $2,10 \mathrm{E}+11$ \\
\hline & PXY & 0,29 & 0,29 & 0,29 & 0,29 & 0,29 & 0,29 & 0,29 \\
\hline & DNS & 7890 & 7890 & 7890 & 7890 & 7890 & 7890 & 7890 \\
\hline \multirow[t]{21}{*}{$\begin{array}{c}\text { Nodal } \\
\text { deflections }\end{array}$} & Node 1 & $5,09 \mathrm{E}-06$ & $3,22 \mathrm{E}-06$ & $1,25 \mathrm{E}-06$ & $7,90 \mathrm{E}-07$ & $2,86 \mathrm{E}-06$ & $4,92 \mathrm{E}-06$ & $1,12 \mathrm{E}-05$ \\
\hline & Node 2 & $8,00 \mathrm{E}-08$ & $6,00 \mathrm{E}-08$ & $5,00 \mathrm{E}-08$ & $5,00 \mathrm{E}-08$ & $6,00 \mathrm{E}-08$ & $7,00 \mathrm{E}-08$ & $1,25 \mathrm{E}-05$ \\
\hline & Node 3 & 2,61E-06 & 1,92E-06 & $1,30 \mathrm{E}-06$ & $7,00 \mathrm{E}-07$ & $9,00 \mathrm{E}-08$ & $5,80 \mathrm{E}-07$ & $3,10 \mathrm{E}-06$ \\
\hline & Node 4 & $7,12 \mathrm{E}-06$ & $5,73 \mathrm{E}-06$ & $4,21 \mathrm{E}-06$ & $2,57 \mathrm{E}-06$ & $8,60 \mathrm{E}-07$ & $8,80 \mathrm{E}-07$ & $6,52 \mathrm{E}-06$ \\
\hline & Node 5 & $6,25 \mathrm{E}-06$ & $8,53 \mathrm{E}-06$ & $1,08 \mathrm{E}-05$ & $1,30 \mathrm{E}-05$ & $1,52 \mathrm{E}-05$ & $1,72 \mathrm{E}-05$ & $1,81 \mathrm{E}-05$ \\
\hline & Node 6 & $6,00 \mathrm{E}-08$ & $4,00 \mathrm{E}-08$ & $2,00 \mathrm{E}-08$ & $1,00 \mathrm{E}-08$ & $0,00 \mathrm{E}+00$ & $1,00 \mathrm{E}-08$ & 1,91E-05 \\
\hline & Node 7 & $3,10 \mathrm{E}-06$ & 3,79E-06 & $4,50 \mathrm{E}-06$ & $5,22 \mathrm{E}-06$ & $5,94 \mathrm{E}-06$ & $6,65 \mathrm{E}-06$ & $5,28 \mathrm{E}-06$ \\
\hline & Node 8 & $5,76 \mathrm{E}-06$ & 7,79E-06 & $9,84 \mathrm{E}-06$ & $1,19 \mathrm{E}-05$ & $1,38 \mathrm{E}-05$ & $1,57 \mathrm{E}-05$ & $1,58 \mathrm{E}-05$ \\
\hline & Node 9 & $2,23 \mathrm{E}-04$ & $2,20 \mathrm{E}-04$ & $2,16 \mathrm{E}-04$ & $2,11 \mathrm{E}-04$ & $2,05 \mathrm{E}-04$ & $1,97 \mathrm{E}-04$ & $1,35 \mathrm{E}-04$ \\
\hline & Node 10 & $8,87 \mathrm{E}-06$ & 6,71E-06 & $5,27 \mathrm{E}-06$ & $4,85 \mathrm{E}-06$ & $5,33 \mathrm{E}-06$ & 6,39E-06 & 2,38E-06 \\
\hline & Node 11 & $6,96 \mathrm{E}-05$ & $6,73 \mathrm{E}-05$ & $6,75 \mathrm{E}-05$ & $6,96 \mathrm{E}-05$ & $7,25 \mathrm{E}-05$ & $7,55 \mathrm{E}-05$ & $6,12 \mathrm{E}-05$ \\
\hline & Node 12 & $1,95 \mathrm{E}-04$ & 1,97E-04 & $1,98 \mathrm{E}-04$ & $1,97 \mathrm{E}-04$ & $1,95 \mathrm{E}-04$ & $1,92 \mathrm{E}-04$ & $1,62 \mathrm{E}-04$ \\
\hline & Node 13 & $2,00 \mathrm{E}-08$ & $1,00 \mathrm{E}-08$ & $1,00 \mathrm{E}-08$ & $1,00 \mathrm{E}-08$ & $1,00 \mathrm{E}-08$ & $1,00 \mathrm{E}-08$ & $1,00 \mathrm{E}-08$ \\
\hline & Node 14 & $9,00 \mathrm{E}-08$ & $0,00 \mathrm{E}+00$ & $9,00 \mathrm{E}-08$ & $1,70 \mathrm{E}-07$ & $2,40 \mathrm{E}-07$ & $3,10 \mathrm{E}-07$ & $2,00 \mathrm{E}-08$ \\
\hline & Node 15 & $4,00 \mathrm{E}-08$ & $0,00 \mathrm{E}+00$ & $3,00 \mathrm{E}-08$ & $5,00 \mathrm{E}-08$ & $8,00 \mathrm{E}-08$ & $1,00 \mathrm{E}-07$ & $0,00 \mathrm{E}+00$ \\
\hline & Node 16 & $0,00 \mathrm{E}+00$ & $0,00 \mathrm{E}+00$ & $0,00 \mathrm{E}+00$ & $0,00 \mathrm{E}+00$ & $0,00 \mathrm{E}+00$ & $0,00 \mathrm{E}+00$ & $3,00 \mathrm{E}-08$ \\
\hline & Node 17 & $1,00 \mathrm{E}-07$ & $9,00 \mathrm{E}-08$ & $7,00 \mathrm{E}-08$ & $6,00 \mathrm{E}-08$ & $5,00 \mathrm{E}-08$ & $3,00 \mathrm{E}-08$ & $3,50 \mathrm{E}-07$ \\
\hline & Node 18 & $3,00 \mathrm{E}-08$ & $3,00 \mathrm{E}-08$ & $2,00 \mathrm{E}-08$ & $2,00 \mathrm{E}-08$ & $1,00 \mathrm{E}-08$ & $1,00 \mathrm{E}-08$ & $1,30 \mathrm{E}-07$ \\
\hline & Node 19 & $0,00 \mathrm{E}+00$ & $0,00 \mathrm{E}+00$ & $0,00 \mathrm{E}+00$ & $0,00 \mathrm{E}+00$ & $0,00 \mathrm{E}+00$ & $0,00 \mathrm{E}+00$ & $0,00 \mathrm{E}+00$ \\
\hline & Node 20 & $1,00 \mathrm{E}-07$ & 1,00E-07 & $1,00 \mathrm{E}-07$ & $9,00 \mathrm{E}-08$ & $9,00 \mathrm{E}-08$ & $9,00 \mathrm{E}-08$ & $8,00 \mathrm{E}-08$ \\
\hline & Node 21 & $4,00 \mathrm{E}-08$ & $4,00 \mathrm{E}-08$ & $3,00 \mathrm{E}-08$ & $3,00 \mathrm{E}-08$ & $3,00 \mathrm{E}-08$ & $3,00 \mathrm{E}-08$ & $4,00 \mathrm{E}-08$ \\
\hline $\begin{array}{l}\text { Objective } \\
\text { function }\end{array}$ & $q(x)$ & $5,27 \mathrm{E}-04$ & $5,23 \mathrm{E}-04$ & $5,19 \mathrm{E}-04$ & $5,17 \mathrm{E}-04$ & $5,16 \mathrm{E}-04$ & $5,17 \mathrm{E}-04$ & 4,53E-04 \\
\hline
\end{tabular}

Table A16-Variable values, obtained nodal deflections, and objective function for the LG5 variable analysis (tubular beam model) 


\section{A2.1.2.3 LG6 Variable}

\begin{tabular}{|c|c|c|c|c|c|c|c|c|}
\hline $\begin{array}{c}\text { Variable } \\
\text { values }\end{array}$ & LG4 & 0,021 & 0,021 & 0,021 & 0,021 & 0,021 & 0,021 & 0,021 \\
\hline & LG5 & 0,008 & 0,008 & 0,008 & 0,008 & 0,008 & 0,008 & 0,008 \\
\hline & LG6 & 0,066 & 0,071 & 0,076 & 0,081 & 0,086 & 0,091 & 0,096 \\
\hline & EX & $2,10 \mathrm{E}+11$ & $2,10 \mathrm{E}+11$ & $2,10 \mathrm{E}+11$ & $2,10 \mathrm{E}+11$ & $2,10 \mathrm{E}+11$ & $2,10 \mathrm{E}+11$ & $2,10 \mathrm{E}+11$ \\
\hline & PXY & 0,29 & 0,29 & 0,29 & 0,29 & 0,29 & 0,29 & 0,29 \\
\hline & DNS & 7890 & 7890 & 7890 & 7890 & 7890 & 7890 & 7890 \\
\hline \multirow[t]{21}{*}{$\begin{array}{c}\text { Nodal } \\
\text { deflections } \\
\end{array}$} & Node 1 & $0,00 \mathrm{E}+00$ & $0,00 \mathrm{E}+00$ & $0,00 \mathrm{E}+00$ & 7,90E-07 & $6,30 \mathrm{E}-07$ & $4,80 \mathrm{E}-07$ & $3,60 \mathrm{E}-07$ \\
\hline & Node 2 & $4,60 \mathrm{E}-07$ & $4,20 \mathrm{E}-07$ & $3,90 \mathrm{E}-07$ & $5,00 \mathrm{E}-08$ & $5,00 \mathrm{E}-08$ & $7,00 \mathrm{E}-08$ & $8,00 \mathrm{E}-08$ \\
\hline & Node 3 & $3,60 \mathrm{E}-07$ & $3,40 \mathrm{E}-07$ & $3,40 \mathrm{E}-07$ & $7,00 \mathrm{E}-07$ & $8,10 \mathrm{E}-07$ & $9,20 \mathrm{E}-07$ & $1,03 \mathrm{E}-06$ \\
\hline & Node 4 & $6,85 \mathrm{E}-06$ & $6,43 \mathrm{E}-06$ & $6,12 \mathrm{E}-06$ & $2,57 \mathrm{E}-06$ & $2,55 \mathrm{E}-06$ & $2,53 \mathrm{E}-06$ & $2,51 \mathrm{E}-06$ \\
\hline & Node 5 & $1,60 \mathrm{E}-04$ & $1,34 \mathrm{E}-04$ & $1,12 \mathrm{E}-04$ & $1,30 \mathrm{E}-05$ & $1,27 \mathrm{E}-05$ & $1,24 \mathrm{E}-05$ & $1,22 \mathrm{E}-05$ \\
\hline & Node 6 & $1,89 \mathrm{E}-04$ & $1,57 \mathrm{E}-04$ & $1,31 \mathrm{E}-04$ & $1,00 \mathrm{E}-08$ & $2,00 \mathrm{E}-08$ & $2,00 \mathrm{E}-08$ & $3,00 \mathrm{E}-08$ \\
\hline & Node 7 & $2,32 \mathrm{E}-04$ & $1,87 \mathrm{E}-04$ & $1,50 \mathrm{E}-04$ & $5,22 \mathrm{E}-06$ & $5,05 \mathrm{E}-06$ & $4,91 \mathrm{E}-06$ & $4,81 \mathrm{E}-06$ \\
\hline & Node 8 & $8,92 \mathrm{E}-05$ & $7,56 \mathrm{E}-05$ & $6,51 \mathrm{E}-05$ & $1,19 \mathrm{E}-05$ & $1,15 \mathrm{E}-05$ & $1,13 \mathrm{E}-05$ & $1,11 \mathrm{E}-05$ \\
\hline & Node 9 & 1,04E-06 & $1,02 \mathrm{E}-06$ & $9,30 \mathrm{E}-07$ & $2,11 \mathrm{E}-04$ & $1,96 \mathrm{E}-04$ & $1,83 \mathrm{E}-04$ & $1,72 \mathrm{E}-04$ \\
\hline & Node 10 & $1,65 \mathrm{E}-05$ & $1,43 \mathrm{E}-05$ & $1,29 \mathrm{E}-05$ & $4,85 \mathrm{E}-06$ & 4,66E-06 & 4,79E-06 & $5,16 \mathrm{E}-06$ \\
\hline & Node 11 & $8,22 \mathrm{E}-05$ & $7,66 \mathrm{E}-05$ & $7,26 \mathrm{E}-05$ & $6,96 \mathrm{E}-05$ & $6,62 \mathrm{E}-05$ & $6,39 \mathrm{E}-05$ & $6,24 \mathrm{E}-05$ \\
\hline & Node 12 & 4,00E-07 & $4,00 \mathrm{E}-07$ & $3,60 \mathrm{E}-07$ & $1,97 \mathrm{E}-04$ & $1,85 \mathrm{E}-04$ & $1,76 \mathrm{E}-04$ & $1,68 \mathrm{E}-04$ \\
\hline & Node 13 & $1,60 \mathrm{E}-07$ & $1,40 \mathrm{E}-07$ & $1,20 \mathrm{E}-07$ & $1,00 \mathrm{E}-08$ & $1,00 \mathrm{E}-08$ & $1,00 \mathrm{E}-08$ & $1,00 \mathrm{E}-08$ \\
\hline & Node 14 & $7,00 \mathrm{E}-08$ & $6,00 \mathrm{E}-08$ & $5,00 \mathrm{E}-08$ & $1,70 \mathrm{E}-07$ & $1,60 \mathrm{E}-07$ & $1,60 \mathrm{E}-07$ & $1,60 \mathrm{E}-07$ \\
\hline & Node 15 & $0,00 \mathrm{E}+00$ & $0,00 \mathrm{E}+00$ & $0,00 \mathrm{E}+00$ & $5,00 \mathrm{E}-08$ & $5,00 \mathrm{E}-08$ & $4,00 \mathrm{E}-08$ & $4,00 \mathrm{E}-08$ \\
\hline & Node 16 & $6,10 \mathrm{E}-07$ & $4,50 \mathrm{E}-07$ & $3,30 \mathrm{E}-07$ & $0,00 \mathrm{E}+00$ & $0,00 \mathrm{E}+00$ & $0,00 \mathrm{E}+00$ & $0,00 \mathrm{E}+00$ \\
\hline & Node 17 & $3,60 \mathrm{E}-07$ & $2,80 \mathrm{E}-07$ & $2,30 \mathrm{E}-07$ & $6,00 \mathrm{E}-08$ & $5,00 \mathrm{E}-08$ & $5,00 \mathrm{E}-08$ & $4,00 \mathrm{E}-08$ \\
\hline & Node 18 & $6,00 \mathrm{E}-08$ & $5,00 \mathrm{E}-08$ & $4,00 \mathrm{E}-08$ & $2,00 \mathrm{E}-08$ & $1,00 \mathrm{E}-08$ & $1,00 \mathrm{E}-08$ & $1,00 \mathrm{E}-08$ \\
\hline & Node 19 & $1,02 \mathrm{E}-05$ & $9,23 \mathrm{E}-06$ & $8,46 \mathrm{E}-06$ & $0,00 \mathrm{E}+00$ & $0,00 \mathrm{E}+00$ & $0,00 \mathrm{E}+00$ & $0,00 \mathrm{E}+00$ \\
\hline & Node 20 & $4,05 \mathrm{E}-06$ & $3,52 \mathrm{E}-06$ & 3,07E-06 & $9,00 \mathrm{E}-08$ & $8,00 \mathrm{E}-08$ & $6,00 \mathrm{E}-08$ & $5,00 \mathrm{E}-08$ \\
\hline & Node 21 & $1,57 \mathrm{E}-05$ & $1,41 \mathrm{E}-05$ & $1,28 \mathrm{E}-05$ & $3,00 \mathrm{E}-08$ & $3,00 \mathrm{E}-08$ & $2,00 \mathrm{E}-08$ & $2,00 \mathrm{E}-08$ \\
\hline $\begin{array}{c}\text { Objective } \\
\text { function }\end{array}$ & $q(x)$ & $8,10 \mathrm{E}-04$ & $6,80 \mathrm{E}-04$ & $5,78 \mathrm{E}-04$ & $5,17 \mathrm{E}-04$ & $4,86 \mathrm{E}-04$ & 4,61E-04 & 4,40E-04 \\
\hline
\end{tabular}

Table A17-Variable values, obtained nodal deflections, and objective function for the LG6 variable analysis (tubular beam model) 


\section{A2.1.2.4 EX Variable}

\begin{tabular}{|c|c|c|c|c|c|c|c|c|}
\hline $\begin{array}{l}\text { Variable } \\
\text { values }\end{array}$ & LG4 & 0,021 & 0,021 & 0,021 & 0,021 & 0,021 & 0,021 & 0,021 \\
\hline & LG5 & 0,008 & 0,008 & 0,008 & 0,008 & 0,008 & 0,008 & 0,008 \\
\hline & LG6 & 0,081 & 0,081 & 0,081 & 0,081 & 0,081 & 0,081 & 0,081 \\
\hline & EX & $1,95 \mathrm{E}+11$ & $2,00 \mathrm{E}+11$ & $2,05 \mathrm{E}+11$ & $2,10 \mathrm{E}+11$ & $2,15 \mathrm{E}+11$ & $2,20 \mathrm{E}+11$ & $2,25 \mathrm{E}+11$ \\
\hline & PXY & 0,29 & 0,29 & 0,29 & 0,29 & 0,29 & 0,29 & 0,29 \\
\hline & DNS & 7890 & 7890 & 7890 & 7890 & 7890 & 7890 & 7890 \\
\hline \multirow[t]{21}{*}{$\begin{array}{c}\text { Nodal } \\
\text { deflections }\end{array}$} & Node 1 & $8,50 \mathrm{E}-07$ & $8,30 \mathrm{E}-07$ & $8,10 \mathrm{E}-07$ & $7,90 \mathrm{E}-07$ & $7,70 \mathrm{E}-07$ & $7,60 \mathrm{E}-07$ & $7,40 \mathrm{E}-07$ \\
\hline & Node 2 & $5,00 \mathrm{E}-08$ & $5,00 \mathrm{E}-08$ & $5,00 \mathrm{E}-08$ & $5,00 \mathrm{E}-08$ & $5,00 \mathrm{E}-08$ & $5,00 \mathrm{E}-08$ & $4,00 \mathrm{E}-08$ \\
\hline & Node 3 & $7,60 \mathrm{E}-07$ & $7,40 \mathrm{E}-07$ & $7,20 \mathrm{E}-07$ & $7,00 \mathrm{E}-07$ & $6,90 \mathrm{E}-07$ & $6,70 \mathrm{E}-07$ & $6,60 \mathrm{E}-07$ \\
\hline & Node 4 & 2,77E-06 & $2,70 \mathrm{E}-06$ & $2,63 \mathrm{E}-06$ & $2,57 \mathrm{E}-06$ & $2,51 \mathrm{E}-06$ & $2,45 \mathrm{E}-06$ & $2,40 \mathrm{E}-06$ \\
\hline & Node 5 & $1,40 \mathrm{E}-05$ & 1,37E-05 & $1,33 \mathrm{E}-05$ & $1,30 \mathrm{E}-05$ & $1,27 \mathrm{E}-05$ & $1,24 \mathrm{E}-05$ & $1,22 \mathrm{E}-05$ \\
\hline & Node 6 & $1,00 \mathrm{E}-08$ & $1,00 \mathrm{E}-08$ & $1,00 \mathrm{E}-08$ & $1,00 \mathrm{E}-08$ & $1,00 \mathrm{E}-08$ & $1,00 \mathrm{E}-08$ & $1,00 \mathrm{E}-08$ \\
\hline & Node 7 & $5,62 \mathrm{E}-06$ & $5,48 \mathrm{E}-06$ & 5,34E-06 & $5,22 \mathrm{E}-06$ & $5,10 \mathrm{E}-06$ & 4,98E-06 & $4,87 \mathrm{E}-06$ \\
\hline & Node 8 & $1,28 \mathrm{E}-05$ & $1,24 \mathrm{E}-05$ & $1,21 \mathrm{E}-05$ & $1,19 \mathrm{E}-05$ & $1,16 \mathrm{E}-05$ & $1,13 \mathrm{E}-05$ & $1,11 \mathrm{E}-05$ \\
\hline & Node 9 & $2,27 \mathrm{E}-04$ & $2,22 \mathrm{E}-04$ & $2,16 \mathrm{E}-04$ & $2,11 \mathrm{E}-04$ & $2,06 \mathrm{E}-04$ & $2,01 \mathrm{E}-04$ & $1,97 \mathrm{E}-04$ \\
\hline & Node 10 & $5,22 \mathrm{E}-06$ & $5,09 \mathrm{E}-06$ & $4,97 \mathrm{E}-06$ & $4,85 \mathrm{E}-06$ & 4,74E-06 & $4,63 \mathrm{E}-06$ & $4,53 \mathrm{E}-06$ \\
\hline & Node 11 & $7,49 \mathrm{E}-05$ & $7,30 \mathrm{E}-05$ & $7,13 \mathrm{E}-05$ & $6,96 \mathrm{E}-05$ & $6,79 \mathrm{E}-05$ & $6,64 \mathrm{E}-05$ & $6,49 \mathrm{E}-05$ \\
\hline & Node 12 & $2,12 \mathrm{E}-04$ & $2,06 \mathrm{E}-04$ & 2,01E-04 & 1,97E-04 & $1,92 \mathrm{E}-04$ & $1,88 \mathrm{E}-04$ & $1,84 \mathrm{E}-04$ \\
\hline & Node 13 & $1,00 \mathrm{E}-08$ & $1,00 \mathrm{E}-08$ & $1,00 \mathrm{E}-08$ & $1,00 \mathrm{E}-08$ & $1,00 \mathrm{E}-08$ & $1,00 \mathrm{E}-08$ & $1,00 \mathrm{E}-08$ \\
\hline & Node 14 & $1,80 \mathrm{E}-07$ & $1,80 \mathrm{E}-07$ & 1,70E-07 & $1,70 \mathrm{E}-07$ & $1,70 \mathrm{E}-07$ & $1,60 \mathrm{E}-07$ & $1,60 \mathrm{E}-07$ \\
\hline & Node 15 & $6,00 \mathrm{E}-08$ & $6,00 \mathrm{E}-08$ & $6,00 \mathrm{E}-08$ & $5,00 \mathrm{E}-08$ & $5,00 \mathrm{E}-08$ & $5,00 \mathrm{E}-08$ & $5,00 \mathrm{E}-08$ \\
\hline & Node 16 & $0,00 \mathrm{E}+00$ & $0,00 \mathrm{E}+00$ & $0,00 \mathrm{E}+00$ & $0,00 \mathrm{E}+00$ & $0,00 \mathrm{E}+00$ & $0,00 \mathrm{E}+00$ & $0,00 \mathrm{E}+00$ \\
\hline & Node 17 & $6,00 \mathrm{E}-08$ & $6,00 \mathrm{E}-08$ & $6,00 \mathrm{E}-08$ & $6,00 \mathrm{E}-08$ & $6,00 \mathrm{E}-08$ & $6,00 \mathrm{E}-08$ & $6,00 \mathrm{E}-08$ \\
\hline & Node 18 & $2,00 \mathrm{E}-08$ & $2,00 \mathrm{E}-08$ & $2,00 \mathrm{E}-08$ & $2,00 \mathrm{E}-08$ & $2,00 \mathrm{E}-08$ & $2,00 \mathrm{E}-08$ & $2,00 \mathrm{E}-08$ \\
\hline & Node 19 & $0,00 \mathrm{E}+00$ & $0,00 \mathrm{E}+00$ & $0,00 \mathrm{E}+00$ & $0,00 \mathrm{E}+00$ & $0,00 \mathrm{E}+00$ & $0,00 \mathrm{E}+00$ & $0,00 \mathrm{E}+00$ \\
\hline & Node 20 & $1,00 \mathrm{E}-07$ & $1,00 \mathrm{E}-07$ & $9,00 \mathrm{E}-08$ & $9,00 \mathrm{E}-08$ & $9,00 \mathrm{E}-08$ & $9,00 \mathrm{E}-08$ & $9,00 \mathrm{E}-08$ \\
\hline & Node 21 & $4,00 \mathrm{E}-08$ & $3,00 \mathrm{E}-08$ & $3,00 \mathrm{E}-08$ & $3,00 \mathrm{E}-08$ & $3,00 \mathrm{E}-08$ & $3,00 \mathrm{E}-08$ & $3,00 \mathrm{E}-08$ \\
\hline $\begin{array}{l}\text { Objective } \\
\text { function }\end{array}$ & $q(x)$ & $5,56 \mathrm{E}-04$ & $5,43 \mathrm{E}-04$ & $5,29 \mathrm{E}-04$ & $5,17 \mathrm{E}-04$ & $5,05 \mathrm{E}-04$ & 4,93E-04 & $4,82 \mathrm{E}-04$ \\
\hline
\end{tabular}

Table A18-Variable values, obtained nodal deflections, and objective function for the EX variable analysis (tubular beam model) 


\section{A2.1.2.5 PXY Variable}

\begin{tabular}{|c|c|c|c|c|c|c|c|c|}
\hline $\begin{array}{l}\text { Variable } \\
\text { values }\end{array}$ & LG4 & 0,021 & 0,021 & 0,021 & 0,021 & 0,021 & 0,021 & 0,021 \\
\hline & LG5 & 0,008 & 0,008 & 0,008 & 0,008 & 0,008 & 0,008 & 0,008 \\
\hline & LG6 & 0,081 & 0,081 & 0,081 & 0,081 & 0,081 & 0,081 & 0,081 \\
\hline & EX & $2,10 \mathrm{E}+11$ & $2,10 \mathrm{E}+11$ & $2,10 \mathrm{E}+11$ & $2,10 \mathrm{E}+11$ & $2,10 \mathrm{E}+11$ & $2,10 \mathrm{E}+11$ & $2,10 \mathrm{E}+11$ \\
\hline & PXY & 0,23 & 0,25 & 0,27 & 0,29 & 0,31 & 0,33 & 0,35 \\
\hline & DNS & 7890 & 7890 & 7890 & 7890 & 7890 & 7890 & 7890 \\
\hline $\begin{array}{c}\text { Nodal } \\
\text { deflections }\end{array}$ & Node 1 & $6,90 \mathrm{E}-07$ & $7,20 \mathrm{E}-07$ & $7,60 \mathrm{E}-07$ & $7,90 \mathrm{E}-07$ & $8,30 \mathrm{E}-07$ & $8,70 \mathrm{E}-07$ & $9,10 \mathrm{E}-07$ \\
\hline & Node 2 & $5,00 \mathrm{E}-08$ & 5,00E-08 & $5,00 \mathrm{E}-08$ & $5,00 \mathrm{E}-08$ & $5,00 \mathrm{E}-08$ & $5,00 \mathrm{E}-08$ & $5,00 \mathrm{E}-08$ \\
\hline & Node 3 & $7,50 \mathrm{E}-07$ & $7,40 \mathrm{E}-07$ & $7,20 \mathrm{E}-07$ & $7,00 \mathrm{E}-07$ & $6,90 \mathrm{E}-07$ & $6,70 \mathrm{E}-07$ & $6,50 \mathrm{E}-07$ \\
\hline & Node 4 & $2,66 \mathrm{E}-06$ & $2,64 \mathrm{E}-06$ & $2,60 \mathrm{E}-06$ & $2,57 \mathrm{E}-06$ & $2,54 \mathrm{E}-06$ & $2,50 \mathrm{E}-06$ & $2,46 \mathrm{E}-06$ \\
\hline & Node 5 & $1,31 \mathrm{E}-05$ & $1,31 \mathrm{E}-05$ & $1,30 \mathrm{E}-05$ & $1,30 \mathrm{E}-05$ & $1,30 \mathrm{E}-05$ & $1,30 \mathrm{E}-05$ & $1,30 \mathrm{E}-05$ \\
\hline & Node 6 & $2,00 \mathrm{E}-08$ & $2,00 \mathrm{E}-08$ & $1,00 \mathrm{E}-08$ & $1,00 \mathrm{E}-08$ & $0,00 \mathrm{E}+00$ & $0,00 \mathrm{E}+00$ & $1,00 \mathrm{E}-08$ \\
\hline & Node 7 & $5,24 \mathrm{E}-06$ & $5,24 \mathrm{E}-06$ & $5,23 \mathrm{E}-06$ & $5,22 \mathrm{E}-06$ & $5,21 \mathrm{E}-06$ & $5,20 \mathrm{E}-06$ & $5,19 \mathrm{E}-06$ \\
\hline & Node 8 & $1,19 \mathrm{E}-05$ & $1,19 \mathrm{E}-05$ & $1,19 \mathrm{E}-05$ & $1,19 \mathrm{E}-05$ & $1,18 \mathrm{E}-05$ & $1,18 \mathrm{E}-05$ & $1,18 \mathrm{E}-05$ \\
\hline & Node 9 & $2,15 \mathrm{E}-04$ & $2,14 \mathrm{E}-04$ & $2,12 \mathrm{E}-04$ & $2,11 \mathrm{E}-04$ & $2,10 \mathrm{E}-04$ & $2,08 \mathrm{E}-04$ & 2,07E-04 \\
\hline & Node 10 & 4,93E-06 & 4,91E-06 & $4,88 \mathrm{E}-06$ & $4,85 \mathrm{E}-06$ & $4,82 \mathrm{E}-06$ & $4,80 \mathrm{E}-06$ & 4,77E-06 \\
\hline & Node 11 & $7,07 \mathrm{E}-05$ & $7,03 \mathrm{E}-05$ & $7,00 \mathrm{E}-05$ & $6,96 \mathrm{E}-05$ & 6,91E-05 & $6,87 \mathrm{E}-05$ & $6,82 \mathrm{E}-05$ \\
\hline & Node 12 & 2,01E-04 & 1,99E-04 & $1,98 \mathrm{E}-04$ & $1,97 \mathrm{E}-04$ & $1,95 \mathrm{E}-04$ & $1,93 \mathrm{E}-04$ & $1,92 \mathrm{E}-04$ \\
\hline & Node 13 & $1,00 \mathrm{E}-08$ & $1,00 \mathrm{E}-08$ & $1,00 \mathrm{E}-08$ & $1,00 \mathrm{E}-08$ & $1,00 \mathrm{E}-08$ & $1,00 \mathrm{E}-08$ & $1,00 \mathrm{E}-08$ \\
\hline & Node 14 & $1,70 \mathrm{E}-07$ & $1,70 \mathrm{E}-07$ & $1,70 \mathrm{E}-07$ & $1,70 \mathrm{E}-07$ & $1,70 \mathrm{E}-07$ & $1,70 \mathrm{E}-07$ & $1,70 \mathrm{E}-07$ \\
\hline & Node 15 & $5,00 \mathrm{E}-08$ & $5,00 \mathrm{E}-08$ & $5,00 \mathrm{E}-08$ & $5,00 \mathrm{E}-08$ & $5,00 \mathrm{E}-08$ & $6,00 \mathrm{E}-08$ & $6,00 \mathrm{E}-08$ \\
\hline & Node 16 & $0,00 \mathrm{E}+00$ & $0,00 \mathrm{E}+00$ & $0,00 \mathrm{E}+00$ & $0,00 \mathrm{E}+00$ & $0,00 \mathrm{E}+00$ & $0,00 \mathrm{E}+00$ & $0,00 \mathrm{E}+00$ \\
\hline & Node 17 & $6,00 \mathrm{E}-08$ & $6,00 \mathrm{E}-08$ & $6,00 \mathrm{E}-08$ & $6,00 \mathrm{E}-08$ & $6,00 \mathrm{E}-08$ & $6,00 \mathrm{E}-08$ & $6,00 \mathrm{E}-08$ \\
\hline & Node 18 & $2,00 \mathrm{E}-08$ & $2,00 \mathrm{E}-08$ & $2,00 \mathrm{E}-08$ & $2,00 \mathrm{E}-08$ & $2,00 \mathrm{E}-08$ & $2,00 \mathrm{E}-08$ & $2,00 \mathrm{E}-08$ \\
\hline & Node 19 & $0,00 \mathrm{E}+00$ & $0,00 \mathrm{E}+00$ & $0,00 \mathrm{E}+00$ & $0,00 \mathrm{E}+00$ & $0,00 \mathrm{E}+00$ & $0,00 \mathrm{E}+00$ & $0,00 \mathrm{E}+00$ \\
\hline & Node 20 & $9,00 \mathrm{E}-08$ & $9,00 \mathrm{E}-08$ & $9,00 \mathrm{E}-08$ & $9,00 \mathrm{E}-08$ & $9,00 \mathrm{E}-08$ & $9,00 \mathrm{E}-08$ & $9,00 \mathrm{E}-08$ \\
\hline & Node 21 & $3,00 \mathrm{E}-08$ & $3,00 \mathrm{E}-08$ & $3,00 \mathrm{E}-08$ & $3,00 \mathrm{E}-08$ & $3,00 \mathrm{E}-08$ & $3,00 \mathrm{E}-08$ & $3,00 \mathrm{E}-08$ \\
\hline $\begin{array}{l}\text { Objective } \\
\text { function }\end{array}$ & $q(x)$ & $5,26 \mathrm{E}-04$ & $5,23 \mathrm{E}-04$ & $5,20 \mathrm{E}-04$ & $5,17 \mathrm{E}-04$ & $5,13 \mathrm{E}-04$ & $5,10 \mathrm{E}-04$ & $5,06 \mathrm{E}-04$ \\
\hline
\end{tabular}

Table A19-Variable values, obtained nodal deflections, and objective function for the PXY variable analysis (tubular beam model) 


\section{A2.1.2.6 DNS Variable}

\begin{tabular}{|c|c|c|c|c|c|c|c|c|}
\hline $\begin{array}{c}\text { Variable } \\
\text { values }\end{array}$ & LG4 & 0,021 & 0,021 & 0,021 & 0,021 & 0,021 & 0,021 & 0,021 \\
\hline & LG5 & 0,008 & 0,008 & 0,008 & 0,008 & 0,008 & 0,008 & 0,008 \\
\hline & LG6 & 0,081 & 0,081 & 0,081 & 0,081 & 0,081 & 0,081 & 0,081 \\
\hline & EX & $2,10 \mathrm{E}+11$ & $2,10 \mathrm{E}+11$ & $2,10 \mathrm{E}+11$ & $2,10 \mathrm{E}+11$ & $2,10 \mathrm{E}+11$ & $2,10 \mathrm{E}+11$ & $2,10 \mathrm{E}+11$ \\
\hline & PXY & 0,29 & 0,29 & 0,29 & 0,29 & 0,29 & 0,29 & 0,29 \\
\hline & DNS & 7860 & 7870 & 7880 & 7890 & 7900 & 7910 & 7920 \\
\hline \multirow[t]{21}{*}{$\begin{array}{c}\text { Nodal } \\
\text { deflections }\end{array}$} & Node 1 & $7,90 \mathrm{E}-07$ & 7,90E-07 & 7,90E-07 & 7,90E-07 & 7,90E-07 & 7,90E-07 & $7,90 \mathrm{E}-07$ \\
\hline & Node 2 & $5,00 \mathrm{E}-08$ & $5,00 \mathrm{E}-08$ & $5,00 \mathrm{E}-08$ & $5,00 \mathrm{E}-08$ & $5,00 \mathrm{E}-08$ & $5,00 \mathrm{E}-08$ & $5,00 \mathrm{E}-08$ \\
\hline & Node 3 & $7,00 \mathrm{E}-07$ & $7,00 \mathrm{E}-07$ & $7,00 \mathrm{E}-07$ & $7,00 \mathrm{E}-07$ & $7,00 \mathrm{E}-07$ & $7,00 \mathrm{E}-07$ & $7,00 \mathrm{E}-07$ \\
\hline & Node 4 & $2,57 \mathrm{E}-06$ & $2,57 \mathrm{E}-06$ & $2,57 \mathrm{E}-06$ & $2,57 \mathrm{E}-06$ & $2,57 \mathrm{E}-06$ & $2,57 \mathrm{E}-06$ & $2,57 \mathrm{E}-06$ \\
\hline & Node 5 & $1,30 \mathrm{E}-05$ & $1,30 \mathrm{E}-05$ & $1,30 \mathrm{E}-05$ & $1,30 \mathrm{E}-05$ & $1,30 \mathrm{E}-05$ & $1,30 \mathrm{E}-05$ & $1,30 \mathrm{E}-05$ \\
\hline & Node 6 & $1,00 \mathrm{E}-08$ & $1,00 \mathrm{E}-08$ & $1,00 \mathrm{E}-08$ & $1,00 \mathrm{E}-08$ & $1,00 \mathrm{E}-08$ & $1,00 \mathrm{E}-08$ & $1,00 \mathrm{E}-08$ \\
\hline & Node 7 & $5,22 \mathrm{E}-06$ & $5,22 \mathrm{E}-06$ & $5,22 \mathrm{E}-06$ & $5,22 \mathrm{E}-06$ & $5,22 \mathrm{E}-06$ & $5,22 \mathrm{E}-06$ & $5,22 \mathrm{E}-06$ \\
\hline & Node 8 & $1,19 \mathrm{E}-05$ & $1,19 \mathrm{E}-05$ & $1,19 \mathrm{E}-05$ & $1,19 \mathrm{E}-05$ & $1,19 \mathrm{E}-05$ & $1,19 \mathrm{E}-05$ & $1,19 \mathrm{E}-05$ \\
\hline & Node 9 & $2,11 \mathrm{E}-04$ & $2,11 \mathrm{E}-04$ & $2,11 \mathrm{E}-04$ & $2,11 \mathrm{E}-04$ & $2,11 \mathrm{E}-04$ & $2,11 \mathrm{E}-04$ & $2,11 \mathrm{E}-04$ \\
\hline & Node 10 & $4,85 \mathrm{E}-06$ & $4,85 \mathrm{E}-06$ & $4,85 \mathrm{E}-06$ & $4,85 \mathrm{E}-06$ & $4,85 \mathrm{E}-06$ & $4,85 \mathrm{E}-06$ & $4,85 \mathrm{E}-06$ \\
\hline & Node 11 & $6,96 \mathrm{E}-05$ & $6,96 \mathrm{E}-05$ & $6,96 \mathrm{E}-05$ & $6,96 \mathrm{E}-05$ & $6,96 \mathrm{E}-05$ & $6,96 \mathrm{E}-05$ & $6,96 \mathrm{E}-05$ \\
\hline & Node 12 & $1,97 \mathrm{E}-04$ & $1,97 \mathrm{E}-04$ & $1,97 \mathrm{E}-04$ & $1,97 \mathrm{E}-04$ & $1,97 \mathrm{E}-04$ & $1,97 \mathrm{E}-04$ & $1,97 \mathrm{E}-04$ \\
\hline & Node 13 & $1,00 \mathrm{E}-08$ & $1,00 \mathrm{E}-08$ & $1,00 \mathrm{E}-08$ & $1,00 \mathrm{E}-08$ & $1,00 \mathrm{E}-08$ & $1,00 \mathrm{E}-08$ & $1,00 \mathrm{E}-08$ \\
\hline & Node 14 & $1,70 \mathrm{E}-07$ & $1,70 \mathrm{E}-07$ & $1,70 \mathrm{E}-07$ & $1,70 \mathrm{E}-07$ & $1,70 \mathrm{E}-07$ & $1,70 \mathrm{E}-07$ & $1,70 \mathrm{E}-07$ \\
\hline & Node 15 & $5,00 \mathrm{E}-08$ & $5,00 \mathrm{E}-08$ & $5,00 \mathrm{E}-08$ & $5,00 \mathrm{E}-08$ & $5,00 \mathrm{E}-08$ & $5,00 \mathrm{E}-08$ & $5,00 \mathrm{E}-08$ \\
\hline & Node 16 & $0,00 \mathrm{E}+00$ & $0,00 \mathrm{E}+00$ & $0,00 \mathrm{E}+00$ & $0,00 \mathrm{E}+00$ & $0,00 \mathrm{E}+00$ & $0,00 \mathrm{E}+00$ & $0,00 \mathrm{E}+00$ \\
\hline & Node 17 & $6,00 \mathrm{E}-08$ & $6,00 \mathrm{E}-08$ & $6,00 \mathrm{E}-08$ & $6,00 \mathrm{E}-08$ & $6,00 \mathrm{E}-08$ & $6,00 \mathrm{E}-08$ & $6,00 \mathrm{E}-08$ \\
\hline & Node 18 & $2,00 \mathrm{E}-08$ & $2,00 \mathrm{E}-08$ & $2,00 \mathrm{E}-08$ & $2,00 \mathrm{E}-08$ & $2,00 \mathrm{E}-08$ & $2,00 \mathrm{E}-08$ & $2,00 \mathrm{E}-08$ \\
\hline & Node 19 & $0,00 \mathrm{E}+00$ & $0,00 \mathrm{E}+00$ & $0,00 \mathrm{E}+00$ & $0,00 \mathrm{E}+00$ & $0,00 \mathrm{E}+00$ & $0,00 \mathrm{E}+00$ & $0,00 \mathrm{E}+00$ \\
\hline & Node 20 & $9,00 \mathrm{E}-08$ & $9,00 \mathrm{E}-08$ & $9,00 \mathrm{E}-08$ & $9,00 \mathrm{E}-08$ & $9,00 \mathrm{E}-08$ & $9,00 \mathrm{E}-08$ & $9,00 \mathrm{E}-08$ \\
\hline & Node 21 & $3,00 \mathrm{E}-08$ & $3,00 \mathrm{E}-08$ & $3,00 \mathrm{E}-08$ & $3,00 \mathrm{E}-08$ & $3,00 \mathrm{E}-08$ & $3,00 \mathrm{E}-08$ & $3,00 \mathrm{E}-08$ \\
\hline $\begin{array}{l}\text { Objective } \\
\text { function }\end{array}$ & $q(x)$ & $5,17 \mathrm{E}-04$ & $5,17 \mathrm{E}-04$ & $5,17 \mathrm{E}-04$ & $5,17 \mathrm{E}-04$ & $5,17 \mathrm{E}-04$ & $5,17 \mathrm{E}-04$ & $5,17 \mathrm{E}-04$ \\
\hline
\end{tabular}

Table A20-Variable values, obtained nodal deflections, and objective function for the DNS variable analysis (tubular beam model) 


\section{A2.2 Variable Analysis Charts}

\section{A2.2.1 Model 1: Ribbed plate}

\section{LG1 variable}

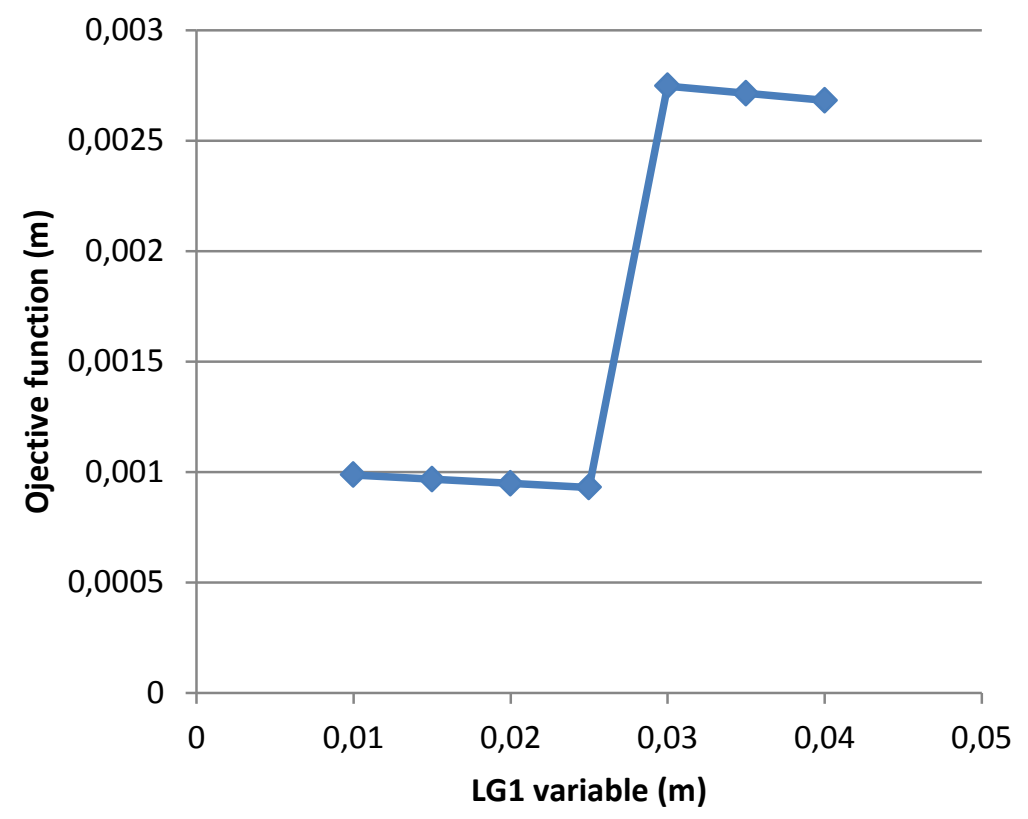

Fig. A9-q(x)=f(LG1) chart for the model 1

\section{LG2 variable}

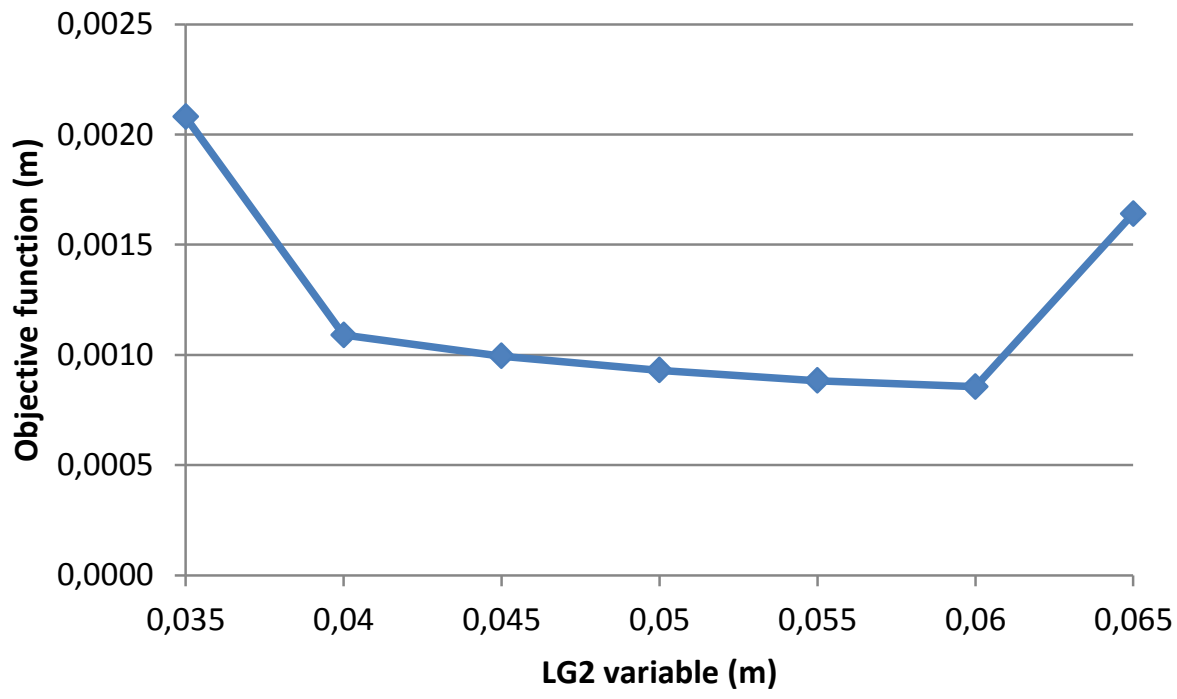

Fig. A10-q(x)=f(LG2) chart for the model 


\section{LG3 variable}

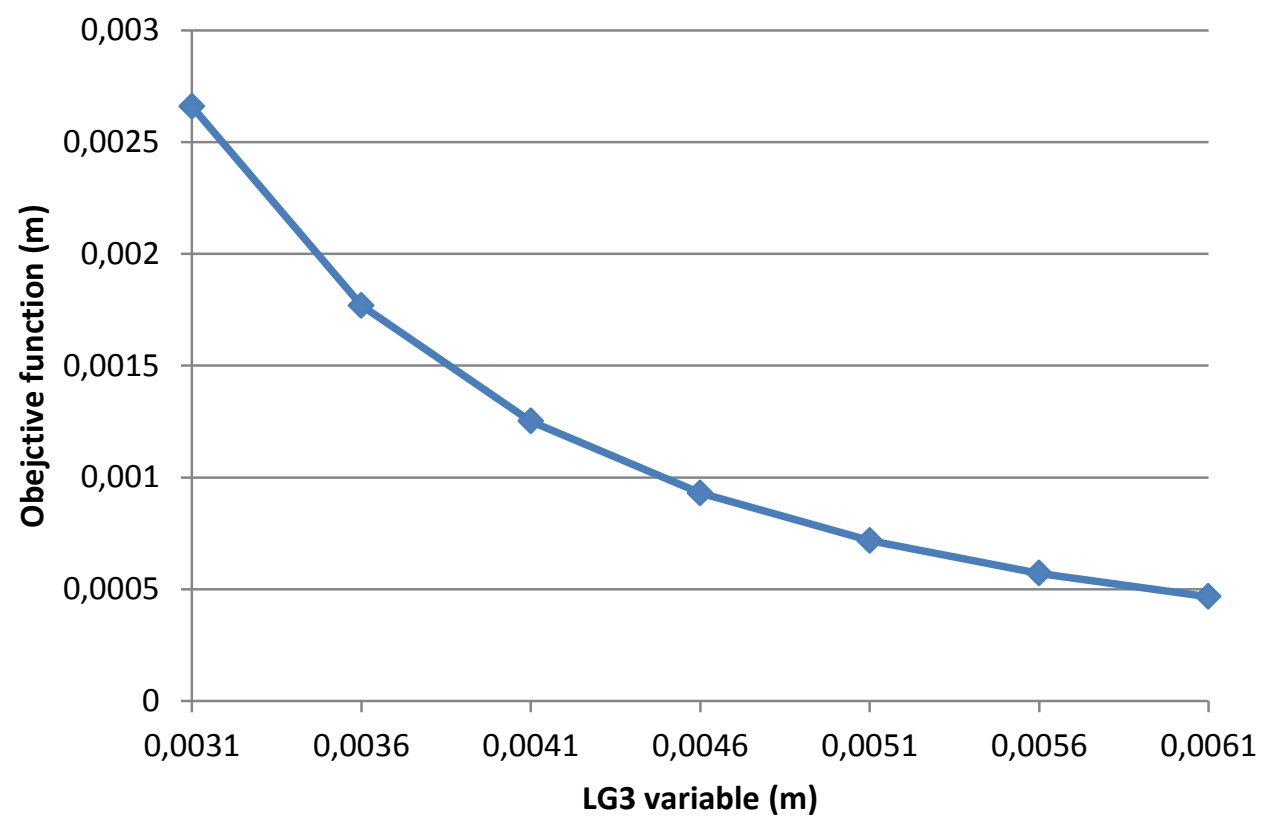

Fig. A11-q(x)=f(LG3) chart for the model 1

\section{EX variable}



Fig. $A 12-q(x)=f(E X)$ chart for the model 1 


\section{PXY variable}

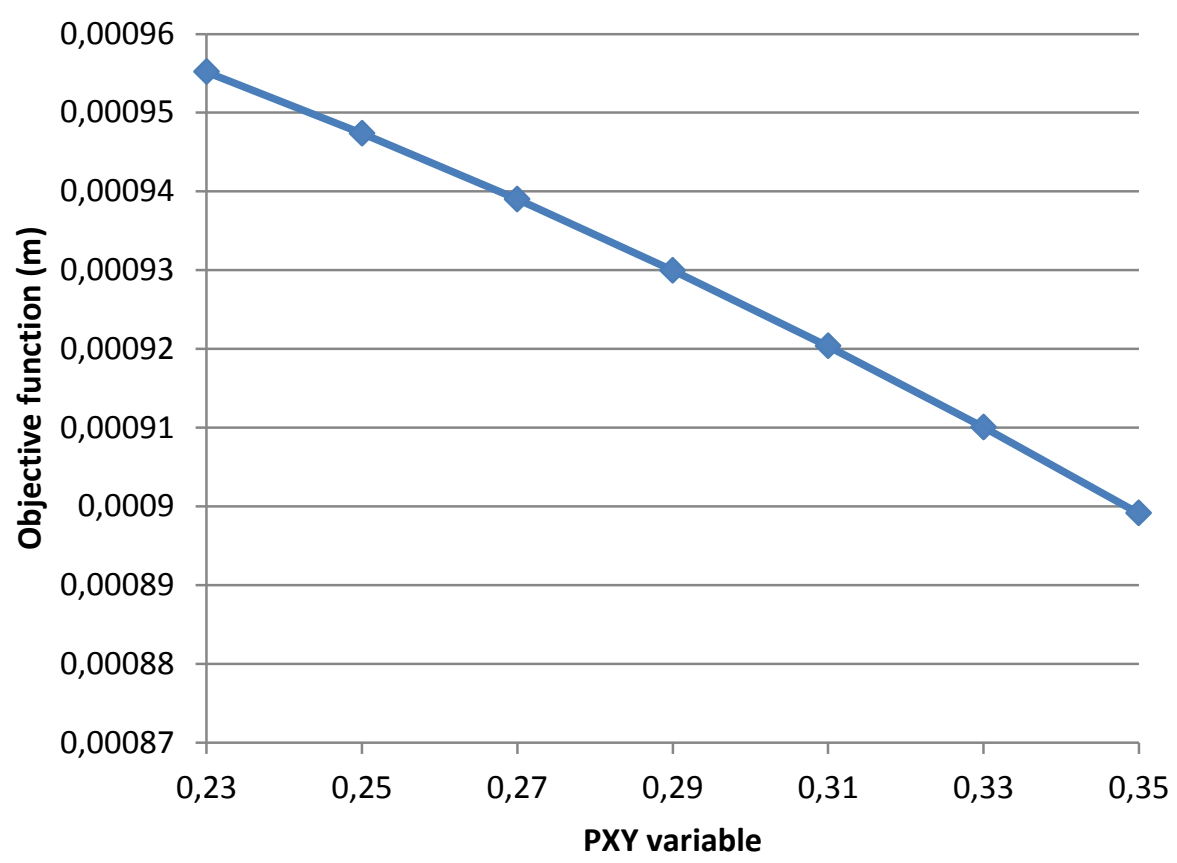

Fig. A13-q(x)=f(PXY) chart for the model 1

\section{DNS variable}

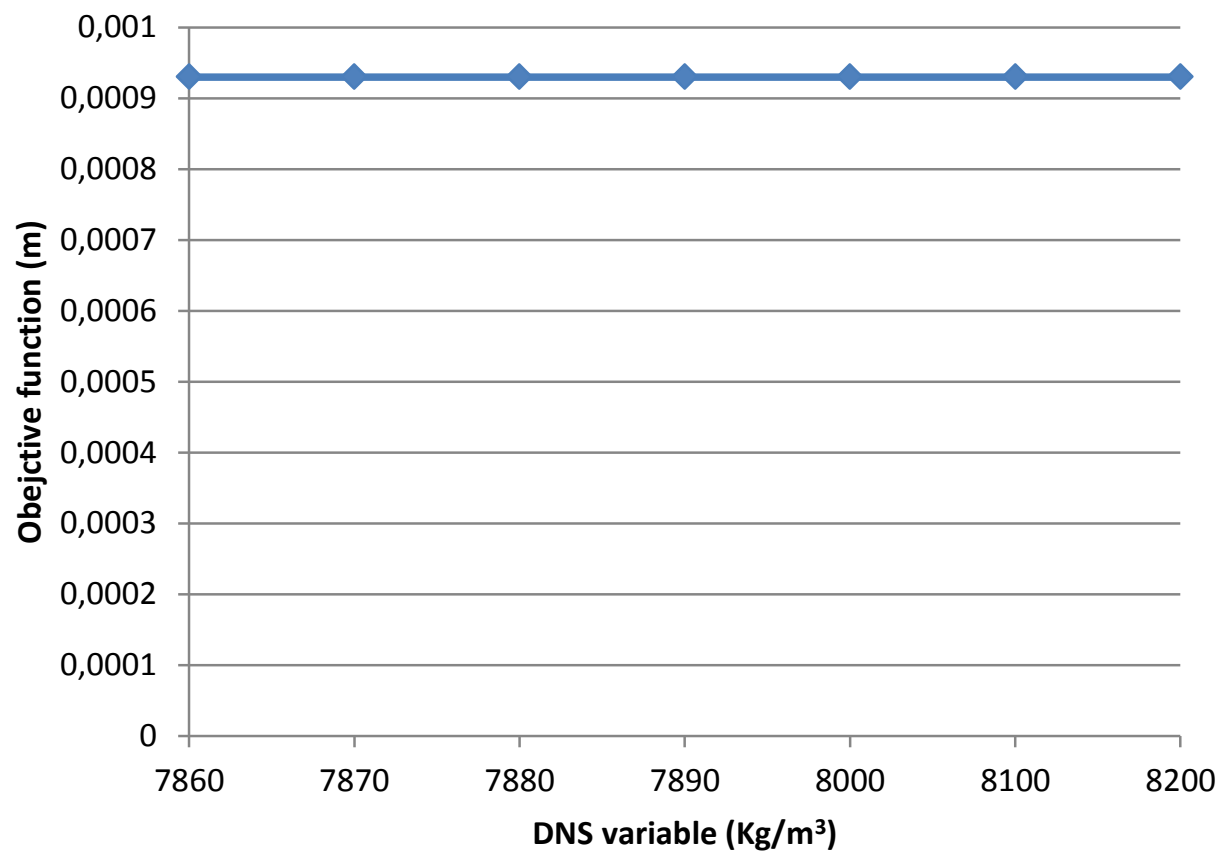

Fig. A14- $q(x)=f(D N S)$ chart for the model 1 


\section{A2.2.2 Model 2: tubular beam}

\section{LG4 variable}

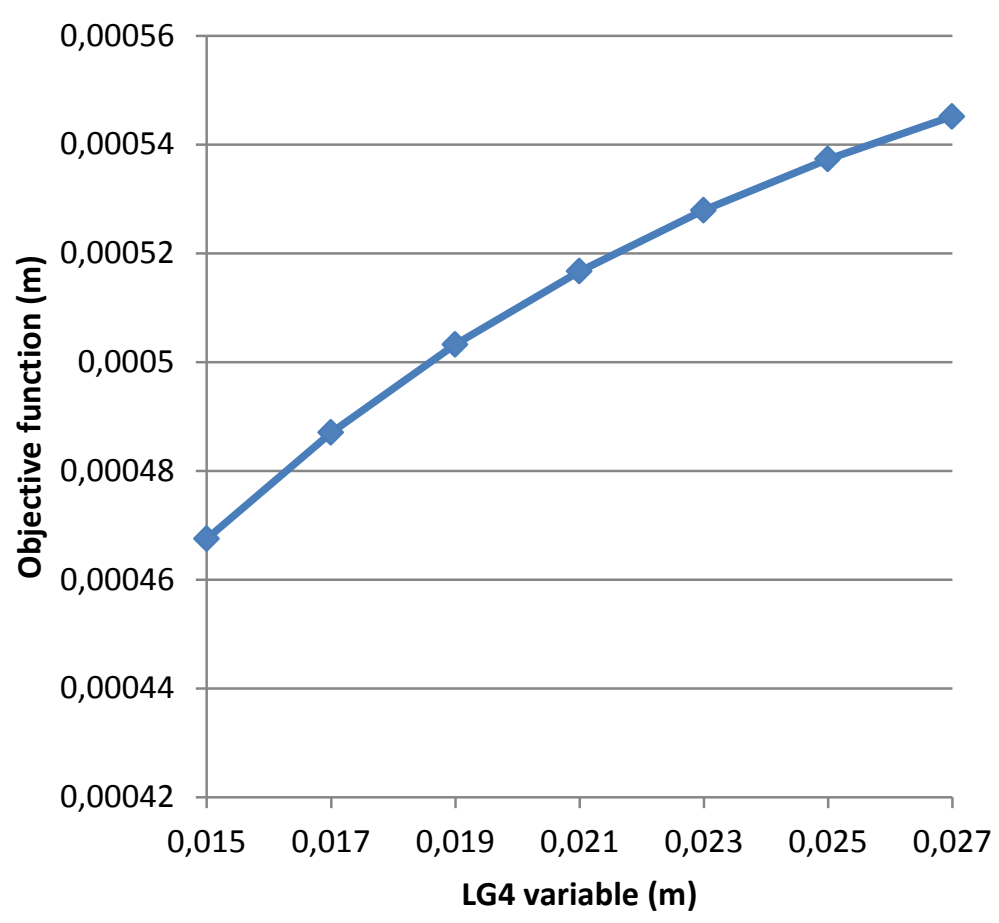

Fig. $A 15-q(x)=f(L G 4)$ chart for the model 2

\section{LG5 variable}

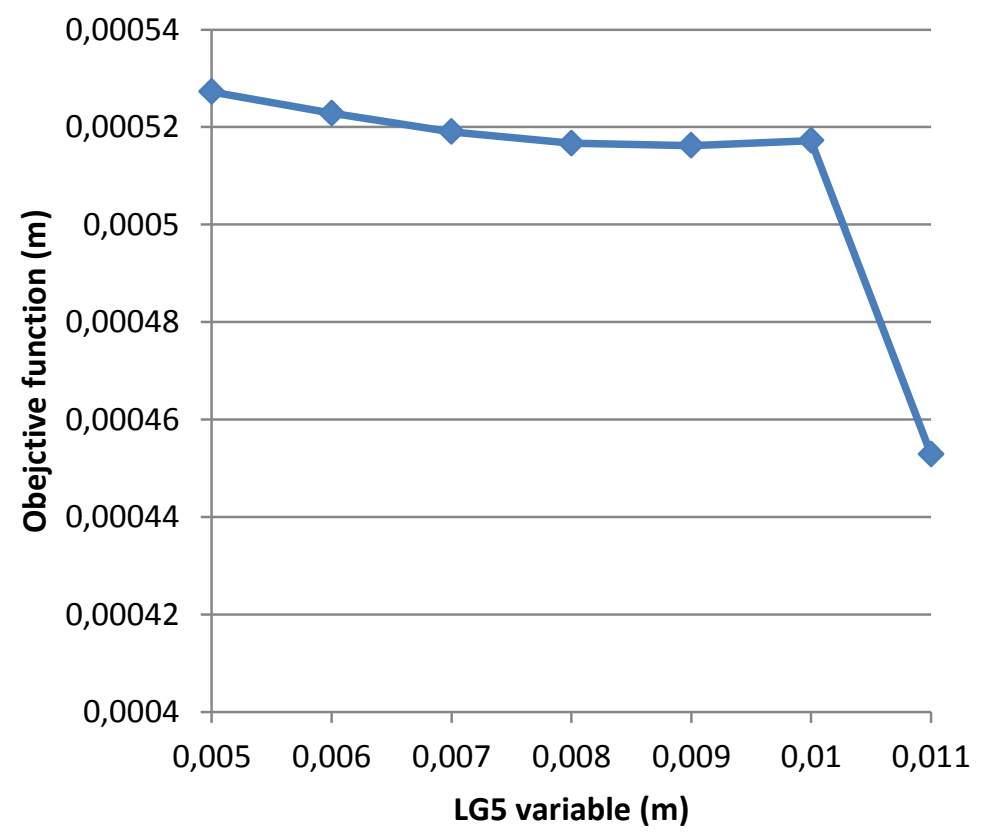

Fig. A16-q(x)=f(LG5) chart for the model 2 


\section{LG6 variable}

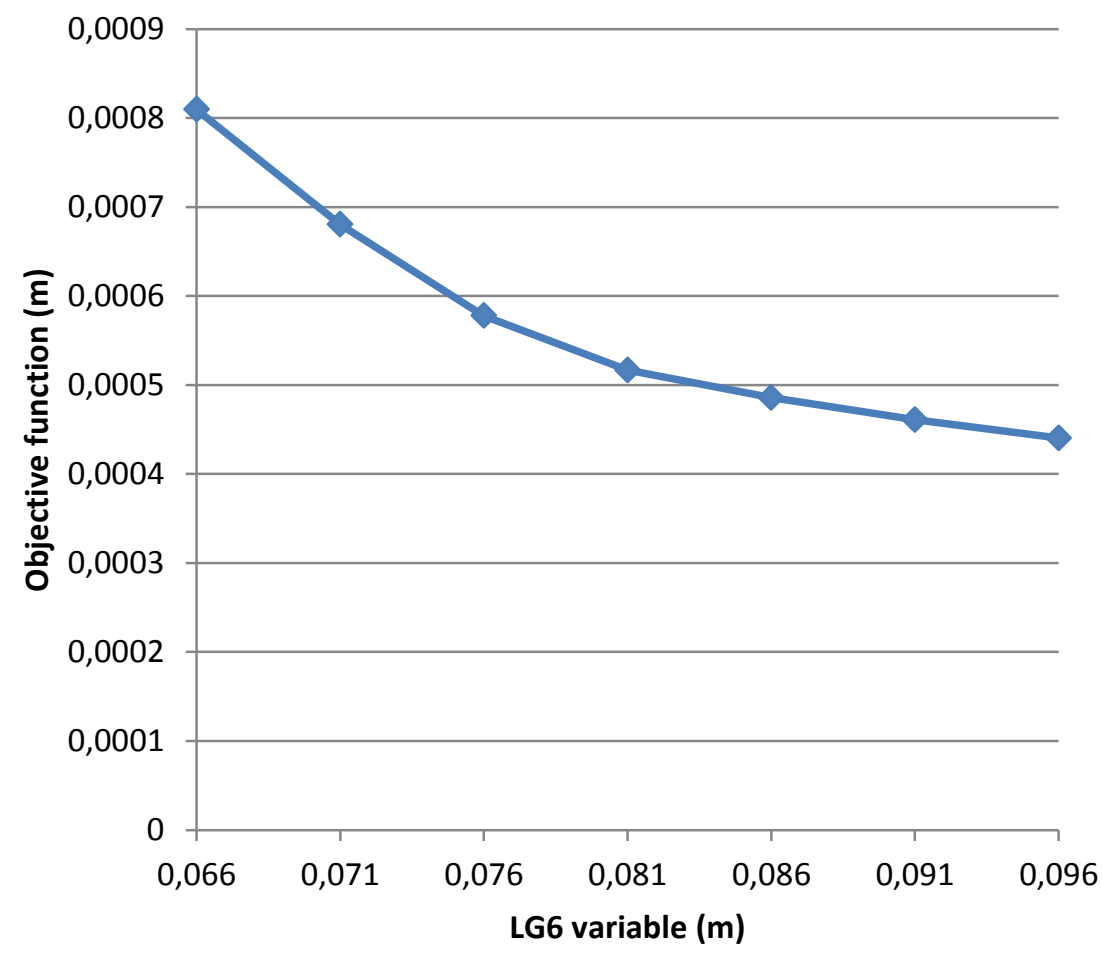

Fig. A17-q(x)=f(LG6) chart for the model 2

\section{EX variable}

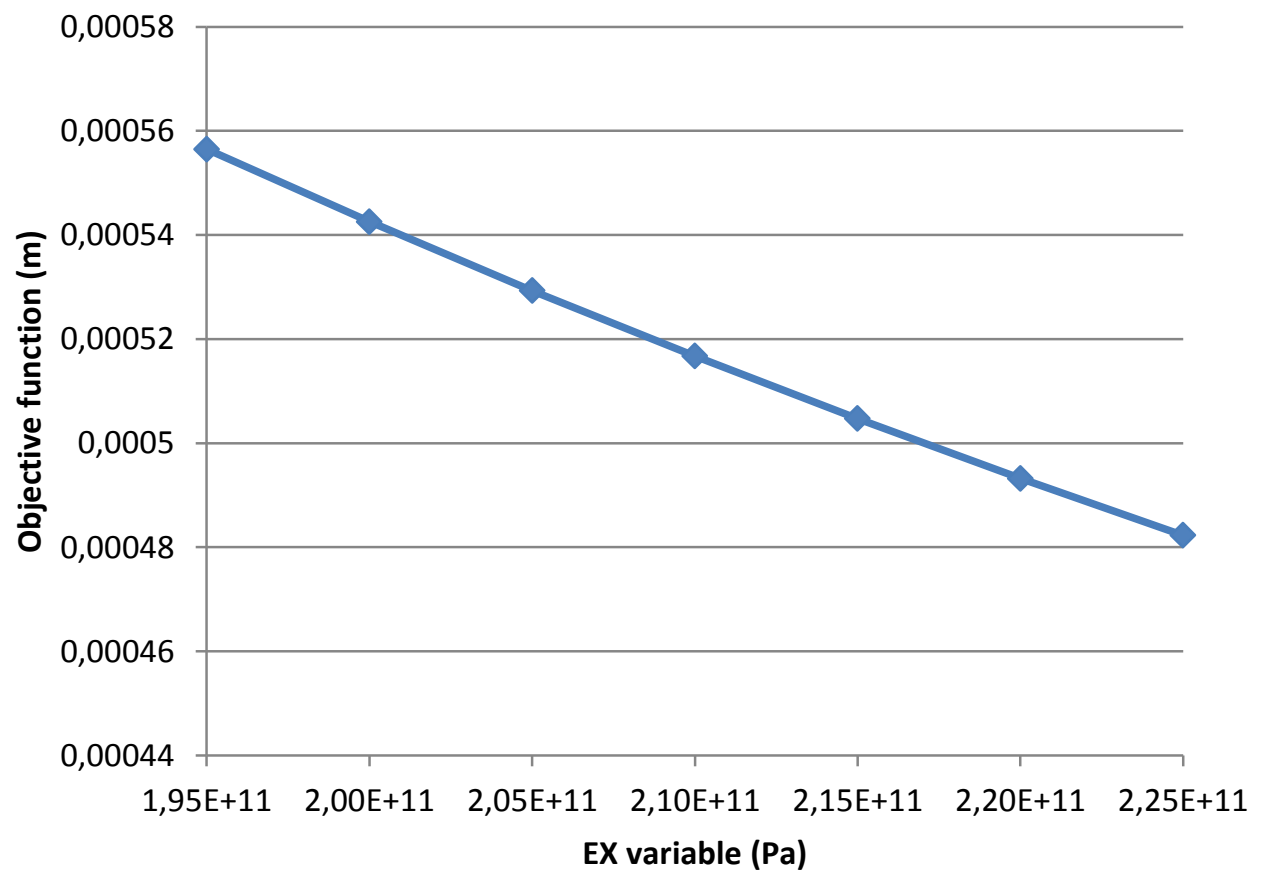

Fig. A18-q(x)=f(EX) chart for the model 2 


\section{PXY variable}

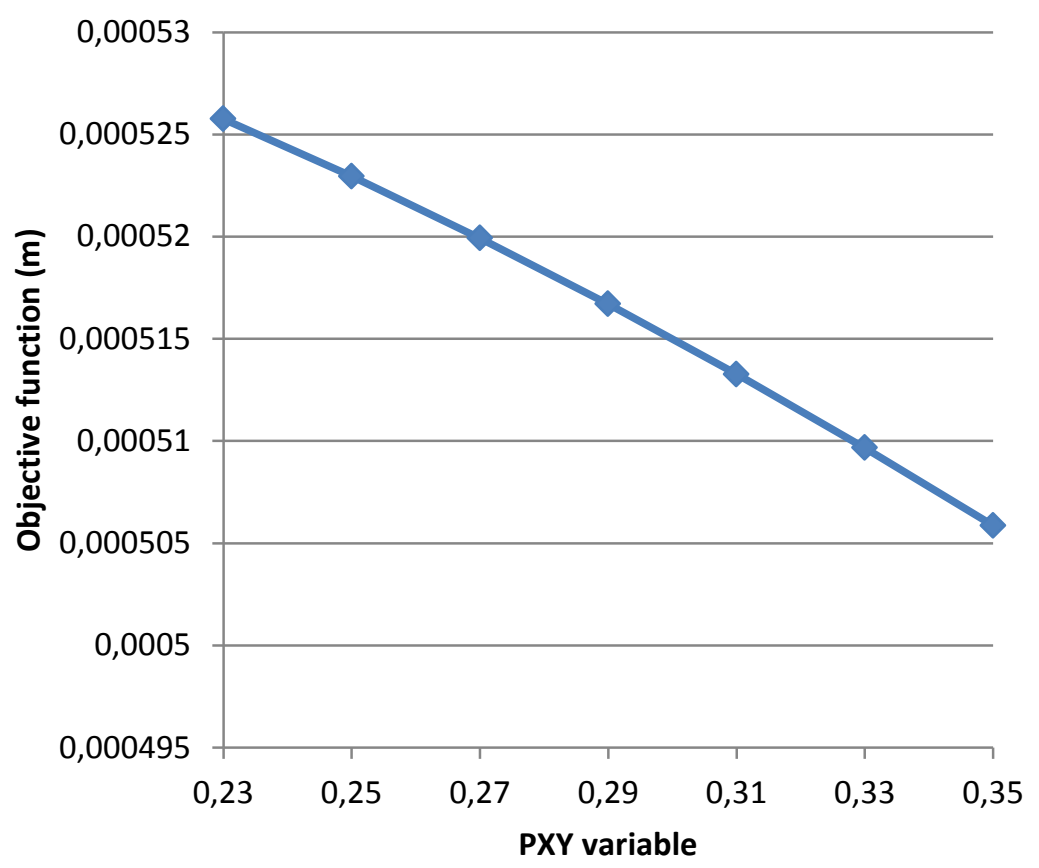

Fig. A19-q $(x)=f(P X Y)$ chart for the model 2

\section{DNS variable}

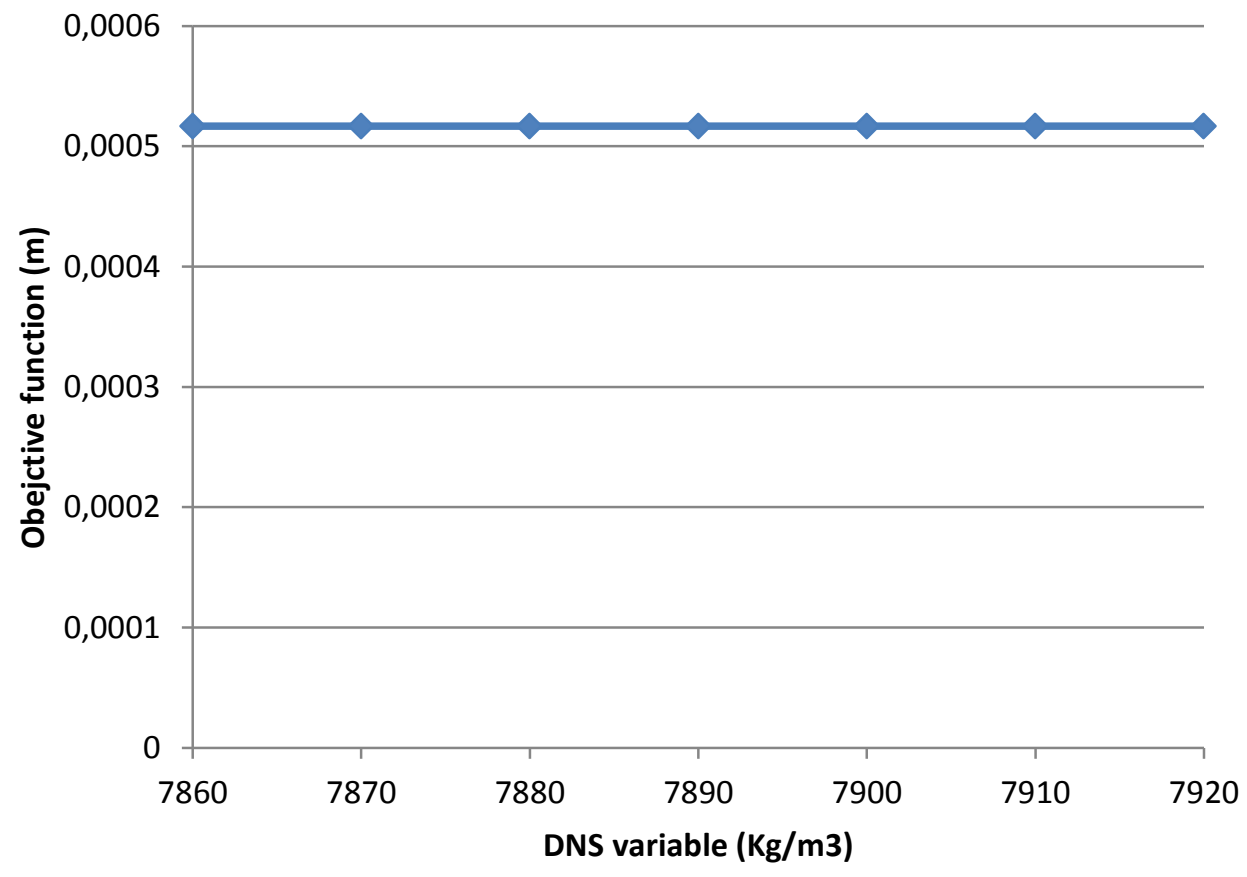

Fig. $A 20-q(x)=f(D N S)$ chart for the model 2 
ANNEX 3-FINITE ELEMENT MODEL FILES 


\section{A3.1-Model 1: ribbed plate}

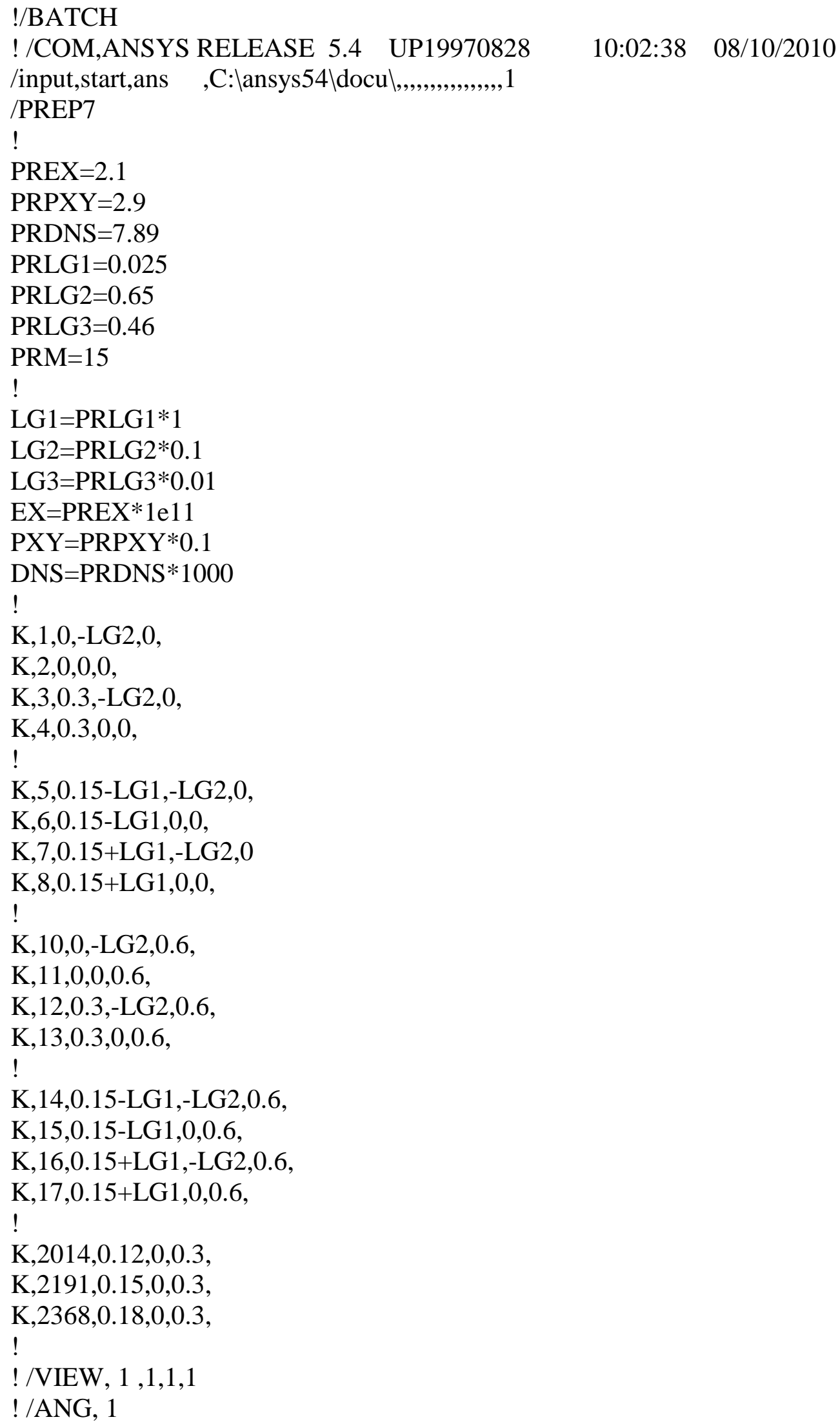




\section{! /REP,FAST}

$\mathrm{K}, 3000,0.12,0,0.6$,

$\mathrm{K}, 4000,0.15,0,0.6$,

$\mathrm{K}, 5000,0.18,0,0.6$,

$\mathrm{K}, 6000,0.12,0,0$,

!

$\mathrm{K}, 7000,0.15,0,0$,

$\mathrm{K}, 8000,0.18,0,0$,

! /VIEW, $1,1,1,1$

! /ANG, 1

! /REP,FAST

$\mathrm{K}, 9000,0.3,0,0.3$,

$\mathrm{K}, 10000,0.15+\mathrm{LG} 1,0,0.3$,

!

$\mathrm{K}, 11000,0,0,0.3$,

$\mathrm{K}, 12000,0.15-\mathrm{LG} 1,0,0.3$,

$\mathrm{K}, 13000,0.15+\mathrm{LG} 1,-\mathrm{LG} 2,0.3$,

K, 14000,0.15-LG1,-LG2,0.3,

!

$\mathrm{K}, 15000,0,-\mathrm{LG} 2,0.3$,

$\mathrm{K}, 16000,0.3,-\mathrm{LG} 2,0.3$,

!

! /REPLOT

! /AUTO, 1

! /REP

! /AUTO, 1

! /REP

! /AUTO, 1

! /REP

! klist,all,,,coord

LSTR, 14, 15

LSTR, 15， 12000

LSTR，12000， 6

LSTR， 2, 11000

LSTR, 11000, 11

LSTR, 11, 10

LSTR, 10, 1

LSTR, 5, 14

LSTR, 5, 6

LSTR, 1, 2

LSTR， 3000， 2014

LSTR， 2014， 6000

LSTR， 7000， 2191

LSTR， 2191， 4000

LSTR， 5000， 2368

LSTR， 2368， 8000

LSTR， 4，9000

LSTR，9000， 13

LSTR, 13, 12 
LSTR, $12, \quad 3$

LSTR, 3, 4

LSTR, 8, 10000

LSTR, 10000, 17

LSTR, $17, \quad 16$

LSTR, 16, 7

LSTR, $7, \quad 8$

LSTR, $8, \quad 4$

LSTR, 10000, 9000

LSTR， 4, 8000

LSTR， 8000， 7000

LSTR， 7000， 6000

LSTR, 6000, 2

LSTR, 2, 6

LSTR，12000， 11000

LSTR, 11000, 2014

LSTR， 2014， 2191

LSTR， 2191， 2368

LSTR， 2368， 9000

LSTR, 17, 13

LSTR, 13， 5000

LSTR， 5000， 4000

LSTR， 4000， 3000

LSTR, 3000, 11

LSTR, $11, \quad 15$

LSTR，10000， 13000

LSTR, 12000, 14000

FLST,2,4,4,ORDE,4

FITEM,2,7

FITEM,2,-8

FITEM,2,20

FITEM,2,25

LDELE,P51X

! /REPLOT

GPLOT

LSTR，15000， 11000

LSTR, 16000, 9000

LSTR, 13000, 16

LSTR， 16000, 12

LSTR, 7，13000

LSTR, 3, 16000

LSTR, 1， 15000

LSTR, 15000, 10

LSTR, 14000, 14

LSTR, 14000, 5

FLST, 2,4,4

FITEM,2,2

FITEM,2,51

FITEM, 2,1

FITEM,2,46 
AL,P51X

FLST, 2,4,4

FITEM,2,46

FITEM,2,3

FITEM,2,9

FITEM,2,52

AL,P51X

FLST, 2,4,4

FITEM, 2,6

FITEM,2,5

FITEM,2,7

FITEM,2,50

AL,P51X

FLST, 2,4,4

FITEM,2,4

FITEM,2,10

FITEM,2,49

FITEM,2,7

AL,P51X

FLST, 2,4,4

FITEM,2,44

FITEM,2,5

FITEM,2,34

FITEM,2,2

AL,P51X

FLST, 2,4,4

FITEM,2,3

FITEM,2,33

FITEM,2,4

FITEM,2,34

AL,P51X

FLST, 2,4,4

FITEM,2,43

FITEM,2,35

FITEM,2,5

FITEM,2,11

AL,P51X

FLST, 2,4,4

FITEM,2,4

FITEM,2,32

FITEM,2,12

FITEM,2,35

AL,P51X

FLST, 2,4,4

FITEM,2,15

FITEM,2,14

FITEM,2,41

FITEM,2,37

AL,P51X

FLST, 2,4,4 
FITEM,2,36

FITEM,2,42

FITEM,2,11

FITEM,2,14

AL,P51X

FLST, $2,4,4$

FITEM,2,12

FITEM,2,31

FITEM,2,13

FITEM,2,36

AL,P51X

FLST, 2,4,4

FITEM,2,37

FITEM,2,16

FITEM,2,30

FITEM,2,13

AL,P51X

FLST, 2,4,4

FITEM,2,19

FITEM,2,25

FITEM, 2,8

FITEM,2,18

AL,P51X

FLST, 2,4,4

FITEM,2,24

FITEM,2,23

FITEM,2,45

FITEM,2,20

AL,P51X

FLST, 2,4,4

FITEM,2,8

FITEM,2,48

FITEM,2,21

FITEM,2,17

AL,P51X

FLST, 2,4,4

FITEM,2,45

FITEM,2,22

FITEM,2,26

FITEM,2,47

AL,P51X

FLST, 2,4,4

FITEM,2,39

FITEM,2,18

FITEM,2,28

FITEM,2,23

AL,P51X

FLST, 2,4,4

FITEM,2,28

FITEM,2,17 
FITEM,2,27

FITEM,2,22

AL,P51X

FLST, $2,4,4$

FITEM, 2,40

FITEM,2,38

FITEM,2,15

FITEM,2,18

AL,P51X

FLST, $2,4,4$

FITEM,2,16

FITEM,2,29

FITEM,2,17

FITEM,2,38

AL,P51X

!*

! /VIEW, $1,1,1,1$

! /ANG, 1

! /REP,FAST

!*

ET,1,SHELL63

!

R,1,LG3,LG3,LG3,LG3, , ,

RMORE, , ,

!*

!*

UIMP,1,EX, , ,EX,

UIMP,1,DENS, , ,DNS,

UIMP, 1,ALPX, , , ,

UIMP, 1,REFT, , , ,

UIMP,1,NUXY, , ,PXY,

UIMP, 1,PRXY, , , ,

UIMP,1,GXY, , , ,

UIMP, 1,MU, , , ,

UIMP, 1,DAMP, , , ,

UIMP, 1,KXX, , , ,

UIMP, $1, C$, , , ,

UIMP, 1,ENTH, , , ,

UIMP, $1, \mathrm{HF}$, , , ,

UIMP, 1,EMIS, , , ,

UIMP,1,QRATE, , , ,

UIMP, 1,RSVX, , , ,

UIMP, 1,PERX, , , ,

UIMP, 1, VISC, , , ,

UIMP, 1, SONC, , , ,

!*

TYPE, 1

MAT, 1

REAL, 1

ESYS, 0 
!*

ESIZE, 0.02,0,

MSHAPE, $0,2 \mathrm{D}$

MSHKEY,1

!*

FLST, 5, 20,5,ORDE,2

FITEM,5,1

FITEM,5,-20

CM,_Y,AREA

ASEL, , , ,P51X

CM,_Y1,AREA

CHKMSH,'AREA'

CMSEL,S,_Y

!*

AMESH,_Y1

!*

CMDEL,_Y

CMDEL,_Y1

CMDEL,_Y2

!*

FINISH

/SOLU

! KPLOT

FLST,2,1,3,ORDE, 1

FITEM,2,2191

FK,P51X,FY,-3528,

FLST, 2, 1,3,ORDE, 1

FITEM,2,2368

FK,P51X,FY,-5120,

FLST, 2, 1,3, ORDE, 1

FITEM,2,2014

FK,P51X,FY,5120,

FLST,2,16,3,ORDE,4

FITEM, 2,1

FITEM,2,-8

FITEM,2,10

FITEM,2,-17

DK,P51X, , , ,0,ALL

!

! FKLIST, ALL

! FLIST, ALL

/SOLU

FLST,2,899,1,ORDE,2

FITEM,2,1

FITEM,2,-899

FDELE,P51X,ALL

! FKLIST, ALL

!

! /STAT,SOLU 


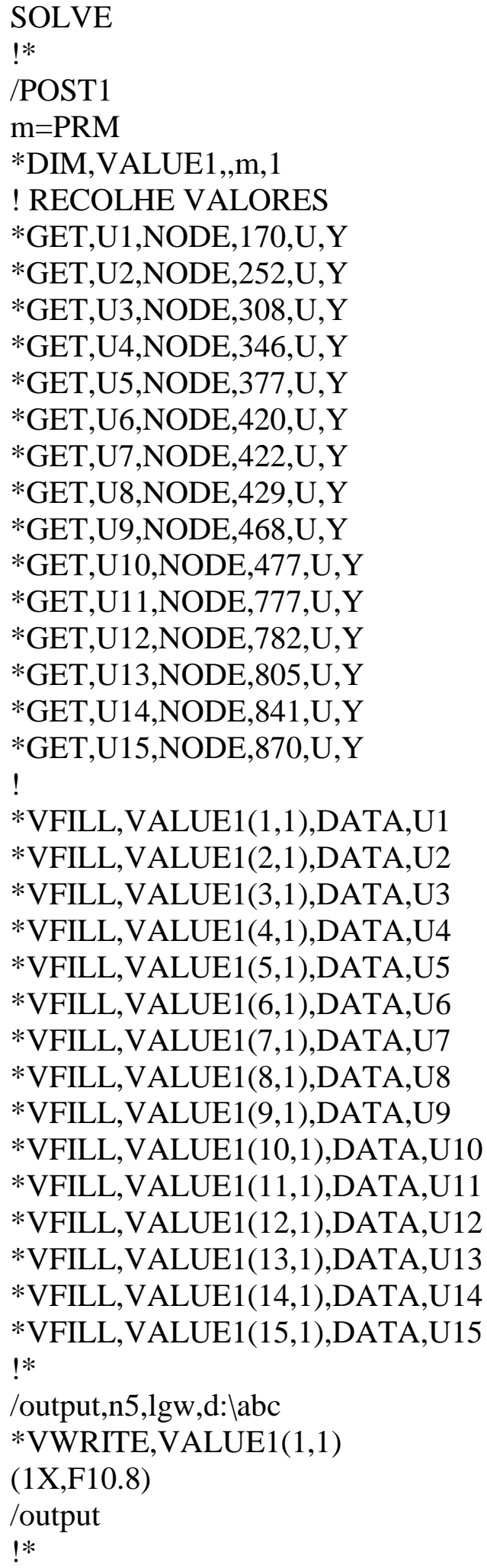




\section{A3.2-Model 2: Tubular beam}

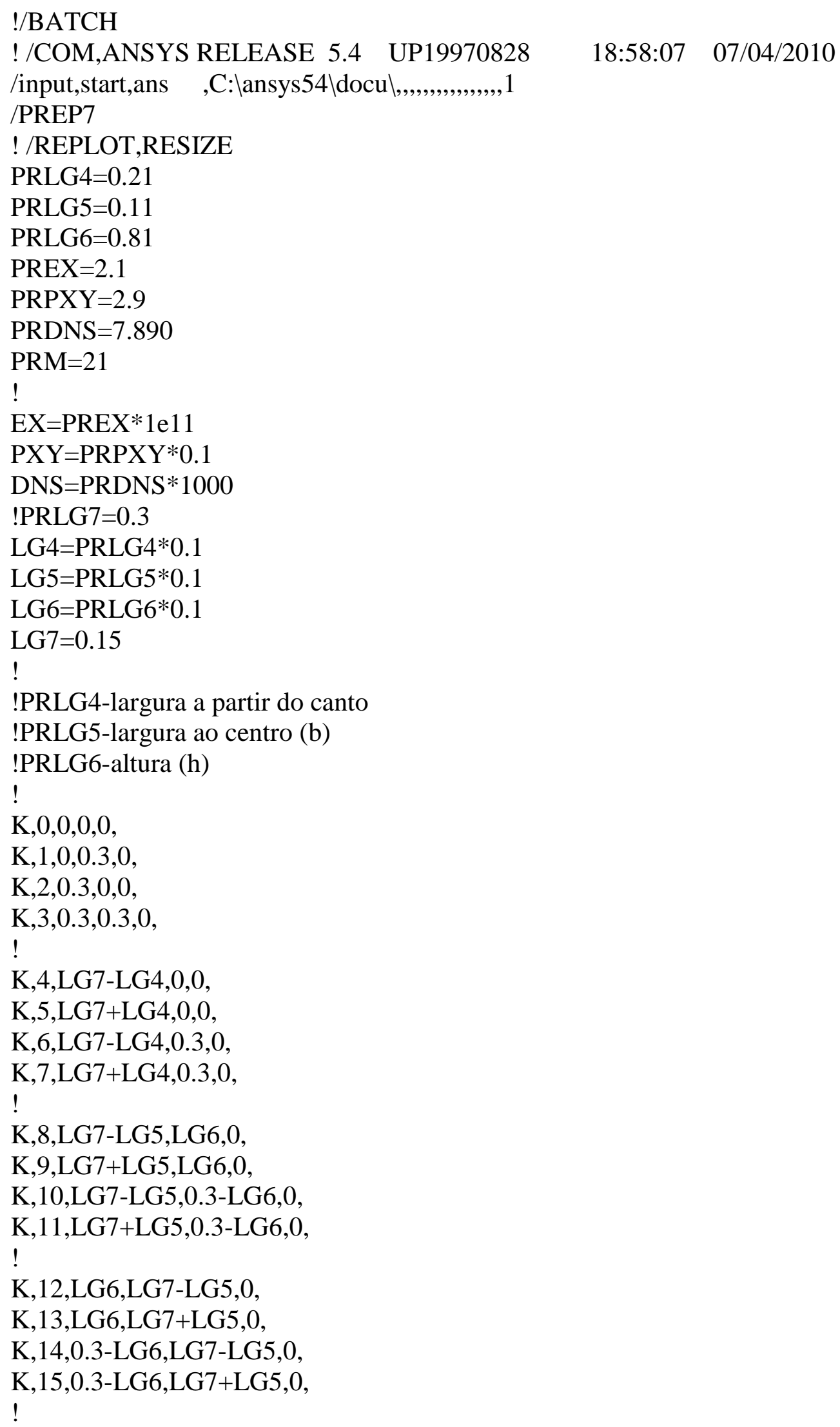


K,16,0,LG7-LG4,0,

$\mathrm{K}, 17,0.3$,LG7-LG4,0,

$\mathrm{K}, 18,0, \mathrm{LG} 7+\mathrm{LG} 4,0$,

$\mathrm{K}, 19,0.3, \mathrm{LG} 7+\mathrm{LG} 4,0$,

$\mathrm{K}, 20,0,0,0$,

!

$\mathrm{K}, 100,0,0,1$,

$\mathrm{K}, 101,0,0.3,1$,

$\mathrm{K}, 102,0.3,0,1$,

$\mathrm{K}, 103,0.3,0.3,1$,

!

K,104,LG7-LG4,0,1,

$\mathrm{K}, 105, \mathrm{LG} 7+\mathrm{LG} 4,0,1$,

K, 106,LG7-LG4,0.3,1,

$\mathrm{K}, 107, \mathrm{LG} 7+\mathrm{LG} 4,0.3,1$,

!

K,108,LG7-LG5,LG6,1,

K,109,LG7+LG5,LG6,1,

K,110,LG7-LG5,0.3-LG6,1,

K,111,LG7+LG5,0.3-LG6,1,

!

K,112,LG6,LG7-LG5,1,

K,113,LG6,LG7+LG5,1,

K,114,0.3-LG6,LG7-LG5,1,

K,115,0.3-LG6,LG7+LG5,1,

!

K,116,0,LG7-LG4,1,

K, 117,0.3,LG7-LG4,1,

$\mathrm{K}, 118,0, \mathrm{LG} 7+\mathrm{LG} 4,1$,

$\mathrm{K}, 119,0.3, \mathrm{LG} 7+\mathrm{LG} 4,1$,

!

$\mathrm{K}, 1000,0.15,0.3-\mathrm{LG} 6,0$,

K,2000,0.15,0.3-LG6,1,

K,3000,LG7-LG5,0.3-LG6,0.5,

K,4000,0.15,0.3-LG6,0.5,

!

K,5000,LG7+LG5,0.3-LG6,0.5,

$\mathrm{K}, 6000,0,0,0.5$,

$\mathrm{K}, 7000,0,0.3,0.5$,

$\mathrm{K}, 8000,0.3,0,0.5$,

!

$\mathrm{K}, 9000,0.3,0.3,0.5$,

K, 10000,LG7-LG4,0,0.5,

$\mathrm{K}, 11000$,LG7+LG4,0,0.5,

K, 12000,LG7-LG4,0.3,0.5,

!

K,13000,LG7+LG4,0.3,0.5,

K,14000,LG7-LG5,LG6,0.5,

K,15000,LG7+LG5,LG6,0.5,

K,16000,LG6,LG7-LG5,0.5, 
!

K,17000,LG6,LG7+LG5,0.5,

K,18000,0.3-LG6,LG7-LG5,0.5,

K,19000,0.3-LG6,LG7+LG5,0.5,

K,20000,0,LG7-LG4,0.5,

1

K,21000,0.3,LG7-LG4,0.5,

$\mathrm{K}, 22000,0.3, \mathrm{LG} 7+\mathrm{LG} 4,0.5$,

$\mathrm{K}, 23000,0, \mathrm{LG} 7+\mathrm{LG} 4,0.5$,

!

! /VIEW, $1,1,1,1$

! /ANG, 1

! /REP,FAST

LSTR, 101, 118

LSTR, 118, 113

LSTR, 113, 112

LSTR, 112, 116

LSTR, 116, 100

LSTR, 100, 104

LSTR, 104, 108

LSTR, 108, 109

LSTR， 109， 105

LSTR, 105, 102

LSTR, 102, 117

LSTR, 117, 114

LSTR, 114, 115

LSTR, 115, 119

LSTR, 119, 103

LSTR, 103, 107

LSTR, 107, 111

LSTR， 111， 2000

LSTR，2000， 110

LSTR, 110， 106

LSTR, 106, 101

LSTR，7000， 23000

LSTR，23000， 17000

LSTR, 17000, 16000

LSTR, 16000, 20000

LSTR，20000， 6000

LSTR， 6000， 10000

LSTR, 10000, 14000

LSTR，14000， 15000

LSTR，15000， 11000

LSTR, 11000, 8000

LSTR， 8000， 21000

LSTR，21000， 18000

LSTR，18000, 19000

LSTR，19000， 22000

LSTR，22000， 9000

LSTR, 9000, 13000 
LSTR， 13000， 5000

LSTR, 5000， 4000

LSTR, 4000, 3000

LSTR, 3000, 12000

LSTR, 12000, 7000

LSTR, $\quad 1, \quad 18$

LSTR, 18, 13

LSTR, $13, \quad 12$

LSTR, $12, \quad 16$

LSTR, $\quad 16, \quad 20$

LSTR, 20, 4

LSTR, 4, 8

LSTR, $\quad 8, \quad 9$

LSTR, 9, 5

LSTR, 5, 2

LSTR, 2, 17

LSTR, 17, 14

LSTR, $\quad 14, \quad 15$

LSTR, 15, 19

LSTR, 19, 3

LSTR, 3, 7

LSTR, 7, 11

LSTR, 11, 1000

LSTR, 1000, 10

LSTR, 10, 6

LSTR, 6, 1

LSTR, 101, 7000

LSTR, 7000, 1

LSTR, 118, 23000

LSTR, 23000, 18

LSTR, 113, 17000

LSTR, 17000, 13

LSTR, 112, 16000

LSTR, 16000, 12

LSTR， 116， 20000

LSTR，20000， 16

LSTR, 100, 6000

LSTR， 6000， 20

LSTR, 104, 10000

LSTR, 10000, 4

LSTR, 108， 14000

LSTR, 14000, 8

LSTR, 109， 15000

LSTR, 15000, 9

LSTR, 105, 11000

LSTR, 11000, 5

LSTR, 102， 8000

LSTR, 8000, 2

LSTR, 117, 21000

LSTR, 21000, 17 
LSTR， 114， 18000

LSTR, 18000, 14

LSTR, 115， 19000

LSTR，19000, 15

LSTR, 119， 22000

LSTR，22000, 19

LSTR， 103， 9000

LSTR, 9000, 3

LSTR, 107, 13000

LSTR, 13000, 7

LSTR, 111， 5000

LSTR， 5000， 11

LSTR， 2000， 4000

LSTR， 4000， 1000

LSTR, 110， 3000

LSTR， 3000， 10

LSTR, 106, 12000

LSTR, 12000, 6

FLST, 2,4,4

FITEM, 2,6

FITEM,2,74

FITEM,2,27

FITEM,2,76

AL,P51X

FLST, 2,4,4

FITEM,2,5

FITEM,2,72

FITEM,2,26

FITEM,2,74

AL,P51X

FLST, 2,4,4

FITEM, 2,4

FITEM,2,70

FITEM,2,25

FITEM,2,72

AL,P51X

FLST, 2,4,4

FITEM,2,3

FITEM,2,68

FITEM,2,24

FITEM,2,70

AL,P51X

FLST, $2,4,4$

FITEM,2,2

FITEM,2,66

FITEM,2,23

FITEM,2,68

AL,P51X

FLST, $2,4,4$

FITEM,2,1 
FITEM,2,64

FITEM,2,22

FITEM,2,66

AL,P51X

FLST, $2,4,4$

FITEM,2,21

FITEM,2,64

FITEM,2,42

FITEM,2,104

AL,P51X

FLST, 2,4,4

FITEM,2,20

FITEM,2,102

FITEM,2,41

FITEM,2,104

AL,P51X

FLST, 2,4,4

FITEM,2,19

FITEM,2,102

FITEM,2,40

FITEM,2,100

AL,P51X

FLST, 2,4,4

FITEM,2,100

FITEM,2,18

FITEM,2,98

FITEM,2,39

AL,P51X

FLST, 2,4,4

FITEM,2,98

FITEM,2,17

FITEM,2,96

FITEM,2,38

AL,P51X

LSTR， 103， 9000

! LPLOT

FLST, 2,4,4

FITEM,2,94

FITEM,2,16

FITEM,2,96

FITEM,2,37

AL,P51X

GPLOT

FLST, 2,4,4

FITEM,2,94

FITEM,2,15

FITEM,2,36

FITEM,2,92

AL,P51X

FLST, 2,4,4 
FITEM,2,14

FITEM,2,90

FITEM,2,35

FITEM,2,92

AL,P51X

FLST, $2,4,4$

FITEM, 2,7

FITEM,2,78

FITEM,2,28

FITEM,2,76

AL,P51X

FLST, $2,4,4$

FITEM, 2,8

FITEM,2,78

FITEM,2,29

FITEM,2,80

AL,P51X

FLST, 2,4,4

FITEM,2,9

FITEM,2,80

FITEM,2,30

FITEM,2,82

AL,P51X

FLST, 2,4,4

FITEM, 2,10

FITEM,2,82

FITEM,2,31

FITEM,2,84

AL,P51X

FLST, 2,4,4

FITEM,2,11

FITEM,2,86

FITEM,2,32

FITEM,2,84

AL,P51X

FLST, 2,4,4

FITEM,2,12

FITEM,2,88

FITEM,2,33

FITEM,2,86

AL,P51X

FLST, 2,4,4

FITEM,2,13

FITEM,2,88

FITEM,2,34

FITEM,2,90

AL,P51X

! /ANG, 1 ,-30.000000,YS, 1

! /REP,FAST

! /ANG, $1,30.000000, Y S, 1$ 
! /REP,FAST

! /ANG, $1,30.000000, Y S, 1$

! /REP,FAST

! /VIEW, $1,1,1,1$

! /ANG, 1

! /REP,FAST

FLST, $2,4,4$

FITEM,2,22

FITEM,2,65

FITEM,2,43

FITEM,2,67

AL,P51X

FLST, $2,4,4$

FITEM,2,23

FITEM,2,67

FITEM,2,44

FITEM,2,69

AL,P51X

FLST, 2,4,4

FITEM,2,24

FITEM,2,69

FITEM,2,45

FITEM,2,71

AL,P51X

FLST, 2,4,4

FITEM,2,25

FITEM,2,73

FITEM,2,46

FITEM,2,71

AL,P51X

FLST, 2,4,4

FITEM,2,26

FITEM,2,73

FITEM,2,47

FITEM,2,75

AL,P51X

FLST, 2,4,4

FITEM,2,27

FITEM,2,75

FITEM,2,48

FITEM,2,77

AL,P51X

FLST, 2,4,4

FITEM,2,28

FITEM,2,77

FITEM,2,49

FITEM,2,79

AL,P51X

FLST, 2,4,4

FITEM,2,29 
FITEM,2,79

FITEM,2,50

FITEM,2,81

AL,P51X

FLST, $2,4,4$

FITEM, 2,30

FITEM,2,81

FITEM,2,51

FITEM,2,83

AL,P51X

FLST, 2,4,4

FITEM,2,32

FITEM,2,87

FITEM,2,53

FITEM,2,85

AL,P51X

FLST, 2,4,4

FITEM,2,33

FITEM,2,89

FITEM,2,54

FITEM,2,87

AL,P51X

FLST, 2,4,4

FITEM,2,34

FITEM,2,55

FITEM,2,89

FITEM,2,91

AL,P51X

FLST, 2,4,4

FITEM,2,35

FITEM,2,93

FITEM,2,56

FITEM,2,91

AL,P51X

FLST, 2,4,4

FITEM,2,36

FITEM,2,95

FITEM,2,57

FITEM,2,93

AL,P51X

FLST, 2,4,4

FITEM,2,37

FITEM,2,95

FITEM,2,58

FITEM,2,97

AL,P51X

FLST, 2,4,4

FITEM,2,42

FITEM,2,65

FITEM,2,63 
FITEM,2,105

AL,P51X

FLST, $2,4,4$

FITEM,2,41

FITEM, 2,103

FITEM,2,62

FITEM,2,105

AL,P51X

FLST, 2,4,4

FITEM, 2,40

FITEM,2,103

FITEM,2,61

FITEM,2,101

AL,P51X

FLST, $2,4,4$

FITEM,2,39

FITEM,2,60

FITEM,2,101

FITEM,2,99

AL,P51X

FLST, $2,4,4$

FITEM,2,38

FITEM,2,99

FITEM,2,59

FITEM,2,97

AL,P51X

!

! /VIEW, $1,1,1,1$

! /ANG, 1

! /REP,FAST

!*

ET,1,SHELL63

!*

!*

$\mathrm{R}, 1,0.002,0.002,0.002,0.002$, ,

RMORE, , ,

!*

!*

UIMP, 1,EX, , ,EX,

UIMP,1,DENS, , ,DNS,

UIMP, 1,ALPX, , , ,

UIMP, 1,REFT, , , ,

UIMP,1,NUXY, , ,PXY,

UIMP, 1,PRXY, , , ,

UIMP, 1,GXY, , , ,

UIMP, 1,MU, , , ,

UIMP, 1,DAMP, , , ,

UIMP, 1,KXX, , , ,

UIMP, $1, \mathrm{C}$, , , ,

UIMP,1,ENTH, , , , 
UIMP, $1, \mathrm{HF},$, , ,

UIMP,1,EMIS, , , ,

UIMP,1,QRATE, , , ,

UIMP, 1,RSVX, , , ,

UIMP, 1,PERX, , , ,

UIMP, 1,VISC, , , ,

UIMP, 1,SONC, , , ,

!*

TYPE, 1

MAT, 1

REAL, 1

ESYS, 0

!*

ESIZE,0.05,0,

ESIZE,0.02,0,

MSHAPE,0,2D

MSHKEY, 1

!*

FLST,5,41,5,ORDE, 2

FITEM,5,1

FITEM,5,-41

CM,_Y,AREA

ASEL, , , ,P51X

CM,_Y1,AREA

CHKMSH,'AREA'

CMSEL,S,_Y

!*

AMESH,_Y1

!*

CMDEL,_Y

CMDEL,_Y1

CMDEL,_Y2

!*

FINISH

/SOLU

! KPLOT

FLST,2,1,3,ORDE,1

FITEM,2,4000

FK,P51X,FY,-3528,

FLST, 2, 1,3,ORDE, 1

FITEM,2,5000

FK,P51X,FY,-5120,

FLST, 2, 1,3,ORDE,1

FITEM,2,3000

FK,P51X,FY,5120,

FLST,2,40,3,ORDE,4

FITEM,2,1

FITEM,2,-20

FITEM,2,100

FITEM,2,-119 





*VFILL,VALUE1(18,1),DATA,U18

*VFILL,VALUE1(19,1),DATA,U19

*VFILL,VALUE1(20,1),DATA,U20

*VFILL,VALUE1(21,1),DATA,U21

!*

/output,n5,lgw,d:\abc

*VWRITE,VALUE1 $(1,1)$

(1X,F10.8)

/output

!*

FINISH

!*

!/EXIT 
ANNEX 4-SCIENTIFIC PAPER 


\title{
Determination of material/geometry of the section most adequate for a static loaded beam subjected to a combination of bending and torsion
}

\author{
Hugo Miguel Silva ${ }^{1, a}$, José Filipe Meireles ${ }^{1, b}$ \\ ${ }^{1}$ Department of Mechanical Engineering, University of Minho, campus de Azurém, \\ 4800-058 Guimarães, Portugal
}

aa40601@alunos.uminho.pt (corresponding author), 'bmeireles@dem.uminho.pt,

Keywords: Finite Element Method, Finite Element Model Updating, Optimization, MATLAB, ANSYS, Structural Static Analysis, Materials Selection, Strength

\begin{abstract}
The acceleration of industrial machines mobile parts has been increasing over the last few years, due to the need of higher production in a short period of time. The machines were dimensioned for a lower value of acceleration, which means there is not enough rigidity for the correct operation at much higher accelerations. Nowadays, the accelerations can be near 12 times the acceleration of gravity. There is the need of improving rigidity to make possible the correct machine operation without undesired vibrations that can ultimately lead to failure. The main applications of this work are plotters and laser cutting machines. To improve rigidity, one must improve the relevant material properties, and the relevant geometric variables of the model.[1] A novel Finite Element Model Updating methodology is presented in this paper. The considered models were : a ribbed plate and a tubular beam. The models were built by means of the Finite Element Method (FEM), and MATLAB was used to control the optimization process, using a programming code. Both material properties and geometric parameters were optimized. The main aim of the materials modeling is to know how the value of the objective function changes with the value of the material properties. Materials selection was performed, using material selection charts, to select the best material for the application. The value of these properties was not in the catalogue, and the properties used to perform the material selection were related to a material sub-class, Eg. Steel. The final material selection determined the best specific material for the application, and that material was mechanically tested. The mechanical tests performed were: Tensile Test and Extensometry Test, to obtain the relevant material properties, mainly Young Modulus, Poisson Coefficient and Yield Stress. The deflection of the optimized models reduced strongly in comparison to the initial models.
\end{abstract}

\section{Introduction}

This paper consists mainly in the development and analysis of a finite element model updating application for structural static analysis to reduce the models deflections to a minimum when subjected to static bending and torsion combined loads. To achieve the aim of deflection reduction, one must optimize both geometric parameters and material properties, focusing two main factors: The Young Modulus and the Inertia Moment, with the goal of maximizing the rigidity and minimizing the object mass. The Young Modulus is only dependent of the chosen material, and the Inertia Moment is highly dependent of the geometric characteristics of the object. Rigidity is very important in what relates to engineering parts, because it determines the work capability of engineering industrial equipments. The importance of rigidity can be higher than resistance in what relates to equipment reliability.[1] The use of numeric methods of calculus, such as the Finite Element Method (FEM), controlled by optimization 
processes that can help the designer in the most adequate selection between the existing valid solutions can be very useful.

\section{Bending and torsion combined load}

In practice is very common to find situations where the structural parts are loaded with a combination of bending and torsion. Bending is usually due to moments or centered transverse loads, and torsion can be due to non-centered transverse load. In some situations, these two types of loads act at the same time, and so, one have a combination of bending and torsion. In bending there are only normal stresses, and in torsion there are only shear stresses.

The deflection due to bending can be calculated by (1):

$$
\frac{d^{2} y_{b}}{d x^{2}}=\frac{P L}{48 E I} \text {. }
$$

The models in this work are simply supported at its ends. For this type of support, the bending deflection due to transverse load can be obtained by (2):

$$
y_{b}=\frac{P L^{3}}{48 E I} *\left(\frac{3 x^{2}}{L^{2}}-\frac{4 x^{3}}{L^{3}}\right) .
$$

where:

$\mathrm{y}_{\mathrm{b}}$ is the deflection due to bending, $\mathrm{P}$ is the applied load, $\mathrm{L}$ is the beam's length, $\mathrm{E}$ is the Young Modulus, $\mathrm{I}$ is the axial inertia moment, $\mathrm{x}$ is the $\mathrm{x}$ coordinate

In a similar manner, the maximum distortion angle for hollow-box beams of low thickness subjected to torsion is (3):

$$
\theta=\frac{M_{t} M}{4 G A_{0}{ }^{2} t}=\frac{C M}{2 G A_{0} t} .
$$

where:

$\theta$ is the twist angle, $\mathrm{C}$ is the shear flux, $\mathrm{M}$ is the mean line perimeter, $\mathrm{G}$ is the transversal elasticity modulus, $\mathrm{A}_{0}$ is the mean line area, $\mathrm{t}$ is the object thickness, $\mathrm{Mt}$ is the torsion moment

The deflection due to torsion can be calculated by (4):

$$
y_{t}=\frac{D}{2} \theta L \text {. }
$$

where:

$\mathrm{y}_{\mathrm{t}}$ is the deflection due to torsion, $\mathrm{D}$ is the diagonal length of the object

The total deflection can be expressed as the sum of the contributions of bending and torsion (5):

$$
y_{\text {total }}=y_{b}+y_{t} \text {. }
$$

In a bending and torsion combined load, the resulting deflection is a consequence of the combination of the normal stresses due to bending and the shear stresses due to torsion.[2,3] 


\section{The FEM models}

In order to validate the Finite Element Model Updating methodology done during this work two models were built: a ribbed plate, named model one and a tubular beam, named model two. In both models one considered three geometric variables and three material properties variables. Due to the different nature of the two objects the geometric variables are different in the two models. However, the material properties were the same in the two models: Poisson coefficient, Density and Young Modulus. The variables of the FEM models are in the table 1(ribbed plate) and in the table 2(tubular beam). The figure 1 and 2 shows the areas of the FEM models, as well as its variables:
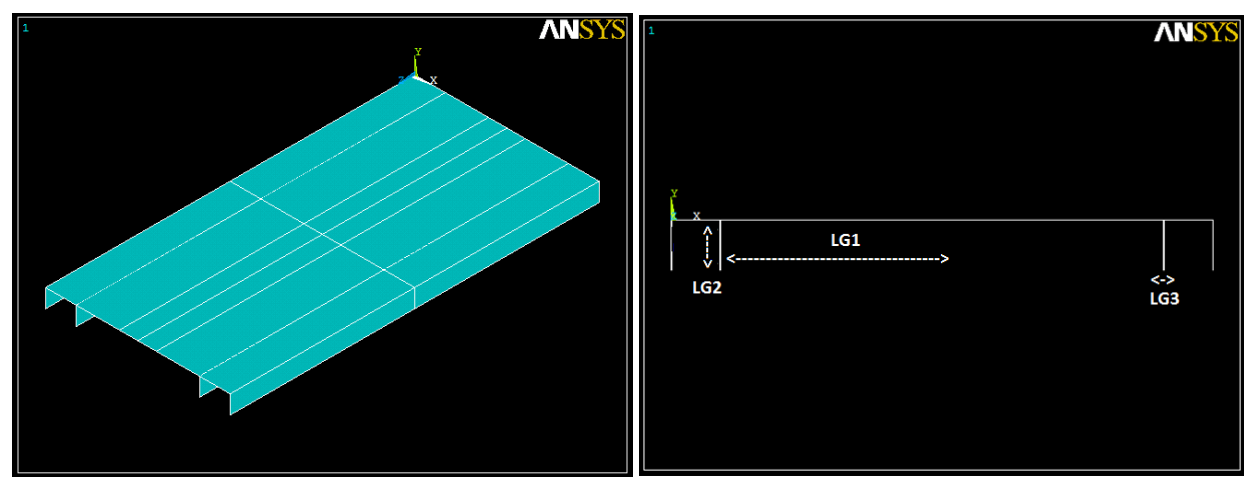

Fig.1-Areas (left) and variables (right) of the ribbed plate FEM model

Variables of the ribbed plate FEM model

\begin{tabular}{|l|l|l|l|}
\hline \multicolumn{2}{|c|}{ Geometric variables } & \multicolumn{2}{c|}{ Material properties } \\
\hline LG1 & Distance of inner ribs to the center & EX & Young modulus \\
\hline LG2 & Rib Height & PXY & Poisson coefficient \\
\hline LG3 & Thickness & DNS & Density \\
\hline
\end{tabular}

Table 1- Variables of the ribbed plate FEM model
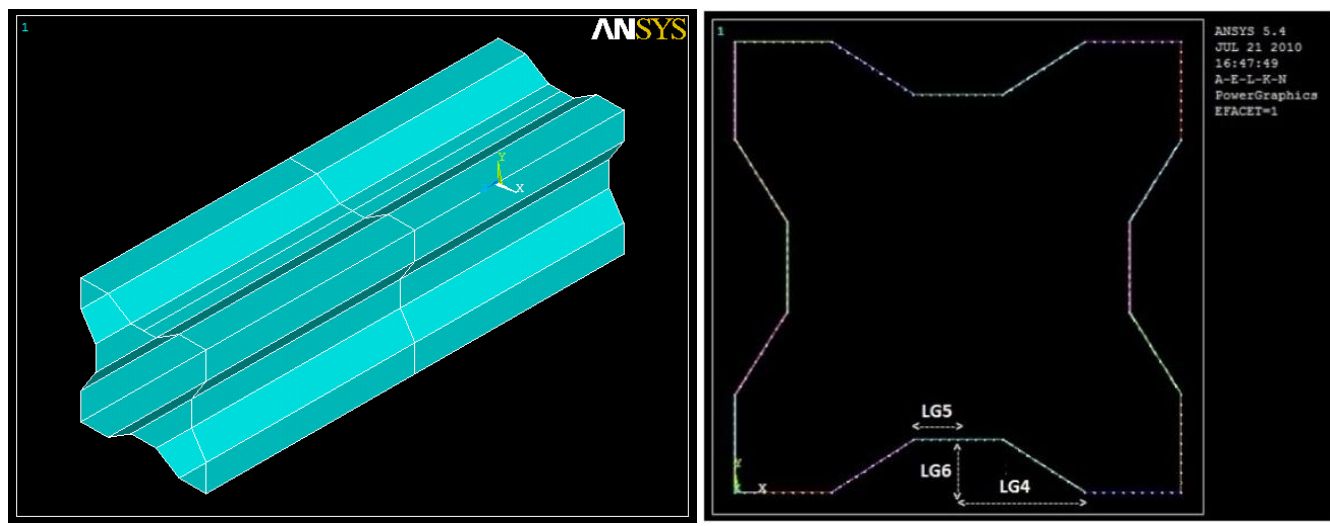

Fig.2-Areas (left) and variables (right) of the tubular beam FEM model

Variables of the tubular beam FEM model

\begin{tabular}{|l|l|l|l|}
\hline \multicolumn{2}{|c|}{ Geometric variables } & \multicolumn{2}{c|}{ Material properties } \\
\hline LG4 & Center to corner segment distance & EX & Young modulus \\
\hline LG5 & Half width of the central segment & PXY & Poisson coefficient \\
\hline LG6 & Height of the central part on the wall & DNS & Density \\
\hline
\end{tabular}

Table 2- Variables of the tubular beam FEM model 


\section{Optimization Model}

The MATLAB program is used together with ANSYS. MATLAB controls the optimization process and ANSYS solves the FEM problem, by sending the deflections in specific nodes to a text file, that MATLAB can read. Then MATLAB calculates a new objective function value, changes variable values and sends orders to ANSYS to recalculate the deflections for the new variable values. The objective function $q(U)$ can be defined as:

$$
q(U)=\sum A B S(U i)
$$

where:

$\mathrm{q}(\mathrm{U})$ is the objective function, $\mathrm{Ui}$ is the deflection on each nodal points (nodes), ABS is absolute value of an argument.

The objective function $\mathrm{q}(\mathrm{U})$ was minimized by a MATLAB function named fmincon (nonlinear minimization). The objective function value is better the closer it is to zero. The figure 3 shows the interaction between ANSYS and the MATLAB optimization program:

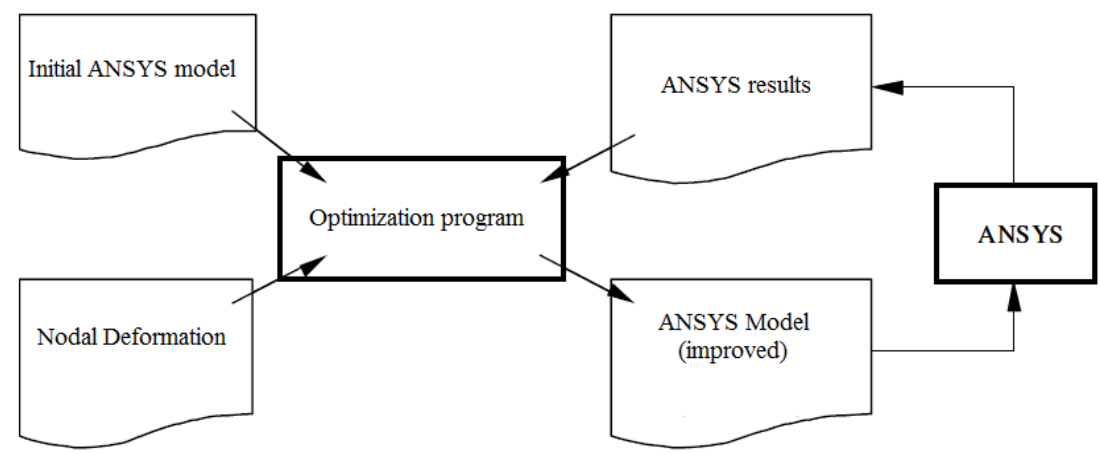

Fig.3-Functional fluxogram of the optimization methodology [4]

\section{Materials selection}

The first step in the materials selection is the definition of the relevant properties for the application. In this work, the desired properties are (Table3):

Relevant properties for the materials selection

\begin{tabular}{|l|l|}
\hline - Young modulus & (highest possible) \\
\hline - Toughness & (highest possible) \\
\hline - Cost of the material & (lowest possible) \\
\hline - Density & (lowest possible) \\
\hline \multicolumn{2}{|l}{ Table 3- Desired properties for materials selection }
\end{tabular}

For the initial materials selection it is necessary to choose a material class, not a specific material, because one has more mobility to change to another material in the same class with better properties for the application. The materials selection was performed using the Young Modulus/Density and Young Modulus/Cost materials selection charts (Fig.4). 

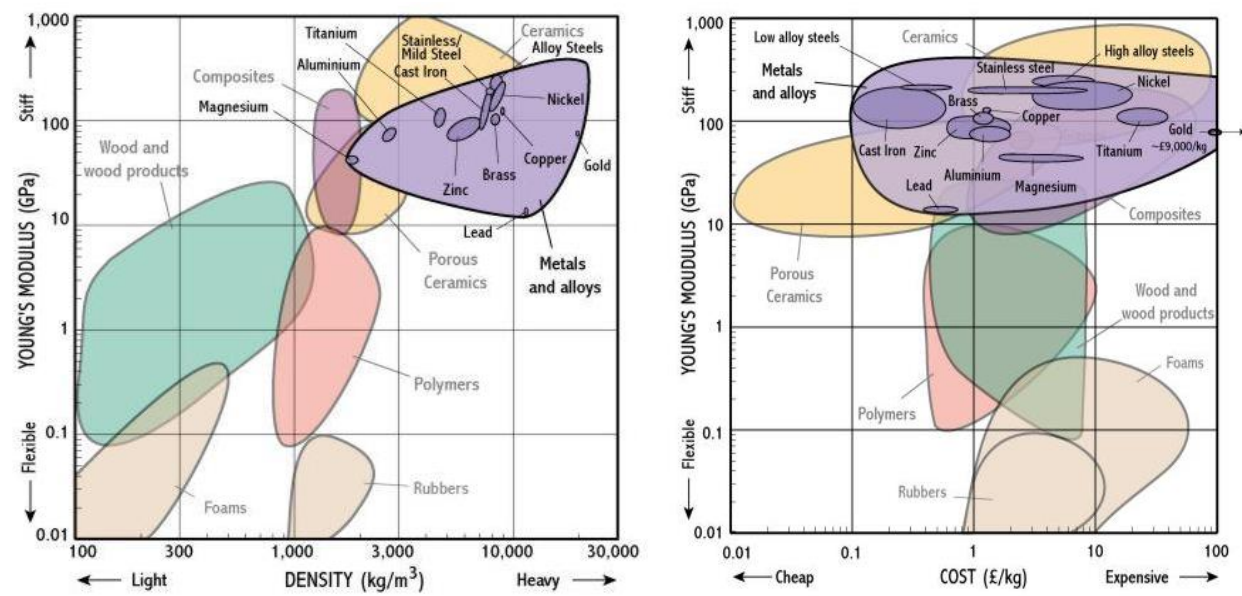

Fig.4-Materials selection charts Young Modulus/Density (left) and Young Modulus/Cost (right) [5]

In both charts(fig.4), the best classes are the ceramics, the composites with high Young Modulus and the metals. The ceramics are too brittle for this application. The composites with high Young Modulus are expensive (Eg. CFRP- Carbon Fiber Reinforced Polymer). The cheaper Composites have a low density but a lower Young Modulus than Metals. The Metals have a high Toughness and high Young Modulus. Some Composites have a low density and high Young Modulus, but their cost is much higher, so they are not the best choice. The best material class is the Metals and Alloys, which is the best class in both charts. In a detailed view of the Density/Young modulus diagram (fig.4), one can see that the best materials for this application are: Steel, Cast Iron and Nickel, whose have a high Young Modulus and a relatively low density, compared with some metals, such as Gold or Lead. A detailed view of the diagram Cost/Young modulus (fig.4) shows that the best materials for this application are: Low alloy Steels and Stainless Steel, whose have a high Young modulus and a relatively low cost. One can say that the best material for this application is the Steel, which has a good position in both diagrams. Of all steels, the dual-phase steels seem to be the most promising material for this application. Dual phase steels allows decreasing the objects thickness and improving the inertia moment of the section to obtain lower deflections with a similar material cost. The dual phase steel has high yield stress, which means it can be subjected to high loads without entering the plastic domain. The commercial dual phase steel DOCOL is the selected material.

\section{Results}

\subsection{Tensile test results}

In order to determine Young Modulus, one must plot the Stress-Strain chart of the elastic domain only, and do a linear fit to find the slope of the recta. The Yield Stress was calculated using a $0,2 \%$ offset. The obtained Young Modulus and Yield Stress is shown on the table 4:

Young Modulus and Yield Stress obtained in tensile test

\begin{tabular}{|c|c|c|c|}
\hline Specimen number & Specimen designation & Young Modulus Value & Yield Stress value \\
\hline Specimen 1 & DOCOL 600 DL Long & $193,2[\mathrm{GPa}]$ & $309,12[\mathrm{MPa}]$ \\
\hline Specimen 2 & DOCOL 800 DP Long & $168,2[\mathrm{GPa}]$ & $555,06[\mathrm{MPa}]$ \\
\hline
\end{tabular}

Table 4- Young modulus and Yield Stress obtained in the extensometry test 


\subsection{Extensometry test results}

The table 5 shows the Young Modulus range and the mean Poisson coefficient for the four specimens tested by extensometry test:

Poisson coefficient and Young Modulus obtained in Extensometry test

\begin{tabular}{|c|c|c|c|}
\hline Specimen number & Specimen designation & Poisson coefficient & Young modulus \\
\hline Specimen 3 & DOCOL 600 DL Trans & 0,285 & $182-198[\mathrm{GPa}]$ \\
\hline Specimen 4 & DOCOL 600 DL Long & 0,284 & $176-186[\mathrm{GPa}]$ \\
\hline Specimen 5 & DOCOL 800 DP Trans & 0,287 & $186-192[\mathrm{GPa}]$ \\
\hline Specimen 6 & DOCOL 800 DP Long & 0,270 & $184-203[\mathrm{GPa}]$ \\
\hline
\end{tabular}

Table 5- Poisson coefficient and Young modulus obtained in the extensometry test.

\subsection{Optimization results}

The final variable values for the ribbed plate model are shown in the table 6 . The final value of the objective function was: $\mathrm{q}(\mathrm{x})=0,00092$ for the geometric parameters optimization and $\mathrm{q}(\mathrm{x})=0,04258$ for the material properties optimization.

Final variable values for the ribbed plate model

\begin{tabular}{|c|c|c|c|c|c|}
\hline \multicolumn{2}{|c|}{ Geometric parameters optimization } & \multicolumn{3}{c|}{ Material properties optimization } \\
\hline Variable & $\begin{array}{c}\text { Initial } \\
\text { Value[m] }\end{array}$ & $\begin{array}{c}\text { Final } \\
\text { Value[m] }\end{array}$ & Variable & Initial Value & Final Value \\
\hline LG1 & 0,100 & 0,025 & EX & $2,1^{*} 10^{11}[\mathrm{~Pa}]$ & $2,31^{*} 10^{11}[\mathrm{~Pa}]$ \\
\hline LG2 & 0,03 & 0,0507 & PXY & 0,29 & 0,435 \\
\hline LG3 & 0,002 & 0,0046 & DNS & $7890\left[\mathrm{Kg} / \mathrm{m}^{3}\right]$ & $7890\left[\mathrm{Kg} / \mathrm{m}^{3}\right]$ \\
\hline
\end{tabular}

Table 6-Final variable values for the geometric parameters optimization (ribbed plate)

The final variable values for the tubular beam model are shown in the table 7 . The final value of the objective function was: $\mathrm{q}(\mathrm{x})=0,00053$ for the geometric parameters optimization and $\mathrm{q}(\mathrm{x})=0,01151$ for the material properties optimization.

Final variable values for the tubular beam model

\begin{tabular}{|c|c|c|c|c|c|}
\hline \multicolumn{2}{|c|}{ Geometric parameters optimization } & \multicolumn{3}{c|}{ Material properties optimization } \\
\hline Variable & $\begin{array}{c}\text { Initial } \\
\text { Value[m] }\end{array}$ & $\begin{array}{c}\text { Final } \\
\text { Value[m] }\end{array}$ & Variable & $\begin{array}{c}\text { Initial } \\
\text { Value[m] }\end{array}$ & Final Value \\
\hline LG4 & 0,085 & 0,0213 & EX & $2,1^{*} 10^{11}[\mathrm{~Pa}]$ & $2,31 * 10^{11}[\mathrm{~Pa}]$ \\
\hline LG5 & 0,030 & 0,0076 & PXY & 0,29 & 0,292 \\
\hline LG6 & 0,035 & 0,0805 & DNS & $7890\left[\mathrm{Kg} / \mathrm{m}^{3}\right]$ & $7890\left[\mathrm{Kg} / \mathrm{m}^{3}\right]$ \\
\hline
\end{tabular}
beam)

Table 7-Final variable values for the material properties optimization (tubular

\section{Results discussion and conclusions}

In tensile test, the specimen 1 has the highest Young Modulus of the two specimens tested: 193,2 GPa. The specimen 2 has a Young Modulus of near 168,2 GPa. The Young Modulus obtained by extensometry test ranged from near 180 to $200 \mathrm{GPa}$. The 
Young Modulus values are lower than the regular value of the steel, which is $210 \mathrm{GPa}$. The manufacturing processes may be the reason of such values of Young Modulus, because the material is conformed, and as a result of the increase in plasticity, the Young Modulus may decrease. The Specimen 1 has a lower Yield Stress, which is expected, because its designation is 600 and the specimen 2 is 800 . This number is related to the Yield Stress in relative terms, which means that a lower number designation means a lower Yield Stress when comparing two specimens. The obtained Poisson Coefficient in extensometry test was near 0,29 , which is the normal value for a steel, except for the specimen 6 , which was near 0,27 . About the optimization results, the obtained objective function is lower in the geometric parameters optimization than in the material properties optimization for both models. The conclusions of this work are: the developed Finite Element Model Updating code can be successfully used to optimize both geometric parameters and material properties. The geometric parameters play a more important role in the optimization process than the material properties, because the obtained objective function is lower in the geometric parameters optimization than in the material properties optimization. The tested specimens have high Yield Stresses, which means the material can be subjected to high loads before entering the plastic domain. In the practical applications of this work (plotters and laser cutting machines) it is very important to ensure that the material doesn't leave the elastic domain, otherwise the permanent deformation will negatively affect the machine operation. Considering this fact, the dual phase steels are an adequate material for the applications of this work. The selected material does not reduce the deflections, because it has a lower Young Modulus, but the deflections can be substantially improved by the optimization of the geometry.

\section{References}

[1] C. M. Branco, J. M. Ferreira, J. D. Costa, A. S. Ribeiro, Projecto de Órgãos de Máquinas, Fundação Calouste Gulbenkian, Lisboa, Portugal, 2005.

[2] F. Beer, Johnston, De Wolf, "Mechanics of Materials, McGraw Hill, Third Edition, 2001

[3] C. Massonnet,"Resistance des matériaux", DUNOD,deuxiéme édition, Paris, 1968

[4] J. F. B. Meireles,"Análise dinâmica de estruturas por modelos de elementos finitos identificados experimentalmente", Ph.D. Thesis, University of Minho,2007

[5] Information on http://www.materials.eng.cam.ac.uk/mpsite/interactive_charts /default.html 